\title{
COMPARISON OF DISPERSION CURVES ACQUIRED USING MULTICHANNEL ANALYSIS OF SURFACE WAVES WITH VARIOUS STRIKER PLATE CONFIGURATIONS
}

\author{
A Thesis \\ Submitted to \\ The Temple University Graduate School
}

\author{
In Partial Fulfillment \\ of The Requirements for The Degree \\ Master of Science \\ (Civil Engineering)
}

Thesis Approvals:

Joseph Thomas Coe (PhD)

Ahmed Faheem $(\mathrm{PhD})$

Felix Udoeyo (PhD) 


\begin{abstract}
There is growing appreciation and research regarding geophysical methods to evaluate near surface soil properties in geotechnical engineering. Geophysical methods are generally non-destructive test (NDT) methods that do not necessitate traditional sampling of soils. Instead, they rely on application of input signals and deduction of soil properties from the measured response of the domain. Geophysical methods include various seismic, magnetic and nuclear techniques applied at the surface and/or subsurface within boreholes. Surface seismic methods, which include Multichannel Analysis of Surface Waves (MASW), are increasing in usage for geotechnical engineering purposes to evaluate stiffness properties of soils.
\end{abstract}

MASW typically involves using a hammer to impact a base plate (also referred to as a striker plate) to transmit surface waves into the ground. These waves propagate through the underlying soils at a site and are received by an array of geophones placed on the ground surface. The manner in which the waves propagate is primarily influenced by soil stiffness, particularly against shear. Therefore, the signals recorded during an MASW survey can be analyzed to estimate the shear stiffness of the soils at a site, a parameter that is extremely important for seismic-related engineering purposes (e.g., site amplification, liquefaction, etc.). Aluminum plates are routinely used in a large number of MASW studies as a striker plate to couple the energy from a sledgehammer blow to the underlying soil layers. Various researchers have postulated that the material make-up of the striker plate has an effect on the frequency of the generated waves and, for that matter, the depth achieved with a typical MASW survey. For example, a less stiff material such 
as ultra-high-molecular-weight (UHMW) polyethylene is often recommended to increase low frequency energy of the input surface wave relative to aluminum. However, very limited research work has been performed in this area to systematically ascertain the effects of modifications to the striker plate material.

Due to the limited direct research related to striker plates, MASW was utilized in this study to measure the dispersion curve resulting from MASW at various sites in the Philadelphia metropolitan area. Different striker plate configurations were used during testing to systematically quantify their effects on typical MASW results. The proposed striker base plate configurations included a one (1.0) inch thick aluminum plate, a one (1.0) inch thick aluminum plate over additional rubber mats of varying thickness, and multiple ultra-high-molecular-weight (UHMW) polyethylene plates of various thicknesses. The purpose of this testing was to examine the performance of each configuration, particularly at the low frequency range of the dispersion results. Also efforts were made to qualitatively access the durability of the configurations with respect to long term exposure to impact load. 


\section{ACKNOWLEDGEMENT}

My heartfelt thanks go to the Almighty God for granting me the grace and peaceable educational atmosphere for me to complete this Thesis and my studies as a whole.

To my beloved wife, Madonna Owusu, and son, Melchizedek Asabere, you are the reason why I do what I do. Even though you may not understand what I have done, I still did it with you in mind. You are my inspiration. God bless you.

I would like to extend my profound appreciation and gratitude to my advisor, Dr. Joseph Coe, for being a mentor and a guide throughout my Graduate studies. Your immense support and guidance in the preparation of this thesis document cannot be overemphasized.

I would also like to thank my Thesis committee members including Dr. Ahmed Faheem and Dr. Felix Udoeyo for their constructive criticism, guidance and support during my Thesis proposal and review periods.

Special mention also goes to the members of the Geotechnical Research Group at Temple University including, Siavash Mahvelatishamsabadi, Jake Sheridan, Alireza Kordzi and Mike Senior. Your inputs and efforts in helping me acquire field data has come a long way to help prepare this thesis document. Thank you my brothers.

My final appreciation goes to all students, staff and faculty members of the Civil/ Environmental Department at Temple University for their contribution towards the ultimate fulfilment of my academic pursuits. God bless you all. 


\section{TABLE OF CONTENTS}

ABSTRACT

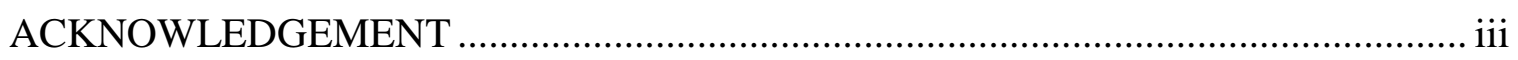

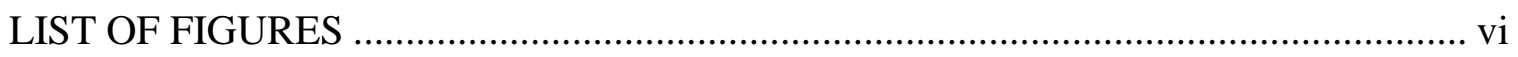

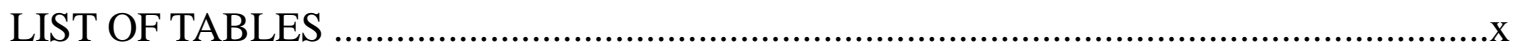

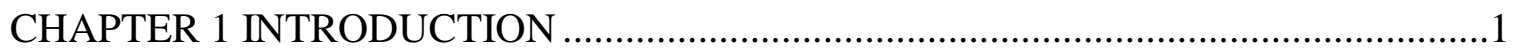

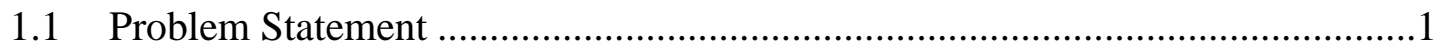

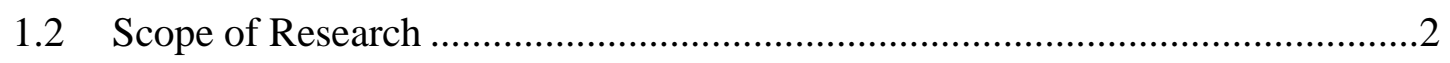

CHAPTER 2 BACKGROUND AND LITERATURE REVIEW ………...........................

2.1 Multichannel Analysis of Surface Waves (MASW) ..........................................

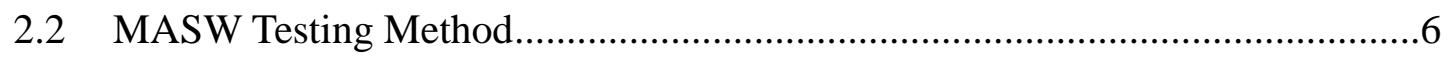

2.2.1 Field Data Acquisition .......................................................................

2.2.1.1 Active Mode........................................................................

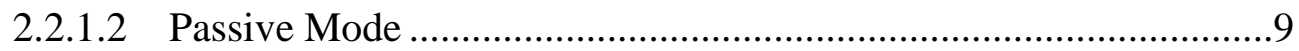

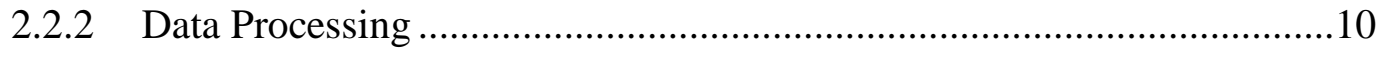

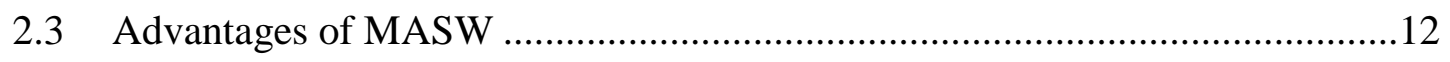

2.4 Limitations of MASW …………………………........................................13

2.5 The Role of Seismic Sources for MASW ………….......................................15

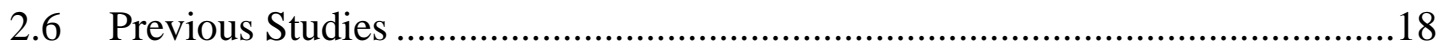

CHAPTER 3 FIELD STUDIES.............................................................................

3.1 General Field Data Acquisition Procedures/ Parameters ...................................40

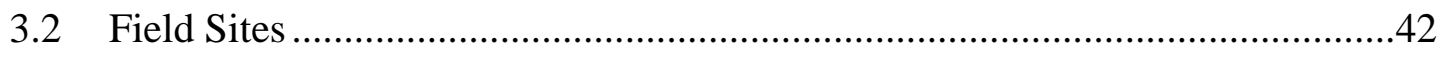

3.2.1 Temple University Ambler Campus (TA1) ..............................................43 
3.2.2 Dendy Recreational Center (DRC) ..................................................43

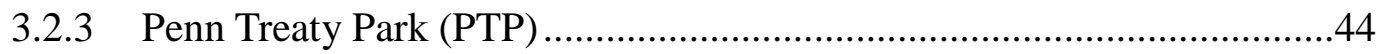

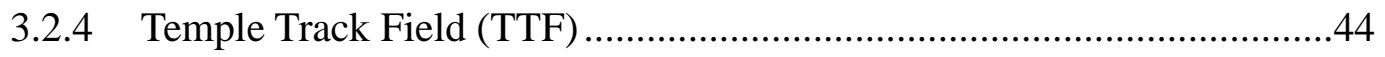

3.2.5 Fairmount Park Edgely Field (FEF) ......................................................45

3.2.6 Martin Luther King Jr. Drive Near Belmont Waterworks (MLK) ...........46 CHAPTER 4 DISCUSSION OF RESULTS ………………........................................53

4.1 Dendy Recreational Center (DRC).............................................................5

4.2 Fairmount Park Edgely Field (FEF) ...........................................................58

4.3 Martin Luther King Drive (MLK) .............................................................60

4.4 Temple University Ambler Campus (TA1) ………………………………......61

$4.5 \quad$ Temple Track Field (TTF) .....................................................................62

4.6 Penn Treaty Park (PTP) …………………………....................................64

CHAPTER 5 CONCLUSION AND RECOMMENDATIONS ……………….................82

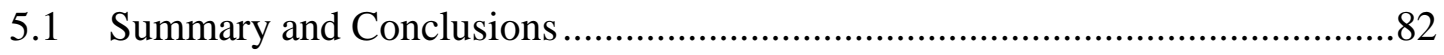

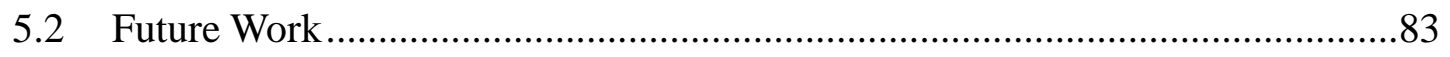

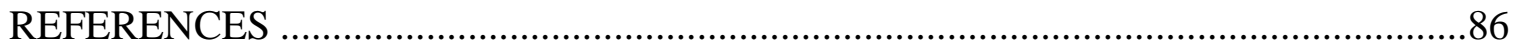

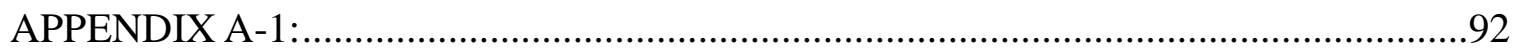

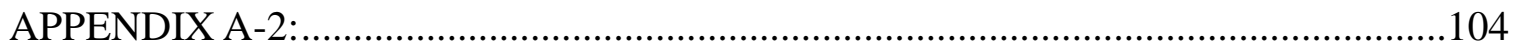

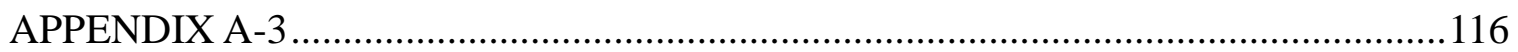

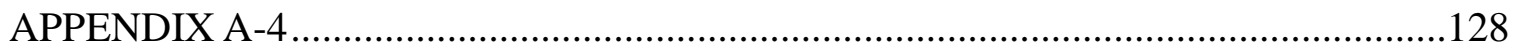

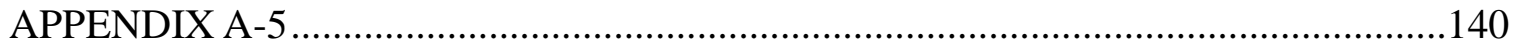

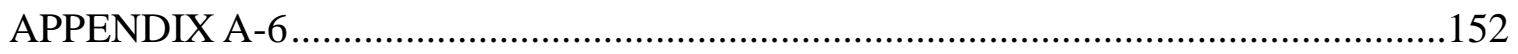




\section{LIST OF FIGURES}

Fig. 2-1: Surface waves travel primarily near the surface of a medium in comparison to body waves that radiate in all directions internally within the medium (Park et al., 2002).26 Fig. 2-2: Variation of wave amplitudes between body waves ( $\mathrm{P}$ and $\mathrm{S}$ ) and surface (Rayleigh) waves (Kayal, 2000). .26

Fig. 2-3: An illustration of how a typical surface wave spreads out as the wave propagates away from the source (Xia et al., 1999). .27

Fig. 2-4: Depth dependency of Rayleigh wave motion as a function of wavelength (i.e., frequency) (Rix And Stokoe, 1989). .28

Fig. 2-5: Schematic of data acquisition and processing in the MASW method (Park et al., 2007). .29

Fig. 2-6: Typical MASW data acquisition using an active source (Park et al., 2000).......30

Fig. 2-7: Illustration of a combined active and passive survey (Park et al., 2007). .31

Fig. 2-8: Comparison of spatial coverage between MASW and conventional drilling (Park et al., 2000). .32

Fig. 2-9: Various seismic sources: (a) Sledgehammer; (b) Accelerated weight drop (Sopher et al., 2014); (c) Betsy seisgun (Miller et al., 1986); (d) Vibsist vibroseis (Sopher et al., 2014). .33

Fig. 2-10: Illustration of the variation in surface wave (white bars) versus body wave (grey bars) energy for various sources (Miller et al., 1986). .34

Fig. 2-11: Illustration of the amplitude variation across various seismic sources (Miller et al., 1992). .35

Fig. 2-12: Comparison of dispersion curves for $10 \mathrm{lb}$ sledgehammer, $20 \mathrm{lb}$ sledgehammer 
and an RAWD (Park et al., 2002). .36

Fig. 2-13: Comparison of dispersion curves for an Industrial Vehicle International T-15000 minivib vibroseis and sledgehammer (Wood and Cox, 2012) 36

Fig. 2-14: The effect of changes of input source energy (E) on wavelength based on impacts from different diameter steel balls for SASW testing (Kumar and Rakaraddi, 2013). .37

Fig. 2-15: Seismic data and relative energy bar graph resulting from an increase in plate mass at a single site. The bar graphs represent the sum of the squares of the amplitudes after correcting gain variation during acquisition for all 24 channels (Keiswetter and Steeples, 1995) 37

Fig. 2-16: Variation in input wave amplitude generated using various striker plates and a $1 \mathrm{~kg}(2.2 \mathrm{lb})$ sledgehammer impact source (Kim and Lee, 2011) .................................38 Fig. 2-17: Variation in frequency content present for input waves generated using various striker plates and a $1 \mathrm{~kg}$ (2.2 lb) sledgehammer impact source (Kim and Lee, 2011).......38 Fig. 2-18: Variation of measured frequency content generated from impacts using a $1 \mathrm{~kg}$ (2.2 lb) hammer with various striker plate shapes when the long side of the plate is perpendicular to the array line (Jeong and Kim, 2012).

Fig. 2-19: Variation of measured power generated from impacts using a $1 \mathrm{~kg}(2.2 \mathrm{lb})$ hammer with various striker plate shapes when the long side of the plate is perpendicular to the array line (Jeong and Kim, 2012). 39

Fig. 3-1: Striker plates used in this study: (a) Al; (b) PE; and (c) Al/EPDM .47

Fig. 3-2: TA1 site: (a) Plan view (courtesy of Google Maps); and (b) MASW array setup.47 Fig. 3-3: DRC site: (a) Plan view (courtesy of Google Maps); and (b) MASW array setup48 
Fig. 3-4: PTP site: (a) Plan view (courtesy of Google Maps); and (b) MASW array setup49 Fig. 3-5: TTF site: (a) Plan view (courtesy of Google Maps); and (b) MASW array setup50 Fig. 3-6: FEF site: (a) Plan view (courtesy of Google Maps); and (b) MASW array setup51 Fig. 3-7: MLK site: (a) Plan view (courtesy of Google Maps); and (b) MASW array setup52 Fig. 4-1: Methodology for estimating the lowest frequency component of the dispersion curve: (a) Dispersion image with automatically selected dispersion curve; (b) Plot that isolates the selected dispersion curve and highlights the selected lowest frequency component on the curve. .66

Fig. 4-2: Lowest frequency component present in DRC dispersion curves generated at various source offsets: (a) $-3 d x$; (b) $-6 d x$; and (c) $-12 d x$.

Fig. 4-3: Summary of lowest frequency component present in DRC dispersion curves based on hammer size: (a) $4 \mathrm{lb}$; (b) $8 \mathrm{lb}$; and (c) $20 \mathrm{lb}$. .68

Fig. 4-4: Lowest frequency component present in FEF dispersion curves generated at various source offsets: (a)-3dx; (b)-6dx; and (c)-12dx.

Fig. 4-5: Summary of lowest frequency component present in FEF dispersion curves based on hammer size: (a) $4 \mathrm{lb}$; (b) $8 \mathrm{lb}$; and (c) $20 \mathrm{lb}$. .70

Fig. 4-6: Lowest frequency component present in MLK dispersion curves generated at various source offsets: (a) $-3 d x$; (b) $-6 d x$; and (c) $-12 d x$. .71 Fig. 4-7: Summary of lowest frequency component present in MLK dispersion curves based on hammer size: (a) $4 \mathrm{lb}$; (b) $8 \mathrm{lb}$; and (c) $20 \mathrm{lb}$. .72 Fig. 4-8: Lowest frequency component present in TA1 dispersion curves generated at various source offsets: (a) $-3 d x$; (b) $-6 d x$; and (c) $-12 d x$. .73 Fig. 4-9: Summary of lowest frequency component present in TA1 dispersion curves 
based on hammer size: (a) $4 \mathrm{lb}$; (b) $8 \mathrm{lb}$; and (c) $20 \mathrm{lb}$.

Fig. 4-10: Lowest frequency component present in TTF dispersion curves generated at various source offsets: (a) $-3 d x$; (b) $-6 d x$; and (c) $-12 d x$.

Fig. 4-11: Summary of lowest frequency component present in TTF dispersion curves based on hammer size: (a) $4 \mathrm{lb}$; (b) $8 \mathrm{lb}$; and (c) $20 \mathrm{lb}$ .76

Fig. 4-12: Lowest frequency component present in PTP dispersion curves generated at various source offsets: (a) $-3 d x$; (b) $-6 d x$; and (c) $-12 d x$ .77

Fig. 4-13: Summary of lowest frequency component present in PTP dispersion curves based on hammer size: (a) $4 \mathrm{lb}$; (b) $8 \mathrm{lb}$; and (c) $20 \mathrm{lb}$. .78 


\section{LIST OF TABLES}

Table 4-1: Summary of the lowest observable frequency component in $\mathrm{Hz}$ for the dispersion curves generated at DRC.

Table 4-2: Summary of the lowest observable frequency component in $\mathrm{Hz}$ for the dispersion curves generated at FEF

Table 4-3: Summary of the lowest observable frequency component in $\mathrm{Hz}$ for the dispersion curves generated at MLK.

Table 4-4: Summary of the lowest observable frequency component in $\mathrm{Hz}$ for the dispersion curves generated at TA1.

Table 4-5: Summary of the lowest observable frequency component in $\mathrm{Hz}$ for the dispersion curves generated at TTF. .81 Table 4-6: Summary of the lowest observable frequency component in $\mathrm{Hz}$ for the dispersion curves generated at PTP. .81 


\section{CHAPTER 1}

\section{INTRODUCTION}

\subsection{Problem Statement}

Since its introduction in the field of geophysics, the Multichannel Analysis of Surface Waves (MASW) method has been increasingly used in the engineering field to evaluate the stiffness properties of in-situ soil, among other applications. Typically, impact sources are used to introduce surface waves into the domain during MASW testing and the subsurface stiffness properties are deduced based on the nature of the wave propagation as measured using surface sensors (e.g., geophones). The depth of evaluation is dependent on the parameters of the MASW setup. These parameters include the spacing and frequency response of the surface sensors as well as the offset and characteristics of the impact source. Several researchers have studied the effect that the shape and material make-up of the impact source (impact tool and striker base plate) as well as the magnitude of the input wave have on the depths and resolution of the results of the MASW survey. Many of the researchers have in the past focused on the characteristics of the impact source (e.g., sledgehammer, vibroseis, etc.) (Miller et al., 1986; Park et al., 2002; Wood and Cox., 2010) and very little systematic research has been performed that evaluates the effect of the striker base plate on the depth of sampling and resolution of the MASW method (e.g., Kim and Lee, 2011). Typically, the larger and heavier the impact source, the deeper the depth of sampling that can be achieved with it. This observation has been tested on several different soil types and at several locations. However, large and heavy impact sources can be limited in application for smaller project due to mobility 
issues and higher costs. Some researchers have demonstrated in parts of their studies that the use of different materials for the base plate can assist in extending the depth of sampling. However, the lack of systematic evaluation of the effects of base plates on MASW results means that very little is known about the effectiveness of substituting different striker plate materials. Therefore, as part of this study, three different configurations of striker base plates [Aluminum, Aluminum with rubber, and Ultra-high-molecular-weight polyethylene (UHMWPE)] were systematically studied to investigate their effects on MASW results.

\subsection{Scope of Research}

The primary objective of this research is to systematically investigate the effects of different types of base plates in an MASW survey, particularly with regards to quantifying the variation in depth of sampling that can be achieved. Initial MASW testing was conducted to see if the surface area and thickness of the plates also has an effect on the depth of sampling. The plates during this initial survey were also monitored for durability in order to select optimum surface areas and thicknesses for the actual study.

After the initial survey, a systematic study was performed at multiple field sites with the three base plates. Variations in the measured surface waves were investigated using the different base plates at six different sites in Philadelphia. The sites were selected to represent broad variations in site subsurface conditions, including overall stiffness and depth to bedrock.

This thesis summarizes the results of the aforementioned field study. The body of thesis is organized into the following chapters: 


\section{Chapter 2: Background and Literature Review}

This chapter gives a description of MASW and it's the application to geotechnical engineering. The various forms of field data acquisition (Active and Passive) are also discussed, as well as equipment utilized in the survey, interpretation of results, advantages, and limitations of the method. A comprehensive review of the role of the striker plates in an MASW survey as well as previous work on the role of seismic source (impact tool, striker plates) are also included in this chapter.

\section{Chapter 3: Field Studies}

Chapter 3 details the general field data acquisition procedures and parameters that were utilized at all test sites. The acquisition parameters include the source distance from the impact source to the first receiver sensor, spacing between two receiver sensors, and the magnitude of impact used to introduce the surface wave.

\section{Chapter 4: Discussion of Results}

Chapter 4 presents the results obtained for each of the sites discussed in Chapter 3. A discussion is also provided regarding interpretation of the results and comparisons for the different base plates.

\section{Chapter 5: Conclusion and Recommendation}

Chapter 5 provides the conclusions of the research with regards to the effects of the different base plates. The consistency of the results across different hammer sizes and source offset location (distance of source to first geophone) is discussed. Finally, recommendations for future work are also presented. 


\section{CHAPTER 2}

\section{BACKGROUND AND LITERATURE REVIEW}

\subsection{Multichannel Analysis of Surface Waves (MASW)}

The Multichannel Analysis of Surface Waves (MASW) method is a type of geophysical seismic survey method that is used primarily to evaluate the elastic conditions of in-situ soils. In this method, seismic stress waves are introduced into the subsurface at a site and recorded by a string of sensors located on the ground surface. The resulting signals can be used to deduce the stiffness of the underlying soil layers because the nature of seismic wave propagation is dependent on this soil property. The method as utilized today was first introduced in Park et al. (1999) and has since been used for several subsurface investigation applications including soil characterization (Park and Miller, 2004), anomaly detection (Xia et al., 2002; Park and Carnevale, 2009), characterization of bedrock topography (Miller et al., 1999), and evaluation of seismic site amplification (Stephenson et al., 2005). However, the concept of multichannel surveys is reported to have been introduced earlier in the petrochemical industry (Gabriels et al., 1987). Surface waves such as Rayleigh and Love waves travel along the surface boundary, in comparison to body waves [i.e., Primary waves (P-waves) and/or Shear waves (S-waves)] that travel in all directions throughout a medium (Fig. 2-1). This characteristic of surface waves offers an advantage when using MASW over other seismic methods such as seismic reflection and refraction techniques that rely on body waves. Due to the differences in geometric spreading, surface waves decay more slowly and are very distinguishable in a seismic recording in comparison to body waves that spread out in all 
directions (Fig. 2-2).

Both surface and body waves can be used to deduce the wave velocity of the medium (which serves as a proxy for stiffness) since wave propagation in the domain will be dependent on this parameter. The MASW technique in particular relies on the dispersive characteristics of Rayleigh waves to estimate the depth variation of the S-wave velocity $\left(\mathrm{V}_{\mathrm{s}}\right)$ of layered systems. Dispersion means that Rayleigh waveforms are not preserved as they propagate. They tend to spread out during propagation (Fig. 2-3). To better understand how the dispersive characteristic of Rayleigh waves is utilized in MASW, it is important to note that the characteristic frequency of a Rayleigh wave determines how deep the wave motion penetrates from the ground surface into the underlying soils. Typically for any given seismic wave generated with a seismic source, we generate a broadband of waves ranging from low frequency to high frequency. The longer wavelength (i.e., low frequency) components of a Rayleigh wave will sample deeper soil layers and shorter wavelengths (i.e., high frequencies) will be relegated to soils closer to the surface (Fig. 2-4). As the stiffness of soils varies with depth, the various frequency components of a typical Rayleigh wave will propagate at different velocities. Since deeper soil layers normally have larger $V_{s}$ values (Park et al., 1999), the low frequency components of the Rayleigh wave tend to propagate at a relatively faster velocity than the higher frequency components. After the waveform has been acquired, a dispersion image can then be generated that examines this frequency-velocity dependence (as detailed in chapter 2.2.2). From the resulting dispersion image, a dispersion curve is selected that best represents the dispersive behavior of the Rayleigh waves at the site of interest. The frequency limits of the dispersion curve are dependent on the depth of subsurface 
investigation required and the frequency content of the input wave. Once the dispersion curve has been extracted from the dispersion image, it is then used to generate a corresponding $\mathrm{V}_{\mathrm{s}}$ profile through an iterative inversion process (see chapter 2.2.2 for details). Fig. 2-5 shows the process from data acquisition to creation of the corresponding site $\mathrm{V}_{\mathrm{s}}$ profile.

Prior to the introduction of MASW, Spectral Analysis of Surface Waves (SASW) also utilized Rayleigh waves to evaluate shear wave velocities of soils. However, SASW typically uses a limited number of receivers [e.g., two (2) to four (4) geophones] to record the surface wave data. This increases the complexity of field data acquisition and analysis of the results because multiple receiver offsets must be used to adequately capture the broad range of frequencies necessary to define the dispersion curve of a site. The challenges associated with SASW inspired the discovery of the MASW. Unlike the SASW setup that has two (2) to four (4) receivers as part of its setup, MASW typically uses twenty four (24) or more receivers. The higher number of receivers in MASW increases the efficiency of the data acquisition, allows noise to be better distinguished from coherent signals, and incorporates redundancy into the measurements (Park et al., 1999).

\subsection{MASW Testing Method}

Testing using the MASW method is comprised of two main stages:

- Field Data Acquisition

- Data Processing 
The following sections describe various aspects related to each of these stages of the MASW method.

\subsubsection{Field Data Acquisition}

MASW field data acquisition requires equipment that is very similar to other geophysical seismic methods such as Seismic Reflection and Seismic Refraction (Fig. 2-6). The following equipment is typically required for MASW field data acquisition:

- Seismic source (e.g., sledgehammer and base plate, vibroseis, urban traffic, etc.)

- Trigger switch

- Receivers (e.g., vertical or horizontal geophones, typically $<10 \mathrm{~Hz}$ center frequency)

- Multi-channel seismograph (e.g., Geometrics@ Geode)

- Controller (portable computer)

Using this equipment, two modes of data acquisition can be utilized based on the nature of the input surface waves. They are the active and the passive mode.

\subsubsection{Active Mode}

In an active MASW survey, an input surface wave is generated by a seismic source whose excitation time, location relative to the receiver array, and impact power are controlled by the user. Common seismic sources include an impact tool such as a hammer or accelerated weight drop (AWD) mechanism coupled with a striker base plate (Miller et al., 1986), an electromagnetic shaker (Wood and Cox, 2012), a bulldozer, sparker gun (Miller et al., 1986), or even explosives (Pullan and MacAulay, 1987; Miller et al., 1992; 
Miller et al., 1994). These sources are used to generate broadband frequency Rayleigh waves, which are then recorded using a linear string of receivers, typically $4.5 \mathrm{~Hz}$ vertical geophones. The geophones can either be coupled to the ground using spikes or may be fixed onto a land streamer and dragged into position. The choice between using a land streamer and coupling the geophones to the ground using spikes depends on ground conditions of the site, accessibility, and desired productivity rates. The maximum range for depth of investigation of a typical MASW active survey can vary tremendously from a few meters to $20+\mathrm{m}$. This depth is dependent on several factors including the magnitude of the impact load (which itself is a factor of the weight of the impacting tool and the material make-up of the base striker plate, the size of a potential electromagnetic shaker, etc.), frequency content of the input signal, stiffness of the soils, amount of background seismic noise, and length of the receiver array. Typically, sledgehammers are the most common seismic source due to their cost-effectiveness. Heavier impact loads from larger hammers typically result in deeper surveys. Also softer striker plate materials (e.g., plastic, rubber, etc.) are believed to aid with increasing survey depth compared to metallic striker plates at the expense of increased wear and tear on the striker plate (Kim and Lee, 2011). Softer striker plates may generate lower frequencies (longer wavelengths) in the corresponding input surface waves, which equates to greater depth of investigation. Vertical staking, which is the acquisition of multiple records at a given location and their summation into a single record, is encouraged to suppress ambient noise, especially if the survey takes place in an urban area. Finally, the cut-off frequency of the geophones plays a vital role in the acquisition of the broadband signals necessary to develop a dispersion curve over a wide range of frequencies. Geophones are 
manufactured with different cutoff frequencies. A geophone behaves as a simple harmonic oscillator and its cutoff frequency represents a boundary for its response. The sampling record is affected by distortion for waveforms with frequency content below the cutoff frequency, which means the geophone behaves as a low-cut filter. Ideally, low frequency geophones (i.e., < $10 \mathrm{~Hz}$ ) are recommended for MASW surveys to ensure sufficient low frequency energy is acquired. It is also necessary to consider the economics of the setup as the lower the frequency rating, the higher the cost of the geophone.

\subsubsection{Passive Mode}

The concept of passive arrays as a geophysical technique is reported to have been first developed in Japan (Okada 2003). In a passive MASW survey, a controllable seismic source is not actively utilized. Instead, data is collected from waves generated by background sources such as nearby traffic (Obando et al., 2009), ocean wave activity (Carnevale and Park, 2010), trains (Nolan et al., 2013) and artificial blasting (Ha et al., 2013). The passive survey is performed when larger investigation depths are required. This is because background passive seismic sources tend to generate lower frequency waves that sample larger depths. The general recommended spacing between geophones and the total amount of recording time in passive mode should be more than that used for the active survey. The reason for the increase in receiver spacing for a passive array is that the length of the array spread (D) is directly proportional to the longest wavelength $\left(\mathrm{L}_{\max }\right)$. Since passive surveys are typically focused on measuring low frequency components, the corresponding wavelengths are larger than an active survey and the array length must be increased to compensate. Also, the increase in recording time for the 
passive survey is to ensure that passive surface wave generation occurs at some point during the recording. Normally, the timing is set based on local traffic conditions (road survey) or frequency of recurrence of the background noise. Often in practice, active and passive surveys are both utilized in combination to fully characterize a site (Fig. 2-7). In this situation, both shallow and relatively deep $\mathrm{V}_{\mathrm{s}}$ can be obtained. The active mode fills in the relatively higher frequency (shorter wavelength) range in the dispersion image corresponding to shallow subsurface depths, whereas the passive mode provides the lower frequency range (longer wavelength) of the dispersion image associated with deeper strata.

\subsubsection{Data Processing}

After data acquisition in the field, the recorded surface waves are analyzed to develop a profile of $\mathrm{V}_{\mathrm{s}}$ of the underlying soils. The analysis process occurs in two phases: Dispersion and Inversion Analysis. The dispersion analysis precedes the inversion analysis just as in the case of the SASW method.

Dispersion analysis involves estimating the frequency-phase velocity relationship (i.e., dispersion curve) for a given site based on an acquired survey record. Dispersion images can be derived using a number of methods that transform a multichannel record in time (t)-space (x) domain into either frequency (f)-wavenumber (k) or frequency (f)-phase velocity $\left(\mathrm{C}_{\mathrm{f}}\right)$ domain [e.g., f-k method (two dimensional Fourier transform), phase shift method (Park et al., 1998), or pi-omega method (McMechan and Yedlin, 1981)]. The phase shift method is widely used because it has higher resolution than the pi-omega

method (Park et al., 1998; Moro et al., 2003). Once the dispersion image has been 
generated using any of the aforementioned methods, a characteristic dispersion curve that most accurately describes the frequency dependency of phase velocity at the site must then be selected.

Once a characteristic dispersion curve has been selected for the site, inversion analysis is performed to determine a representative $\mathrm{V}_{\mathrm{s}}$ profile. This inversion analysis occurs as an iterative process. An initial estimate of the site $\mathrm{V}_{\mathrm{s}}$ profile is developed and the dispersion curve from such a profile is determined based on a process known as forward modeling, which simulates Rayleigh wave propagation through an idealized model with homogeneous, isotropic, and horizontal layers. This theoretical dispersion curve is compared to the dispersion curve measured in the field. The initial model is adjusted based on the level of misfit between the theoretical dispersion curve and the measured field curve. The process is repeated until the amount of misfit between theory and field is minimized. This inversion process can either be achieved statistically or deterministically. The statistical approach searches for probable layered earth models based on a random approach (e.g., Monte Carlo method). The deterministic approach uses the previous iteration $\mathrm{V}_{\mathrm{s}}$ profile as an input (starting with an initial estimate) and marches through a least squares minimization process. The corresponding $\mathrm{V}_{\mathrm{s}}$ profiles are normally generated as one-dimensional (1D) and located at the midpoint of the survey. Two dimensional (2D) and even three dimensional (3D) profiles can be generated by running multiple surveys at the same site and utilizing an appropriate interpolation scheme where several 1D profiles are organized appropriately.

Dispersion and inversion analyses are performed using one of several available software 
packages (e.g., SeisImager/SW software package developed by Geometrics $\odot$ ). Researchers may also develop custom source codes from computer based programs such as MATLAB to perform these analyses.

\subsection{Advantages of MASW}

There are a number of useful advantages to MASW in relation to other subsurface investigation techniques, both in geotechnical engineering and geophysics. MASW, like other geophysical methods, can sample a larger area of a site compared to conventional subsurface exploration techniques that rely on drilling boreholes. Fig. 2-8 illustrates the superiority of MASW over conventional drilling methods in terms of continuous spatial coverage. Furthermore, MASW has relatively low acquisition, processing, and interpretation costs compared to traditional conventional drilling methods for site characterization (Park et al., 1999). The method can also be used to acquire data in areas of limited access where large drilling equipment or other subsurface equipment such as a Seismic Cone Penetrometer Test (SCPT) truck cannot be utilized.

In comparison to conventional subsurface seismic survey methods such as cross-hole and down-hole, MASW is less expensive and less time consuming. In comparison to other surface seismic methods (e.g., seismic reflection/refraction), MASW has better signal-to-noise ratio (SNR) and does not suffer from limitations related to velocity inversions (e.g., stiff over soft soil layers). The seismic reflection/refraction method requires that the layers at a site continually increase in seismic velocity with each successively deeper layer. MASW is capable of resolving velocity profiles where a low velocity layer underlies a high-velocity layer, which is exceedingly common in urban 
areas where the upper soils may have been altered due to development. Finally, MASW has benefits over electrical and magnetic geophysical methods such as Ground Penetrating Radar (GPR) Electrical Resistivity Imaging (ERI), and Surface Proton Magnetic Resonance Soundings (MRS), among others. This is particularly the case when sampling conductive soils such as clays, because electrical and magnetic signals are heavily attenuated by the conductive soils (Collins et al., 1994).

\subsection{Limitations of MASW}

Even though MASW has better SNR compared to other seismic methods (Park et al., 1999), near-field and far-field effects can affect the accuracy of the phase velocities deduced from MASW during dispersion analysis. Near field effects refer to issues that arise in measured dispersion curves from non-planar surface waves. The theoretical underpinnings of MASW rely on planar surface wave propagation. If the seismic source is too close to the receivers, sufficient distance is not available for the input Rayleigh wave to develop into a plane wave, resulting in reduced accuracy of phase velocities. Studies have shown that near-field effects can be significant at wavelengths greater than one-half the receiver-spread length for linear arrays (Bodet et al., 2009), at wavelengths greater than the mean-source to receiver distance (Yoon and Rix, 2009), or at wavelengths greater than twice the mean source to receiver distance (Li and Rosenblad, 2011). These restrictions must be balanced against field logistics and disadvantages of excessively long arrays (e.g., higher mode contamination, decreased signal to noise ratio at further geophones, etc.). Furthermore, the topography of the site may also influence the efficacy of the method. Either flat ground or a gently sloping site is normally ideal for the deployment of the MASW technique. Vertical gradation changes may pose a challenge to 
the accuracy of MASW if the vertical rise of the surface over the length of the receiver spread is greater than $10 \%$ of the receiver spread length (Park et al., 1999). Specific details regarding appropriate data acquisition parameters and equipment layout have been prescribed by various researchers and documented for use since the development of the method in the late 1990s (e.g., Park et al., 2002).

Lateral heterogeneity of the soil profile is another issue that affects MASW surveys (Yilmaz and Kocaoglu, 2011). Lateral heterogeneity is when one or more layers within the subsurface are discontinuous throughout the area of study. This is very common in naturally occurring subsurface profiles. If the array is setup to record data in an area in which there is lateral heterogeneity, the $\left(\mathrm{V}_{\mathrm{s}}\right)$ profile generated assumes that the layers continue across the entire stretch of the area under study. This can lead to large errors in estimated velocities. A number of researchers have attempted to address this limitation (e.g., Benson et al., 2007; Bignardi et al., 2012) but all commercial software packages model laterally homogeneous layers.

The non-uniqueness of inversion profiles for different soils is another potential limitation of MASW. The soils beneath two completely different sites could have almost the same exact dispersion curve despite very different $\mathrm{V}_{\mathrm{s}}$ profiles. Simply put, multiple $\mathrm{V}_{\mathrm{s}}$ profiles can result in nearly identical dispersion behavior. Since the inversion process is primarily adjusting the $\mathrm{V}_{\mathrm{s}}$ profile to "match" the measured dispersion curve from the field, it is not easy to know if one is obtaining the $\mathrm{V}_{\mathrm{s}}$ profile that best summarizes site conditions or one of several other profiles that can result in a similar dispersion curve. This ambiguity ideally calls for some prior generalized information (e.g., other geophysical test results, 
drilling information, etc.) about the area where MASW is scheduled to be used so that constraints can be introduced into the inversion process.

Finally, issues can arise in MASW from higher mode Rayleigh wave propagation. On a typical dispersion image, there are multiple phase velocities that can be associated with a given frequency component. The lowest phase velocity represents the fundamental mode and the highest phase velocity represents the highest mode. Normally, most commercial software inversion algorithms assume that the fundamental mode dispersion curve has been extracted from the dispersion image. If the modes overlap each other and are not distinguishable in the dispersion image, there is the tendency to extract the dispersion curve across several modes. Inversion based on this mixed mode dispersion curve can yield an inaccurate $\mathrm{V}_{\mathrm{s}}$ profile.

The issues noted in the preceding discussion highlight that MASW must be used appropriately with a thorough understanding of its limitations. In some cases, it may be possible to address some of the limitations. For example, the non-uniqueness issue can be improved by constraining the inversion with a priori information regarding subsurface stratigraphy. In situation where soil profile variability is pronounced, 2D and 3D surveys may help address problems of lateral heterogeneity. However, in some cases the limitations of MASW can render the technique impractical or highly inaccurate at certain sites and care must be exercised in its application.

\subsection{The Role of Seismic Sources for MASW}

Some of the sources typically used for MASW surveys include sledgehammers of various sizes, accelerated weight drops (AWD), vibratory sources (e.g., electro-mechanical 
shakers), and explosive sources (e.g., betsy seisgun) (Fig. 2-9). As noted in section 2.2.1.1, dispersion analysis involves the transformation of a multichannel record in time (t)-space (x) domain into either frequency (f)-wavenumber (k) or frequency (f)-phase velocity $\left(\mathrm{C}_{\mathrm{f}}\right)$ domain. The broad spectrum of frequencies generated from the transformation allows for a smooth dispersion curve that has no gaps. The energy present on a dispersion image will vary based on field acquisition parameters, equipment used, and the nature of the seismic source. For the same active MASW setup, different seismic sources will develop different patterns of energy accumulation at various frequencies on the dispersion image. For example, studies have shown that the wave energy for heavier sources include lower frequencies compared to less heavy sources (Miller et al., 1986; Park et al., 2002; Carnevale and Park, 2010; Wood and Cox, 2012; Kumar and Rakaraddi, 2013). This increase in the low frequency of the input signal typically results in increased depths of investigation, which is highly desirable. An increase in depth of investigation can yield highly useful information, particularly about potential bedrock conditions.

However, the use of heavier sources has some setbacks and notable amongst them is cost. Therefore, from an economic perspective, it is necessary to justify the use of heavier sources. Budgetary constraints on numerous small scale projects do not always afford project owners and researchers alike to use heavier sources for their investigations. Other challenges associated with heavier sources include mobilization issues, lengthy operation procedures, and relatively slow production rates. Passive surveys are an alternative to sample deeper. However, passive testing requires significant background seismic source that is capable of producing low frequency energy. Also, passive MASW requires longer array spreads (e.g., roadside survey) and larger open areas (e.g., remote surveys) for its 
use, which could pose issues with space constraints at certain sites. These challenges therefore present a rationale for a holistic review of seismic sources to identify other potential cost effective options to transmit low frequency energy into the ground and increase depth of investigation.

One aspect that has not been explored in great detail is the influence of the base plate on the input surface wave for MASW testing. The base plate is the medium that receives the impact load from the impact tool such as the sledgehammer. The base plate helps to transmit more effectively the generated waves (body and surface) into the ground. When an object strikes the ground, a small fraction of the total kinetic energy is transformed into useful compression energy. Earthen material (i.e., soil and rock) is typically behaves as a plastic material. Thus, when it is subjected to compressive stress it will under undergo permanent plastic deformation, which is associated with energy loss. Therefore, if an impact tool is applied to the earth surface to generate mechanical stress waves, only a small percentage of the impact energy is converted into the required mechanical stress wave due to the energy loss resulting from the plastic deformation. However, if an intermediate mass with a suitable surface area and elastic behavior is placed at the point of impact, plastic deformation of the earthen material is reduced due to the elastic deformation of the plate itself. The reduction in permanent plastic deformation results in less energy loss and in the generation of more useful mechanical stress wave energy for a given impact (Mereu et al., 1963). The preceding discussion demonstrates that the striker plate is very useful as part of the seismic source. Even though this work by Mereu et al. (1963) was theoretical in nature, the use of a coupling system with a seismic source has been empirically shown to improve energy input during seismic geophysical testing. For 
example, Kumar and Rakaraddi (2013) performed research to demonstrate the usefulness of the base plate in increasing the depth of sampling for seismic geophysical methods. Compared to the impact tool, the base plate is much lighter and easy to move around. Kumar and Rakaraddi (2013) also showed that the base plate can increase the amplitude of the generated wave in seismic testing, which yields results with much higher resolution. It is generally accepted that using a striker plate with softer material (e.g., rubber, plastic, etc.) can enhance the low frequency content of an input Rayleigh wave (Kim and Lee, 2011; Jeong and Kim, 2012). This presents an opportunity to continue using typical smaller seismic sources (e.g., sledgehammers) but to improve the low frequency energy present for interpretation of the measured dispersion curve and to increase depth of investigation. Therefore, there is a definitive need to investigate and quantify striker plate effects on measured dispersion curves, particularly any improvement on the low frequency content and corresponding depths of investigation.

\subsection{Previous Studies}

As previously noted, researchers and practitioners have proposed that the condition (i.e., base plate material and impact load magnitude) of an impact seismic source can affect the desired depth of investigation. A number of studies have been conducted in the field to ascertain the effect of the impact seismic source on the resolution and achievable depths for results from various seismic geophysical methods, including MASW/SASW. Most of these studies have focused on the total energy input by the seismic source or the mechanisms by which the energy was input into the domain (e.g., impact, swept harmonic source, etc.). Relatively few studies have explored the role of the base plate. 
Miller et al. (1986) conducted a study to compare the results for different seismic sources in a seismic reflection setup for a field site near Atlantic City, New Jersey. The results from the sources were displayed as seismograms and corresponding amplitude spectra. The objective of the study was to assist subsurface investigators to select optimum seismic sources for their seismic reflection studies. The sources investigated included sledgehammers, explosives, weight drops, projectile impacts and several configurations of buffalo guns. Specifically, 26 different sources were used to generate waves, of which 15 were compared in the paper. An estimate of the relative energy for each shot record was used to compare the ground roll energy (i.e., surface waves) and the reflection energy of the different sources (Fig. 2-10). The difference in the magnitude of the two forms of energy on the energy bar graph affirms the variable effect that the type of source has on the waveform generated in a geophysical survey. The results demonstrated that the $7.3 \mathrm{~kg}$ sledgehammer used in the study is a relatively low energy source. However, they left the judgment on source selection to the reader given that selection of an optimum source is highly site specific and influenced by a number of parameters besides energy. Miller et al. (1992) performed a similar study at a field site in Chino, California. This study included explosives as alternatives for the seismic sources, something not considered in the original Miller et al. (1986) study. The objective of the Miller et al. (1992) study was to see if they could replicate the results of the earlier studies given different soil and geological conditions. Again, the authors did not publish any clear cut conclusion on the optimum seismic source selection. Fig. 2-11 shows the variation of the amplitude from the 23 sources used for the experiment. Finally, Miller et al. (1994) repeated these observations at a site near Houston, Texas to compare shallow P-wave seismic sources. 
No specific optimum seismic source selection was proposed in this experiment. However, it was observed across all the three experiments that weight drop sources (e.g., sledgehammers) are more suitable and cost effective for sites with dry and stiff soils. In cases of saturated fine-grained soil located in the near-surface, downhole sources are more likely to generate better results, particularly when the fine grained soils are soft.

Park et al. (2002) also reviewed optimum source parameters, this time as applicable for an MASW survey. As part of this study, Park et al. (2002) compared dispersion curves generated using three different sources, which included a $4.5 \mathrm{~kg}(10 \mathrm{lb})$ sledgehammer, a $9 \mathrm{~kg}(20 \mathrm{lb})$ sledgehammer, and a rubber band-aided-weight-drop (RAWD). Based on the results of the study, Park et al. (2002) noted minimal increase in low-frequency $(<10 \mathrm{~Hz})$ energy when the $9 \mathrm{~kg}$ hammer was used in comparison to the $4.5 \mathrm{~kg}$ hammer. Additionally, though counterintuitive, Park et al. (2002) found that using the maximum impact strength of the RAWD resulted in the least amount of low-frequency energy. Instead, the presence of higher mode energy at higher frequencies increased as the source changed from the $9 \mathrm{~kg}$ hammer to the RAWD (Fig. 2-12). Thus, an increase in the impact strength did not necessarily result in greater energy at lower frequencies.

Wood and Cox (2012) compared dispersion curves generated using a $4.5 \mathrm{~kg}$ sledgehammer and a harmonic (vibroseis) source at various offsets from the array setup. Wood and Cox (2012) noted that a $4.5 \mathrm{~kg}$ sledgehammer can generate surface wave energy down to $10-15 \mathrm{~Hz}$. The wavelengths generated from this source can penetrate up to $30 \mathrm{~m}$ into the soil profile depending on the stiffness of the site (i.e., stiffer sites allow increased penetration for a given wave frequency). Wood and Cox (2012) also observed 
that the vibroseis was ideal for deep profiling purposes irrespective of the stiffness properties of the subsurface. Additionally, for frequencies greater than $20 \mathrm{~Hz}$ and wavelengths less than $20 \mathrm{~m}$, both the sledgehammer and vibroseis sources generated very comparable results. For frequencies less than $20 \mathrm{~Hz}$ (i.e., wavelength larger than $20 \mathrm{~m}$ ), Wood et al. (2012) noted as much as $40 \%$ differences in phase velocities when comparing the results from a sledgehammer and a vibroseis (Fig. 2-13). Finally, for frequencies less than $20 \mathrm{~Hz}$ (i.e., wavelength larger than $20 \mathrm{~m}$ ), Wood and Cox (2012) also observed much higher uncertainty in the energy accumulation at a given frequency on the dispersion curve when a sledgehammer was used.

Kumar and Hazra (2014) examined the role of the impact source in SASW testing. A series of SASW tests was performed to evaluate the variation in dispersion curves caused by varying the diameter of the impact source (steel balls), source to nearest receiver distance, receiver spacing, and drop height. Four different steel balls of diameters 25.4 $\mathrm{mm}$ (1 in), $38.1 \mathrm{~mm}(1.5 \mathrm{in}), 50.8 \mathrm{~mm}(2 \mathrm{in})$ and $76.2 \mathrm{~mm}(3 \mathrm{in})$ were used in the experiment. From the experiment, Kumar and Hazra (2014) observed that the input energy from the source increased with increasing steel ball diameter and this also resulted in increasing wavelength (Fig. 2-14). Kumar and Rakaraddi (2013) performed a similar series of SASW testes on two geological sites. As in the previous study, Kumar and Rakaraddi (2013) performed the tests with variations in drop height of a cylindrical mass as well as variations in the source to first receiver distance and receiver spacing. They also performed the experiments by dropping the weight on a plate and also on the bare ground. Based on the results, it was observed that, for a given source to first geophone distance and distance between geophones, larger source drop heights yielded waves with 
longer wavelengths. Under the above conditions, it was also observed that the inclusion of the base plate yielded waves with much longer wavelengths (low frequency) and higher amplitudes compared to without the base plate. This experiment demonstrated that the base plate is useful in sampling deeper strata for an SASW or MASW setup, though a systematic investigation of different base plates (e.g., material types, surface area, mass, etc.) was not undertaken.

The previous references highlighted studies that almost entirely focused on the effects of source type or size on the signals acquired using seismic methods. Only a limited number of studies have examined the role of the base plate. For example, Mereu et al. (1963) theoretically assessed the relevance of the baseplate in the conversion of impact energy into seismic energy. In this study, a review was performed regarding the magnitude of useful compression energy generated when an object is struck against the ground in comparison to when an intermediate mass is placed between the object and the ground. The researchers deduced that the apparent wider plastic region (smaller elastic) in earthen material tends to cause an increase in energy loss in the conversion of kinetic energy into useful compressional energy. Mereu et al. (1963) also noted that the inverse was true in that materials with wider elastic (smaller plastic) region tend to undergo less energy loss during that conversion. Such materials if used as a coupler in the seismic source will enhance the seismic energy generation. Therefore, Mereu et al. (1963) demonstrated that the striker base plate is a necessary component in a seismic source setup as it effectively couples generated waveforms into the receiving body (ground).

With respect to configuration and characteristics of the base plate, Keiswetter and 
Steeples (1995) examined their effects on shallow seismic- reflection data at three sites. Among other things, Keiswetter and Steeples (1995) studied the effects of modifications to the striker plate mass and surface area properties. The objective of the study was to ascertain the optimum characteristics of the seismic source component that reflects high resolution seismic reflection data. The plate mass and surface area variation was between $2.7 \mathrm{~kg}(5.95 \mathrm{lb})$ to $10 \mathrm{~kg}(24 \mathrm{lb})$ and $140 \mathrm{~cm}^{2}\left(0.15 \mathrm{ft}^{2}\right)$ and $548 \mathrm{~cm}^{2}\left(0.59 \mathrm{ft}^{2}\right)$, respectively. Keiswetter and Steeples (1995) deduced from the experiment that the plate mass variation does not really affect the spectral content of the data across the site they tested. Fig. 2-15 shows the seismic data and relative energy bar graph resulting from an increase in plate mass for one of the three sites. Also in terms of the plate area variation with constant impact energy, the researchers reported an increase in seismic energy with an increase in plate surface area for sites with thick soil overlay. However, Keiswetter and Steeples (1995) did not find as large of an increase for sites with surficial sands and gravels. The simple nature of the field experiments meant that the results were highly site specific.

Literature that focused solely on the effects of base plate material and/or shape for surface wave testing was sparse. The limited efforts in this area were international studies performed in Korea. Kim and Lee (2011) summarize one of these studies where a comparison was performed of the signals generated by metal (steel and aluminum) plates and plastic (PE and nylon) plates at a single site in the field. Comparison of the signals included evaluating the amplitude and frequency of the waves generated using the plates. The experiment was a small scale shallow seismic survey setup in which a $1 \mathrm{~kg}(2.2 \mathrm{lb})$ hammer was affixed to a hinge. The amplitude and frequency content of the impact force 
was measured using a force sensor connected to a power measurement test board (Model FP-BTA). From the experiment, Kim and Lee (2011) observed that the waves generated with the metal plates have higher amplitude and higher frequency, with the steel plate generating the highest frequency and amplitude (Fig. 2-17 - 2-18). Kim and Lee (2011) also examined the effect that orientation of the strike plate has on the frequency content of the input wave. Fig. 2-18 illustrates the variation of the input wave frequency content generated using the various striker plates when the long side of the plate is perpendicular to the array line. Kim and Lee (2011) demonstrated that plastic plates can be used instead of aluminum plates for shallow seismic survey if increases in survey depths are required. This is because the waveforms generated from them have very low frequency (higher wavelength). The work performed by Kim and Lee (2011) occurred at a single site and there was no variation in the source offset locations during data sampling, which limits the conclusiveness of the results. It is therefore necessary to ascertain the trends in the results from the study by varying several aspects of the data collection and configuration of components. These include the source offset locations, the hammer sizes, and the sites where data is collected. It may be that a combination of certain features (hammer size, source offsets, etc.) can drastically affect the results. This calls for additional studies. Furthermore, in a similar study, Jeong and Kim (2012) also analyzed the effect that the shape of a PE striker plate has on the recorded signals at a given site. The authors considered a circular, square, and rectangular striker plate for the experiment. The overall experimental setup was similar to Kim and Lee (2011), though Jeong and Kim (2012) performed their experiments at a reduced scale in the laboratory. From the experimental results, the authors deduced that generally, the rectangular plate generates larger signal 
power compared to the other two plates. The authors also suggested that the signal power and characteristic frequency band is the highest when the long side of plate is perpendicular to the array line. Fig. 2-19 illustrates the variation of the measured frequencies and measured signal power for the various striker plate shapes when the long side of the plate is perpendicular to the array line.

From all the literature reviewed, it is evident that the characteristics of seismic impact sources (i.e., impact load and composition of base plates) have significant effects on the energy content (amplitude) and frequency of the generated waves. The resolution and depth of investigation for an MASW survey is a function of the frequency and amplitude of the energy generated by the seismic source (Yordkayhun and Jumras, 2012). It is therefore necessary to optimize the selection of a seismic source such that its characteristics are appropriate for describing the subsurface at the required depth. Multiple studies have demonstrated that the optimum seismic source is site specific (e.g., Miller et al., 1986; Miller et al., 1992; Miller et al., 1993). Therefore, any recommendations regarding the effects of seismic source must be supported by a significant amount of evidence from experiments with multiple ranges in site conditions. A relatively large body of results exists across a wide range of sites to validate general trends regarding the effects of impact amplitude (e.g., Miller et al., 1986; Miller et al., 1992; Miller et al., 1994; Park et al., 2002; Wood and Cox, 2012). However, very little work besides Kim et al. (2011) and Jeong and Kim. (2012) has been devoted to establishing such general trends regarding base plates. In order to develop general recommendations, more research is necessary using the same approach as these studies, but replicated across several sites to see if indeed, softer striker plates aid in sampling 
deeper strata irrespective of the site conditions.

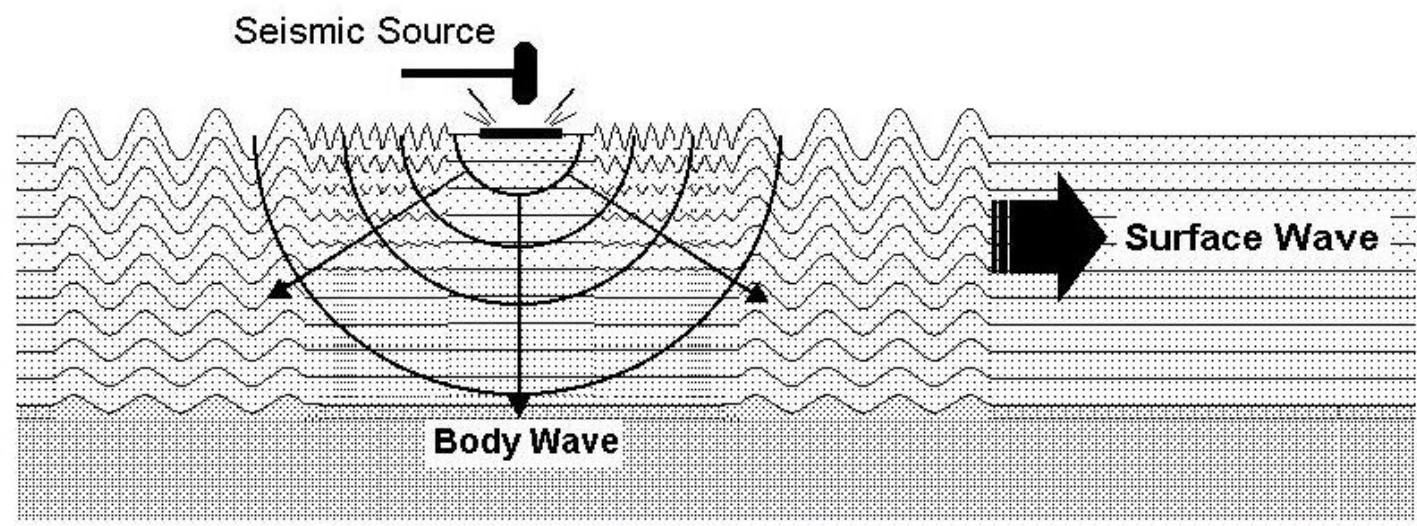

Fig. 2-1: Surface waves travel primarily near the surface of a medium in comparison to body waves that radiate in all directions internally within the medium (Park et al., 2002).

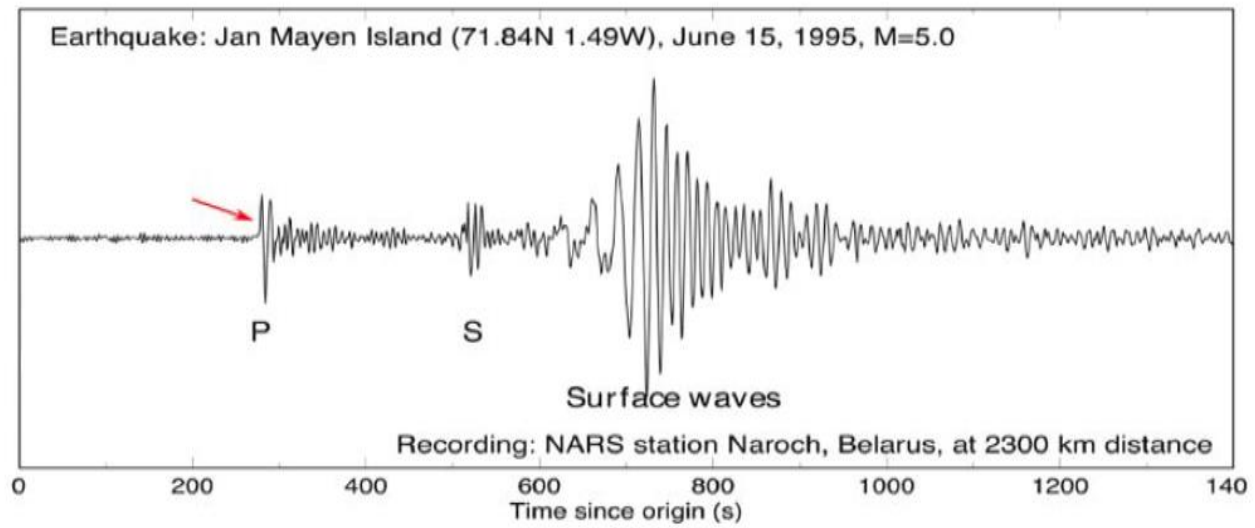

Fig. 2-2: Variation of wave amplitudes between body waves (P and $S)$ and surface (Rayleigh) waves (Kayal, 2000). 


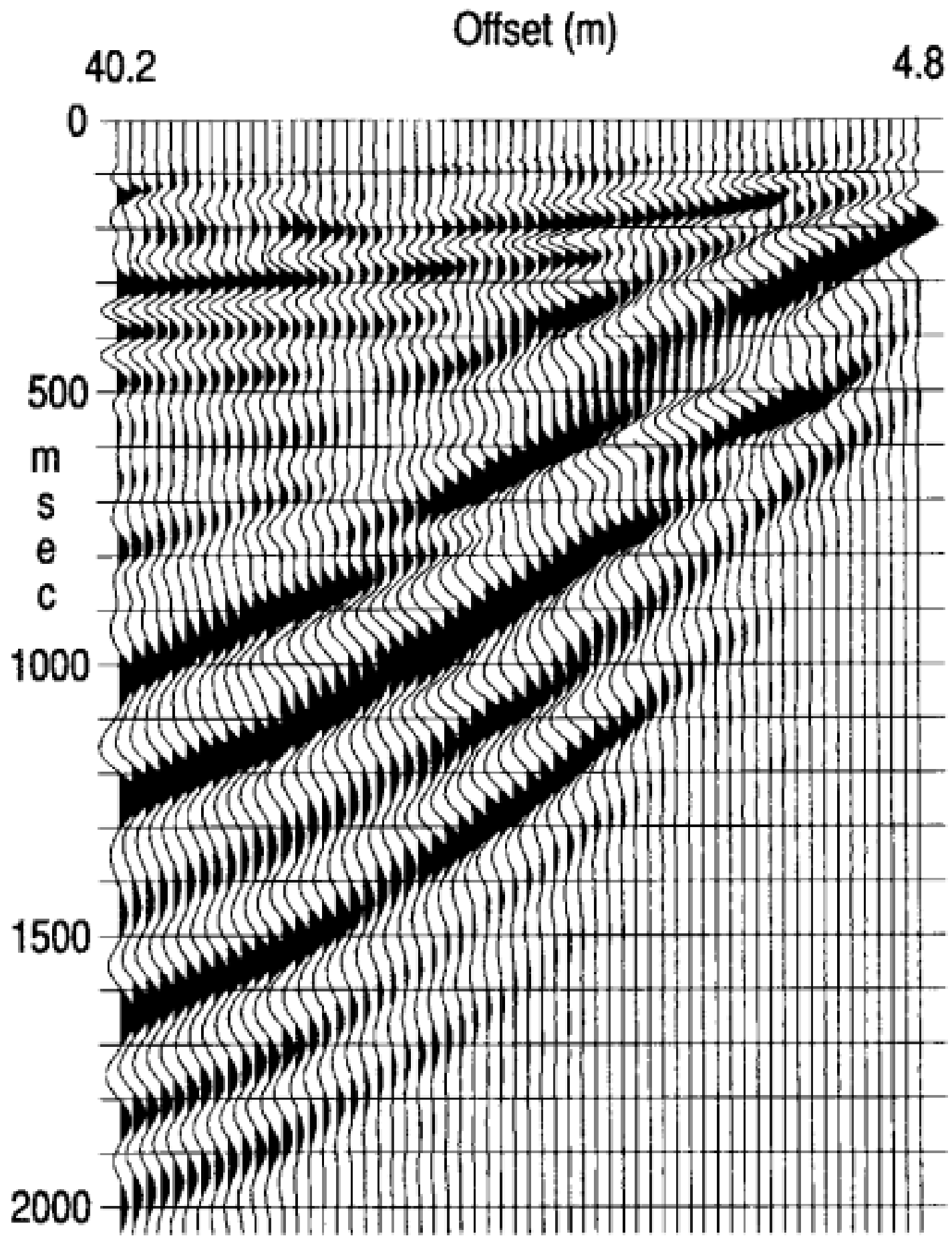

Fig. 2-3: An illustration of how a typical surface wave spreads out as the wave propagates away from the source (Xia et al., 1999). 


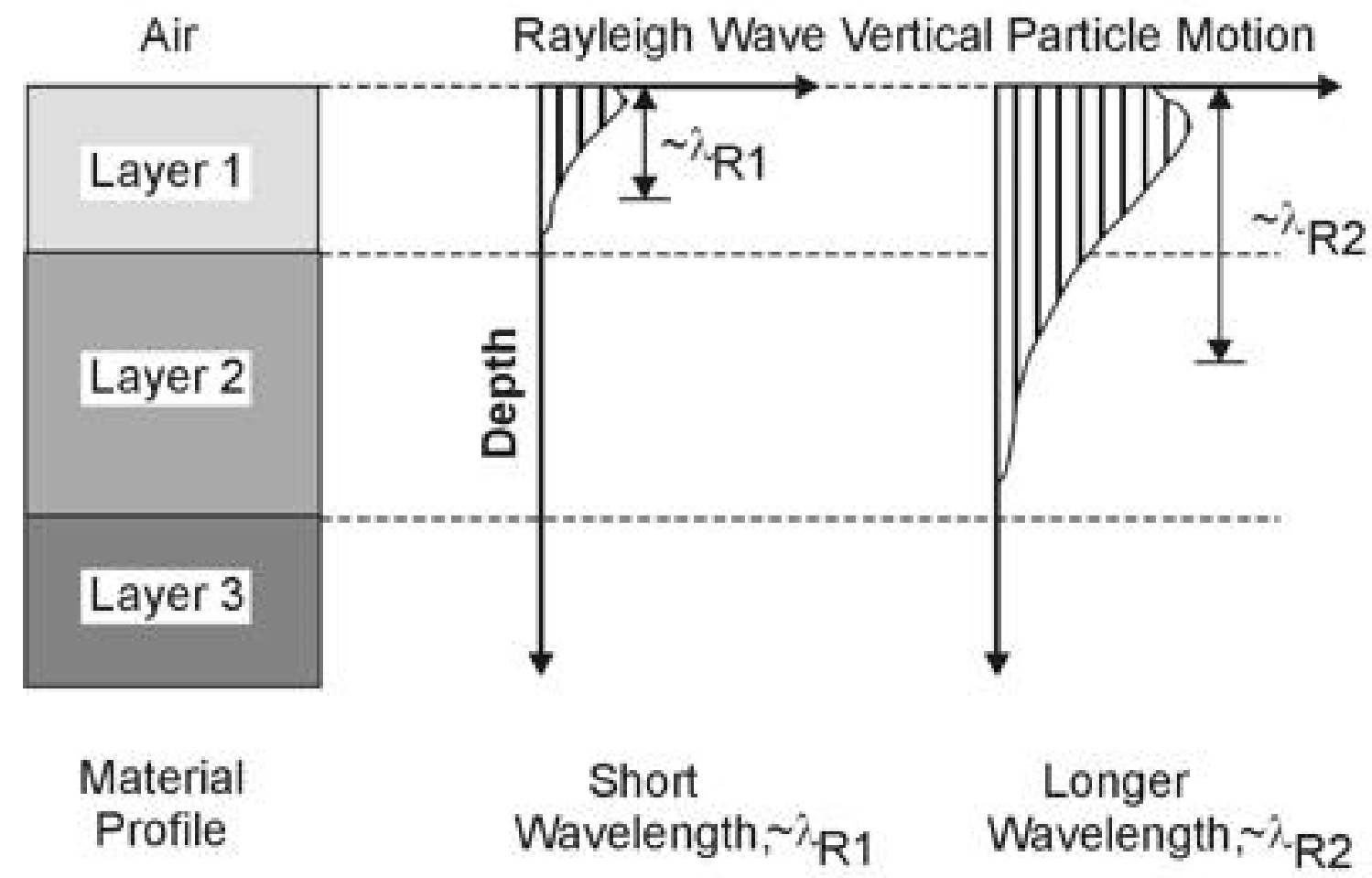

Fig. 2-4: Depth dependency of Rayleigh wave motion as a function of wavelength (i.e., frequency) (Rix and Stokoe, 1989). 


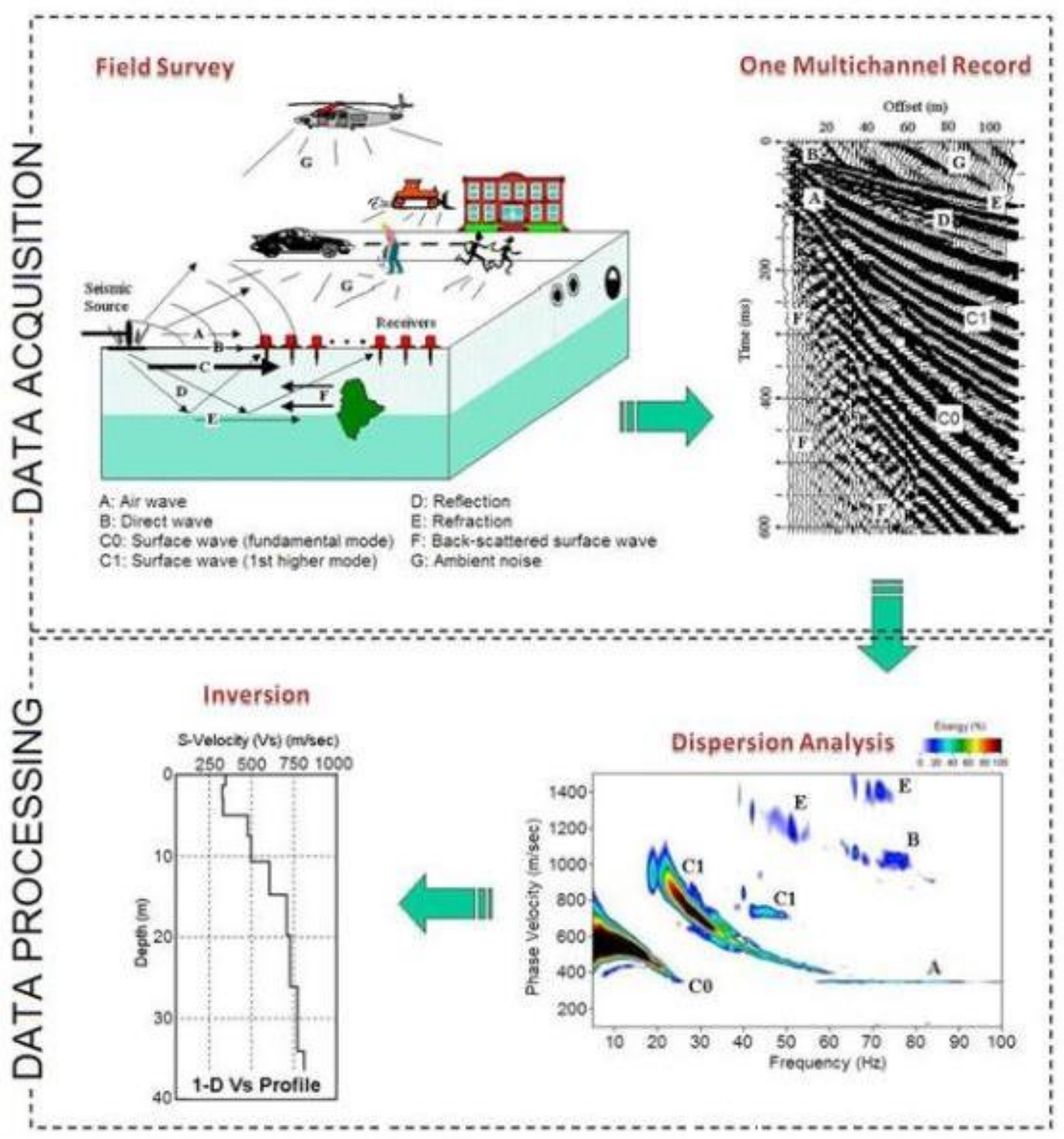

Fig. 2-5: Schematic of data acquisition and processing in the MASW method (Park et al., 2007). 


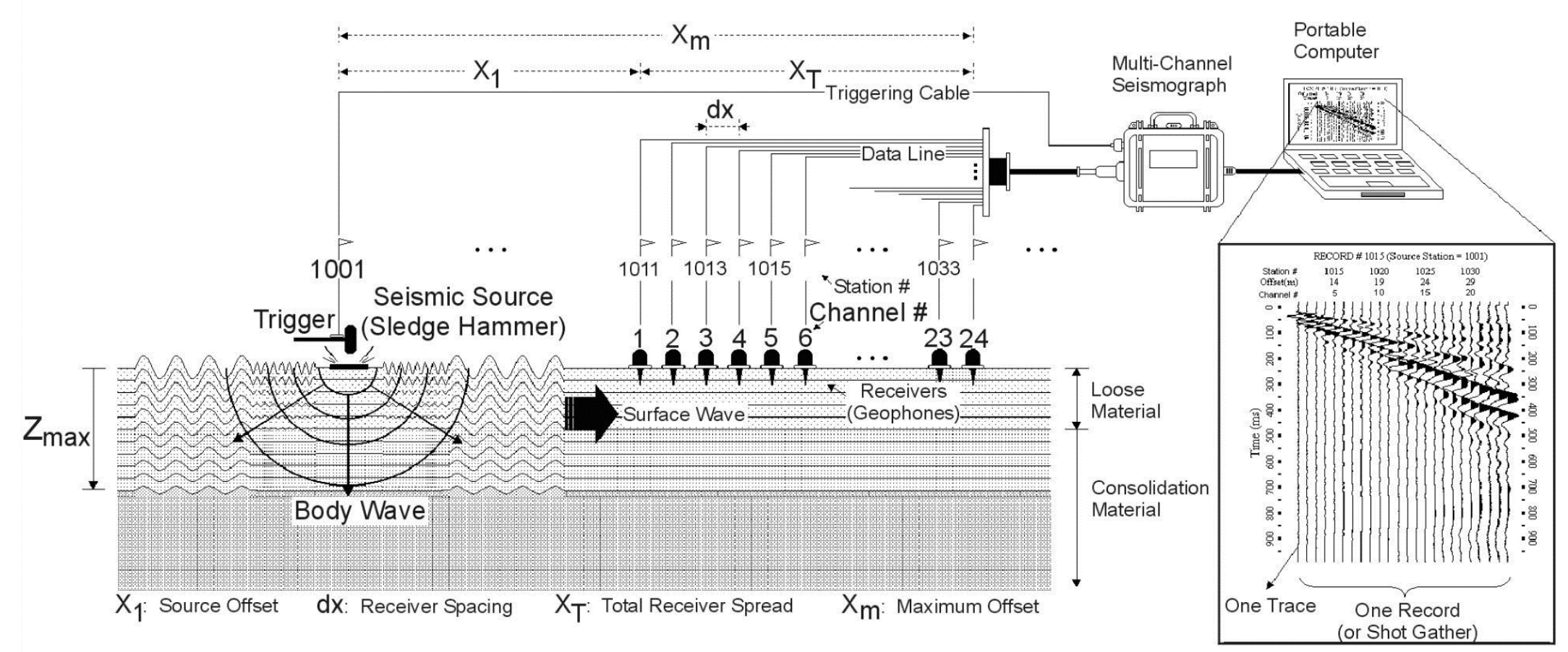

Fig. 2-6: Typical MASW data acquisition using an active source (Park et al., 2000). 


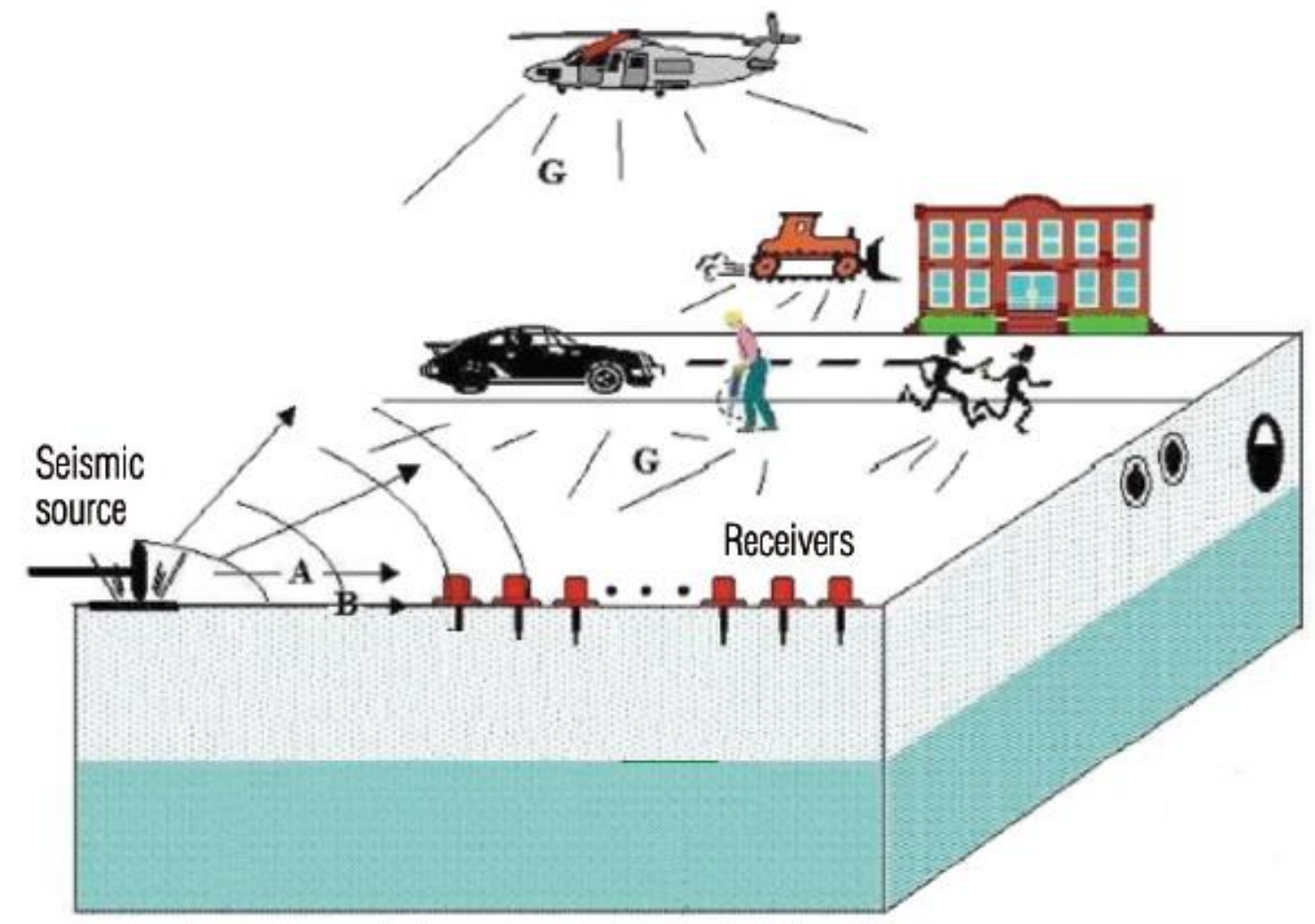

Fig. 2-7: Illustration of a combined active and passive survey (Park et al., 2007). 


\section{SEISMIC SURVEY}

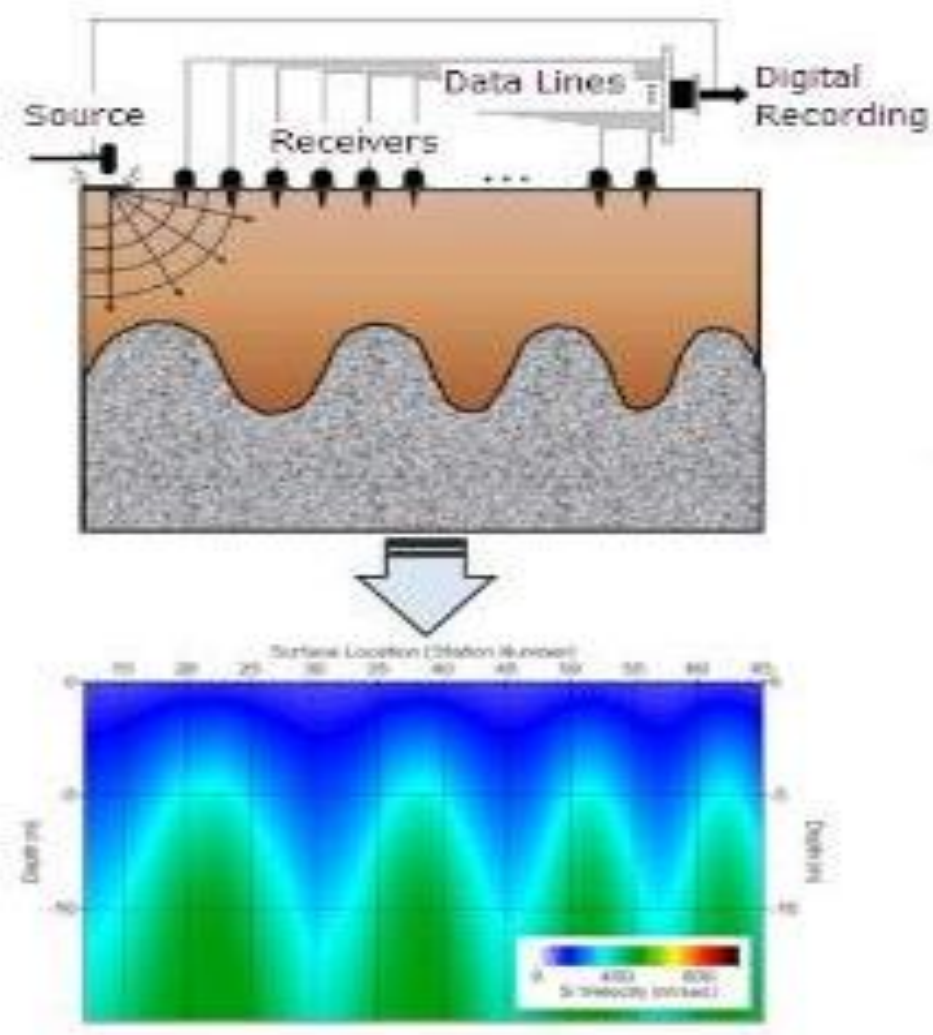

DrILling

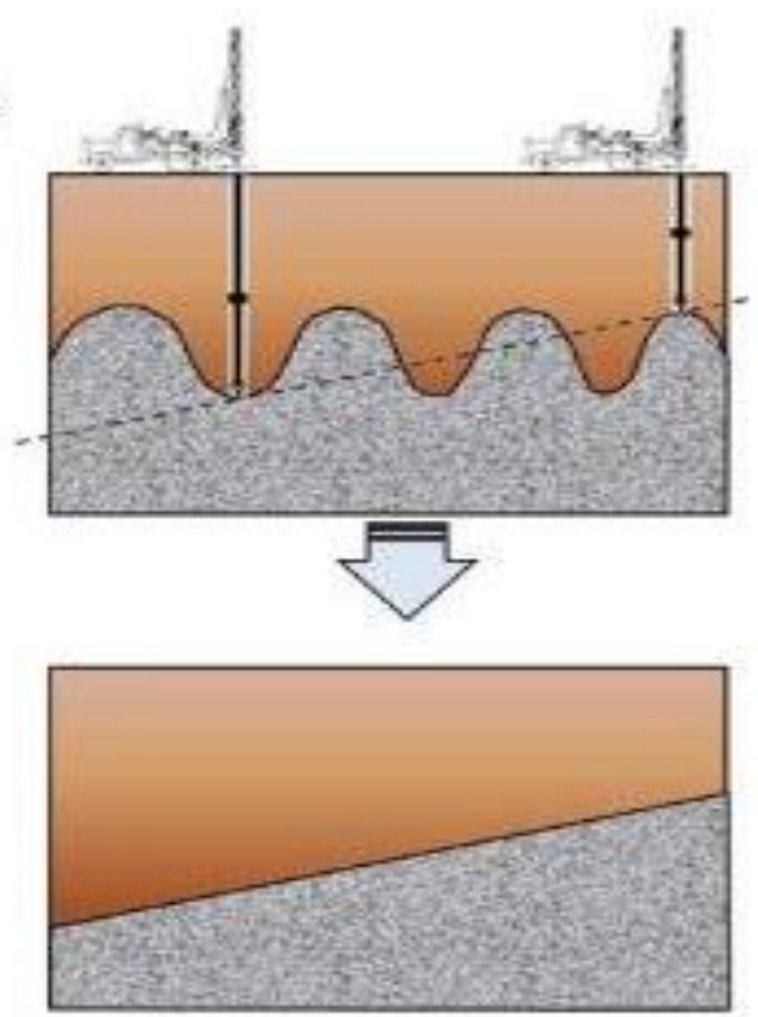

Fig. 2-8: Comparison of spatial coverage between MASW and conventional drilling (Park et al., 2000). 


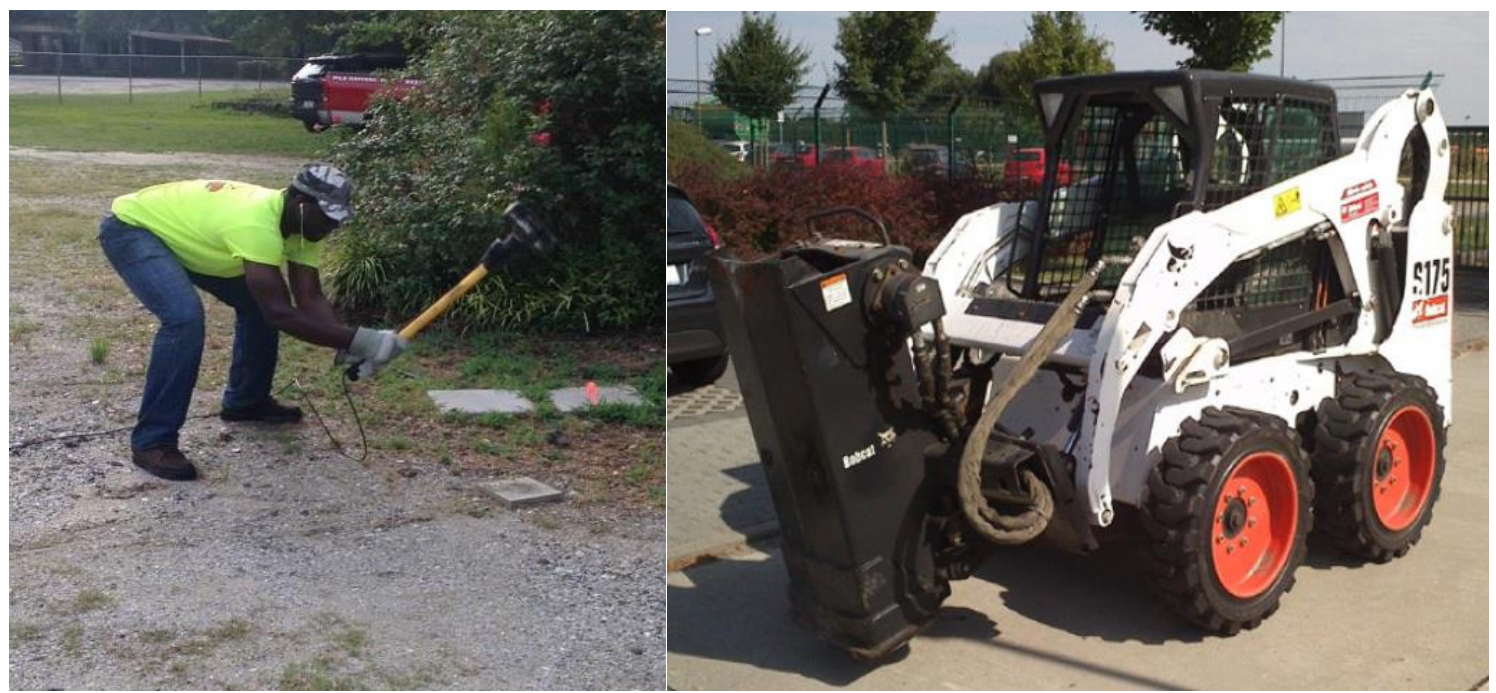

(a)

(b)

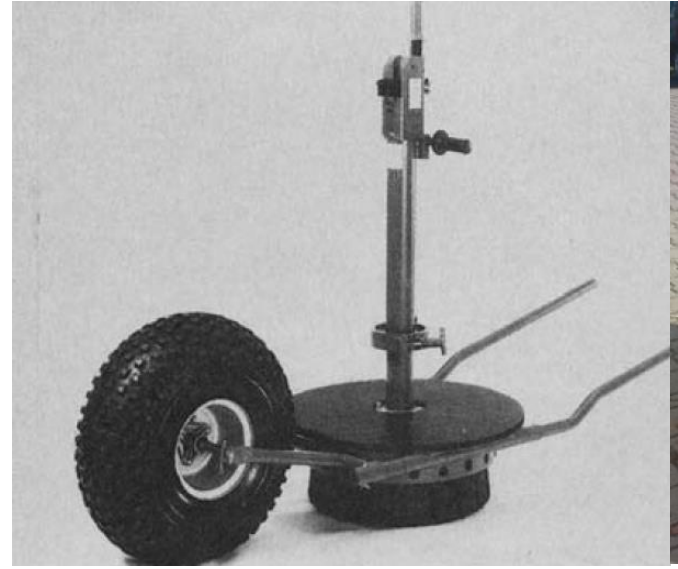

(c)

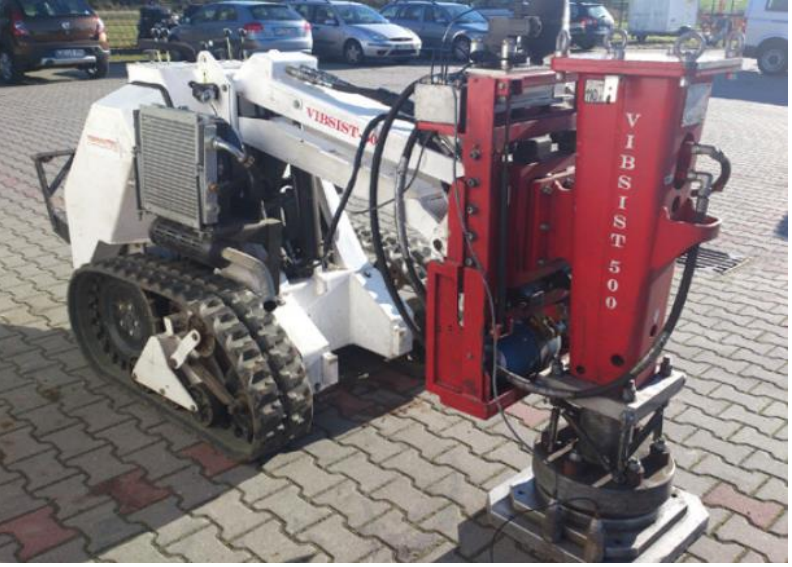

(d)

Fig. 2-9: Various seismic sources: (a) Sledgehammer; (b) Accelerated weight drop (Sopher et al., 2014); (c) Betsy seisgun (Miller et al., 1986); (d) Vibsist vibroseis (Sopher et al., 2014). 


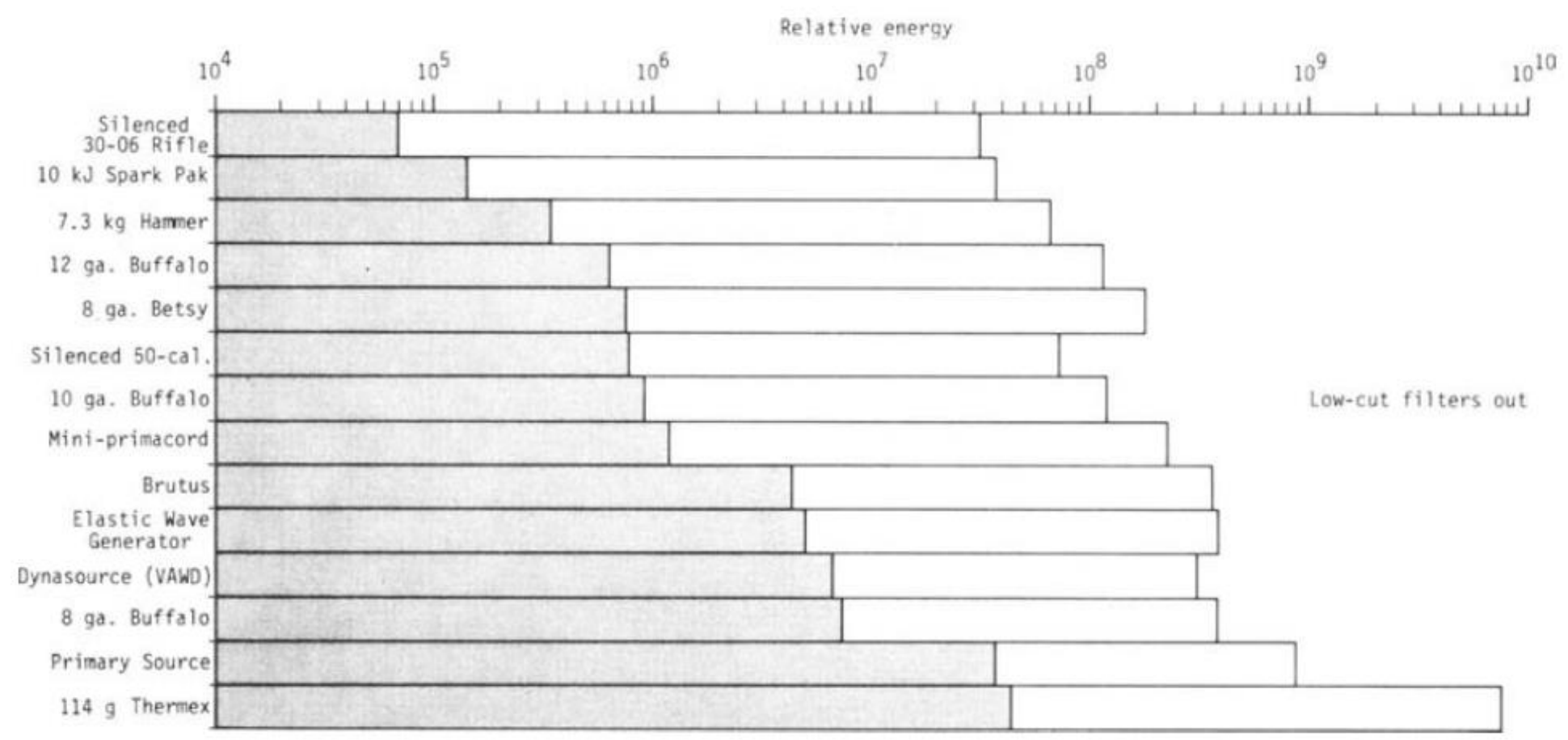

Fig. 2-10: Illustration of the variation in surface wave (white bars) versus body wave (grey bars) energy for various sources (Miller et al., 1986). 


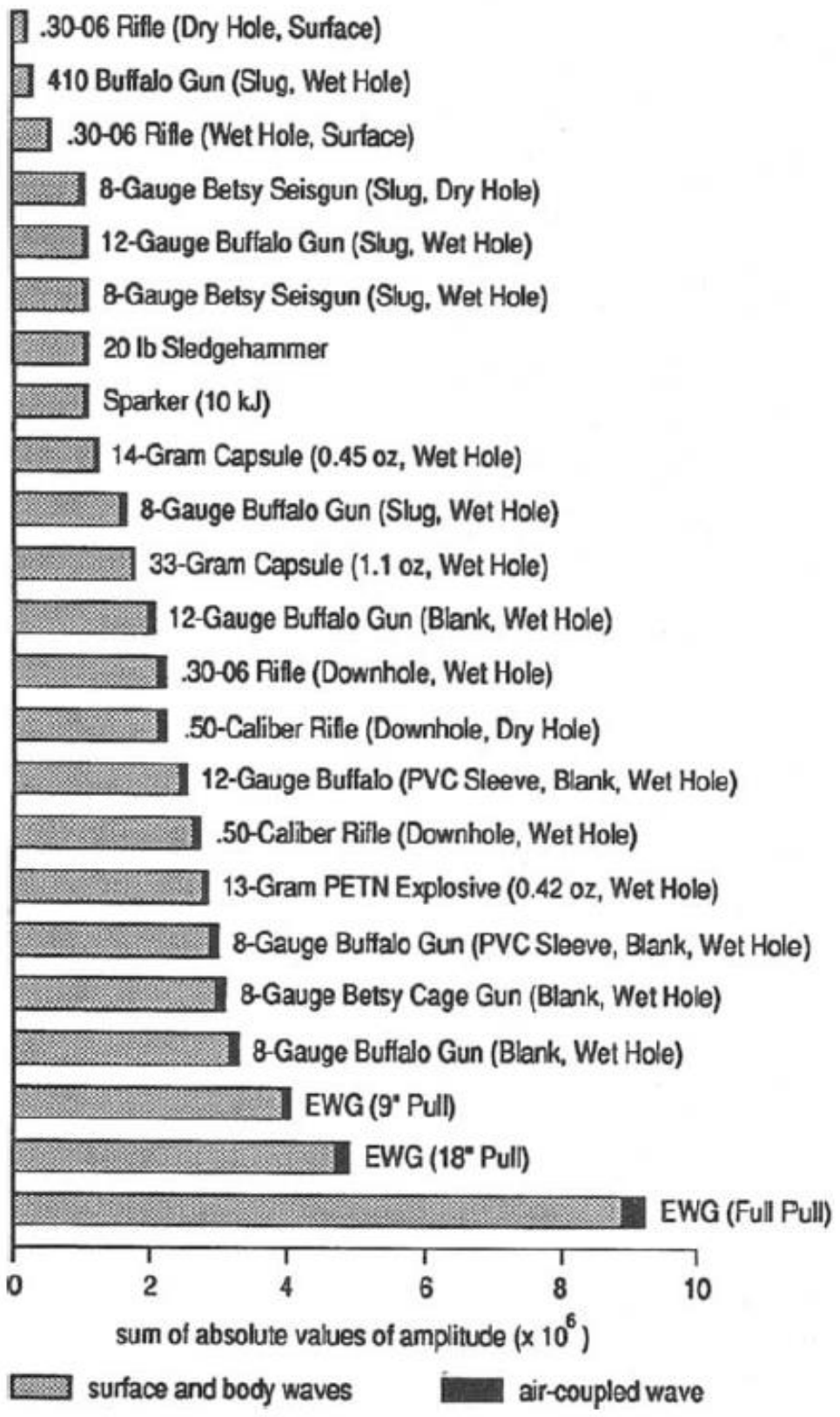

Fig. 2-11: Illustration of the amplitude variation across various seismic sources (Miller et al., 1992). 

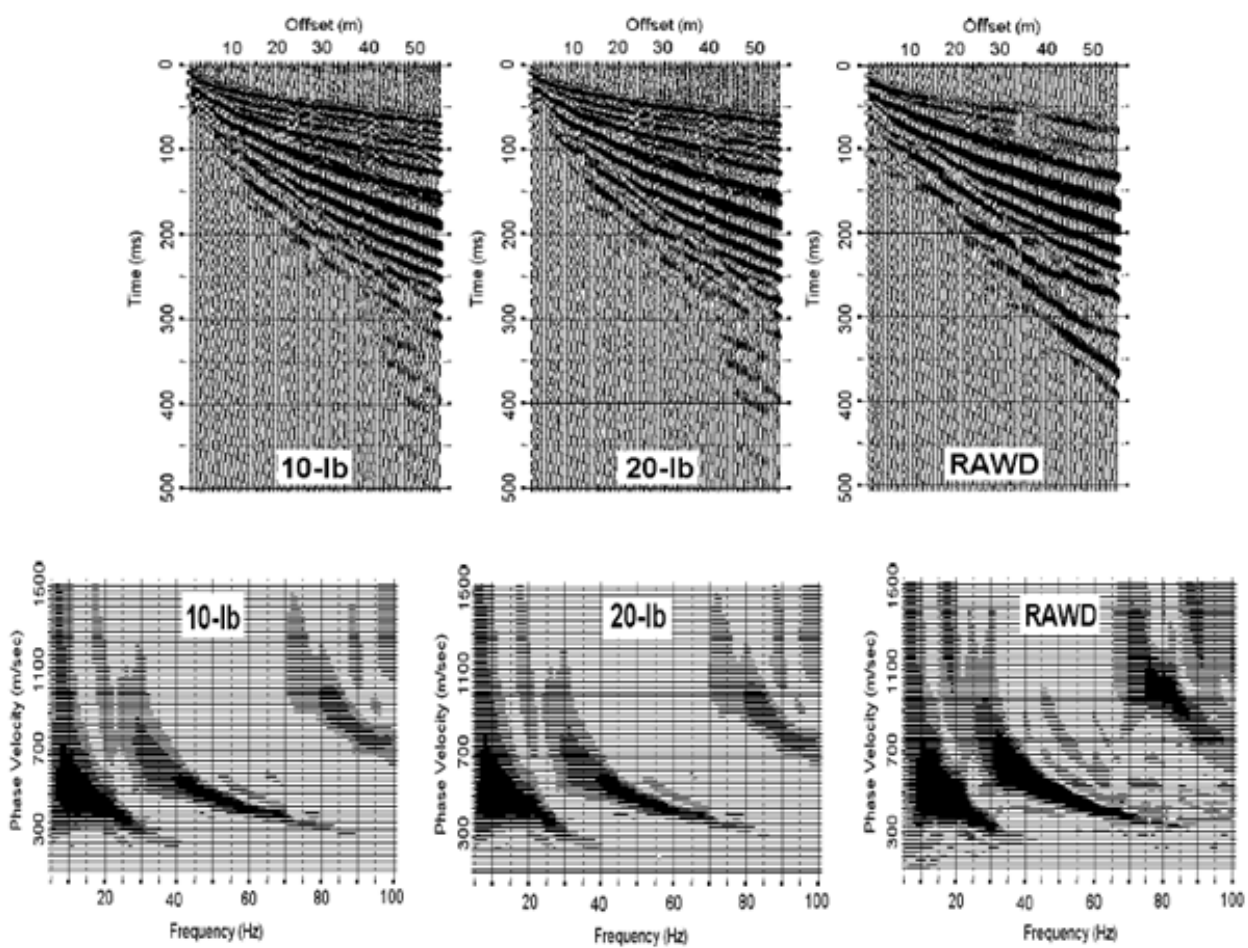

Fig. 2-12: Comparison of dispersion curves for $10 \mathrm{lb}$ sledgehammer, $20 \mathrm{lb}$ sledgehammer and an RAWD (Park et al., 2002).
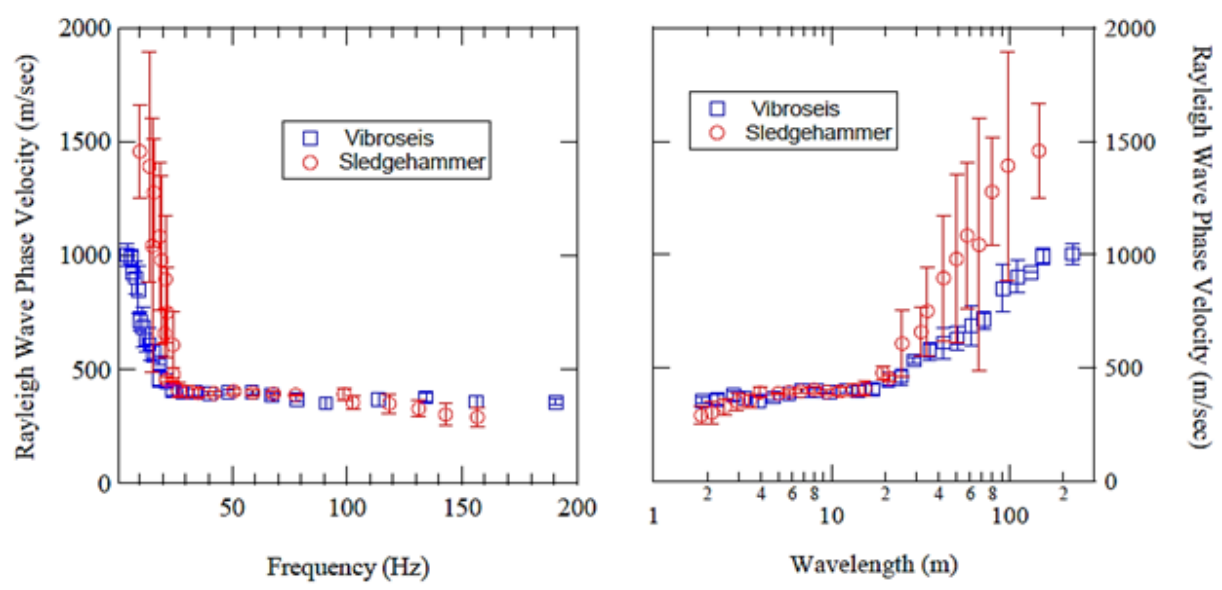

Fig. 2-13: Comparison of dispersion curves for an Industrial Vehicle International T-15000 minivib vibroseis and sledgehammer (Wood and Cox, 2012). 


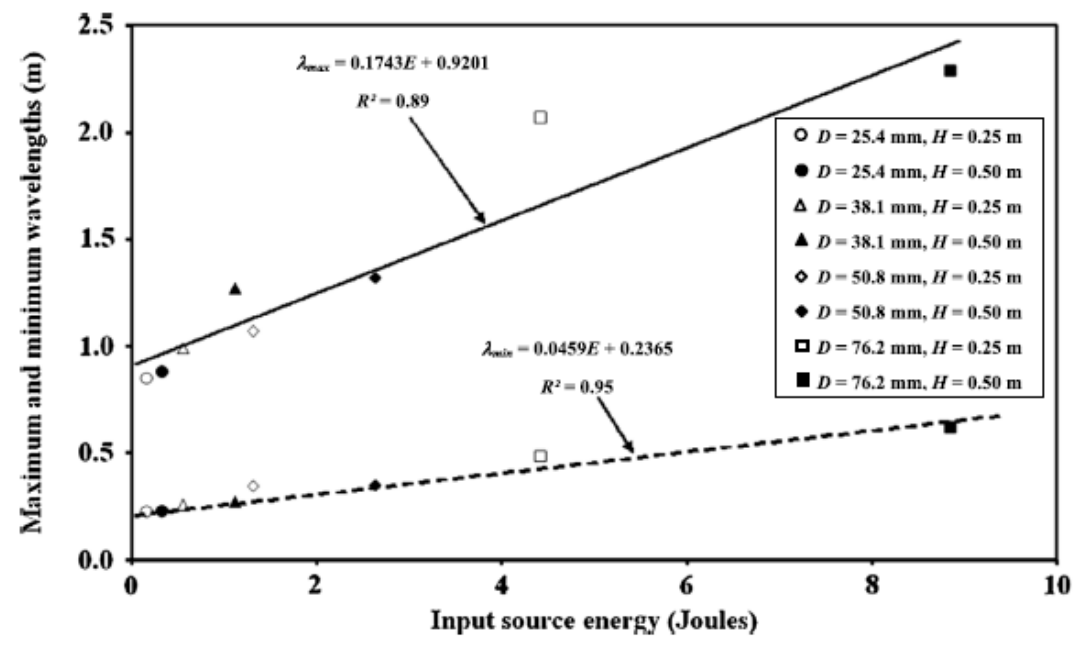

Fig. 2-14: The effect of changes of input source energy (E) on wavelength based on impacts from different diameter steel balls for SASW testing (Kumar and Rakaraddi, 2013).

\section{plate mass $(\mathrm{kg})$}

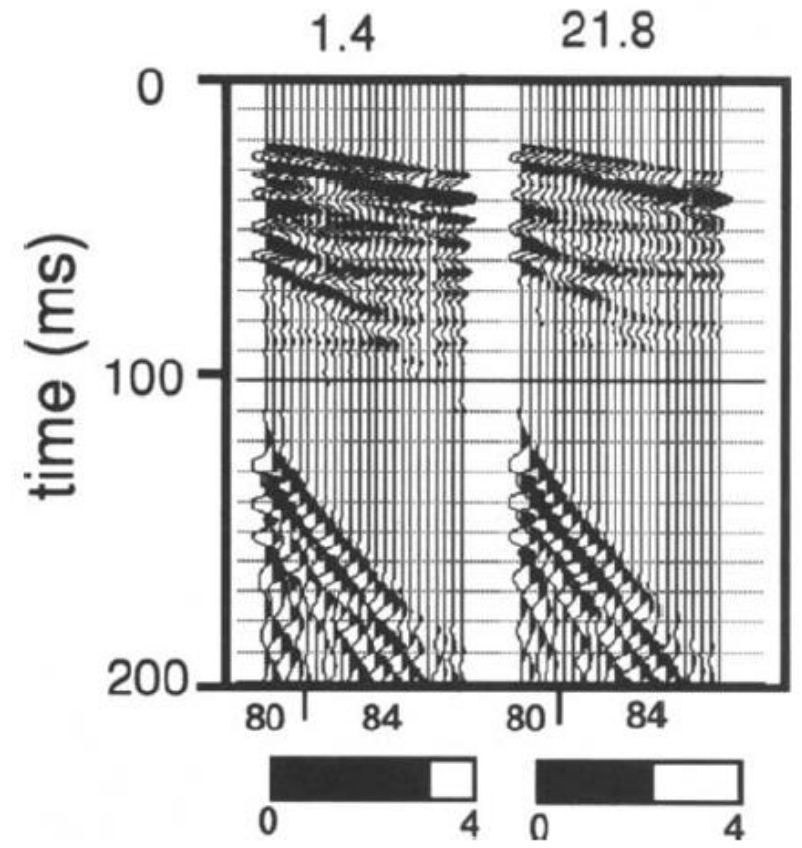

Fig. 2-15: Seismic data and relative energy bar graph resulting from an increase in plate mass at a single site. The bar graphs represent the sum of the squares of the amplitudes after correcting gain variation during acquisition for all 24 channels (Keiswetter and Steeples, 1995). 


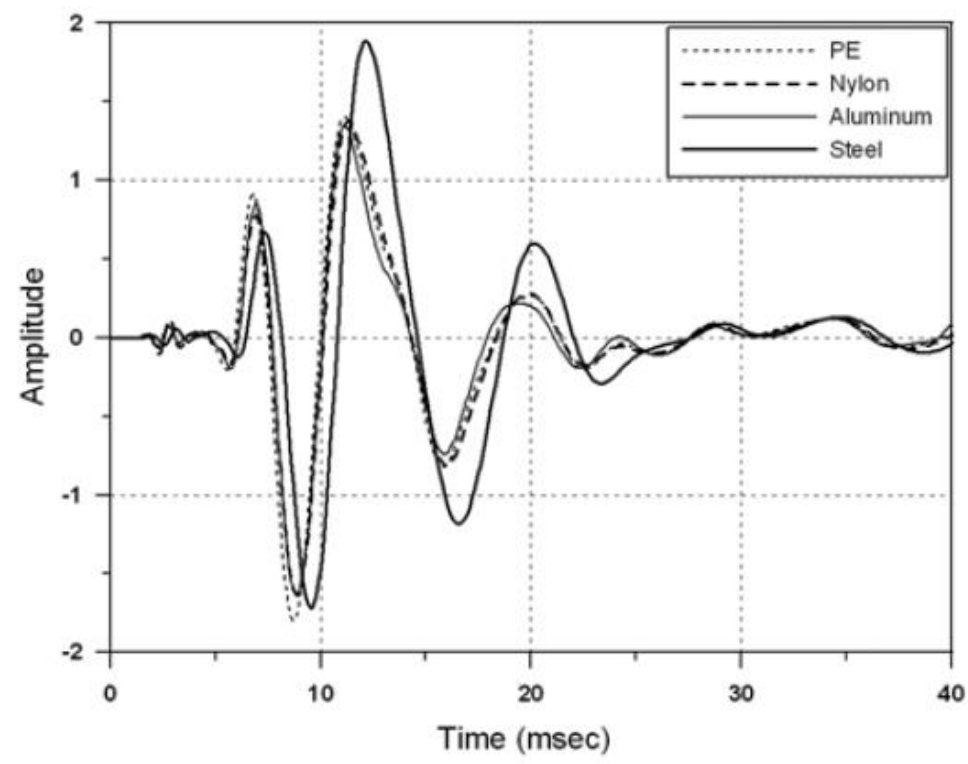

Fig. 2-16: Variation in input wave amplitude generated using various striker plates and a $1 \mathrm{~kg}(2.2 \mathrm{lb})$ sledgehammer impact source (Kim and Lee, 2011).

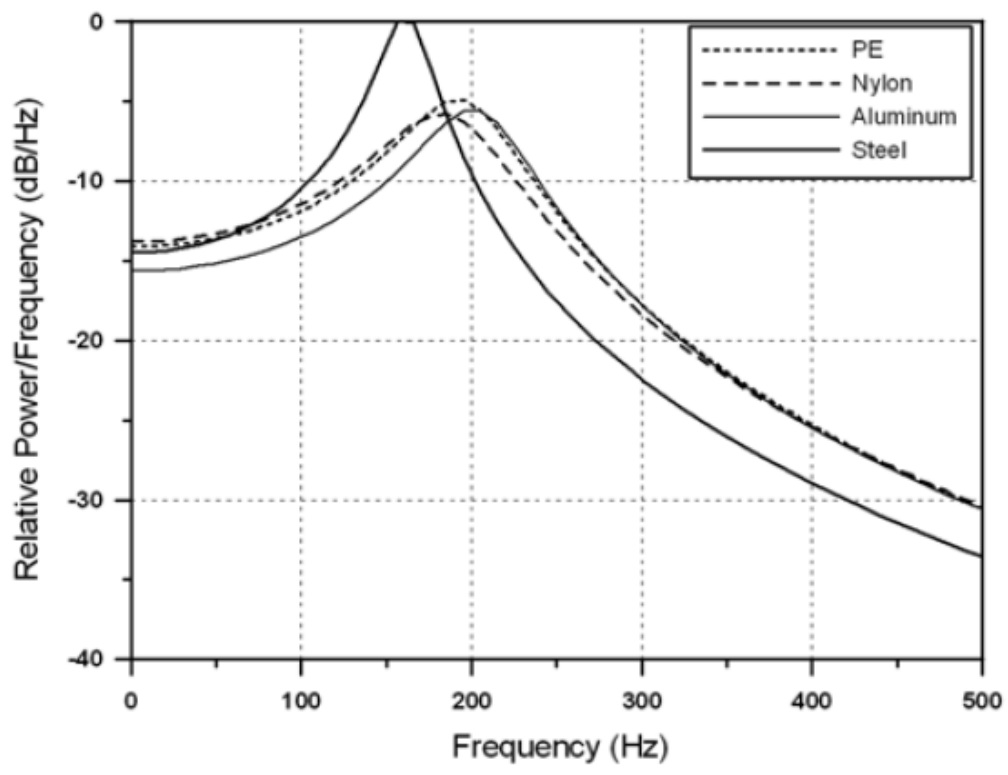

Fig. 2-17: Variation in frequency content present for input waves generated using various striker plates and a $1 \mathrm{~kg}$ (2.2 lb) sledgehammer impact source (Kim and Lee, 2011). 


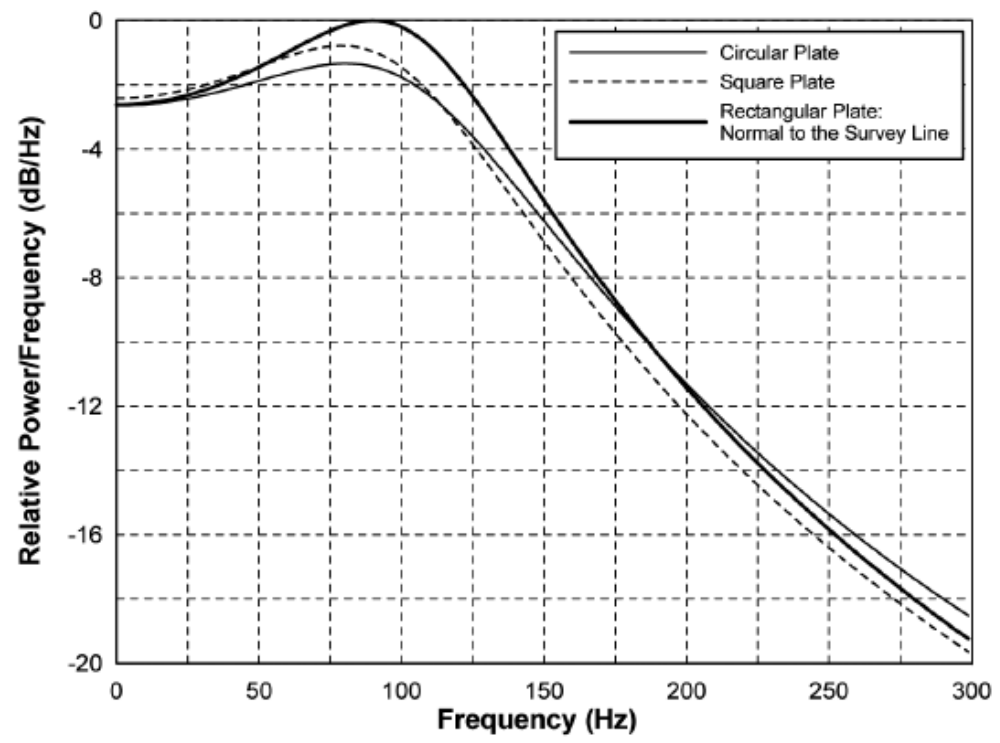

Fig. 2-18: Variation of measured frequency content generated from impacts using a $1 \mathrm{~kg}(2.2 \mathrm{lb})$ hammer with various striker plate shapes when the long side of the plate is perpendicular to the array line (Jeong and Kim, 2012).

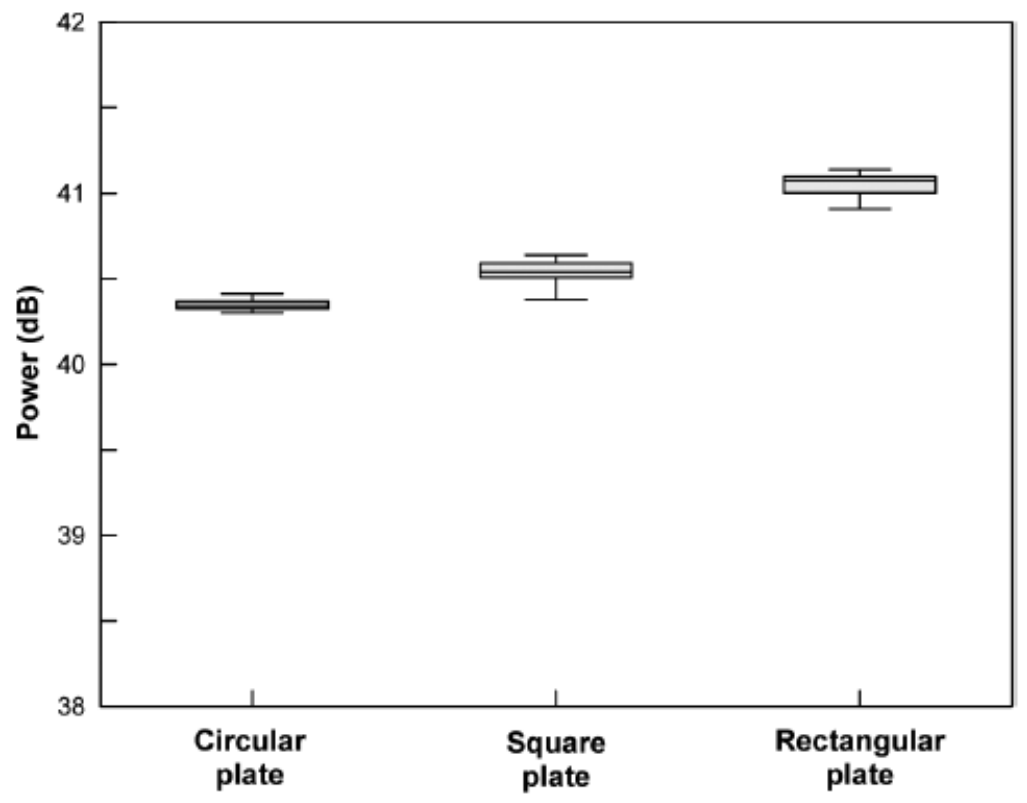

Fig. 2-19: Variation of measured power generated from impacts using a $1 \mathrm{~kg}(2.2 \mathrm{lb})$ hammer with various striker plate shapes when the long side of the plate is perpendicular to the array line (Jeong and Kim, 2012). 


\section{CHAPTER 3}

\section{FIELD STUDIES}

As demonstrated in the literature review, there have been limited studies performed to systematically investigate the role of the seismic source on the dispersion curves measured at a site. This is particularly the case for quantifying the effects of various striker plates, despite general agreement that the striker plate plays a role in the nature of the input surface wave generated for an MASW survey. The shortage of technical papers regarding the effects of base plate material on the dispersion curve has therefore motivated this research. The objective of the proposed study is to quantify the effects caused by using different base plate configurations on the measured dispersion curve across multiple sites. Effort has also been made to qualitatively review the long term durability of the various striker plates in relation to the continuous impacts they will receive during data acquisition.

\subsection{General Field Data Acquisition Procedures/ Parameters}

During these surveys, three striker plates configuration were utilized to couple the impact from a sledgehammer with the underlying ground surface:

- Aluminum plate of $2.54 \mathrm{~cm}$ (1.0 in) in thickness (hereafter referred to as Al base plate).

- Aluminum plate of $2.54 \mathrm{~cm}$ (1.0 in) in thickness over ethylene propylene diene monomer $(\mathrm{EPDM})$ rubber mat of $1.27 \mathrm{~cm}(0.5 \mathrm{in})$ thickness (hereafter referred to as Al/EPDM base plate). 
- Ultra-high-molecular-weight (UHMW) polyethylene (PE) plate of $3.8 \mathrm{~cm}$ (1.5 in) thickness (hereafter referred to as PE base plate).

The plates are all square shaped for consistency with a length and width of $30.48 \mathrm{~cm}$ (12 in) $\mathrm{x} 30.48 \mathrm{~cm}(12$ in). Figure 3.1 shows the striker plate configurations utilized for this research. Prior to selecting the final thickness of the striker plates for the study, a preliminary set of field tests was conducted in which several thicknesses of the striker plates were used, specifically for the PE plate and the rubber of the Al/EPDM plate. The objective of the preliminary testing was to determine an optimum thickness of the base plates, particularly for PE where significant wear and tear on the plate was anticipated. The thickness was also optimized to ensure that the base plate remains planted on the ground after hammer strikes. No significant variation in the dispersion curve results was observed using various thickness values for the PE and so a thickness of $3.8 \mathrm{~cm}$ was selected. Finally, several offset locations of the source from the array were performed on site to investigate the effects of base plates on the measured dispersion curves in combination with changes in source offset.

Data was collected at each of the sites over a period of several months between August, 2015 and October, 2015. For all the selected sites, a 1-D active survey line was performed using a total of 24 receivers ( $4.5 \mathrm{~Hz}$ vertical geophones). The spacing between geophones was kept at $1.5 \mathrm{~m}$, which resulted in a total receiver array length of $34.5 \mathrm{~m}$. The seismic source location was positioned at several offset locations on both sides of the receiver array. The offset locations included $\pm 1 \mathrm{dx}, \pm 3 \mathrm{dx}, \pm 6 \mathrm{dx}, \pm 12 \mathrm{dx}$ and $\pm 24 \mathrm{dx}$ where $\mathrm{dx}$ represents the spacing $(1.5 \mathrm{~m})$ between two consecutive geophones and the signs represent offsets from opposite ends of the array line. This was done to observe any 
variations, if any, on the dispersion curves measured using impacts on either side of the receiver array. The total length of the survey line considering the source offset locations on both sides of the receivers was $106.5 \mathrm{~m}$. Data acquisition was performed using a Geometrics@ Geode seismograph connected to a rugged field laptop running the Geometrics@ Seismodule Controller Software (SCS). Sledgehammers were used as the impact source at each source offset in combination with each of the various striker plate configurations. Specifically, a $4 \mathrm{lb}, 8 \mathrm{lb}$ and $20 \mathrm{lb}$ hammers were used for the survey. Multiple hammer strikes were recorded and stacked to improve the SNR at each source offset for each hammer size ( 5 stacks for the $4 \mathrm{lb}$ hammer and 3 stacks for the $8 \mathrm{lb}$ and 16 lb hammers). An effort was made to reduce background noise and prevent interference with resolution and accuracy of the data. This was achieved by striking the base plates during periods of little nearby traffic and or wind. GPS data was also recorded to locate the start and end point of the receiver array at each site. Finally, we recorded each shot for a total of $2.048 \mathrm{~s}$ with a sampling interval of $0.125 \mathrm{~ms}$.

\subsection{Field Sites}

For this research, MASW surveys were conducted at several sites within the Philadelphia metro area. These sites include:

- Temple University Ambler Campus (TA1)

- Dendy Recreation Center (DRC)

- Penn Treaty Park (PTP)

- Temple University Track Field (TTF) 
- Fairmount Park Edgely Field (FEF)

- Martin Luther King Jr. Drive near Belmont Waterworks (MLK)

\subsubsection{Temple University Ambler Campus (TA1)}

This field site is located across the main entrance to the Temple University Ambler Campus and it is adjacent to the visitor's parking lot. The site is bordered on the north by Meetinghouse Road and the south-east by Woods Drive (Fig. 4.1). Meetinghouse Road is a moderately used suburban thoroughfare with increases in traffic after classes at the Ambler campus and in the late afternoon. The site itself is a moderately busy location, with occasional recreational activities taking place in the adjacent field. As a result, the exact position of the array relative to the site was selected to minimize interference from ongoing recreational activities (Fig. 4.1). Data was also acquired at the site when there was minimal activity taking place. The ground surface at the testing location was observed to be fairly soft, which allowed for adequate geophone coupling with minimal issues during planting of the instrumentation.

\subsubsection{Dendy Recreational Center (DRC)}

The Dendy Recreational Center site is located in a residential neighborhood north-east of 10th and Jefferson Street in northern Philadelphia. The site is in close proximity to the Temple University main campus. The park is bordered by 10th Street on the west and runs between Oxford Street to the north and Jefferson Street to the south. An Amtrak railway line runs parallel to the site on its eastern boundary. The trains on the railway coupled with the traffic on the adjacent streets generate significant background noise that affects the efficacy and accuracy of the active MASW testing. Thus, effort was made at 
every stage to minimize the effect of these background noises during data collection, particularly by waiting for limited traffic activities and for trains to pass the site. The geophone coupling to the ground was accomplished with minimal issues during planting of the instrumentation as the ground was fairly soft.

\subsubsection{Penn Treaty Park (PTP)}

Penn Treaty Park is a 7 acre recreational area located on the banks of the Delaware River on the eastern boundary of Philadelphia. The park is bordered on its northwestern boundary by Beach Street right as it branches from Delaware Avenue and intersects Columbia Avenue. Immediately adjacent to the park are an abandoned warehouse to the west and an electrical substation to the east. There is significant background noise as a result of the traffic on nearby Delaware Avenue and Interstate 95 (I-95) coupled with on-site recreational activities. Also, at the time of the study, construction projects associated with rehabilitation of I-95 along the Delaware River were generating significant noise levels. Aside from these background noise constraints, the cable connector for one of the geophones was observed to be faulty after the acquiring data at this site. This caused the data collected on one channel to have excessive electrical interference noise and data from only 23 geophones were used in the analyses. As a result

of the aforementioned noise issues, the overall data quality at PTP was less than ideal relative to other sites tested in this study. Like DRC, this site is fairly soft and ground coupling of instrumentation was fairly easy.

\subsubsection{Temple Track Field (TTF)}

This site is the main track and field area of the sports complex at Temple University's 
main campus and it is in close proximity to the Liacouras Center. The track is bordered by Norris Street on the north and Montgomery Street on the south between 15th and 16th Streets. The traffic on the adjacent streets coupled with several other recreational activities (e.g., joggers) on the site generates some background noise. However, the background noise is not that significant to affect the accuracy and SNR of the active data collected on the site. The ground surface at the testing location is fairly stiff. This necessitated additional effort to ensure adequate geophone coupling during planting of the instrumentation.

\subsubsection{Fairmount Park Edgely Field (FEF)}

Edgely Field is an athletic field and one of several recreational facilities within the Fairmount Park municipal system northwest of Center City Philadelphia. The site itself is adjacent the Laurel Hill Mansion (a national historical landmark) and is encircled by Randolph Drive and Reservoir Drive on its eastern side. It is also in close proximity to Kelly Drive, a very busy roadway that connects Center City Philadelphia to neighboring inner-ring suburbs. Kelly Drive is often used by suburban commuters to bypass or connect with Interstate 76 (I-76), which generates significant background traffic noise during peak commute hours. Like the other busy sites, data was only collected at off-peak hours when the background traffic noise as a whole was observed to be low enough as to not drastically affect SNR and data quality. This was ensured by monitoring the noise signals on the display monitor of the field laptop. The nature of the ground at the site is similar to DRC and the ground coupling of the geophones was accomplished with no issues. 


\subsubsection{Martin Luther King Jr. Drive Near Belmont Waterworks (MLK)}

This site is an open field adjacent to the Schuylkill River in West Philadelphia. The site is located off of Martin Luther King Jr. Drive near its intersection with Montgomery Drive and the Columbia Bridge across the Schuylkill River. The site is bordered to the north by the Belmont Waterworks and to the south by Black Road. The western border of the site is adjacent to I-76, which is an extremely busy thoroughfare connecting Center City to the main western and northern suburbs of Philadelphia. Additionally, the traffic on Martin Luther King Jr. is also significant. Thus, data was only collected at this site when the background noise was observed to be low enough as to not cause issues with SNR and data quality. This was ensured by monitoring the noise signals on the display monitor of the field laptop. The ground surface at the testing location was similar to DRC (i.e., fairly soft) and planting of geophones was thus accomplished with no coupling issues. 


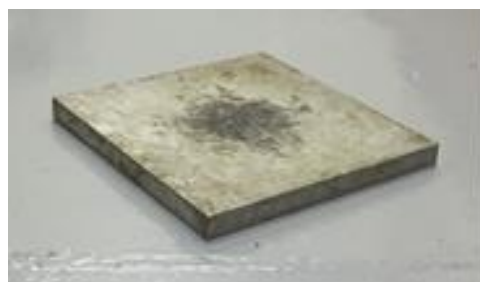

(a)

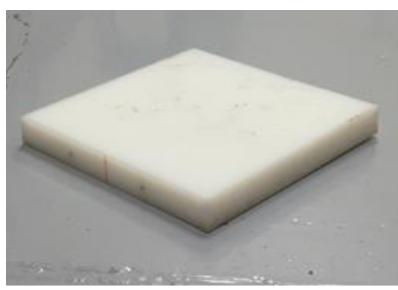

(b)

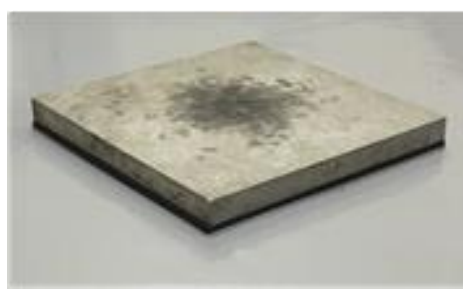

(c)

Fig. 3-1: Striker plates used in this study: (a) Al; (b) PE; and (c) Al/EPDM.

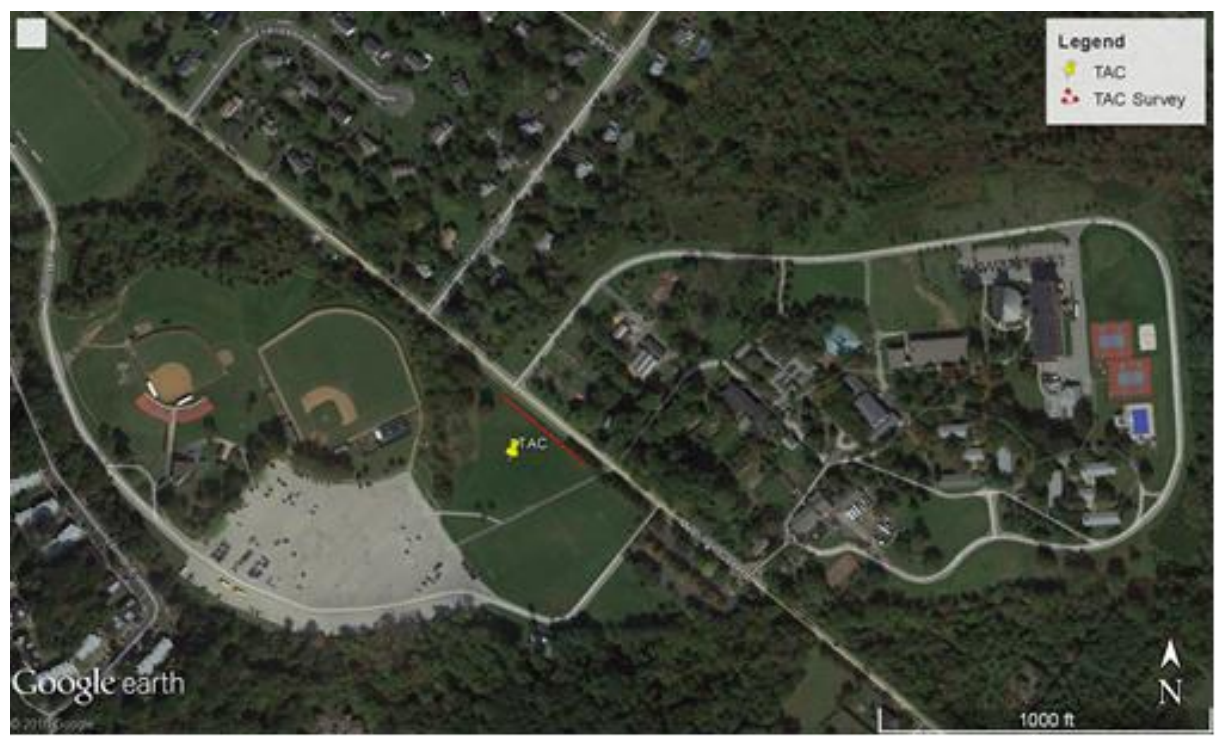

(a)

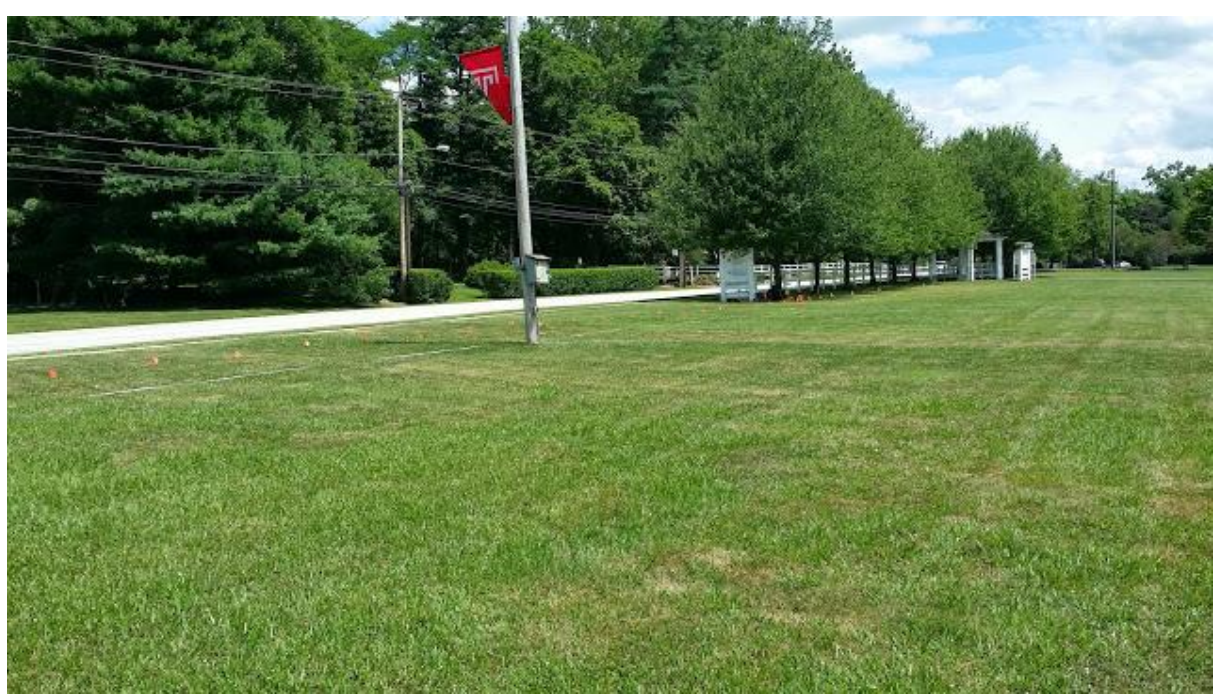

(b)

Fig. 3-2: TA1 site: (a) Plan view (courtesy of Google Maps); and (b) MASW array setup. 


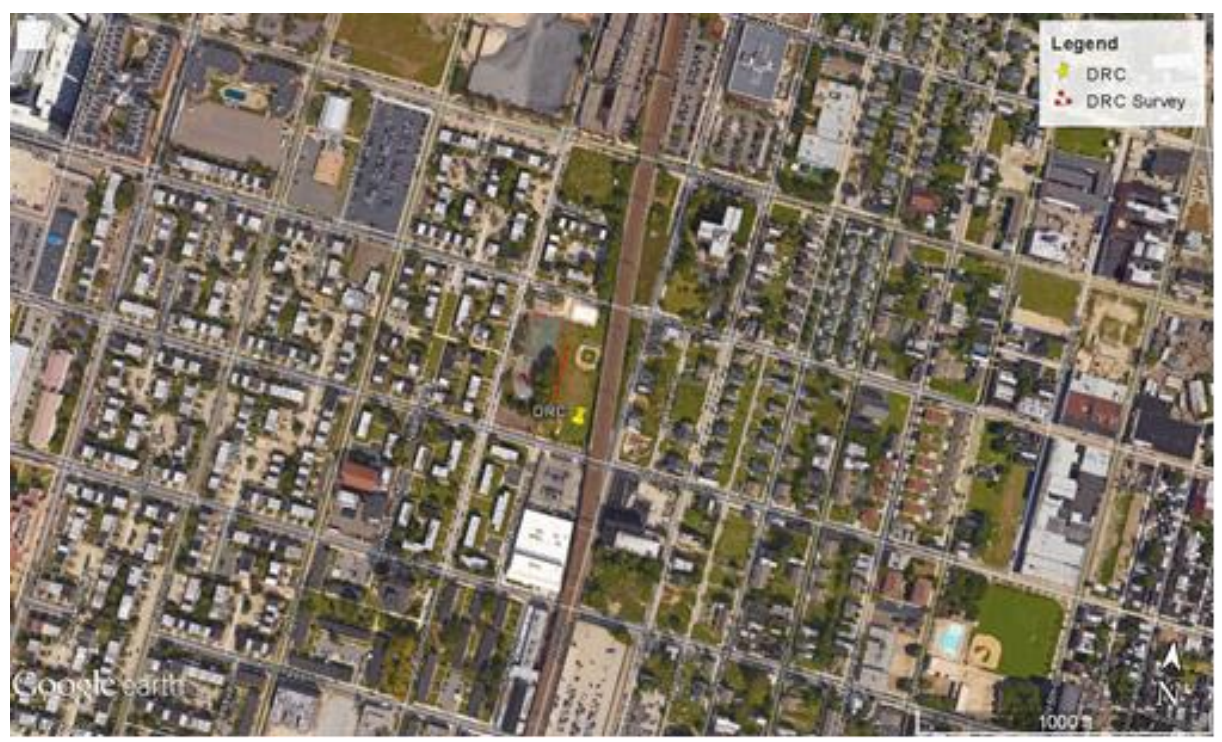

(a)

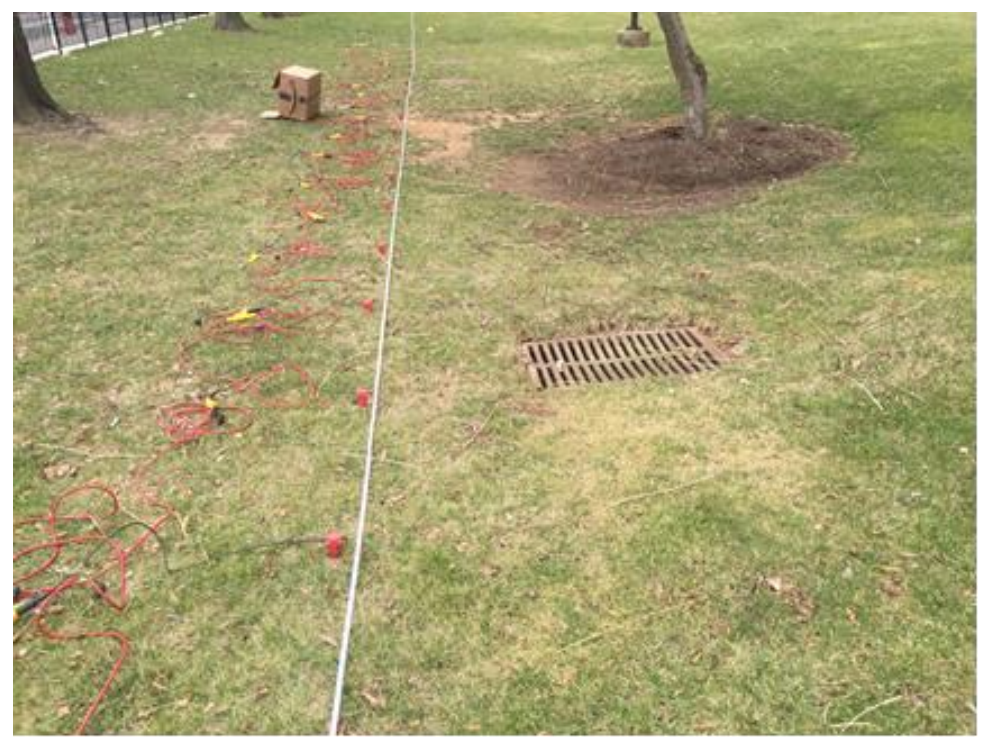

(b)

Fig. 3-3: DRC site: (a) Plan view (courtesy of Google Maps); and (b) MASW array setup 


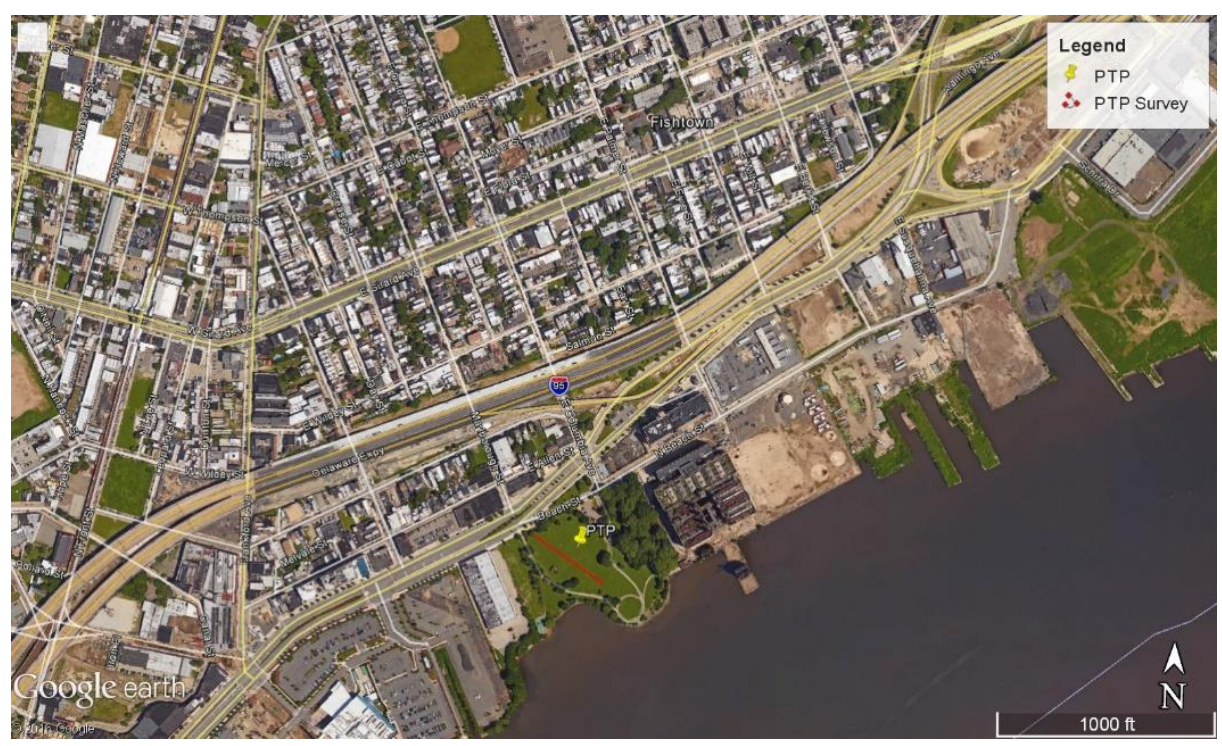

(a)

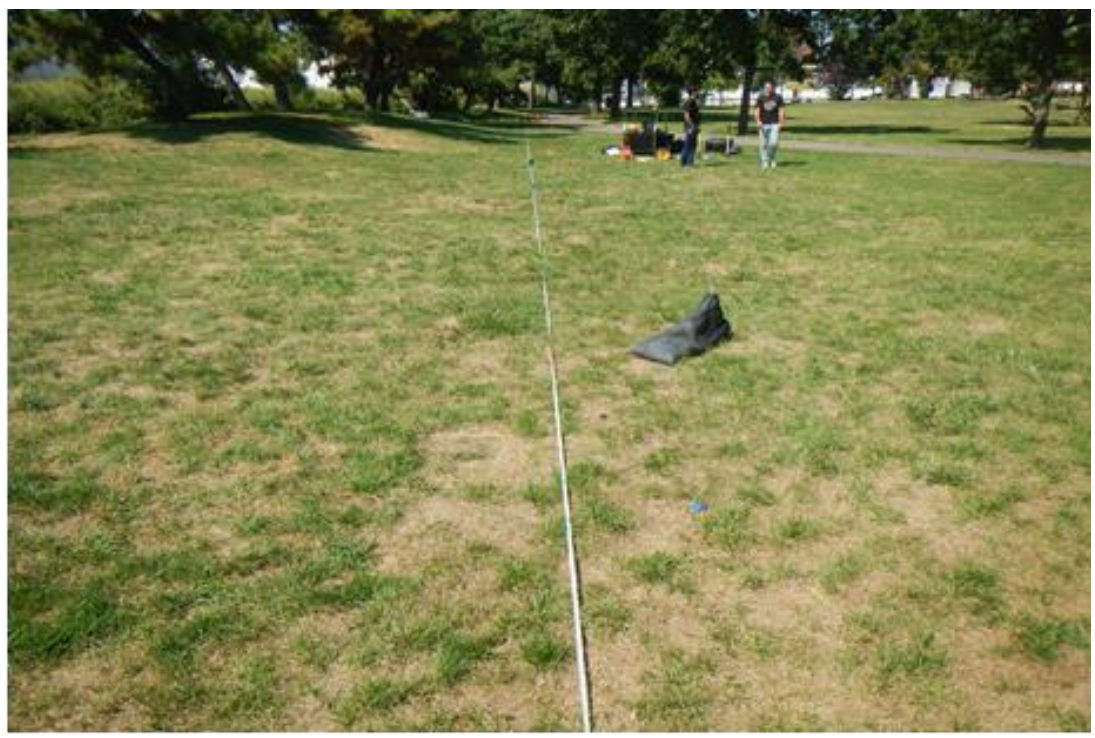

(b)

Fig. 3-4: PTP site: (a) Plan view (courtesy of Google Maps); and (b) MASW array setup 


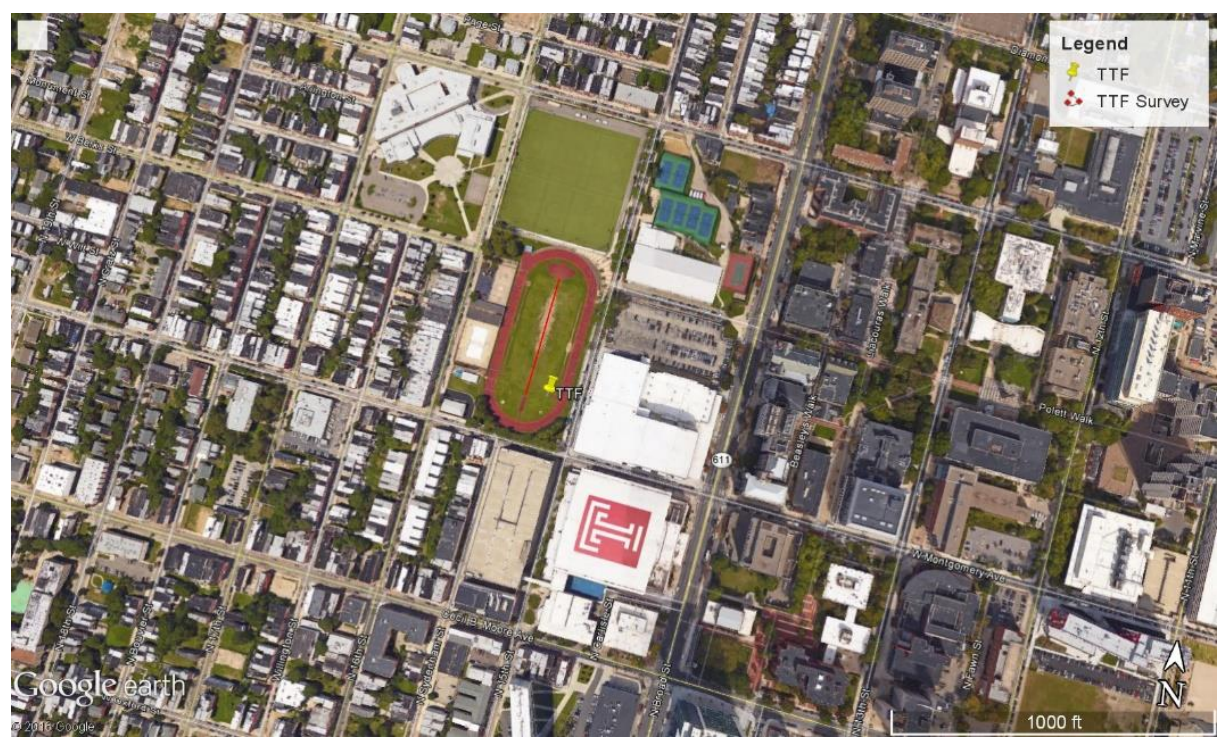

(a)

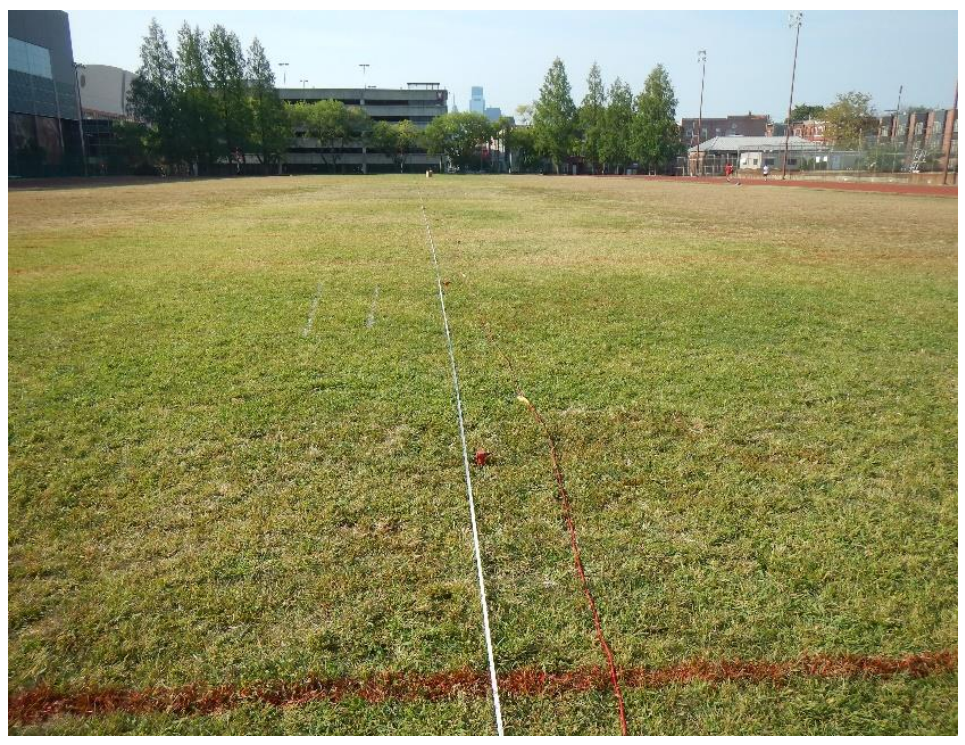

(b)

Fig. 3-5: TTF site: (a) Plan view (courtesy of Google Maps); and (b) MASW array setup 


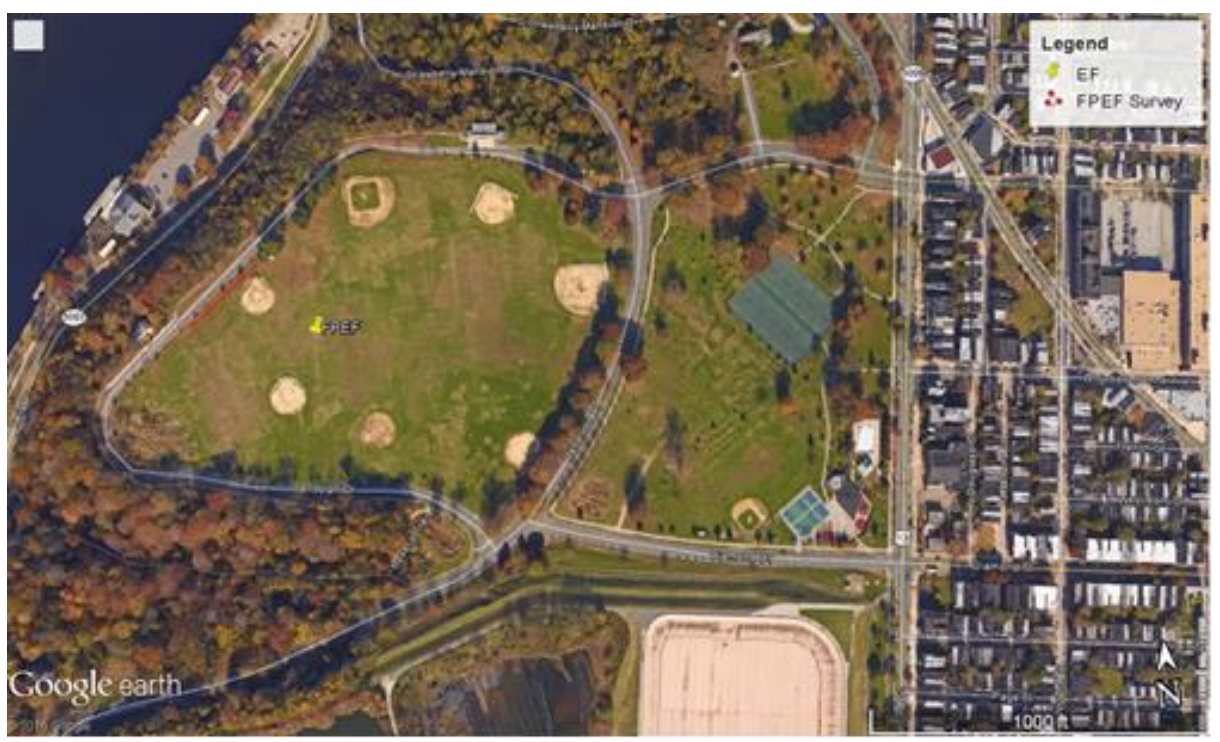

(a)

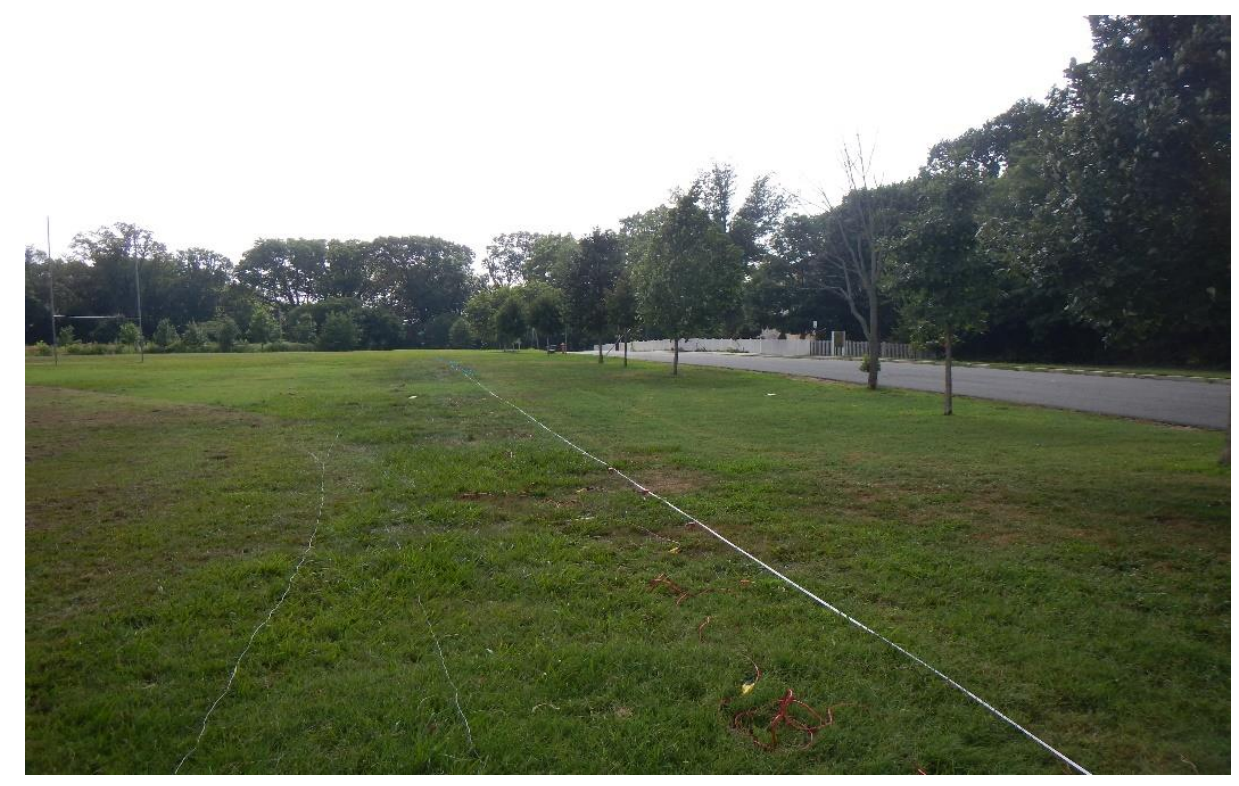

(b)

Fig. 3-6: FEF site: (a) Plan view (courtesy of Google Maps); and (b) MASW array setup 


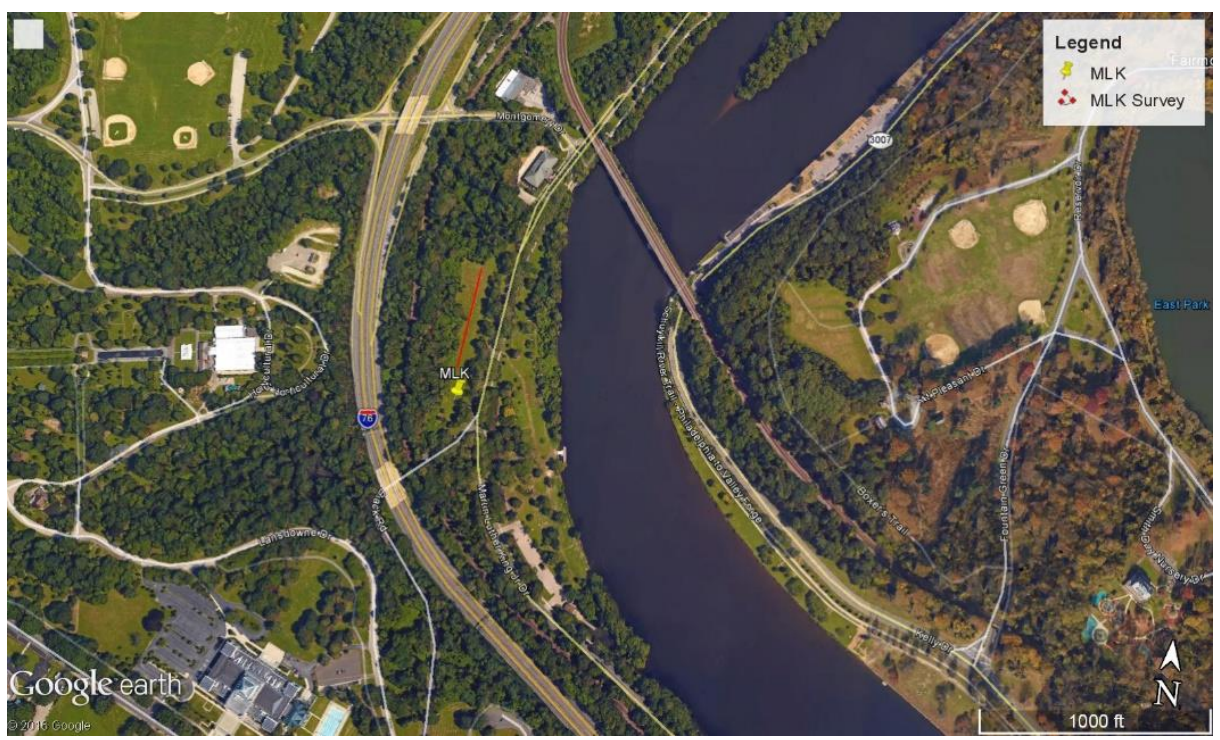

(a)

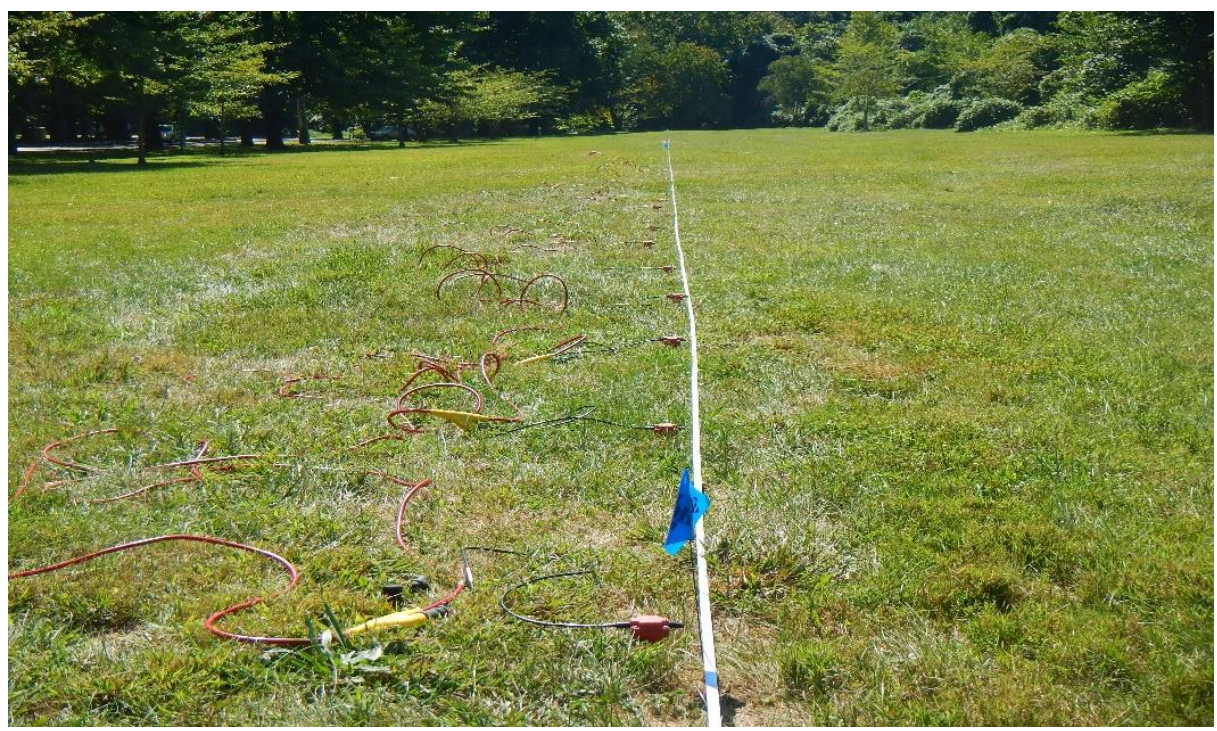

(b)

Fig. 3-7: MLK site: (a) Plan view (courtesy of Google Maps); and (b) MASW array setup 


\section{CHAPTER 4}

\section{DISCUSSION OF RESULTS}

As noted in the preceding chapter, MASW testing at each site consisted of five distinct shot locations $(1 \mathrm{dx}, 3 \mathrm{dx}, 6 \mathrm{dx}, 12 \mathrm{dx}$ and $24 \mathrm{dx})$ on each side of the array, where $\mathrm{dx}$ refers to the distance between two adjacent geophones. At each shot location, three different hammer sizes $(4 \mathrm{lb}, 8 \mathrm{lb}$ and $20 \mathrm{lb}$ ) were used on each of the three striker plates under consideration. Therefore, nine (9) distinct files, three for each plate configuration, were obtained at each shot location. Thus, a total of ninety (90) files were obtained at each site. However, this thesis only discusses the results from the negative (-) dx shot locations because the results from both sides of the array were similar.

After the data was acquired at each site, the waveforms from each shot record were post-processed using the Geometrics Seisimager/SW software package. Seisimager/SW develops a dispersion image from the waveforms using the phase shift method. No filtering was performed on the waveforms prior to generation of the dispersion image. Generally, the quality of the dispersion image decreased at farther shot location at all the sites. The dispersion images generated at the $-24 \mathrm{dx}$ shot location were often of very low quality. In some situations, especially for the $4 \mathrm{lb}$ and $8 \mathrm{lb}$ hammers, the fundamental mode dispersion curve was very difficult or impossible to extract from the dispersion images. This occurred across multiple sites. It was deduced that this was a far field effect problem where the input signal lacked sufficient SNR to perform accurate dispersion image calculations. Therefore, results generated at the $-24 \mathrm{dx}$ location were not included as part of the analysis. The results from $-1 d x$ location were also not included in this 
analysis due to the near field effect. This resulted in a total of only 27 dispersion images per site for analysis. These dispersion images have been provided in Appendix A of this document.

Data analysis for this project entailed the evaluation of base plate effects for each dispersion image based on the following topics: (1) low frequency performance; (2) high frequency performance; and (3) presence of higher modes in the dispersion images. Higher modes represent alternate solutions to the governing equation regarding Rayleigh wave propagation. They are present due to partitioning of the Rayleigh wave energy into a higher velocity-frequency relationship. Low frequency performance was assessed quantitatively by identifying the lower frequency component present in the dispersion image and qualitatively by evaluating the sharpness of the dispersion image in the lower frequency registers. In terms of selecting the lowest frequency values on the dispersion images, a consistent methodology was established to remove bias in interpretation of the results. First, the Seisimager/SW software was used to generate the dispersion image. Afterwards, the software was allowed to automatically select a corresponding dispersion curve that best followed the phase velocity-frequency patterns in the dispersion image as illustrated by the red dotted line in Fig. 4-1(a). The lowest value of frequency for which a data point existed on the dispersion curve was then selected from the plot [Fig. 4-1(b)]. Due to the cutoff frequency limitations of the geophones and the limited size of the seismic sources, data points from $7 \mathrm{~Hz}$ or below were not used in selecting the lowest frequency component present in the dispersion curve. Also, in cases where the dispersion curve had a sudden decrease in phase velocity at the lower frequency range, the lowest frequency value was selected as the one where the peak phase velocity occurred. This is 
because the low frequency range of the dispersion image corresponds to very deep strata and it is extremely unlikely that velocity inversions (i.e., stiff over soft) would exist at such depths. Typically, such decreases in the dispersion image correspond to computational artifacts from attempting to perform the dispersion image calculations on data with increasingly poor SNR. High frequency performance and the presence of multiple modes (items 2 and 3 above) were assessed qualitatively, with the goal of recognizing any patterns of behavior across the dispersion images.

The following sections present data analysis for the dispersion images acquired at each of the aforementioned field sites. General observations are noted for each of the sites separately. A summary discussion of global observations and patterns across all sites is provided in Chapter 5.

\subsection{Dendy Recreational Center (DRC)}

At this site, it was observed that the pattern of energy accumulation resulted in clearly distinguishable fundamental mode dispersion curves. Generally, the quality of the dispersion images reduced as the shot location increased in distance away from the closest geophone in the array. For example, the quality of the dispersion image was very good at $-3 \mathrm{dx}$ and very poor at $-24 \mathrm{dx}$ across all the plates (Al, Al/EPDM, PE) and hammer (4 lb, $8 \mathrm{lb}$ and $16 \mathrm{lb}$ ) combinations. This was due to the reduced SNR as the shot location moved away from the first geophone. In such cases, it was extremely difficult or impossible to select an appropriate fundamental mode dispersion curve. Details of the lowest frequency component present in the dispersion curves associated with the various shot locations are shown in Table 4-1. Figures 4-2 and 4-3 also graphically present the 
information in Table 4-1. Generally speaking, substitution of a PE plate for Al predictably resulted in the presence of lower frequency energy in the dispersion image for a given shot location and hammer combination. More accumulation of lower frequency energy often led to a decrease in the lowest frequency component present in the fundamental mode dispersion curve extracted from the dispersion image. The magnitude of this decrease was typically only on the order of a couple of $\mathrm{Hz}$. The largest decrease was observed with the $20 \mathrm{lb}$ sledgehammer at the $-6 \mathrm{dx}$ shot location where the lowest observable frequency component on the dispersion curve decreased from $16 \mathrm{~Hz}$ to $12 \mathrm{~Hz}$ when a PE striker plate was used in lieu of an $\mathrm{Al}$ plate. The Al/EPDM base plate also sometimes decreased the lowest frequency component observed in the dispersion curves in relation to an $\mathrm{Al}$ base plate. However, the decrease was typically smaller in magnitude when compared to the decrease observed with the PE plate (though as much as a $3-5 \mathrm{~Hz}$ decrease was noted on two occasions with the Al/EPDM base plate). In a limited number of cases, use of a PE or Al/EPDM plate actually increased or did not affect the lowest frequency component observed in the dispersion curve (e.g., Table 4-1 for -6dx shot location and $4 \mathrm{lb}$ sledgehammer). In the cases where an increase was observed, the increase was limited to $1 \mathrm{~Hz}$ for $\mathrm{PE}$, though $\mathrm{Al} / \mathrm{EPDM}$ exhibited as high as a $6 \mathrm{~Hz}$ increase. Given the larger variability in frequency content changes, the Al/EPDM base plate was typically less consistent in its performance. Generally, small changes (e.g., 1 $\mathrm{Hz}$ ) in the lowest frequency observed in the dispersion curve may be insignificant given the potential computational issues involved with generation of the dispersion image. Nonetheless, either an increase or no change in the lowest observable frequency component of the dispersion curve demonstrates that the relationship between base plate 
material and presence of certain frequency bands in dispersion images/curves is complex. A number of factors can also contribute to the interplay between base plate and frequency content. For example, the quality of the strike from the sledgehammer can potentially have an effect. Oblique impacts may produce less energy, have less well-defined dispersion images, and result in dispersion curves with limited low frequency content. Additionally, the shock-absorbing qualities of both PE and EPDM rubber may diminish SNR of the waveforms. This in turn would decrease dispersion image quality and worsen selection of the fundamental mode dispersion curve, particularly at the low frequency range where computational artifacts are more prevalent in the dispersion image.

Further study of Figs. 4-2 and 4-3 highlights another major item of interest. The lowest frequency values for the PE and Al/EPDM base plates were observed at the $-3 \mathrm{dx}$ shot location, typically using the smaller $4 \mathrm{lb}$ sledgehammer. At the $-12 \mathrm{dx}$ shot location, the $\mathrm{Al} / \mathrm{EPDM}$ combination recorded the lowest frequency values for the $8 \mathrm{lb}$ and $20 \mathrm{lb}$ hammer sizes. Except for the lowest frequency values at the $-12 \mathrm{dx}$ shot location that showed several inconsistencies, the remaining results followed a trend of lower frequency values corresponding to closer shot location (and often smaller hammers as well) (Fig. 4-2). This confirmed an observation by Wood and Cox (2012) that an increase in hammer size does not always necessarily translate into a significant increase in lower frequency energy in the dispersion images. Nonetheless, this is actually counterintuitive because larger source offsets and heavier sources are typically associated with an emphasis in the low frequency range of the dispersion image. Higher frequency waves attenuate more quickly with distance and so larger offsets will often contain the most low frequency energy. This was not observed with any of the base plates at this site (including the Al 
plate).

The raw dispersion images for each of the source offset and hammer combinations were also examined to qualitatively evaluate how the base plates affected the presence of high frequency wave energy (i.e., $>30 \mathrm{~Hz}-50 \mathrm{~Hz}$ ) and higher modes of wave propagation (see Appendices A-1 - A-6). Higher modes were not readily observed on the dispersion images at DRC, so it proves impractical to discuss the role of base plates on higher modes for this site. Regarding the high frequency range of the dispersion image, there was less high frequency wave energy accumulated for shot locations farther away from the first geophone location. This was expected given that the high frequency component of seismic energy spatially attenuates more quickly and may fail to reach the last geophones with sufficient SNR. For a given source offset, the highest frequency component observed in the dispersion images was fairly consistent for all base plates, though $\mathrm{Al}$ did sometimes have slightly sharper dispersion images, more well-defined trends, and occasionally a few more $\mathrm{Hz}$ at the higher frequency range of the dispersion image.

\subsection{Fairmount Park Edgely Field (FEF)}

The fundamental mode dispersion curves at this site were distinguishable but not as clear and distinct as those of DRC due to the presence of higher modes. The patterns in dispersion image quality at this site is similar to DRC in that the resolution is good at $-3 \mathrm{dx}$ and poor at $-24 \mathrm{dx}$ across all the plates (Al, Al/EPDM, PE) and hammer (4 lb, $8 \mathrm{lb}$ and $16 \mathrm{lb}$ ) combinations. This was again due to the reduced SNR as the shot locations farther away from the first geophone. Details of the lowest frequency component present 
in the dispersion curves associated with the various shot locations are shown in Table 4-2 and Figures 4-4 - 4-5. Even though the PE plate generally recorded the lowest observable frequency values on the fundamental mode dispersion curves across all hammer sizes, the differences were quite subtle compared to the results from DRC. The decrease in observable lowest frequency was often only $1 \mathrm{~Hz}$, which may be negligible given the aforementioned issues with computational artifacts in dispersion images. In fact, in many cases, there was no difference in lowest observable frequency component when changing the base plate from Al. The largest change in the observable lowest frequency for PE was a decrease of $2 \mathrm{~Hz}$ relative to $\mathrm{Al}$. Al/EPDM performed very similarly to PE. Overall, there was not much variation in the measured low frequency values across the various offset locations for the various seismic source and base plate combinations with the overwhelming majority falling within the range of $12 \mathrm{~Hz}$ to $14 \mathrm{~Hz}$. Generally, the results also demonstrated that heavier impact from larger hammers tended to record lower frequency than the smaller hammers as expected. However, the differences in low frequency response based on hammer size were generally small.

Higher modes were more observable on the dispersion images at this site relative to DRC. The intensity of the higher mode energy tended to increase based on plate configuration. Dispersion images generated from impacts using the PE plate generally encouraged additional energy partitioning into higher modes compared to Al/EPDM and Al. Al/EPDM also increased the presence of higher mode energy in the dispersion images relative to Al. However, in all cases, the increase in the intensity of higher modes is subtle as seen in the dispersion images in Appendices A-2. From examination of these dispersion images, it is also notable that high frequency energy was rarely affected in an 
appreciable manner by the use of different base plates. In the small number of cases where high frequency performance was affected, the "softer" base plates (i.e., A1/EPDM and $\mathrm{PE}$ ) lost a few $\mathrm{Hz}$ of high frequency in the dispersion image.

\subsection{Martin Luther King Jr. Drive Near Belmont Waterworks (MLK)}

Most of the dispersion images at this site had fundamental mode dispersion curves that were relatively straight-forward to extract from the dispersion image. However, the presence of higher mode energy was notable as in FEF. Like the other sites, the quality of the data reduced as the shot location increased with respect to the closest geophone in the array. As before, the resolution of the fundamental mode is very good at $-3 \mathrm{dx}$ and very poor at $-24 \mathrm{dx}$ for all the base plate and hammer combinations due to the reduced SNR for farther shot locations. Details of the lowest observable frequency component in the dispersion curves associated with the various shot locations are provided in Table 4-3 and Figures 4-6 - 4-7. The overall low frequency performance of PE at this site was generally comparable to DRC and FEF. At most shot locations, the lowest observable frequency component on the dispersion curve decreased by approximately $2 \mathrm{~Hz}$ with the PE plate.

For two instances, use of PE resulted in an increase in the lowest observable frequency component in the dispersion curve. However, only one of these cases seemed meaningful (-12dx source offset and $20 \mathrm{lb}$ hammer) as the increase was larger than $1 \mathrm{~Hz}$ (i.e., $3 \mathrm{~Hz}$ total increase). Low frequency performance of Al/EPDM at this site was more inconsistent relative to PE and relative to Al/EPDM at DRC and FEF. In fact, in the majority of the cases at MLK, Al/EPDM low frequency performance was poorer than $\mathrm{Al}$ by as much as $3 \mathrm{~Hz}$. It is unclear why Al/EPDM performed so inconsistently at this site 
relative to others, which warrants additional study in future work at this site. As expected, similar patterns were observed at this site regarding the effects of hammer size, with smaller hammers generally yielding dispersion images with less low frequency energy.

Higher modes were observed at this site on the dispersion images as shown in Appendix A-3. The overall presence and intensity of any higher mode energy in the dispersion images was about as pronounced as the FEF site. Whenever higher modes were observed, the intensity was less for the Al plate and magnified on the AL/EPDM and the PE plates (Appendix A-3). This was a general observation across all the sites whenever higher modes were observed. Like the other sites, there was also less high frequency wave energy accumulated for shot locations farther away from the first geophone location. The highest frequency component observed in the dispersion images was fairly consistent for all base plates at a given source offset.

\subsection{Temple University Ambler Campus (TA1)}

Generally, as has been consistently observed at all sites so far, data quality was reduced as the shot location increased with respect to the closest geophone in the array due to reductions in SNR. Table 4-4 and Figures 4-8 - 4-9 provide the details of the lowest observable frequencies in the dispersion images at the various shot locations and for the various hammer/plate configurations. The TA1 site managed to show the widest ranges in values for lowest observable frequency component in the dispersion curves. On the one hand, the same general pattern emerged where PE tended to demonstrate better low frequency performance (by as much as $5 \mathrm{~Hz}$ in some cases) in relation to $\mathrm{Al}$ and Al/EPDM. On the other hand, one of the largest jumps in low frequency performance was 
highlighted at this site for PE (i.e., a $6 \mathrm{~Hz}$ increase). However, poorer low frequency performance with PE was limited to this $6 \mathrm{~Hz}$ swing for one specific combination of source offset and sledgehammer size (i.e., $4 \mathrm{lb}$ at $-6 \mathrm{dx}$ ). It should be noted that Al/EPDM demonstrated this same $6 \mathrm{~Hz}$ poorer performance with this combination of survey parameters. Besides the aforementioned case, PE tended to yield lower frequencies in the dispersion images, typically on the order of $2 \mathrm{~Hz}-3 \mathrm{~Hz}$. One of the largest improvements in low frequency performance $(5 \mathrm{~Hz}$ decrease) with PE was noted at TA1 for two cases. Generally, A1/EPDM performance was less consistent and less beneficial compared to PE. One final pattern that emerges when examining Table 4-4 is that the use of larger hammers tended to increase the presence of low frequency energy. This result follows typical patterns of low frequency wave generation based on the literature (i.e., larger hammers yield lower frequencies).

The presence of higher modes in the dispersion images for TA1 was less pronounced compared to MLK and FEF. Therefore, it was very difficult to provide qualitative assessments of the effects of base plate on higher modes at TA1. In terms of the high frequency range (i.e., > $30 \mathrm{~Hz}-50 \mathrm{~Hz}$ ) generated in the dispersion images at this site, the effects were rather subtle. In fact, overwhelmingly, there is minimal change in what high frequency components are observed in the dispersion image. None of the plates singularly stood out to have the highest frequency values at all the shot locations and hammer sizes (Appendix A-4).

\subsection{Temple Track Field (TTF)}

Similar to all the sites observed so far, data quality was reduced as the shot location 
increased with respect to the closest geophone in the array due to reductions in SNR. The details of the lowest observable frequency components in the dispersion images at the various shot locations are shown in

\begin{tabular}{|c|c|c|c|c|}
\hline \multirow{2}{*}{\multicolumn{2}{|c|}{ Shot Location $-3 \mathrm{dx}$}} & \multicolumn{3}{|c|}{ Plate Configuration } \\
\hline & & $\mathrm{AL}$ & AL/EPDM & $\mathrm{PE}$ \\
\hline \multirow{3}{*}{$\begin{array}{c}\text { Hammer } \\
\text { Size }\end{array}$} & $4 \mathrm{lb}$ & 16 & 17 & 14 \\
\hline & $8 \mathrm{lb}$ & 12 & 14 & 14 \\
\hline & $20 \mathrm{lb}$ & 13 & 16 & 13 \\
\hline \multirow{2}{*}{\multicolumn{2}{|c|}{ Shot Location $-6 \mathrm{dx}$}} & \multicolumn{3}{|c|}{ Plate Configuration } \\
\hline & & $\mathrm{AL}$ & AL/EPDM & PE \\
\hline \multirow{3}{*}{$\begin{array}{c}\text { Hammer } \\
\text { Size }\end{array}$} & $4 \mathrm{lb}$ & 14 & 18 & 17 \\
\hline & $8 \mathrm{lb}$ & 14 & 14 & 14 \\
\hline & $20 \mathrm{lb}$ & 13 & 16 & 14 \\
\hline \multirow{2}{*}{\multicolumn{2}{|c|}{ Shot Location $-12 \mathrm{dx}$}} & \multicolumn{3}{|c|}{ Plate Configuration } \\
\hline & & $\mathrm{AL}$ & AL/EPDM & $\mathrm{PE}$ \\
\hline \multirow{3}{*}{$\begin{array}{c}\text { Hammer } \\
\text { Size }\end{array}$} & $4 \mathrm{lb}$ & 14 & 14 & 14 \\
\hline & $8 \mathrm{lb}$ & 14 & 14 & 14 \\
\hline & $20 \mathrm{lb}$ & 16 & 14 & 13 \\
\hline
\end{tabular}

Table 4-5 and Figures 4-10-4-11. From these tables and figures, it is noticeable that the lowest observed frequency in the dispersion image generated using the PE plate was lower in relationship to both $\mathrm{Al}$ and Al/EPDM. The Al/EPDM plate on the other hand either performed slightly better than the $\mathrm{Al}$ or provided no improvement in most cases. The overall improvement in low frequency performance for the alternative proposed plates (Al/EPDM and PE) was typically small (i.e., ranged from approximately 1 to 2 $\mathrm{Hz}$ ). This was the only site where low frequency performance was never negatively affected when switching Al for Al/EPDM or for PE.

Pronounced higher modes were observed in the dispersion images at this site. In fact, it would be difficult to provide much information regarding the very shallow near surface 
without the need to perform inversion using higher modes. This is because the high frequency range of the dispersion images is dominated by higher modes at TTF. Therefore, this site was seemingly the most appropriate to qualitatively assess the effects of base plate on higher mode energy partitioning. However, the intensity of the higher modes did not seem to depend significantly on base plate configuration. The effects of base plate were also minimal in terms of the ranges of high frequency observed in the dispersion images at this site The PE plate occasionally resulted in the presence of slightly higher frequency components in relationship to $\mathrm{Al}$ and $\mathrm{Al} / \mathrm{EPDM}$ at certain shot locations and hammer sizes (Appendix A-5). Again, these differences were miniscule in comparison to any changes in low frequency.

\subsection{Penn Treaty Park (PTP)}

Data quality at PTP was relatively poor due to background noise and the presence of complex higher mode energy partitioning. This made selection of the fundamental mode dispersion curve in the dispersion images quite difficult in relation to the other sites. Coupled with this, one of the connectors on the geophone cable was found to be defective after data collection at this site. This means that, only 23 out of the 24 geophones were functional during the data acquisition period. This affected the quality of the resolution of the results. In terms of the frequency values, the PE plate generally recorded lower values compared to the plates. However, there were a number of inconsistencies in the results in terms of low frequency performance of the plates. For example, low frequency performance suffered using the Al/EPDM and PE plate at $-3 \mathrm{dx}$ using the $8 \mathrm{lb}$ hammer and at - $6 \mathrm{dx}$ with the $4 \mathrm{lb}$ hammer. In both these cases, the Al plate performed better compared to the other plates, though the difference was relatively understated. These 
inconsistencies could be attributed to some of previously highlighted issues of background noise, electrical interference from the faulty connector, and/or the increased presence of higher modes at this site relative to other sites. These inconsistencies must be further investigated to identify their true causes in future investigations.

The presence of significant higher mode energy was observed in the majority of the dispersion images at this site. In fact, identification of the fundamental mode is extremely difficult at this site. Like some of the other sites where higher modes were observed, there does seem to be some dependency of the intensity of the higher mode energy on the base plate used. Higher modes tended to be slightly more identifiable in dispersion images generated using $\mathrm{PE}$ in relation to $\mathrm{Al} / \mathrm{EPDM}$ and $\mathrm{Al}$, though the overall affect was relatively subtle. Similar to TTF and the majority of the other sites, differences in the high frequency range observed in the dispersion images were minimal. 


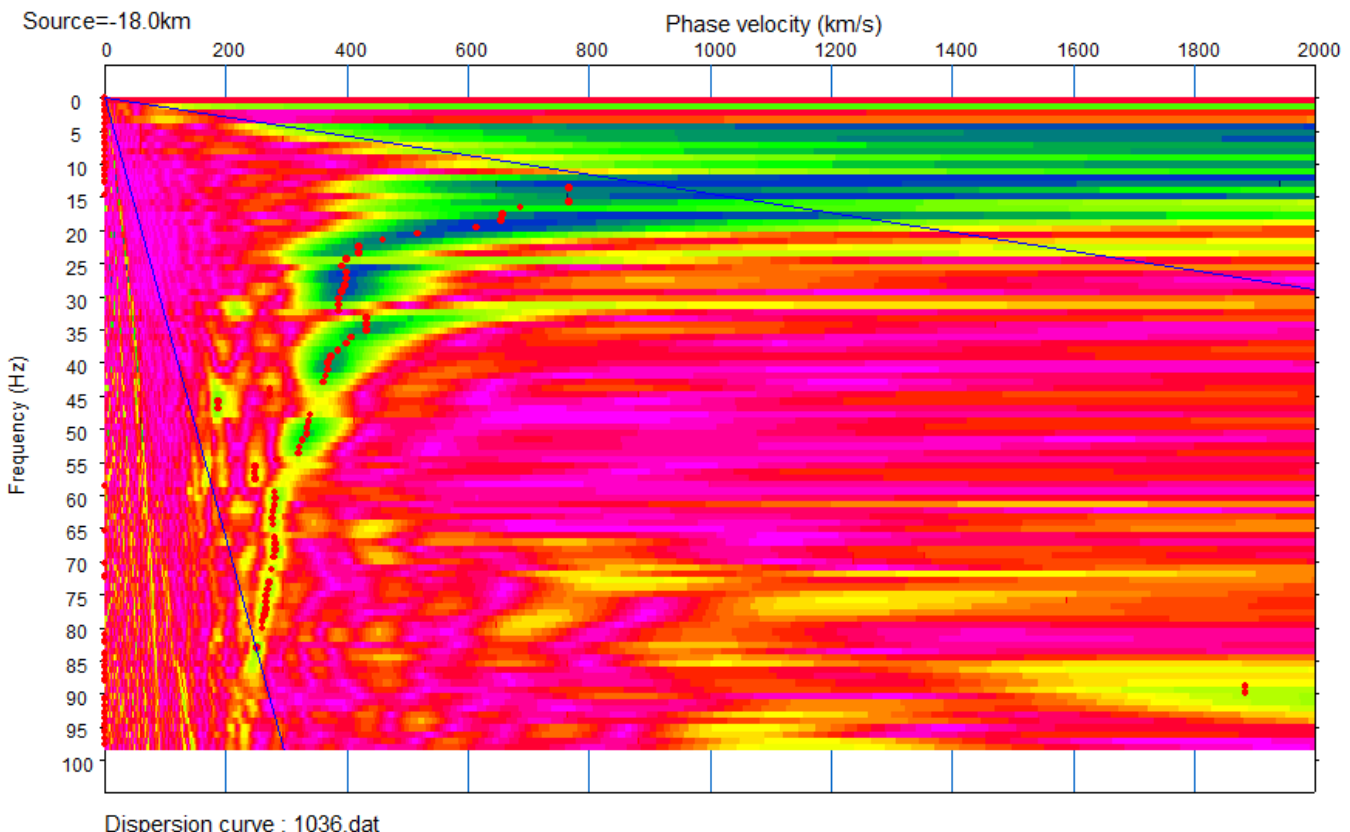

Dispersion curve : 1036 .dat

(a)

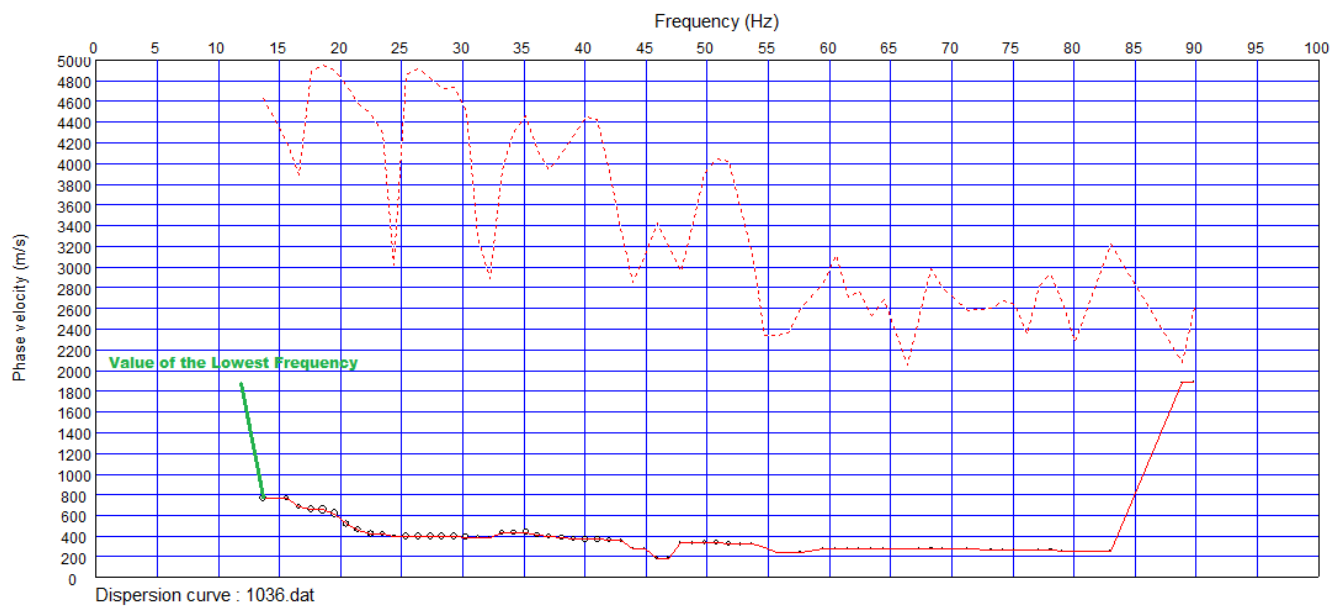

(b)

Fig. 4-1: Methodology for estimating the lowest frequency component of the dispersion curve: (a) Dispersion image with automatically selected dispersion curve; (b) Plot that isolates the selected dispersion curve and highlights the selected lowest frequency component on the curve. 
(a) Source Offset $=-3 d x$

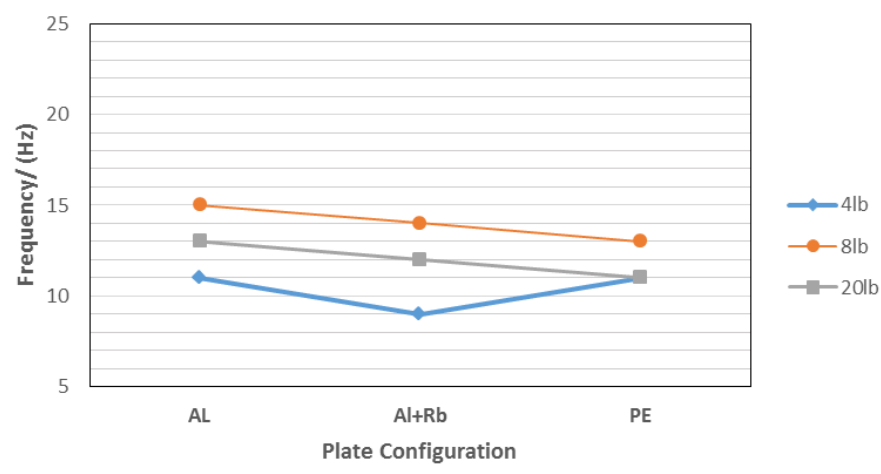

(a)

(c) Source Offset $=-12 \mathrm{dx}$

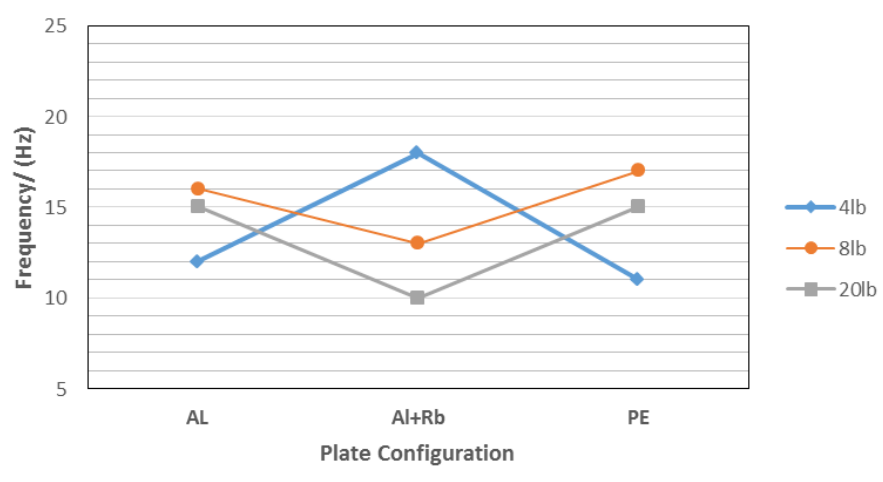

(b)

(b) Source Offset $=-6 \mathrm{dx}$

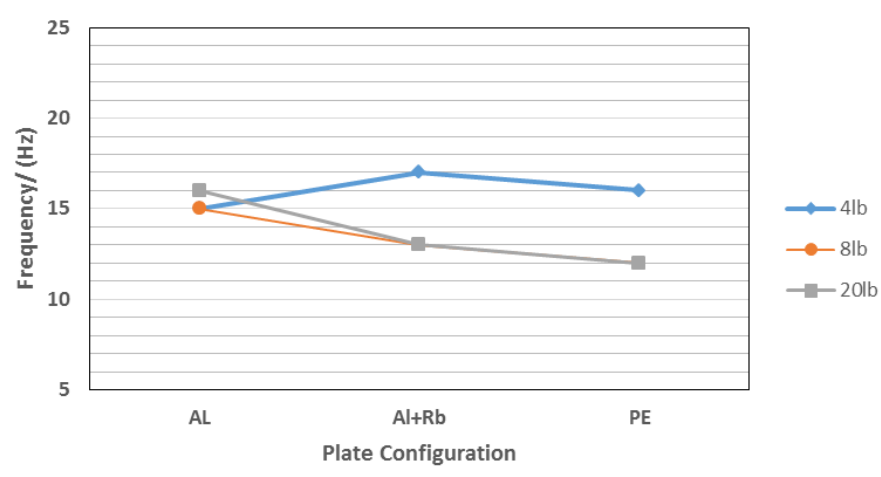

(c)

Fig. 4-2: Lowest frequency component present in DRC dispersion curves generated at various source offsets: (a) $-3 d x$; (b) $-6 d x$; and (c) $-12 \mathrm{dx}$. 


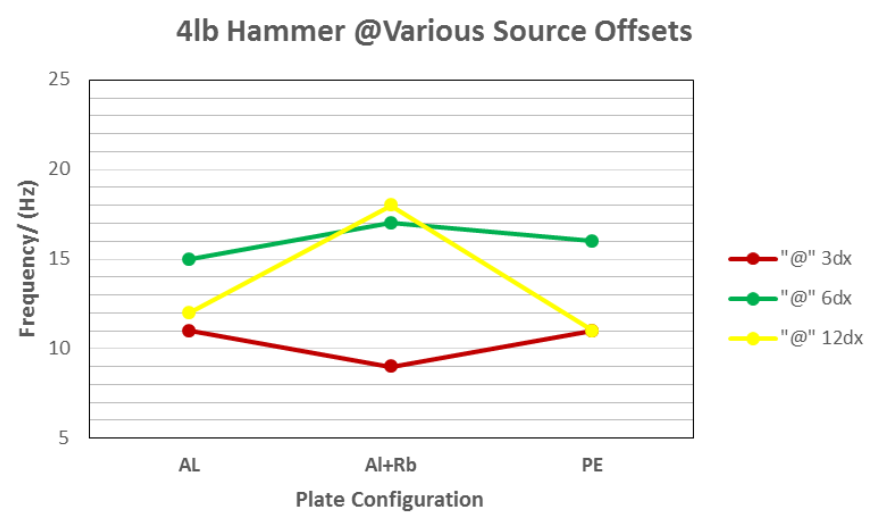

(a)

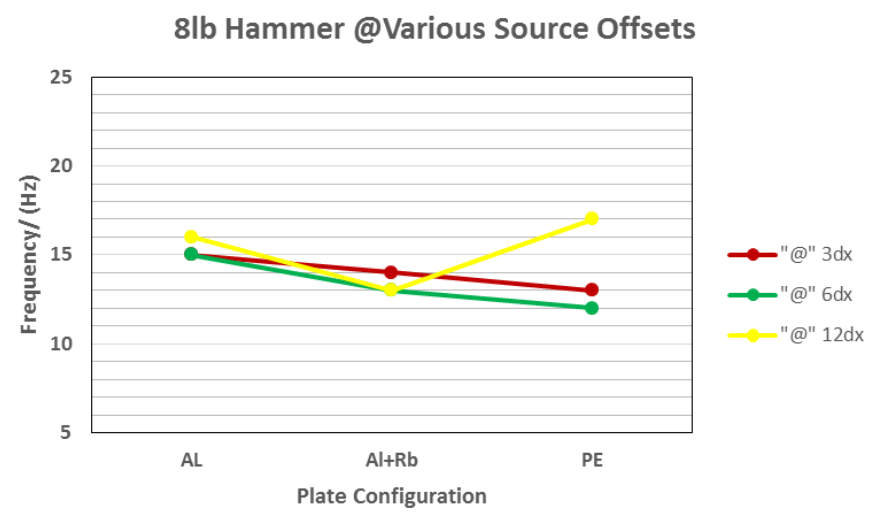

(b)

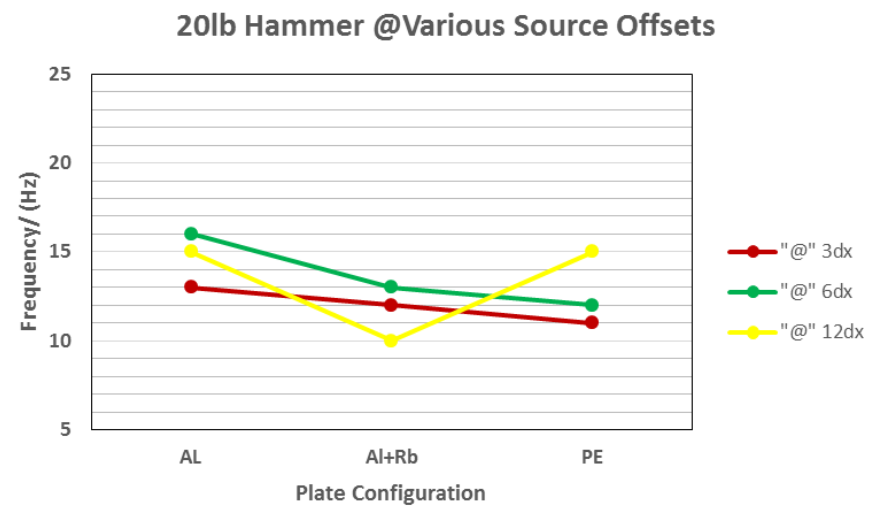

(c)

Fig. 4-3: Summary of lowest frequency component present in DRC dispersion curves based on hammer size: (a) $4 \mathrm{lb}$; (b) $8 \mathrm{lb}$; and (c) $20 \mathrm{lb}$. 
(a) Source Offset $=-3 \mathrm{dx}$

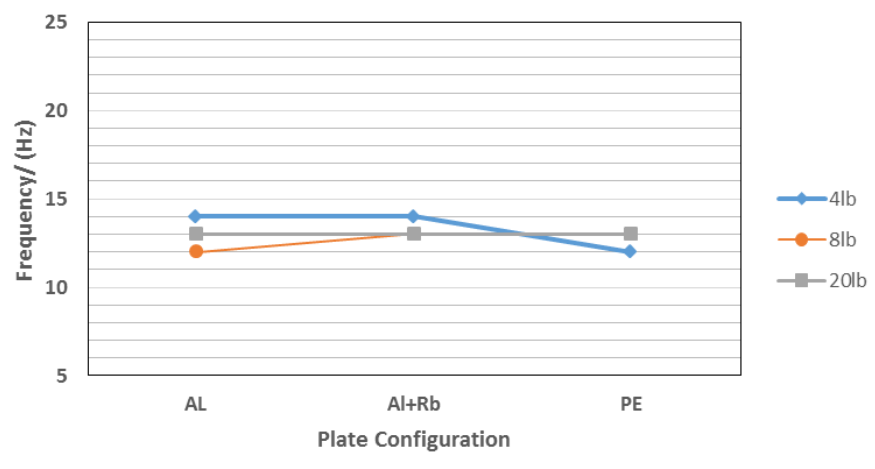

(a)

(b) Source Offset $=-6 \mathrm{dx}$

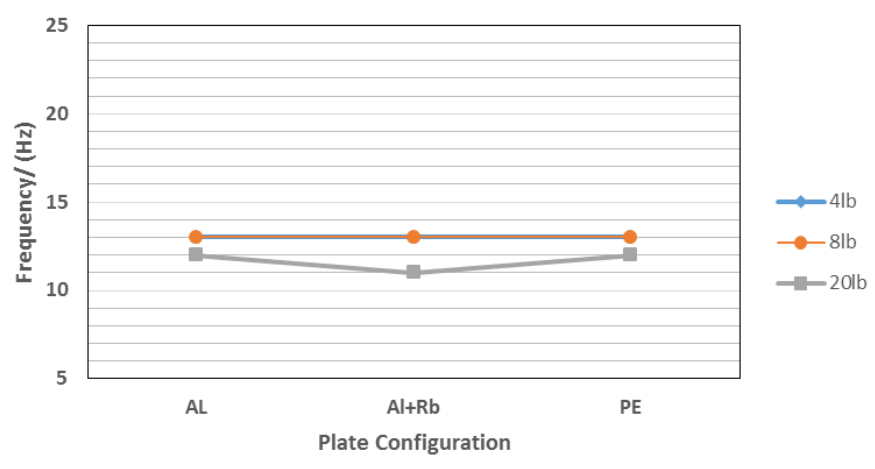

(b)

(c) Source Offset $=-12 \mathrm{dx}$

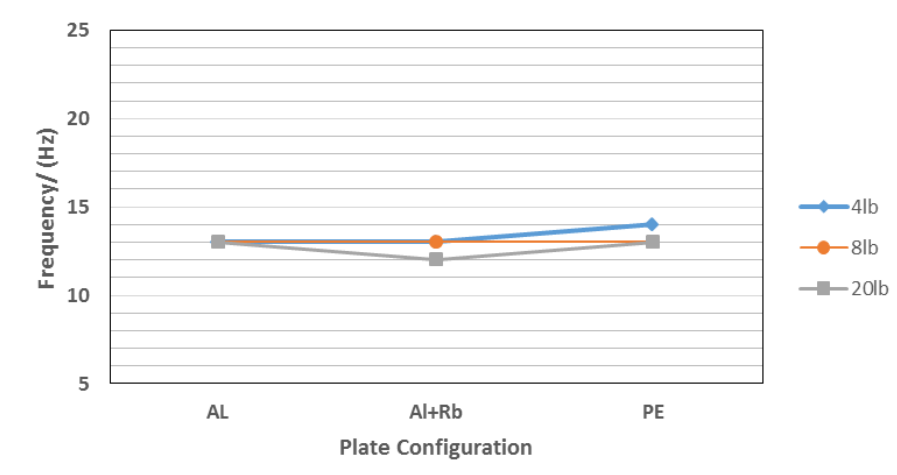

(c)

Fig. 4-4: Lowest frequency component present in FEF dispersion curves generated at various source offsets: (a)-3dx; (b)-6dx; and (c)-12dx. 


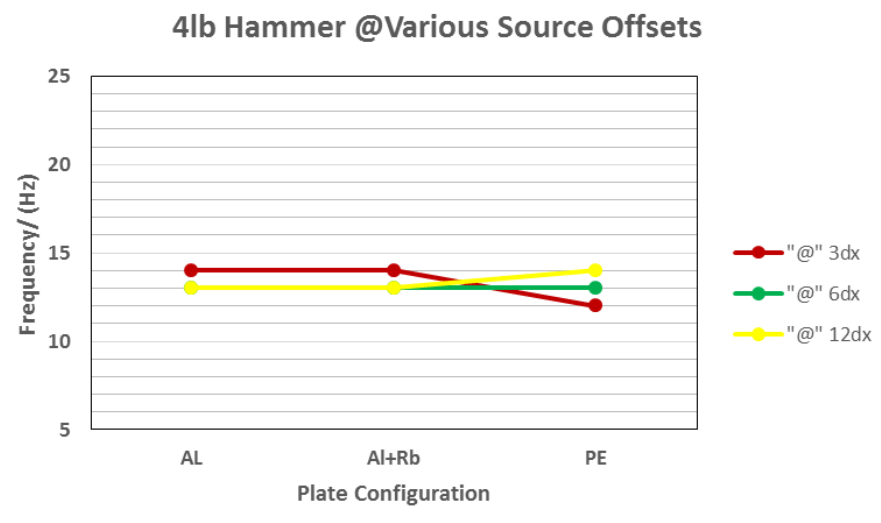

(a)

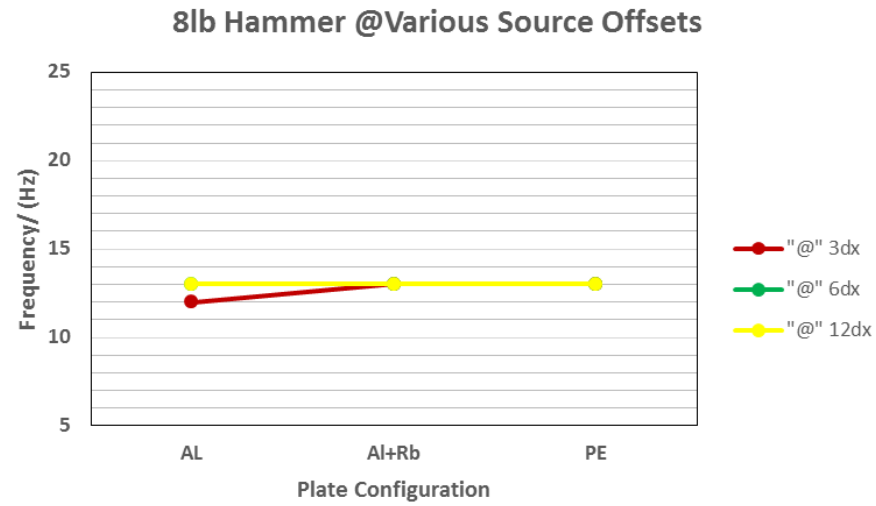

(b)

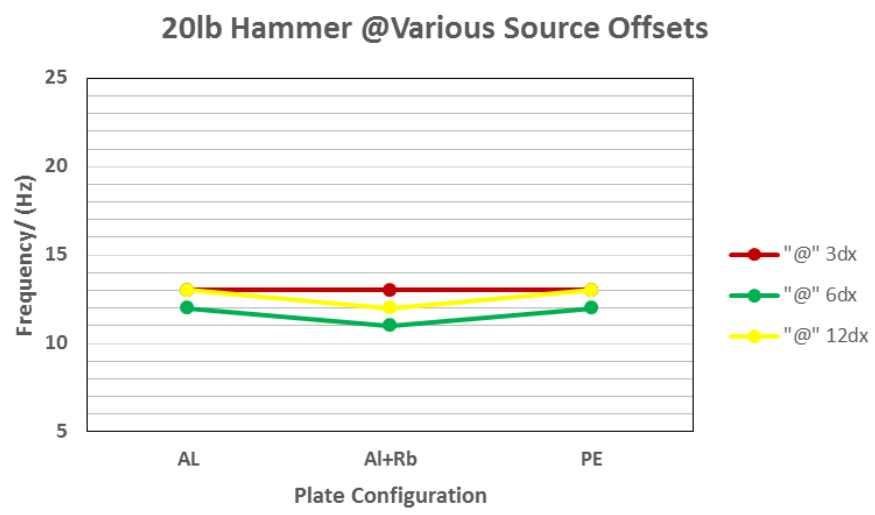

(c)

Fig. 4-5: Summary of lowest frequency component present in FEF dispersion curves based on hammer size: (a) $4 \mathrm{lb}$; (b) $8 \mathrm{lb}$; and (c) $20 \mathrm{lb}$. 
(a) Source Offset $=-3 \mathrm{dx}$

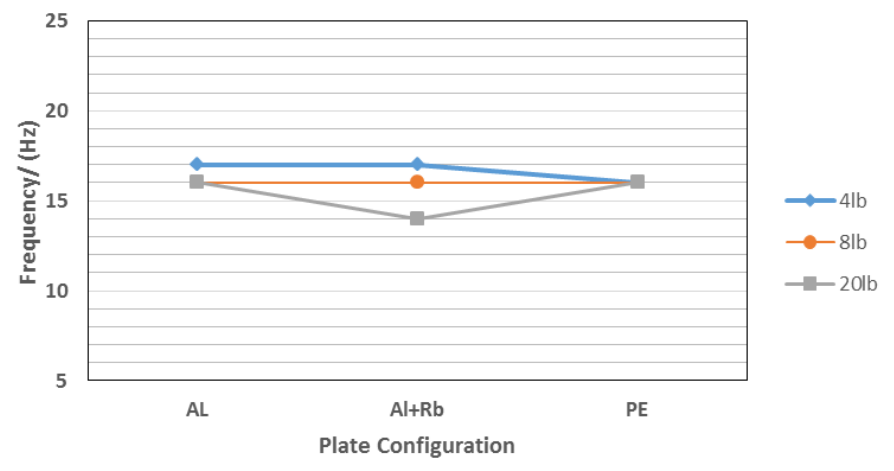

(a)

(c) Source Offset $=-6 \mathrm{dx}$

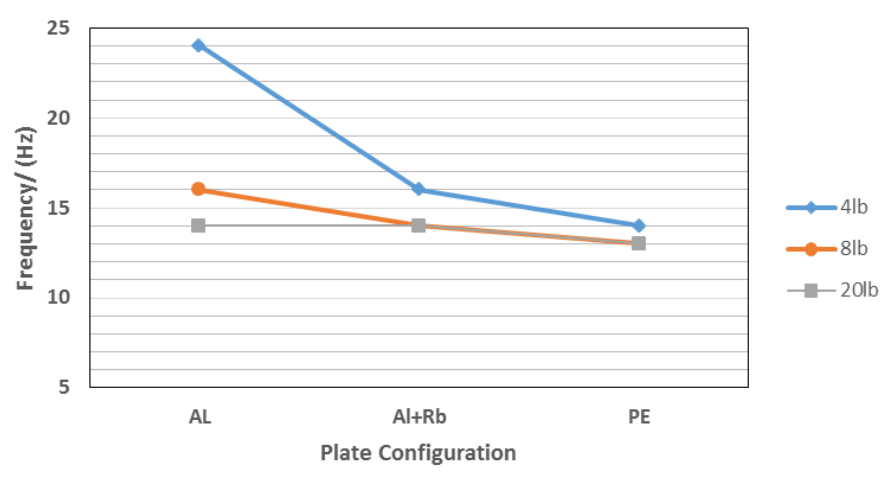

(b)

(c) Source Offset $=-12 \mathrm{dx}$

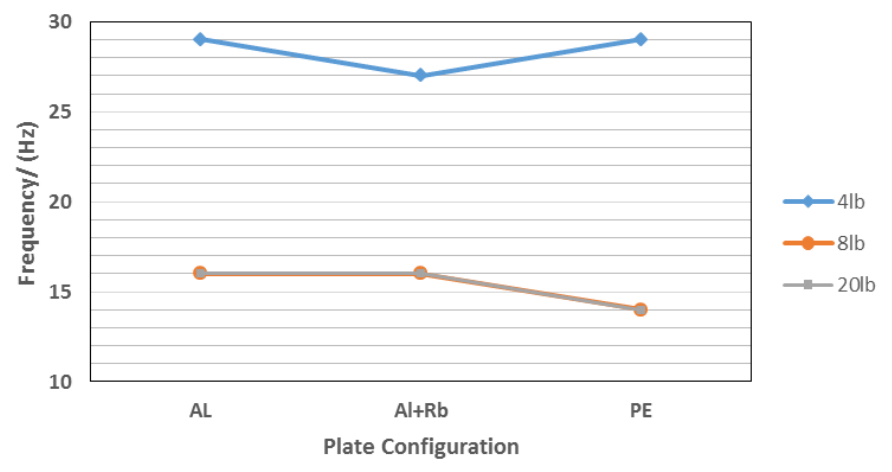

(c)

Fig. 4-6: Lowest frequency component present in MLK dispersion curves generated at various source offsets: (a) $-3 d x$; (b) $-6 d x$; and (c) $-12 \mathrm{dx}$. 


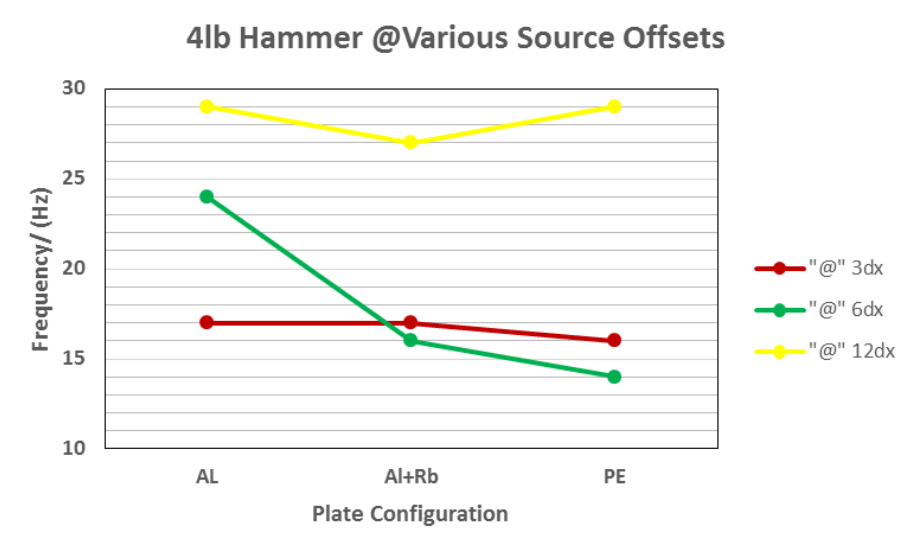

(a)

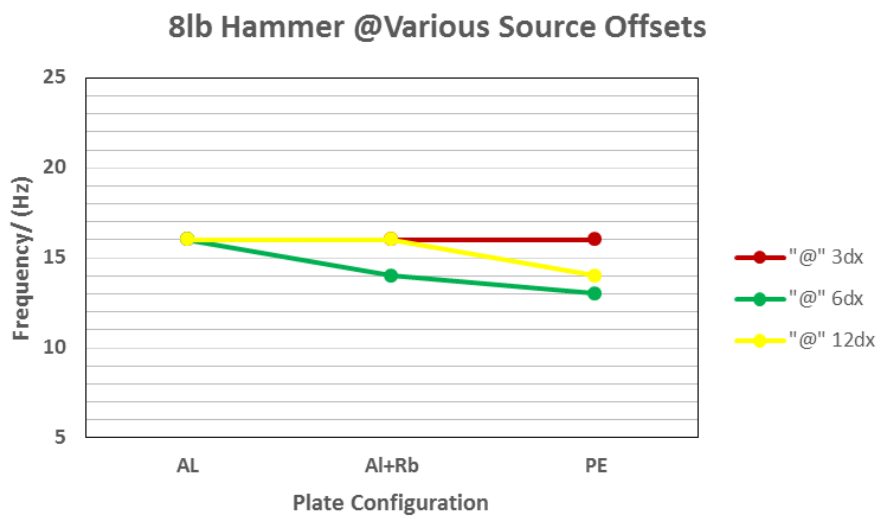

(b)

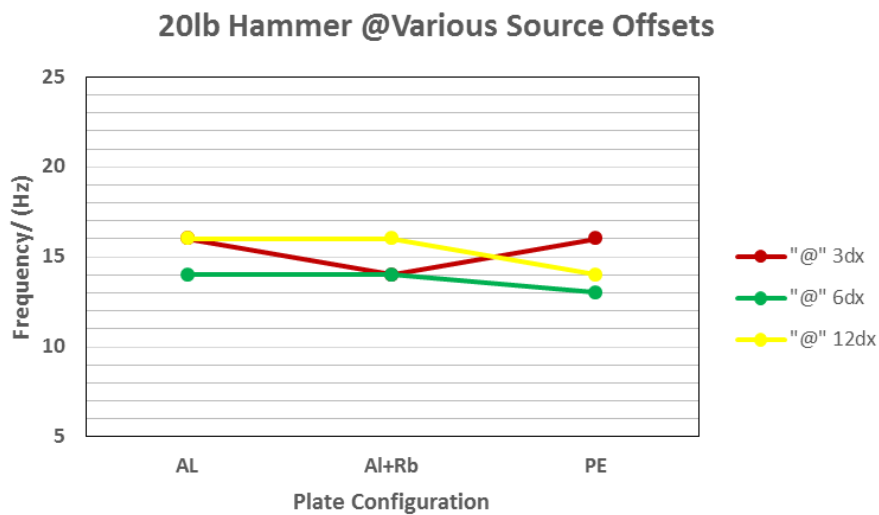

(c)

Fig. 4-7: Summary of lowest frequency component present in MLK dispersion curves based on hammer size: (a) $4 \mathrm{lb}$; (b) $8 \mathrm{lb}$; and (c) $20 \mathrm{lb}$. 


\section{(a) Source Offset $=-3 \mathrm{dx}$}

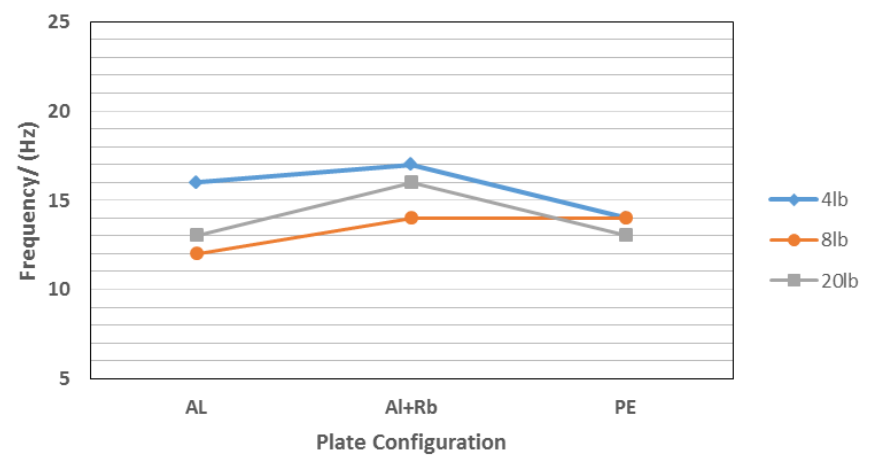

(a)

(b) Source Offset $=-6 \mathrm{dx}$

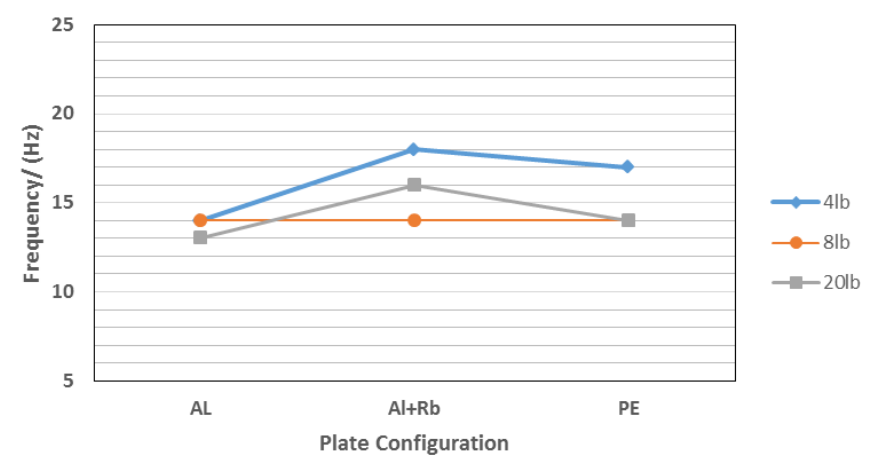

(b)

(c) Source Offset $=-12 \mathrm{dx}$

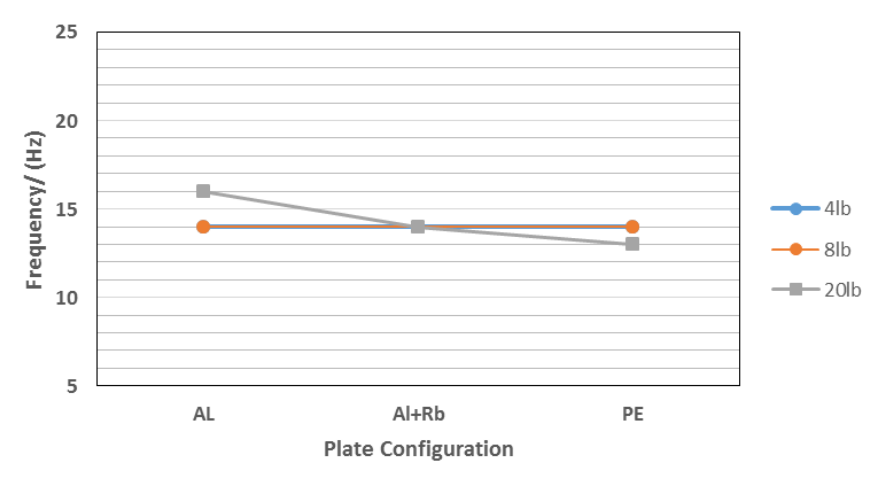

(c)

Fig. 4-8: Lowest frequency component present in TA1 dispersion curves generated at various source offsets: (a) $-3 d x$; (b) $-6 d x$; and (c) $-12 \mathrm{dx}$. 


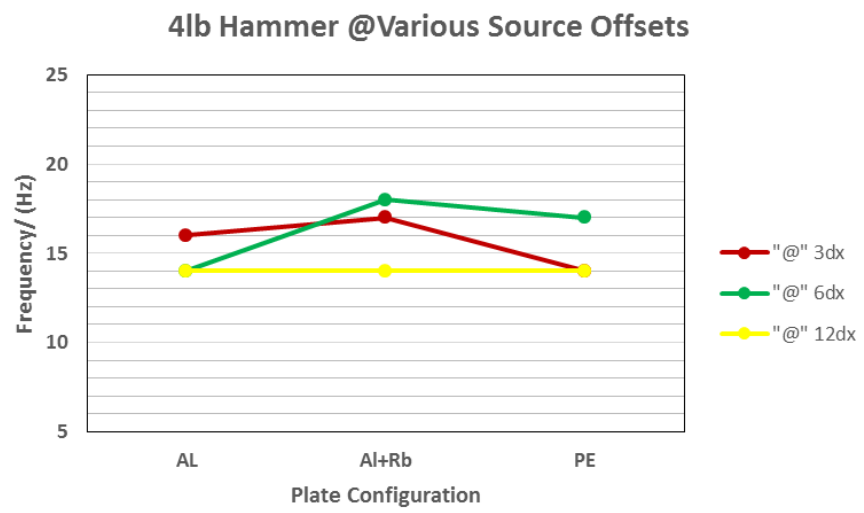

(a)

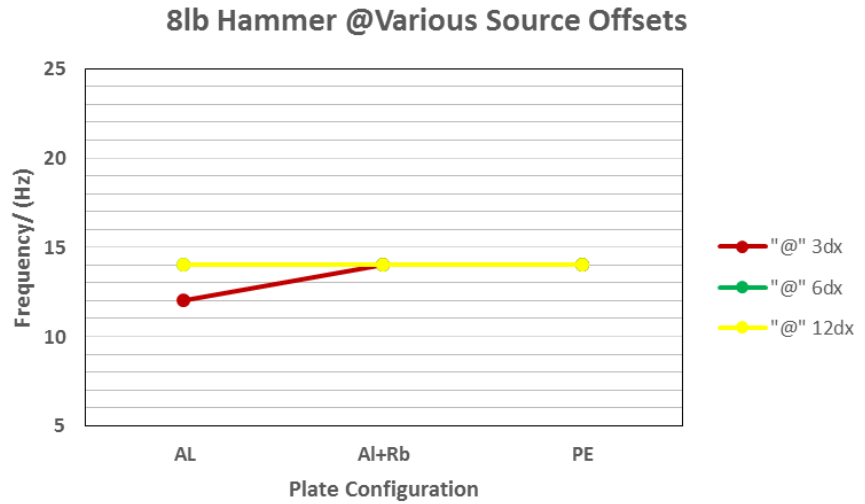

(b)

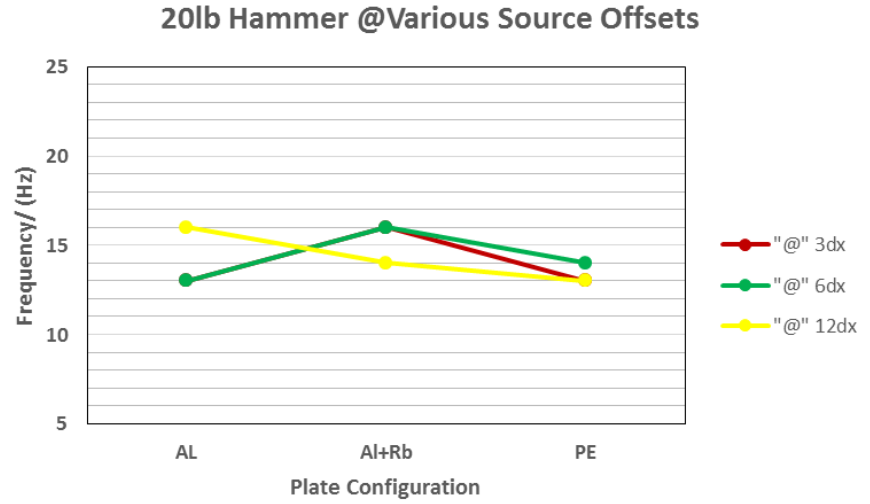

(c)

Fig. 4-9: Summary of lowest frequency component present in TA1 dispersion curves based on hammer size: (a) $4 \mathrm{lb}$; (b) $8 \mathrm{lb}$; and (c) $20 \mathrm{lb}$. 
(a) Source Offset $=-3 \mathrm{dx}$

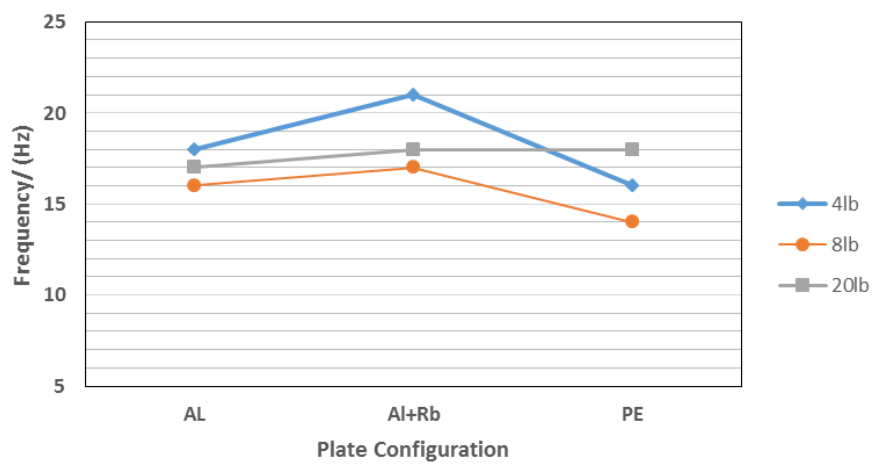

(a)

(b) Source Offset $=-6 d x$

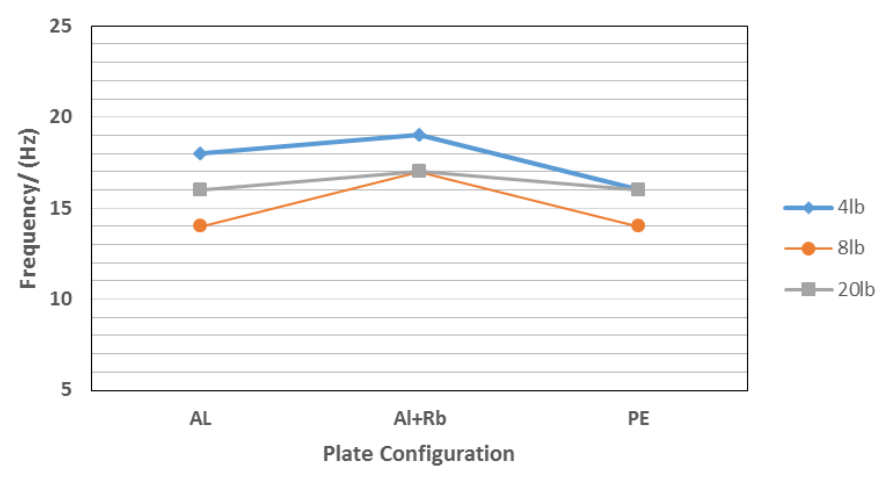

(b)

(c) Source Offset $=-12 \mathrm{dx}$

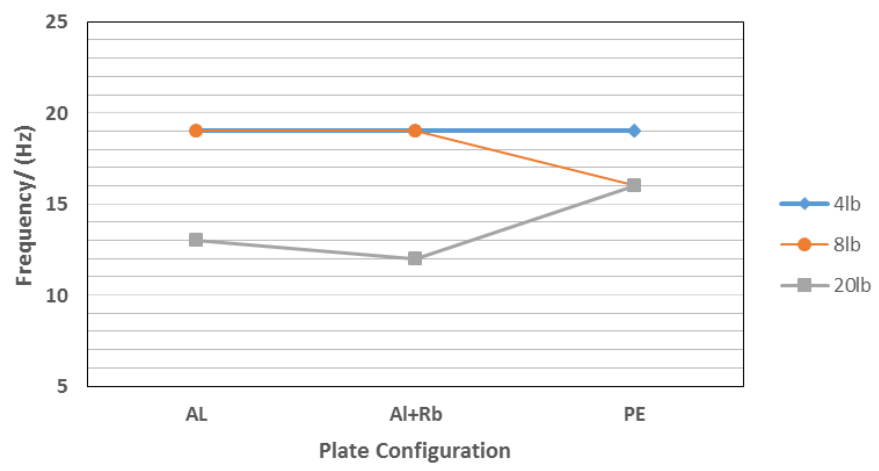

(c)

Fig. 4-10: Lowest frequency component present in TTF dispersion curves generated at various source offsets: (a) $-3 d x$; (b) $-6 d x$; and (c) $-12 d x$. 


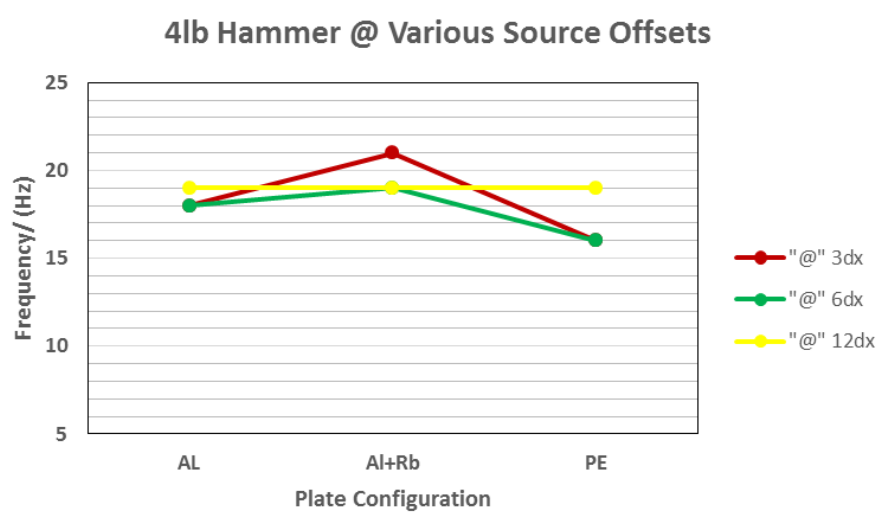

(a)

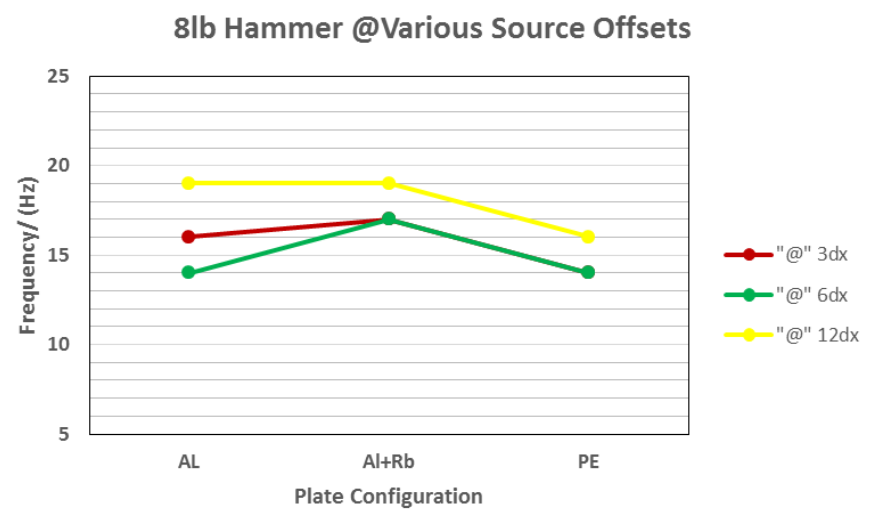

(b)

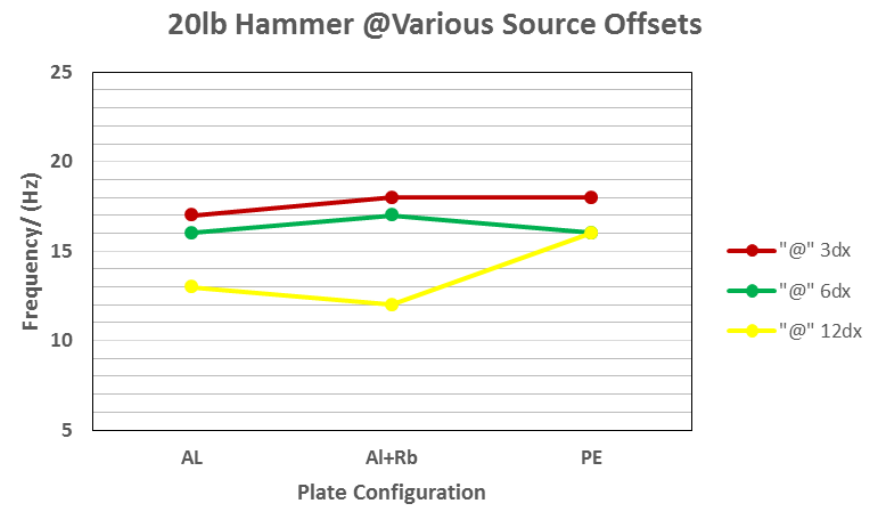

(c)

Fig. 4-11: Summary of lowest frequency component present in TTF dispersion curves based on hammer size: (a) $4 \mathrm{lb}$; (b) $8 \mathrm{lb}$; and (c) $20 \mathrm{lb}$. 
(a) Source Offset $=-3 d x$

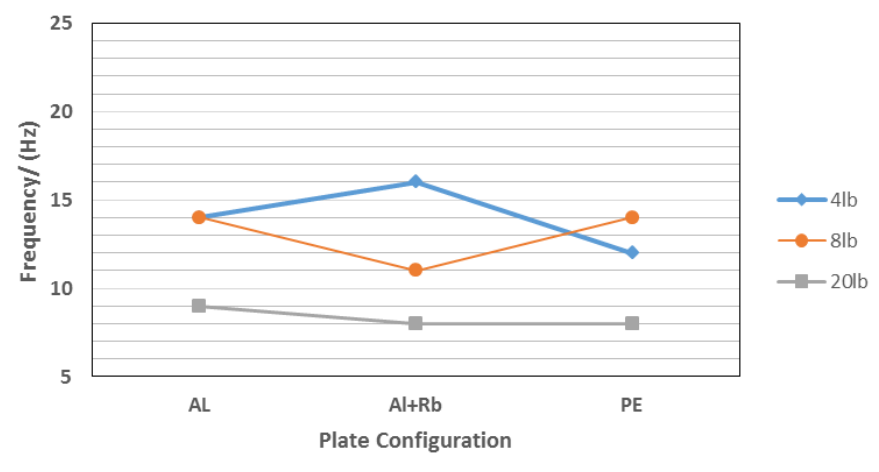

(a)

(b) Source Offset $=-6 \mathrm{dx}$

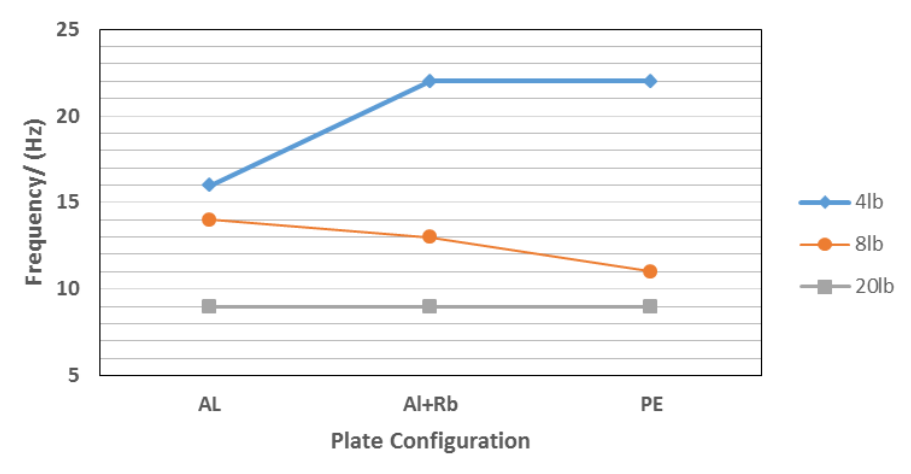

(b)

(c) Source Offset $=-12 \mathrm{dx}$

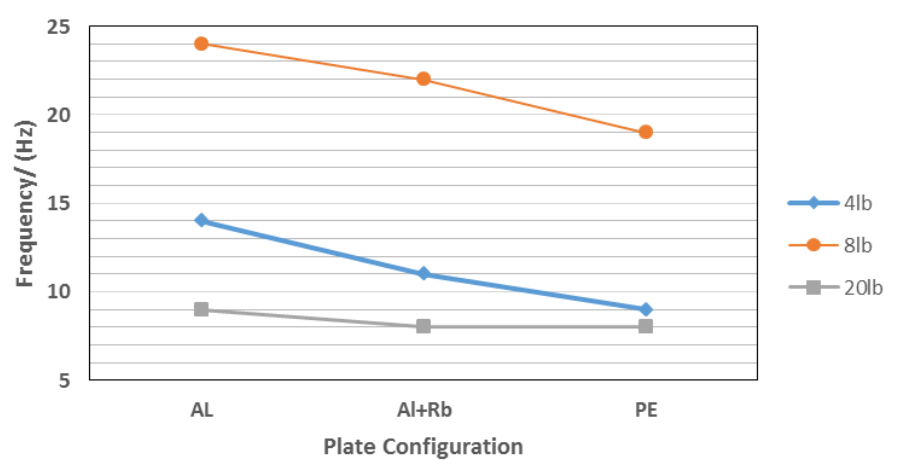

(c)

Fig. 4-12: Lowest frequency component present in PTP dispersion curves generated at various source offsets: (a) $-\mathbf{3 d x}$; (b) $-\mathbf{6 d x}$; and (c) $-\mathbf{1 2} \mathrm{dx}$. 


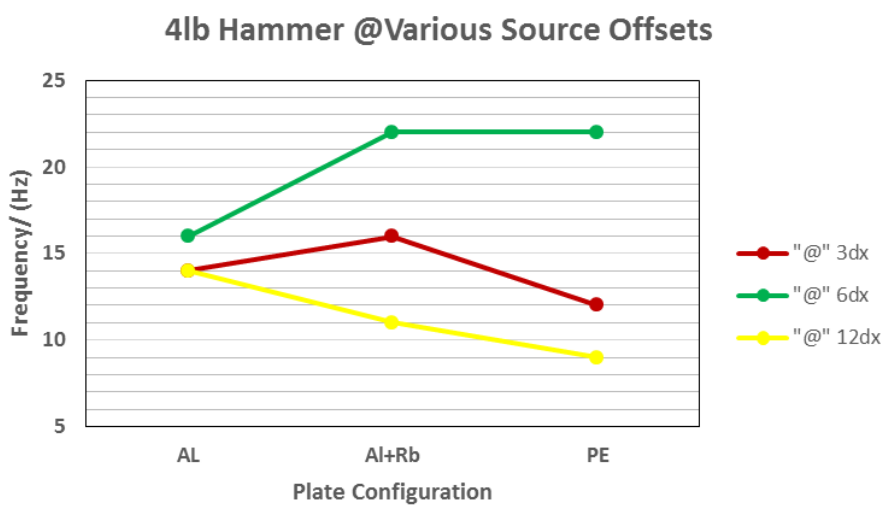

(a)

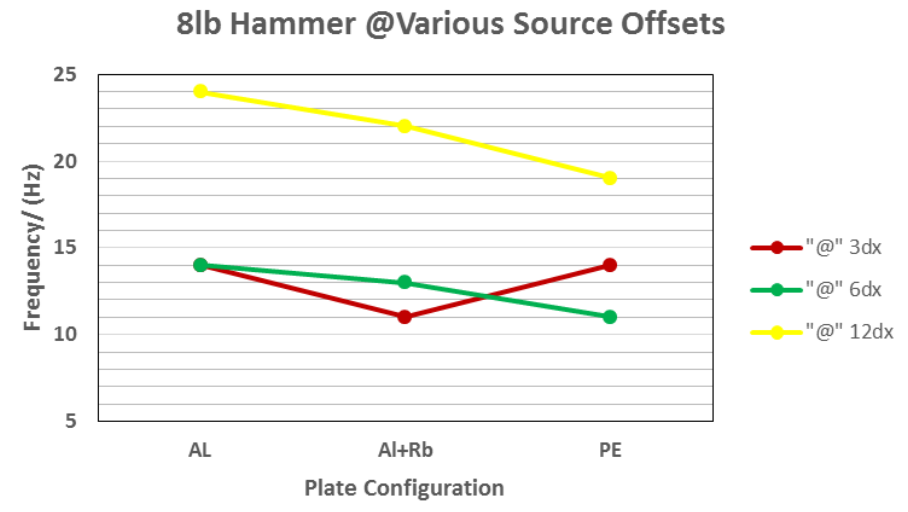

(b)

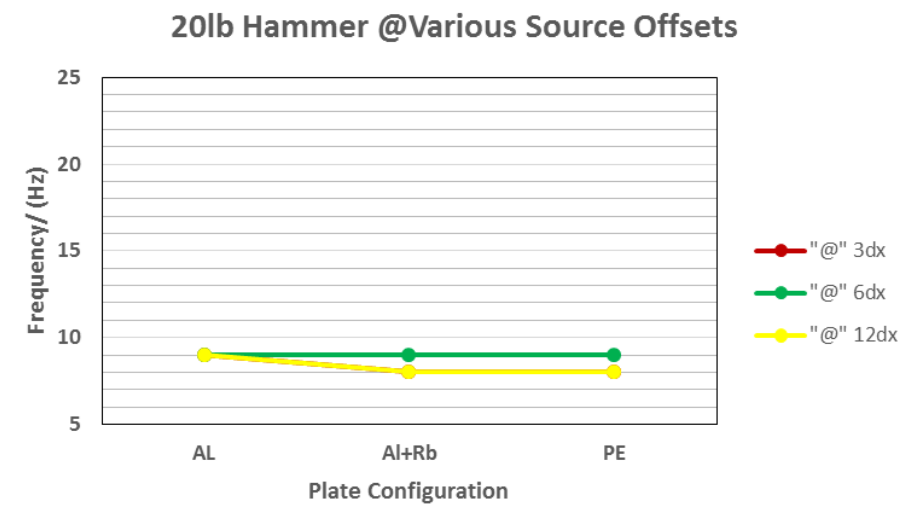

(c)

Fig. 4-13: Summary of lowest frequency component present in PTP dispersion curves based on hammer size: (a) $4 \mathrm{lb}$; (b) $8 \mathrm{lb}$; and (c) $20 \mathrm{lb}$. 
Table 4-1: Summary of the lowest observable frequency component in $\mathrm{Hz}$ for the dispersion curves generated at DRC.

\begin{tabular}{|c|c|c|c|c|}
\hline \multirow{2}{*}{\multicolumn{2}{|c|}{ Shot Location $-3 \mathrm{dx}$}} & \multicolumn{3}{|c|}{ Plate Configuration } \\
\hline & & $\mathrm{AL}$ & AL/EPDM & PE \\
\hline \multirow{3}{*}{$\begin{array}{c}\text { Hammer } \\
\text { Size }\end{array}$} & $4 \mathrm{lb}$ & 11 & 9 & 11 \\
\hline & $8 \mathrm{lb}$ & 15 & 14 & 13 \\
\hline & $20 \mathrm{lb}$ & 13 & 12 & 11 \\
\hline \multirow{2}{*}{\multicolumn{2}{|c|}{ Shot Location $-6 \mathrm{dx}$}} & \multicolumn{3}{|c|}{ Plate Configuration } \\
\hline & & $\mathrm{AL}$ & AL/EPDM & PE \\
\hline \multirow{3}{*}{$\begin{array}{c}\text { Hammer } \\
\text { Size }\end{array}$} & $4 \mathrm{lb}$ & 15 & 17 & 16 \\
\hline & $8 \mathrm{lb}$ & 15 & 13 & 12 \\
\hline & $20 \mathrm{lb}$ & 16 & 13 & 12 \\
\hline \multirow{2}{*}{\multicolumn{2}{|c|}{ Shot Location $-12 \mathrm{dx}$}} & \multicolumn{3}{|c|}{ Plate Configuration } \\
\hline & & $\mathrm{AL}$ & $\overline{\mathrm{AL} / \mathrm{EPDM}}$ & $\mathrm{PE}$ \\
\hline \multirow{3}{*}{$\begin{array}{c}\text { Hammer } \\
\text { Size }\end{array}$} & $4 \mathrm{lb}$ & 12 & 18 & 11 \\
\hline & $8 \mathrm{lb}$ & 16 & 13 & 17 \\
\hline & $20 \mathrm{lb}$ & 15 & 10 & 15 \\
\hline
\end{tabular}

Table 4-2: Summary of the lowest observable frequency component in $\mathrm{Hz}$ for the dispersion curves generated at FEF.

\begin{tabular}{|c|c|c|c|c|}
\hline \multirow{2}{*}{\multicolumn{2}{|c|}{ Shot Location $-3 \mathrm{dx}$}} & \multicolumn{3}{|c|}{ Plate Configuration } \\
\hline & & $\mathrm{AL}$ & AL/EPDM & $\mathrm{PE}$ \\
\hline \multirow{3}{*}{$\begin{array}{c}\text { Hammer } \\
\text { Size }\end{array}$} & $4 \mathrm{lb}$ & 14 & 14 & 12 \\
\hline & $8 \mathrm{lb}$ & 12 & 13 & 13 \\
\hline & $20 \mathrm{lb}$ & 13 & 13 & 13 \\
\hline \multirow{2}{*}{\multicolumn{2}{|c|}{ Shot Location $-6 \mathrm{dx}$}} & \multicolumn{3}{|c|}{ Plate Configuration } \\
\hline & & $\mathrm{AL}$ & AL/EPDM & $\mathrm{PE}$ \\
\hline \multirow{3}{*}{$\begin{array}{c}\text { Hammer } \\
\text { Size }\end{array}$} & $4 \mathrm{lb}$ & 13 & 13 & 13 \\
\hline & $8 \mathrm{lb}$ & 13 & 13 & 13 \\
\hline & $20 \mathrm{lb}$ & 12 & 11 & 12 \\
\hline \multirow{2}{*}{\multicolumn{2}{|c|}{ Shot Location $-12 \mathrm{dx}$}} & \multicolumn{3}{|c|}{ Plate Configuration } \\
\hline & & $\mathrm{AL}$ & AL/EPDM & $\mathrm{PE}$ \\
\hline \multirow{3}{*}{$\begin{array}{c}\text { Hammer } \\
\text { Size }\end{array}$} & $4 \mathrm{lb}$ & 13 & 13 & 14 \\
\hline & $8 \mathrm{lb}$ & 13 & 13 & 13 \\
\hline & $20 \mathrm{lb}$ & 13 & 12 & 13 \\
\hline
\end{tabular}


Table 4-3: Summary of the lowest observable frequency component in $\mathrm{Hz}$ for the dispersion curves generated at MLK.

\begin{tabular}{|c|c|c|c|c|}
\hline \multirow{2}{*}{\multicolumn{2}{|c|}{ Shot Location $-3 \mathrm{dx}$}} & \multicolumn{3}{|c|}{ Plate Configuration } \\
\hline & & $\mathrm{AL}$ & AL/EPDM & $\mathrm{PE}$ \\
\hline \multirow{3}{*}{$\begin{array}{c}\text { Hammer } \\
\text { Size }\end{array}$} & $4 \mathrm{lb}$ & 17 & 17 & 16 \\
\hline & $8 \mathrm{lb}$ & 16 & 16 & 16 \\
\hline & $20 \mathrm{lb}$ & 16 & 14 & 16 \\
\hline \multirow{2}{*}{\multicolumn{2}{|c|}{ Shot Location $-6 \mathrm{dx}$}} & \multicolumn{3}{|c|}{ Plate Configuration } \\
\hline & & $\mathrm{AL}$ & AL/EPDM & $\mathrm{PE}$ \\
\hline \multirow{3}{*}{$\begin{array}{c}\text { Hammer } \\
\text { Size }\end{array}$} & $4 \mathrm{lb}$ & 24 & 16 & 14 \\
\hline & $8 \mathrm{lb}$ & 16 & 14 & 13 \\
\hline & $20 \mathrm{lb}$ & 14 & 14 & 13 \\
\hline \multirow{2}{*}{\multicolumn{2}{|c|}{ Shot Location $-12 d x$}} & \multicolumn{3}{|c|}{ Plate Configuration } \\
\hline & & $\mathrm{AL}$ & AL/EPDM & $\mathrm{PE}$ \\
\hline \multirow{3}{*}{$\begin{array}{c}\text { Hammer } \\
\text { Size }\end{array}$} & $4 \mathrm{lb}$ & 29 & 27 & 29 \\
\hline & $8 \mathrm{lb}$ & 16 & 16 & 14 \\
\hline & $20 \mathrm{lb}$ & 16 & 16 & 14 \\
\hline
\end{tabular}

Table 4-4: Summary of the lowest observable frequency component in $\mathrm{Hz}$ for the dispersion curves generated at TA1.

\begin{tabular}{|c|c|c|c|c|}
\hline \multirow{2}{*}{ Shot Location -3dx } & \multicolumn{3}{|c|}{ Plate Configuration } \\
\cline { 3 - 5 } & $4 \mathrm{lb}$ & 16 & 17 & 14 \\
\hline \multirow{2}{*}{$\begin{array}{c}\text { Hammer } \\
\text { Size }\end{array}$} & $8 \mathrm{lb}$ & 12 & 14 & 14 \\
\cline { 2 - 5 } & $20 \mathrm{lb}$ & 13 & 16 & 13 \\
\hline \multicolumn{4}{|c|}{ Plate Configuration } \\
\hline \multirow{2}{*}{\begin{tabular}{c} 
Shot Location $-6 \mathrm{dx}$ \\
\cline { 3 - 5 }
\end{tabular}} & $4 \mathrm{lb}$ & 14 & 18 & 17 \\
\hline \multirow{2}{*}{$\begin{array}{c}\text { Hammer } \\
\text { Size }\end{array}$} & $8 \mathrm{lb}$ & 14 & 14 & 14 \\
\cline { 2 - 5 } & $20 \mathrm{lb}$ & 13 & 16 & 14 \\
\hline \multicolumn{3}{|c|}{ AL/EPDM } & PE \\
\hline \multirow{2}{*}{\begin{tabular}{c} 
Shot Location $-12 \mathrm{dx}$ \\
\cline { 2 - 5 }
\end{tabular}} & $\mathrm{AL}$ & AL/EPDM & PE \\
\hline \multirow{2}{*}{$\begin{array}{c}\text { Hammer } \\
\text { Size }\end{array}$} & $4 \mathrm{lb}$ & 14 & 14 & 14 \\
\cline { 2 - 5 } & $8 \mathrm{lb}$ & 14 & 14 & 14 \\
\cline { 2 - 5 } & $20 \mathrm{lb}$ & 16 & 14 & 13 \\
\hline
\end{tabular}


Table 4-5: Summary of the lowest observable frequency component in $\mathrm{Hz}$ for the dispersion curves generated at TTF.

\begin{tabular}{|c|c|c|c|c|}
\hline \multirow{2}{*}{ Shot Location -3dx } & \multicolumn{3}{|c|}{ Plate Configuration } \\
\cline { 3 - 5 } & AL & AL/EPDM & PE \\
\hline \multirow{2}{*}{$\begin{array}{c}\text { Hammer } \\
\text { Size }\end{array}$} & $4 \mathrm{lb}$ & 18 & 21 & 16 \\
\cline { 2 - 5 } & $8 \mathrm{lb}$ & 16 & 17 & 14 \\
\cline { 2 - 5 } & $20 \mathrm{lb}$ & 17 & 18 & 18 \\
\hline \multicolumn{3}{|c|}{ Plate Configuration } \\
\hline \multirow{2}{*}{\begin{tabular}{c} 
Shot Location -6dx \\
\cline { 2 - 5 }
\end{tabular}} & $4 \mathrm{lb}$ & 18 & 19 & 16 \\
\hline \multirow{2}{*}{$\begin{array}{c}\text { Hammer } \\
\text { Size }\end{array}$} & $8 \mathrm{lb}$ & 14 & 17 & 14 \\
\cline { 2 - 5 } & $20 \mathrm{lb}$ & 16 & 17 & 16 \\
\hline \multicolumn{3}{|c|}{ Plate Configuration } \\
\hline \multirow{2}{*}{\begin{tabular}{c} 
Shot Location $-12 \mathrm{dx}$ \\
\cline { 2 - 5 }
\end{tabular}} & $\mathrm{AL}$ & AL/EPDM & PE \\
\hline \multirow{2}{*}{$\begin{array}{c}\text { Hammer } \\
\text { Size }\end{array}$} & $4 \mathrm{lb}$ & 19 & 19 & 19 \\
\cline { 2 - 5 } & $8 \mathrm{lb}$ & 19 & 19 & 16 \\
\cline { 2 - 5 } & $20 \mathrm{lb}$ & 13 & 12 & 16 \\
\hline
\end{tabular}

Table 4-6: Summary of the lowest observable frequency component in $\mathrm{Hz}$ for the dispersion curves generated at PTP.

\begin{tabular}{|c|c|c|c|c|}
\hline \multirow{2}{*}{\multicolumn{2}{|c|}{ Shot Location $-3 \mathrm{dx}$}} & \multicolumn{3}{|c|}{ Plate Configuration } \\
\hline & & $\mathrm{AL}$ & AL/EPDM & $\mathrm{PE}$ \\
\hline \multirow{3}{*}{$\begin{array}{c}\text { Hammer } \\
\text { Size }\end{array}$} & $4 \mathrm{lb}$ & 14 & 16 & 12 \\
\hline & $8 \mathrm{lb}$ & 14 & 11 & 14 \\
\hline & $20 \mathrm{lb}$ & 9 & 8 & 8 \\
\hline \multirow{2}{*}{\multicolumn{2}{|c|}{ Shot Location $-6 \mathrm{dx}$}} & \multicolumn{3}{|c|}{ Plate Configuration } \\
\hline & & $\mathrm{AL}$ & AL/EPDM & $\mathrm{PE}$ \\
\hline \multirow{3}{*}{$\begin{array}{c}\text { Hammer } \\
\text { Size }\end{array}$} & $4 \mathrm{lb}$ & 16 & 22 & 22 \\
\hline & $8 \mathrm{lb}$ & 14 & 13 & 11 \\
\hline & $20 \mathrm{lb}$ & 9 & 9 & 9 \\
\hline \multirow{2}{*}{\multicolumn{2}{|c|}{ Shot Location $-12 \mathrm{dx}$}} & \multicolumn{3}{|c|}{ Plate Configuration } \\
\hline & & $\mathrm{AL}$ & AL/EPDM & $\mathrm{PE}$ \\
\hline \multirow{3}{*}{$\begin{array}{c}\text { Hammer } \\
\text { Size }\end{array}$} & $4 \mathrm{lb}$ & 14 & 11 & 9 \\
\hline & $8 \mathrm{lb}$ & 24 & 22 & 19 \\
\hline & $20 \mathrm{lb}$ & 9 & 8 & 8 \\
\hline
\end{tabular}




\section{CHAPTER 5}

\section{CONCLUSION AND RECOMMENDATIONS}

\subsection{Summary and Conclusions}

The primary objective of this research was to ascertain if $\mathrm{PE}$ and or a composite AL/EPDM plate could be used as an alternative for an Al plate in MASW testing, particularly in situations where better low frequency performance is desirable. Better low frequency performance has tremendous potential to provide deeper strata information, which is always a goal in seismic geophysical testing. To that effect, 1-D MASW was performed at six (6) different sites in Philadelphia with these three (3) base plate configurations. The plates were used in combination with different sledge hammers (4 lb, $8 \mathrm{lb}$ and $12 \mathrm{lb}$ ) at several offset locations (1dx, 3dx, 6dx, 12dx, and $24 \mathrm{dx}$ ) on either side of the MASW array. After the data was acquired at each site, the waveforms from each

shot record were post-processed using the Geometrics Seisimager/SW software package to generate individual dispersion images and associated curves. Out of the 162 dispersion images that were generated (i.e., 27 per site and 3 at each source offset within each site), $99(61 \%)$ of the images showed improved low frequency response, supporting the idea that $\mathrm{AL} / \mathrm{EPDM}$ and/or PE plates can substitute the traditional use of $\mathrm{Al}$ as the base plate when sampling of deeper strata is desirable. $18(11 \%)$ of the results on the other hand showed that $\mathrm{Al}$ sampled deeper strata compared to the proposed alternative plates. 45 (28\%) of the images did not demonstrate any changes in observable low frequency response, meaning that the three plates all sample the same depth of strata. Various causes such as the quality of the hammer strike and the shock absorbing qualities of PE and 
EPDM are believed to explain the $39 \%$ of images that do not demonstrate improvements in low frequency response. This phenomenon should be studied further. Also, the different base plate materials subtly affected the presence of higher mode Rayleigh wave energy and the high frequency response in the dispersion images. These issues were only qualitatively assessed in this study and they warrant additional research. Based on the results of this research, a UHMW PE plate is adequate and useful in extending the potential depth of soil strata that can be sampled in a given MASW survey. Due to the constraints of wear and tear on the material as well as the fact that thinner PE plates tend to bounce upon being struck with a hammer, the surface area must be sufficiently large [at least $30.48 \mathrm{~cm}$ (12 in) x $30.48 \mathrm{~cm}$ (12 in)] and the plate must be sufficiently thick (at least $1.5 \mathrm{in}$ ) to avoid performance issues. Even though the preliminary studies highlighted in this thesis did not reveal any effects of plate thickness on the dispersion images, this project did not examine plates with large thicknesses [e.g., above $3.8 \mathrm{~cm}$ (1.5 in)]. Therefore, the observations from this study are limited to cases where the base plates are less than $3.8 \mathrm{~cm}(1.5 \mathrm{in})$ in thickness. It is vital that the long term effects of base plate thickness be explored prior to selecting an optimum PE base plate for MASW surveys.

\subsection{Future Work}

Based on the results of this study, the AL/EPDM and the PE plates have strong potential to be used as alternative for the Al plate, particularly in situations where data from deeper strata is required for MASW testing. However, the inconsistencies in the analyzed data call for investigations into the causes of such variations. Also, the quality of dispersion images at some of the sites was highly variable. In such situations, picking the dispersion curve was difficult. This section presents some ideas to address these issues and improve 
the applicability of the conclusions from this study.

Some of the previously mentioned inconsistencies in this study can be addressed in future studies by performing additional 1D surveys adjacent to the original line. It is recommended that two or more surveys be performed on adjacent lines at each site. This would allow for redundancy in the data and the ability to compare results within the same site. Trends can then be observed to see if they are consistent across each of the 1D surveys performed at the same location within a site.

Another potential consideration for future studies is to carefully select an appropriate impact source. In this study, it was observed that the quality of the images increased with larger hammer sizes. It would be useful for future studies to consider the use of heavier hammer sizes or even accelerated weight drop (AWD) sources. This would likely help improve the quality of the dispersion images and decrease the difficulty in selecting an appropriate dispersion curve. Fewer issues with dispersion curve selection could allow the patterns in base plate performance to be more readily identified.

Also, future studies on the effects of the base plates should consider stiffness and damping properties of the base plate as parameters of interest, rather than focus on such broad categories of materials (i.e., plastics such as PE or rubbers such as EPDM). This will allow for several other materials that have desired stiffness properties to be considered. Some of the materials may have similar or better elastic properties than $\mathrm{PE} / \mathrm{EPDM}$ and may also be more resilient. It is therefore necessary that this criterion be utilized in the selection of base plates for future analysis. 
Finally, geophones with lower cut-off frequency should be considered for future studies, particularly if larger hammer sources will be considered. The cutoff frequency of the geophones used in this study $(4.5 \mathrm{~Hz})$ implies a reduction in the confidence for results that approach the $5 \mathrm{~Hz}-7 \mathrm{~Hz}$ range in frequency. Though the instances were limited where such lower frequencies were observed (e.g., $20 \mathrm{lb}$ hammer at closer offsets), future studies with larger sources would have to consider the limitations imposed by geophone cut-off frequency. The simplest (though most costly) way to do so would be to use geophones with lower cut-off frequencies.

Given the site-specific nature of the observations from this study, it is important that additional work continue to establish a thorough database of results. A wide range of site conditions should be considered in the development of this database, including stiffer strata with bedrock located closer to the surface. The long term goal should be to allow greater confidence in understanding the overall effects of base plate on MASW performance. 


\section{REFERENCES}

Bensen, G.D., Ritzwoller, M.H., Barmin, M.P., Levshin A.L., Lin, F., Moschetti, M.P., Shapiro, N.M., and Yang, Y., 2007, Processing seismic ambient noise data to obtain reliable broad-band surface wave dispersion measurements: Geophys. J. Int., Vol. 169, No. 3, pp. 1239-1260.

Bignardi, S., Fedele, F., Yezzi, A., Rix, G., and Santarato, G., 2012, Geometric Seismic-Wave Inversion by the Boundary Element Method: Bulletin of the Seismological Society of America, Vol. 102, No. 2., pp. 802-811.

Bodet, L., Abraham, O., and Clorennec, D., 2009, Near-offset effects on Rayleigh wave dispersion measurements: physical modeling: Journal of Applied Geophysics, Vol. 68, No. 1, pp. 95-103.

Carnevale, M., and Park, C.B., 2010, Wave Energy Sources for MASW: Proceedings of Symposium on the Application of Geophysics to Engineering and Environmental Problems, Keystone, CO.

Collins, M.E., Cum, M., and Hanninen, P., 1994, Using ground-penetrating radar to investigate a subsurface karst landscape in north-central Florida: Geoderma, Vol. 61, No. $1-2$, pp. $1-15$.

Gabriels, P., Snider, R., and Nolet, G., 1987, In situ measurements of shear-wave velocity in sediments with higher-mode Rayleigh waves: Geophys. Prospecting, Vol. 35, pp. 187-196. 
Ha, I. S., Kim, N.R.,; Lim, and Jeong, Y., 2013, Estimation of Shear Wave Velocity of Earth Dam Materials using Artificial Blasting Test: Journal of the Korean Society of Civil Engineers, Vol. 33, No. 2, pp 619-629.

Jeong, J.H., and Kim, J.H., 2012, Comparison of Signal Powers Generated with Different Shapes of Hammer Plates: Journal of Korean Earth Science Society, Vol. 33, No. 5, pp 395-400.

Kayal, J.R., 2000, Seismic Waves and Earthquake Location: Geological Survey of India, pp. 234 to 253 .

Keiswetter, D. A., and Steeples, D. W., 1995, A Field investigation of Source Parameters for Sledgehammer: Geophysics, Vol. 60, No. 4, pp. 1051-1057.

Kim, J.H., and Lee, Y.,H., 2011, Comparison of signal powers generated with metal hammer plate and plastic hammer plate: Geophysics and Geophysical Exploration, Vol. 14, No. 4, p. 282-288. (In Korean)

Kumar, J., and Hazra, S., 2014, SASW testing of asphaltic pavement by dropping steel balls: International Journal of Geotechnical Engineering, Vol. 8, No. 1, pp. 34- 45.

Kumar, J., and Rakaraddi, P.G., 2013, Effect of Source Energy for SASW Testing on Geological Sites: Geotechnical Geological Engineering, Vol. 31, No. 1, pp. 47- 66.

Li, J., and Rosenblad, B., 2011, Experimental study of near-field effects in multichannel array-based surface wave velocity measurements: Near Surface Geophysics, Vol. 9, No. 4, pp. 357-366. 
McMechan, G., and Yedlin, M.J., 1981, Analysis of dispersive waves by wave field transformation: Geophysics, Vol. 46, No. 6, pp. 869-874.

Mereu, R.F., Uffen, R.J., and Beck, A.E., 1963, The Use of a Coupler in the Conversion of Impact Energy into Seismic Energy: Geophysics, Vol. 28, No. 4, pp. 531-546.

Miller, R.D., Pullan, S.E., Waldner, J.S., and Haeni, F.P., 1986, Field comparison of shallow seismic sources: Geophysics, Vol. 51, No. 11, pp. 2067-2092.

Miller, R.D., Pullan, S.E., Steeples, D.W., and Hunter, J.A., 1992, Field comparison of shallow seismic sources near Chino, California: Geophysics, Vol. 57, No. 5, pp. 693-702.

Miller, R.D., Pullan, S.E., Steeples, D.W., and Hunter, J.A., 1994, Field comparison of shallow seismic sources near Houston, Texas: Geophysics, Vol. 59, No. 11, pp. 1713-1728.

Miller, R.D., Xia, J., Park, C.B., and Ivanov, J., 1999, Using MASW to map bedrock in Olathe, Kansas, SEG Annual Meeting Expanded Abstracts, pp. 433-436.

•Dal Moro, G., Pipan, M., Forte, E., Finetti, I., 2003, Determination of Rayleigh wave dispersion curves for near surface applications in unconsolidated sediments, SEG Annual Meeting Expanded Abstracts, pp. 1247-1250.

Nolan, J.J., Miller, R., Ivanov, I., and Peterie, S., 2013 Near-surface salt dissolution void identification using passive MASW: SEG Annual Meeting Expanded Abstracts, pp. 2212-2217. 
Obando, E.A., Park, C.B., Ryden, N., and Ulriksen, P., 2009, Roadside MASW Surveys Using a Portable Road Bump, A Case Study in Managua, Nicaragua: Proceedings of Symposium on the Application of Geophysics to Engineering and Environmental Problems 2009, pp. 626-635.

Okada, H., 2003, The microtremor survey method; Geophysical monograph series, No. 12, Society of Exploration Geophysicists (SEG), Tulsa, OK.

Park, C.B., and Carnevale, M., 2009, 3D MASW survey: Proceedings of Symposium on the Application of Geophysics to Engineering and Environmental Problems 2009, Fort Worth, TX.

Park, C.B., and Miller R.D., 2004, MASW to map shear-wave velocity of soil: Kansas Geological Survey Open-File Report 2004-30, Lawrence, Kansas.

Park, C.B., Miller, R.D., and Miura H., 2002, Optimum Field Parameters of an MASW Survey, Kansas Geological Survey, Lawrence, Kansas.

Park, C.B., Miller, R.D., and Xia, J., 2000, Multichannel analysis of surface waves dispersion: Geophysics, Vol 66, pp 869-874.

Park, C.B., Miller, R.D., and Xia, J., 1999, Multichannel analysis of surface waves: Geophysics, Vol. 64, No. 3, pp. 800-808.

Park, C.B., Miller, R.D., and Xia, J., 1998, Imaging dispersion curves of surface waves on multi-channel record: SEG Annual Meeting Expanded Abstracts, pp. 1377-1380. 
Park, C.B., Miller, R.D., Xia, J., and Ivanov, J., 2007, Multichannel analysis of surface waves (MASW) - active and passive methods: The Leading Edge, Vol. 26, No. 1, pp. 60-64.

Pulan, S.E., and MacAulay, H.A., 1987, An in-hole shotgun source for engineering seismic surveys: Geophysics, Vol. 52, No. 7, pp. 985-996.

Rix, G., and Stokoe, K.H., II (1989), Stiffness Profiling of Pavement Subgrades:

Transportation Research Record No. 1235, pp. 1-9.

Sopher, D., Juhlin, C., Huang, F., Ivandic, M., and Lueth, S., 2014, Quantitative assessment of seismic source performance: Feasibility of small and affordable seismic sources for long term monitoring at the Ketzin CO2 storage site, Germany: Journal of Applied Geophysics, Vol. 107, pp. 171-186.

Stephenson, W. J., Louie, J. N., Pullammanappallil, S., Williams R. A., and Odum, J. K., 2005, Blind Shear-Wave Velocity Comparison of ReMi and MASW Results with Boreholes to $200 \mathrm{~m}$ in Santa Clara Valley: Implications for Earthquake Ground-Motion Assessment: Bulletin of the Seismological Society of America, Vol. 95, No. 6, pp. 2506-2516.

Wood, C., and Cox, B., 2012, A Comparison of MASW Dispersion Uncertainty and Bias for Impact and Harmonic Sources: Proceedings of GeoCongress, pp. 2756-2765.

Xia, J., Miller, R.D., and Park, C.B., 1999, Estimation of near-surface shear-wave velocity by inversion of Rayleigh waves: Geophysics, Vol. 64, No. 3, pp. 691-700. 
Xia, J., R. D. Miller, C. B. Park, and G. Tian, 2002, Determining Q of near-surface materials from Rayleigh waves: Journal of Applied Geophysics, Vol. 51, No. 2-4, pp. 121-129.

Yilmaz, O., and Kacaoglu, A., 2011, Effect of Lateral Heterogeinity in the Soil Column on Shear-Wave Velocity Estimation by Rayleigh-Wave Inversion: Proceedings of Turkey Earthquake Engineering and Seismology Conference, Metu, Ankara.

Yoon, S. and Rix, G.J., 2009, Near-field effects on array-based surface wave methods with active sources: J. Geotech. Geoenviron. Eng., Vol. 135, No. 3, pp. 399-406.

Yordkayhun, S., and Jumras, N. S., 2012, A university-developed seismic source for shallow seismic surveys: Journal of Applied Geophysics, Vol. 82, pp. 110-118. 


\section{APPENDIX A-1: \\ DISPERSION IMAGES FROM DENDY RECREATIONAL CENTER (DRC)}




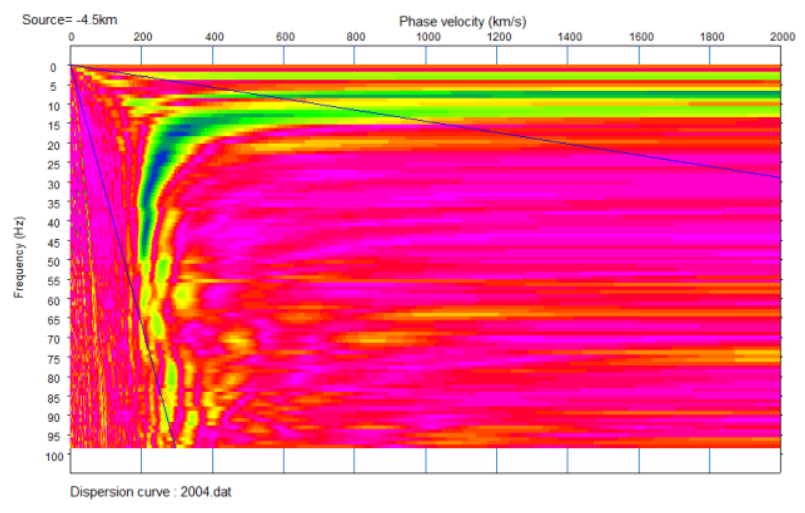

(a)

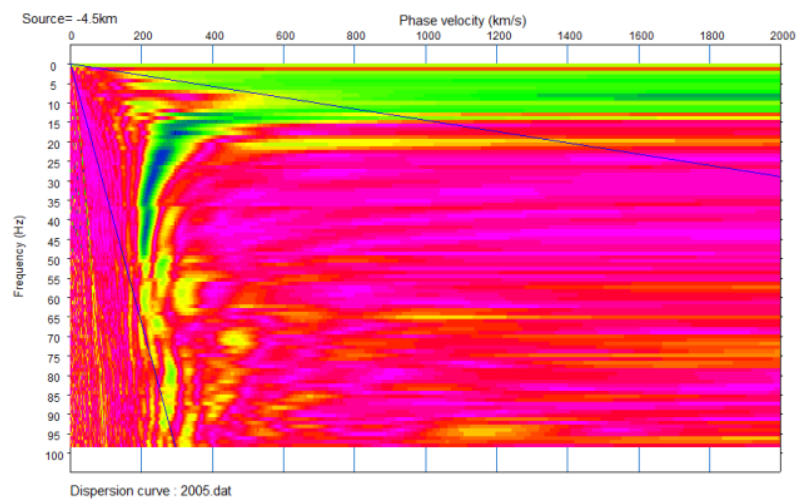

(b)

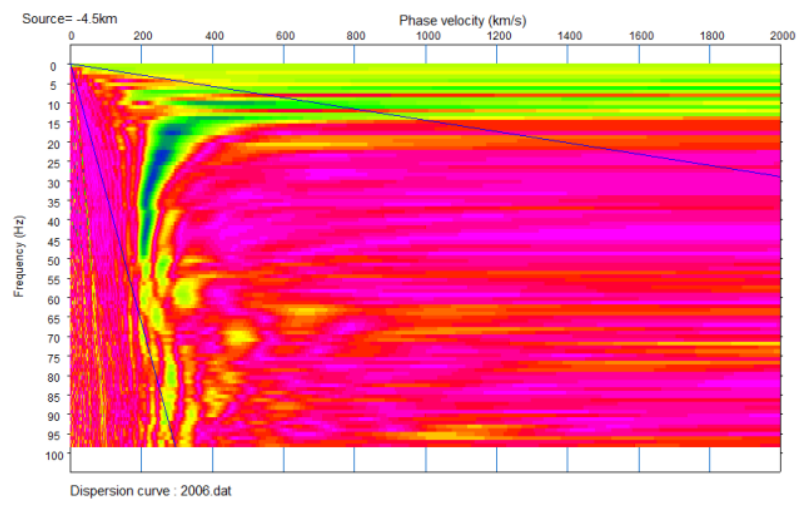

(c)

Fig. A-1: Dispersion images for the DRC site generated using a 20 lb sledgehammer located at $-30 d x$ from the closest geophone: (a) Aluminum base plate; (b) Aluminum over EPDM rubber base plate; and (c) Ultra-high-molecular-weight polyethylene base plate 


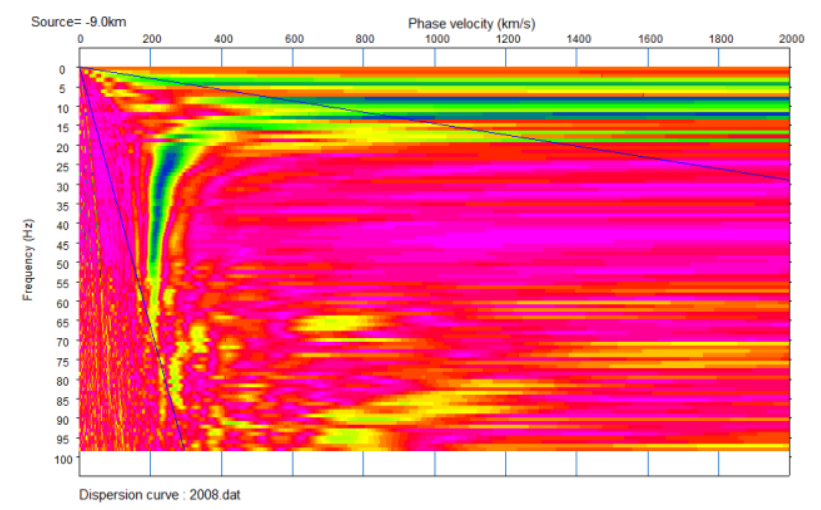

(a)

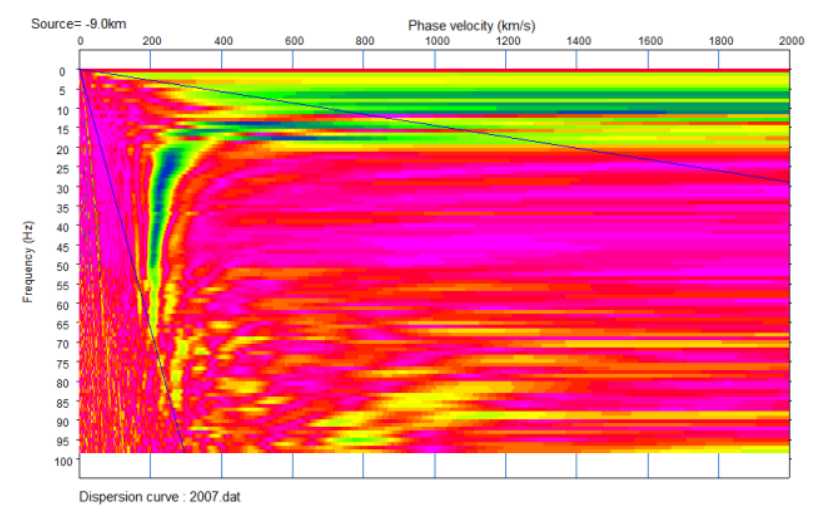

(b)

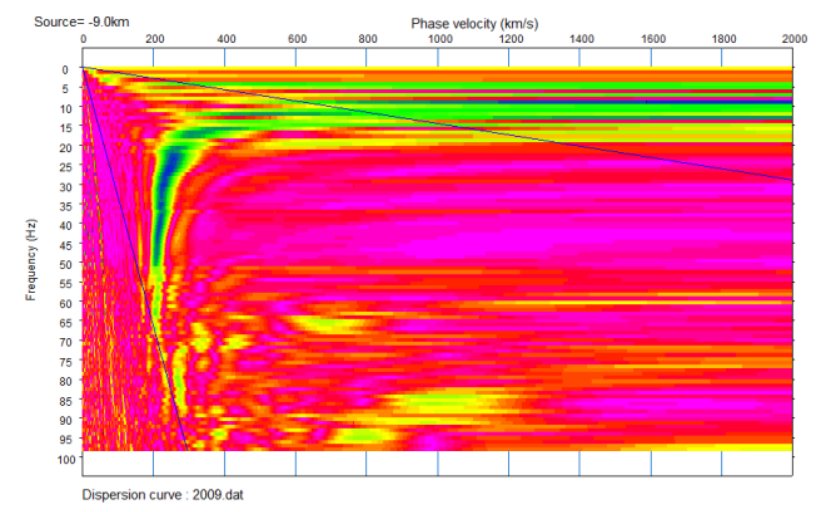

(c)

Fig. A-2: Dispersion images for the DRC site generated using a $20 \mathrm{lb}$ sledgehammer located at -6dx from the closest geophone: (a) Aluminum base plate; (b) Aluminum over EPDM rubber base plate; and (c) Ultra-high-molecular-weight polyethylene base plate 


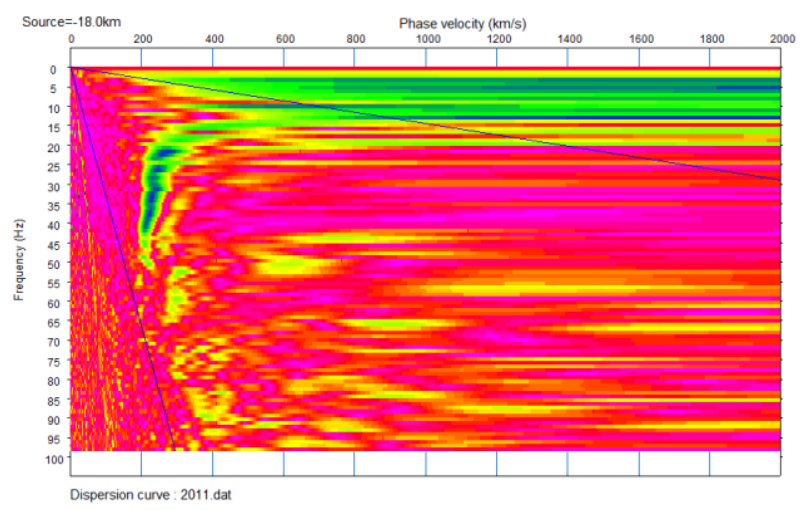

(a)

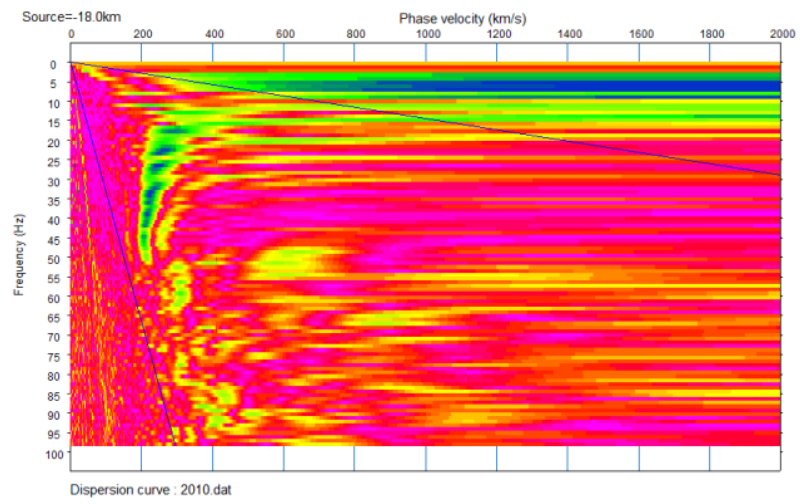

(b)

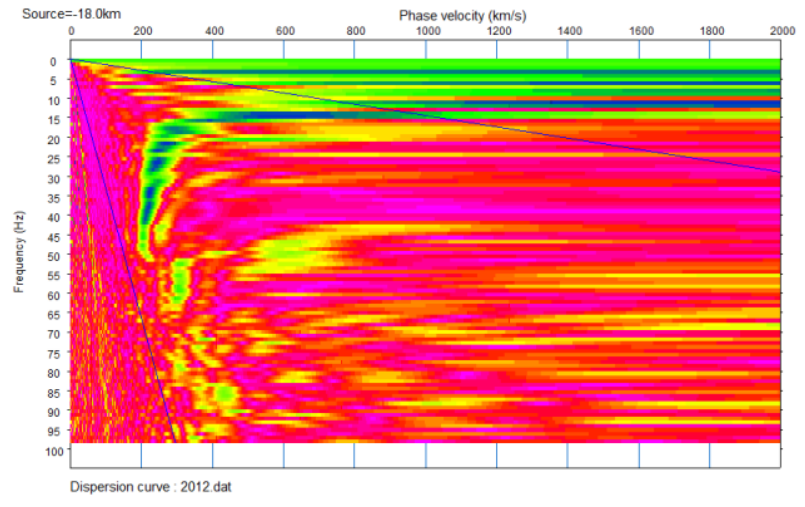

(c)

Fig. A-3: Dispersion images for the DRC site generated using a 20 lb sledgehammer located at -12dx from the closest geophone: (a) Aluminum base plate; (b) Aluminum over EPDM rubber base plate; and (c) Ultra-high-molecular-weight polyethylene base plate 


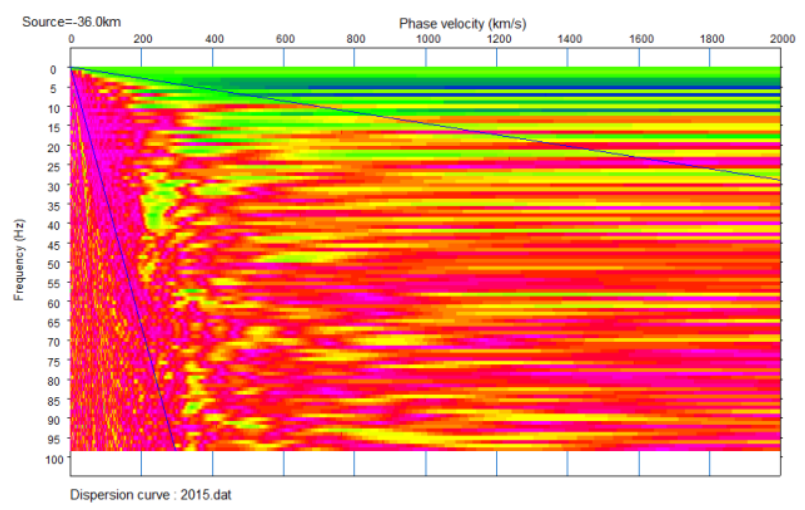

(a)

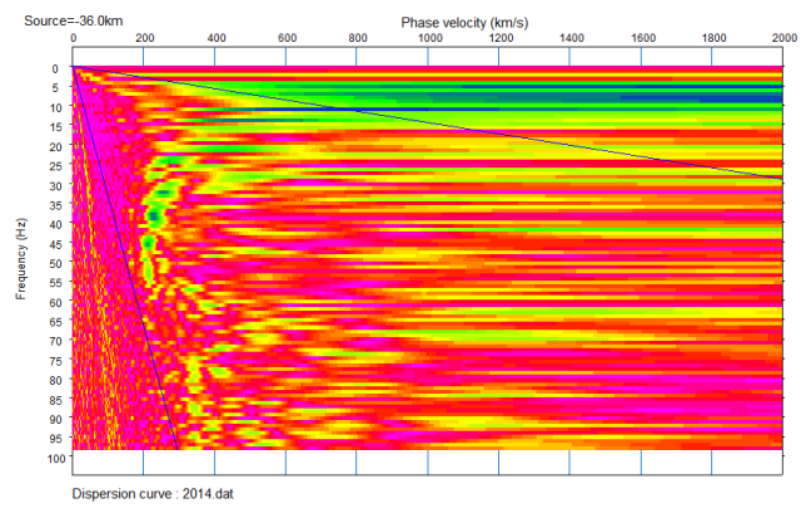

(b)

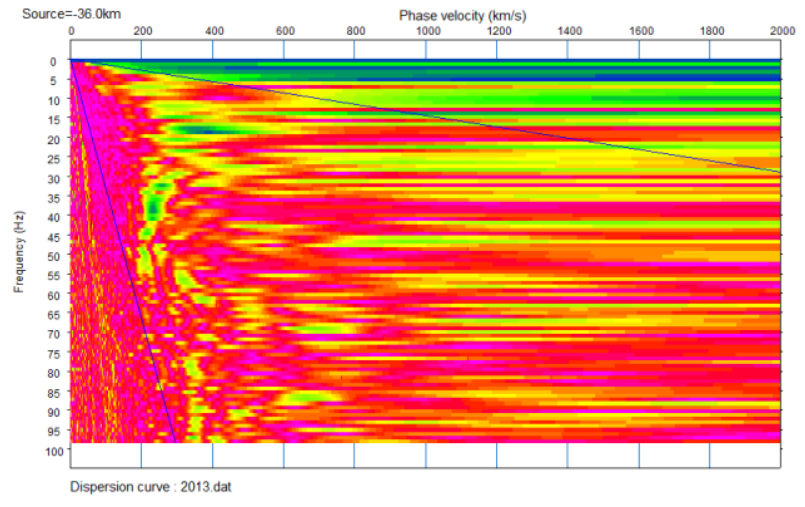

(c)

Fig. A-4: Dispersion images for the DRC site generated using a $20 \mathrm{lb}$ sledgehammer located at -24dx from the closest geophone: (a) Aluminum base plate; (b) Aluminum over EPDM rubber base plate; and (c) Ultra-high-molecular-weight polyethylene base plate 


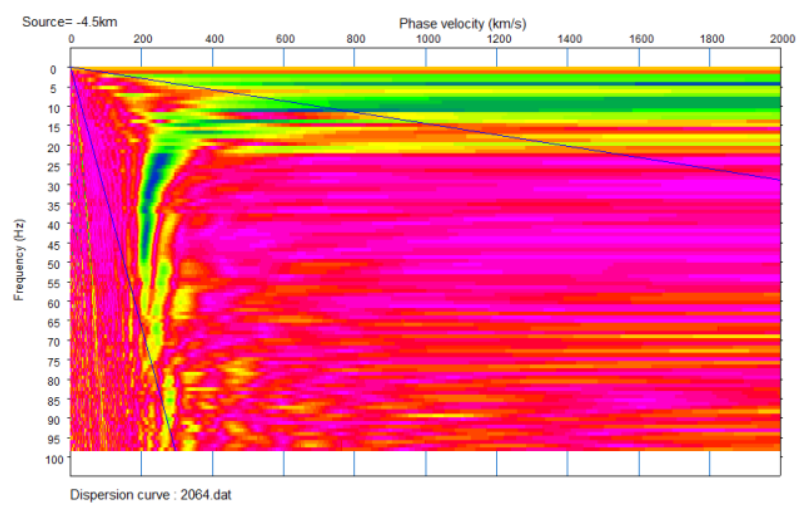

(a)

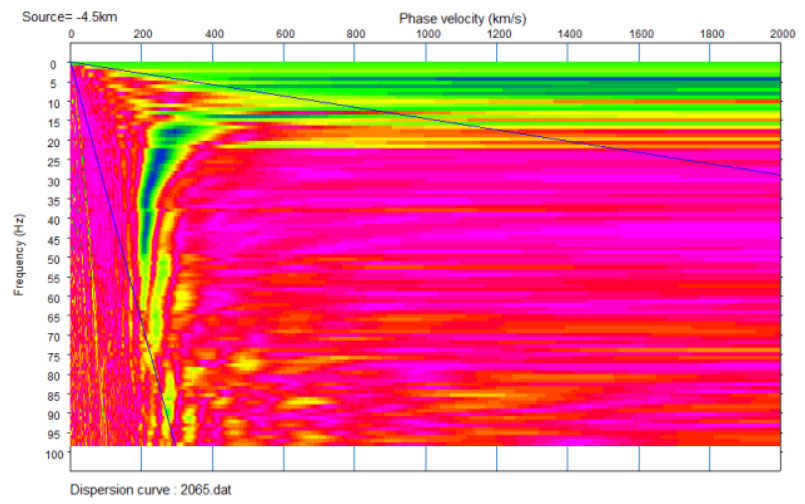

(b)

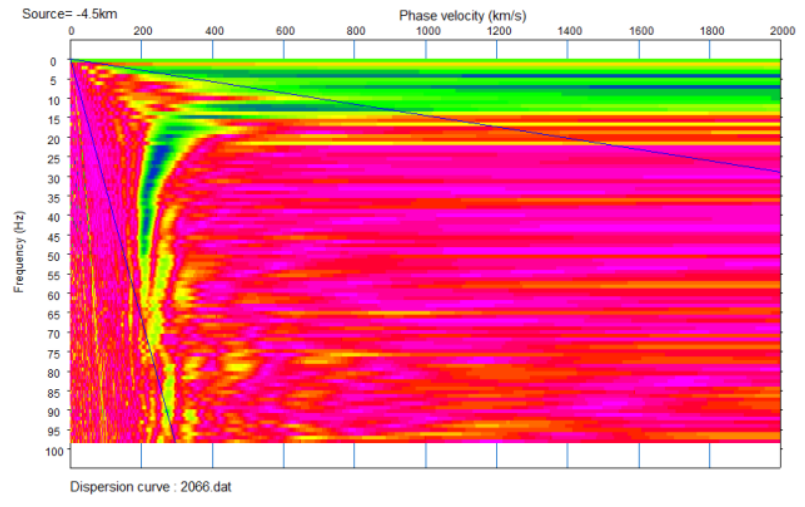

(c)

Fig. A-5: Dispersion images for the DRC site generated using a $4 \mathrm{lb}$ sledgehammer located at -3dx from the closest geophone: (a) Aluminum base plate; (b) Aluminum over EPDM rubber base plate; and (c) Ultra-high-molecular-weight polyethylene base plate 


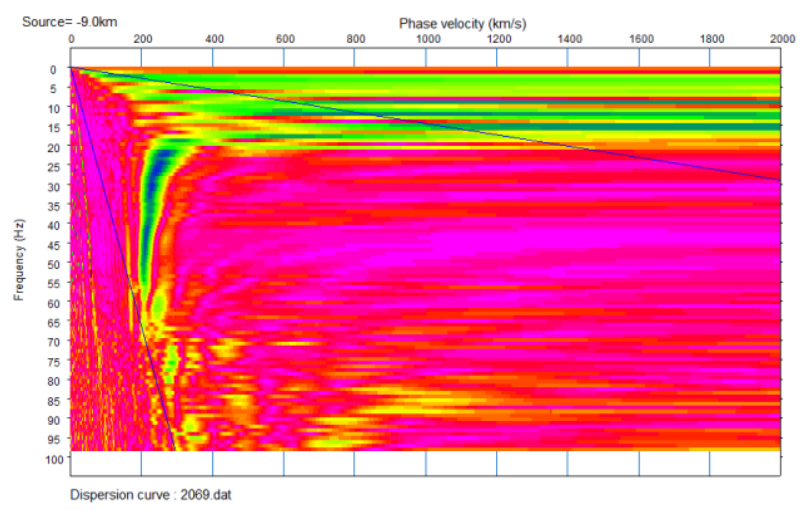

(a)

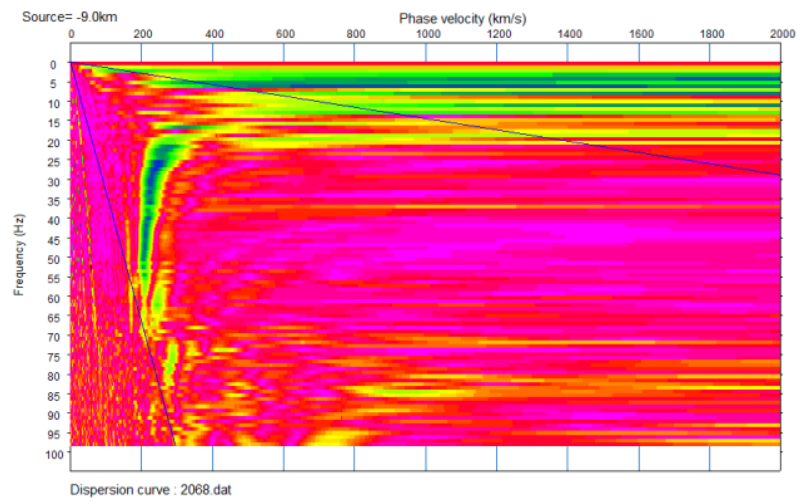

(b)

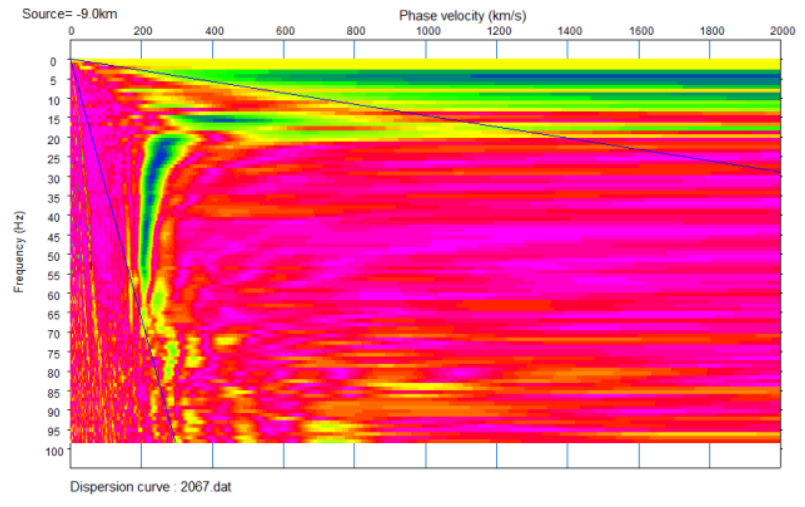

(c)

Fig. A-6: Dispersion images for the DRC site generated using a $4 \mathrm{lb}$ sledgehammer located at -6dx from the closest geophone: (a) Aluminum base plate; (b) Aluminum over EPDM rubber base plate; and (c) Ultra-high-molecular-weight polyethylene base plate 


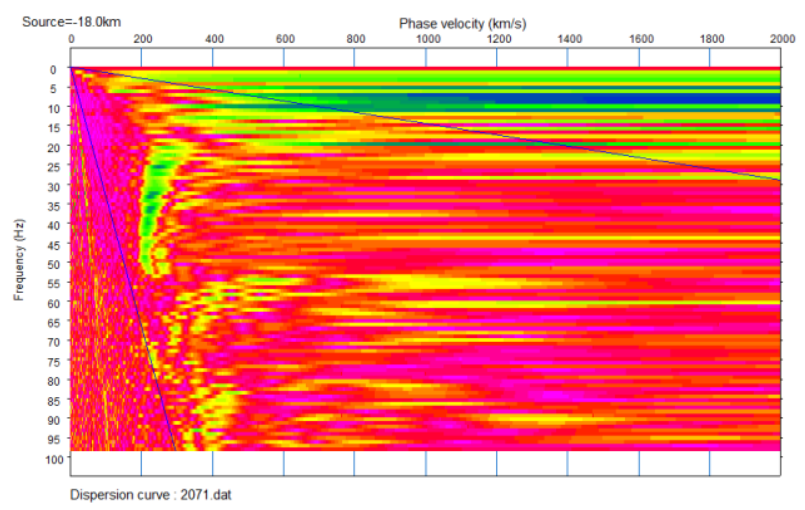

(a)

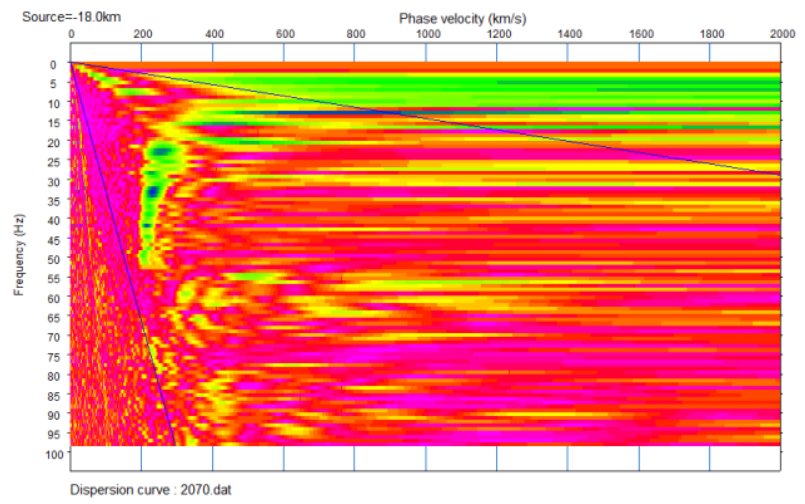

(b)

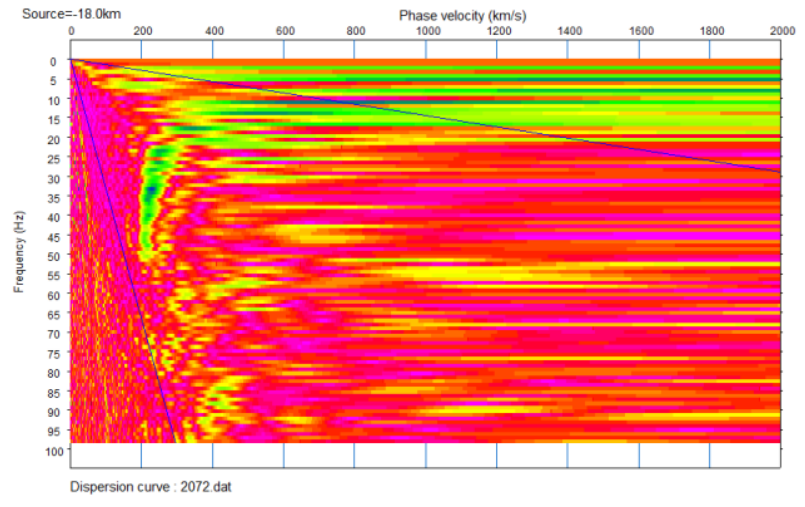

(c)

Fig. A-7: Dispersion images for the DRC site generated using a $4 \mathrm{lb}$ sledgehammer located at $\mathbf{- 1 2 d x}$ from the closest geophone: (a) Aluminum base plate; (b) Aluminum over EPDM rubber base plate; and (c) Ultra-high-molecular-weight polyethylene base plate 


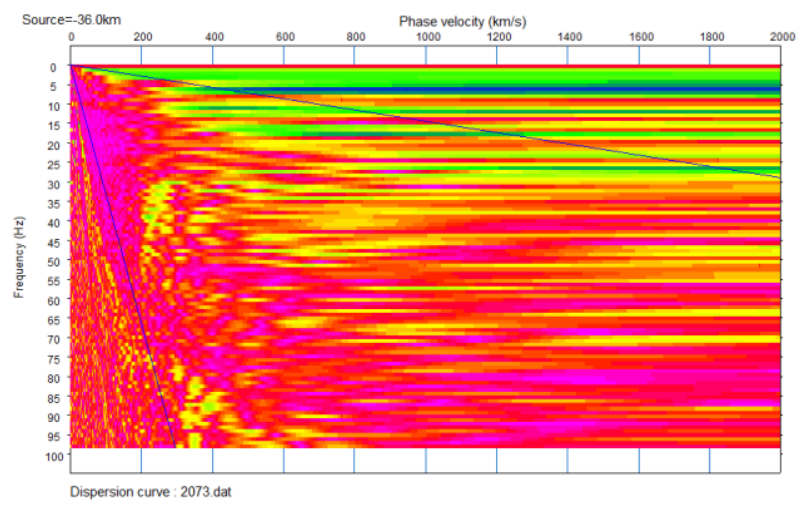

(a)

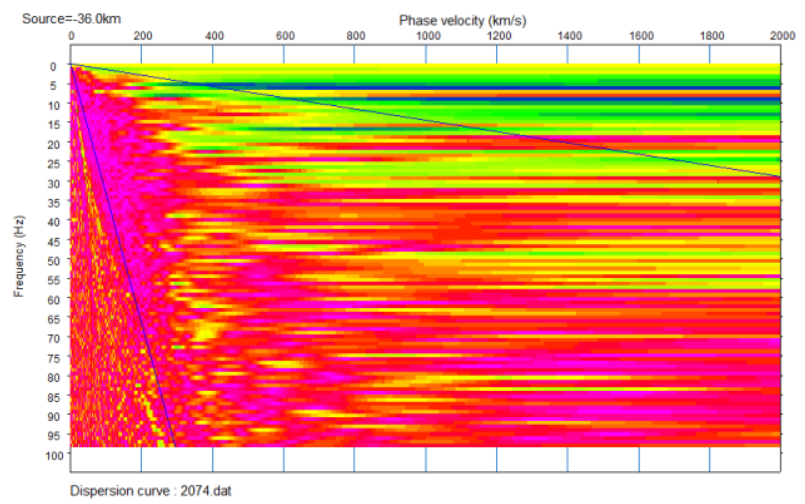

(b)

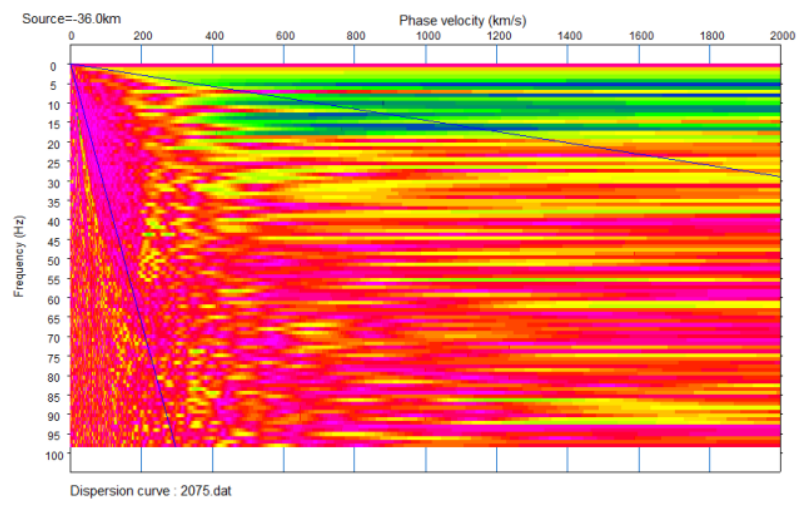

(c)

Fig. A-8: Dispersion images for the DRC site generated using a $4 \mathrm{lb}$ sledgehammer located at -24dx from the closest geophone: (a) Aluminum base plate; (b) Aluminum over EPDM rubber base plate; and (c) Ultra-high-molecular-weight polyethylene base plate 


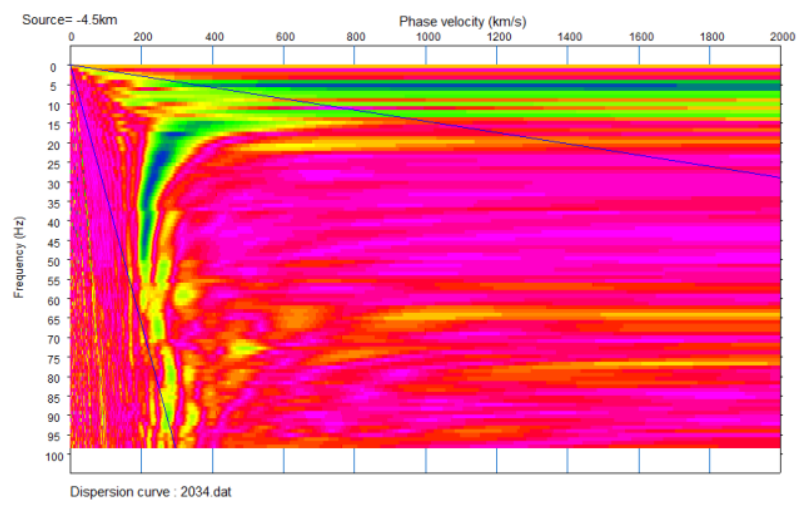

(a)

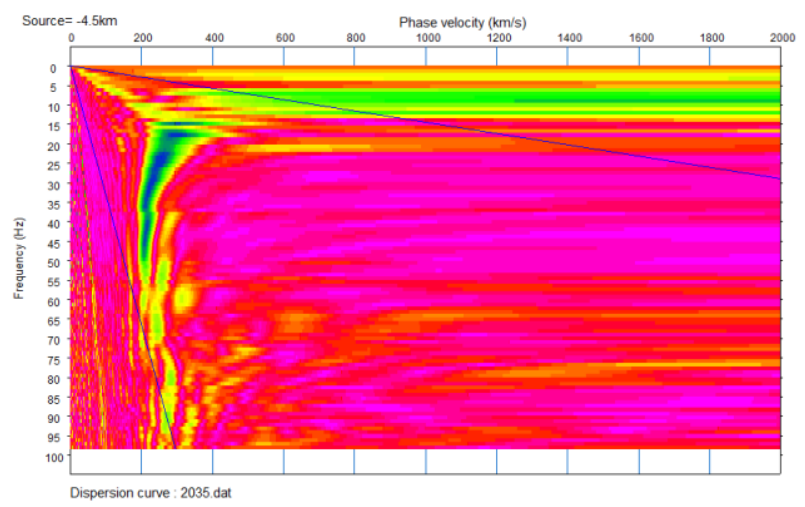

(b)

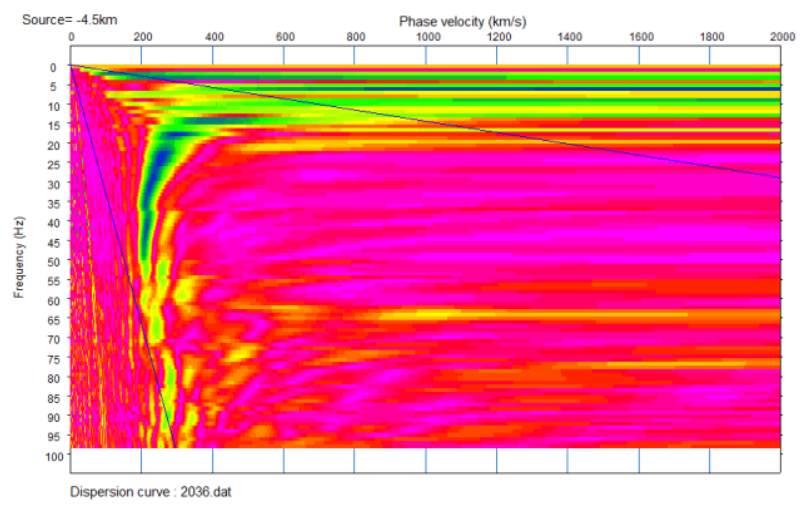

(c)

Fig. A-9: Dispersion images for the DRC site generated using a $8 \mathrm{lb}$ sledgehammer located at $\mathbf{- 3 d x}$ from the closest geophone: (a) Aluminum base plate; (b) Aluminum over EPDM rubber base plate; and (c) Ultra-high-molecular-weight polyethylene base plate 


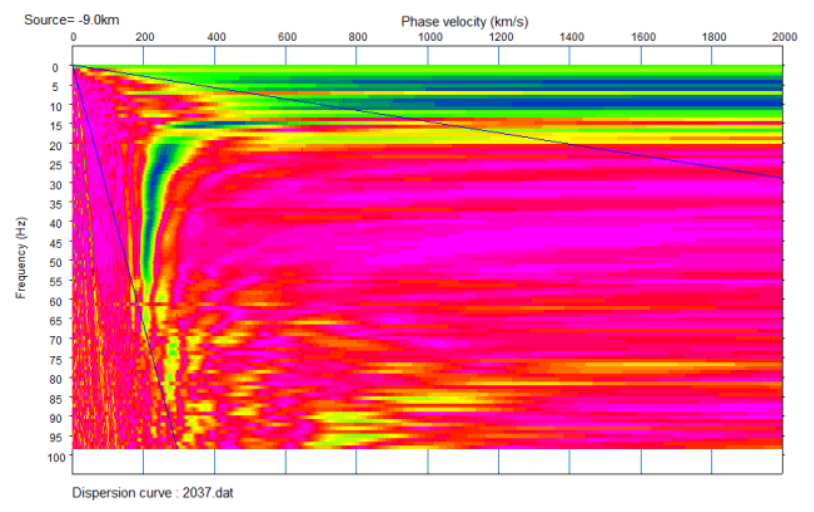

(a)

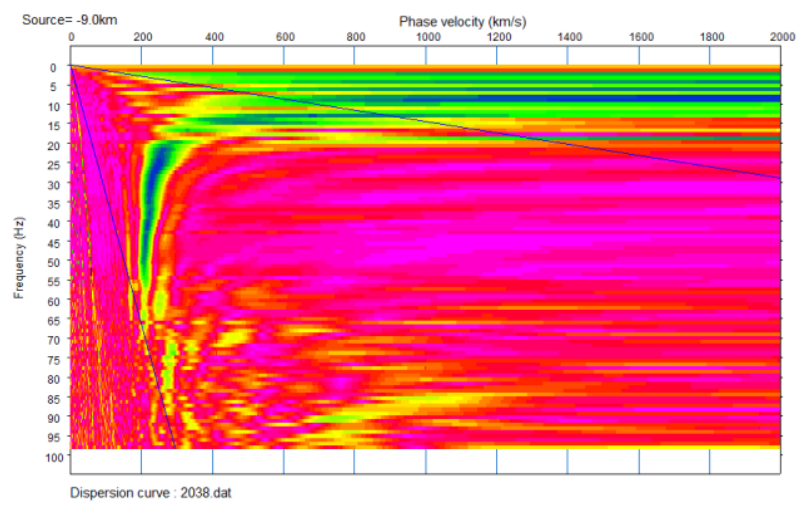

(b)

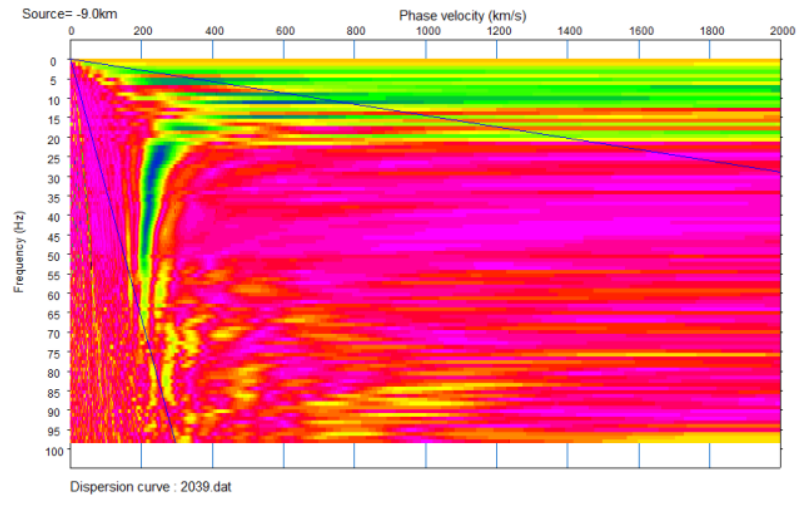

(c)

Fig. A-10: Dispersion images for the DRC site generated using a $8 \mathrm{lb}$ sledgehammer located at -6dx from the closest geophone: (a) Aluminum base plate; (b) Aluminum over EPDM rubber base plate; and (c) Ultra-high-molecular-weight polyethylene base plate 


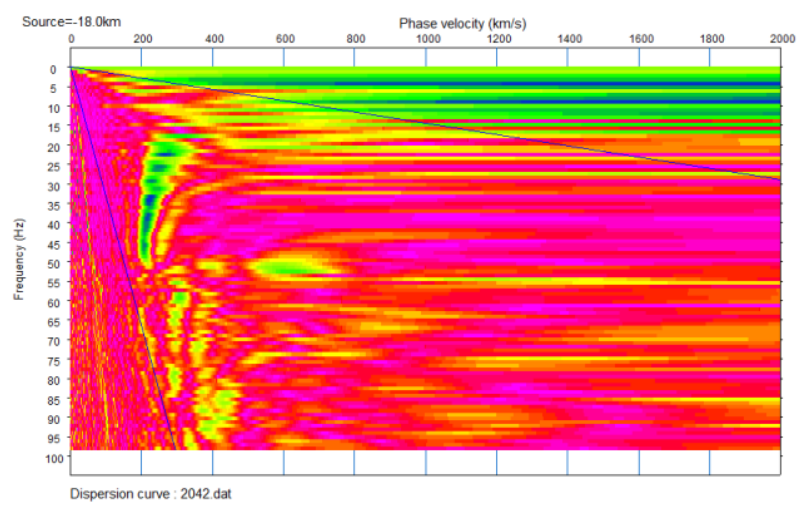

(a)

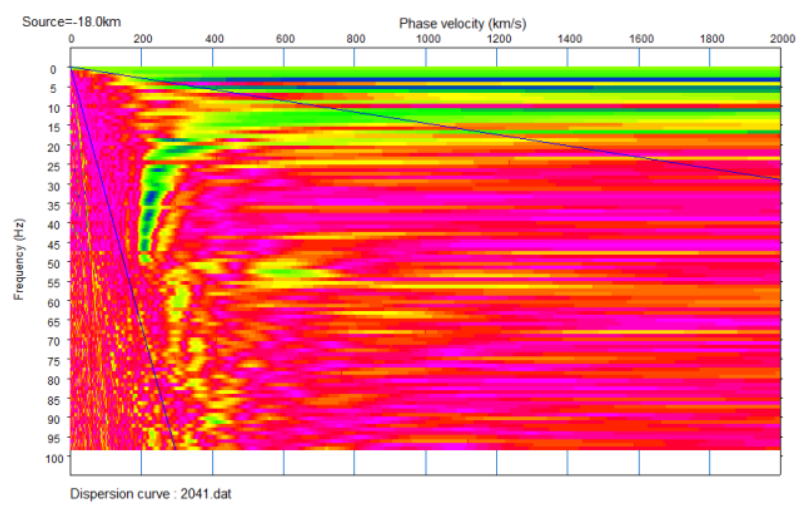

(b)

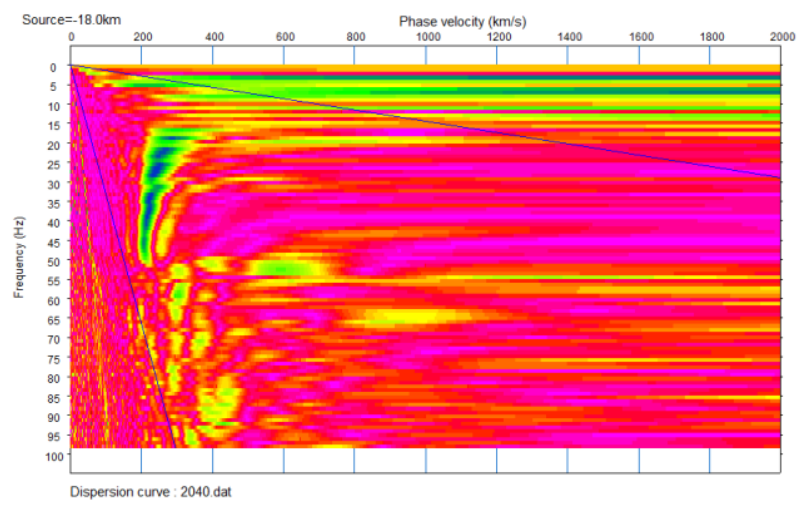

(c)

Fig. A-11: Dispersion images for the DRC site generated using a $8 \mathrm{lb}$ sledgehammer located at $\mathbf{- 1 2 d x}$ from the closest geophone: (a) Aluminum base plate; (b) Aluminum over EPDM rubber base plate; and (c) Ultra-high-molecular-weight polyethylene base plate 


\section{APPENDIX A-2: \\ DISPERSION IMAGES FROM FAIRMOUNT PARK \\ EDGELY FIELD (FEF)}




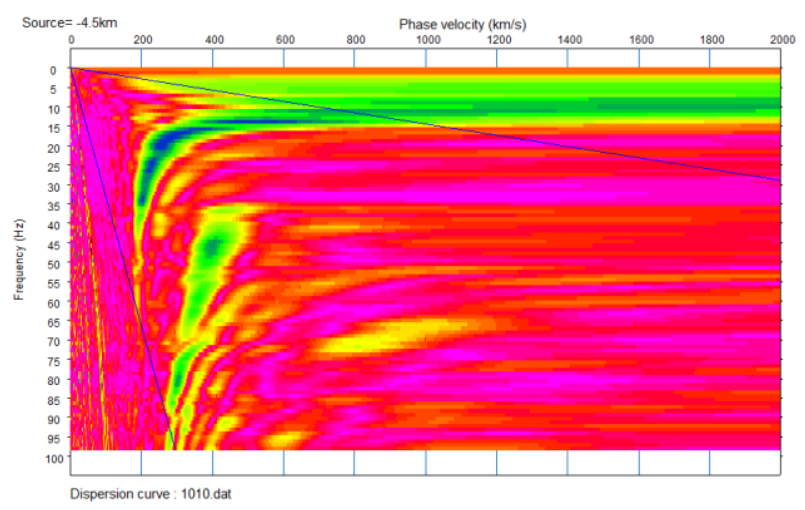

(a)

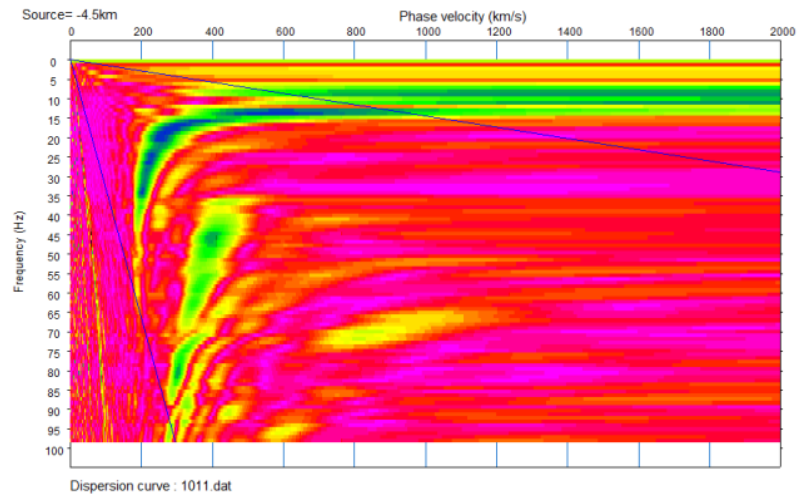

(b)

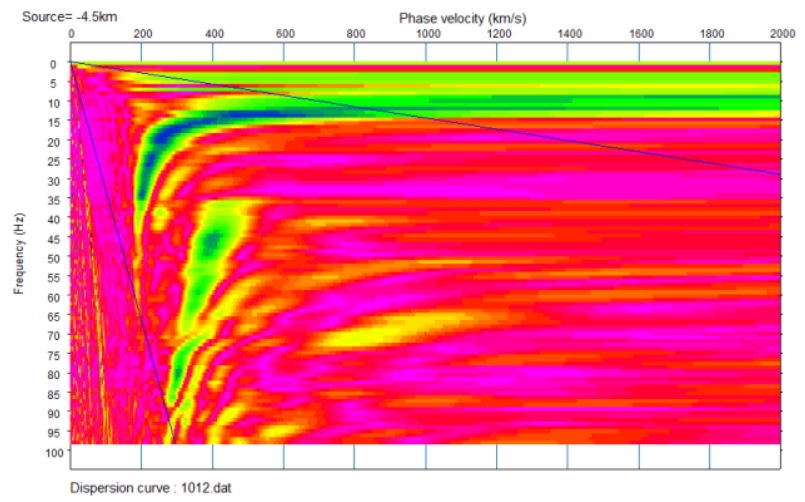

(c)

Fig. A-12: Dispersion images for the FEF site generated using a 20 lb sledgehammer located at -3dx from the closest geophone: (a) Aluminum base plate; (b) Aluminum over EPDM rubber base plate; and (c) Ultra-high-molecular-weight polyethylene base plate. 


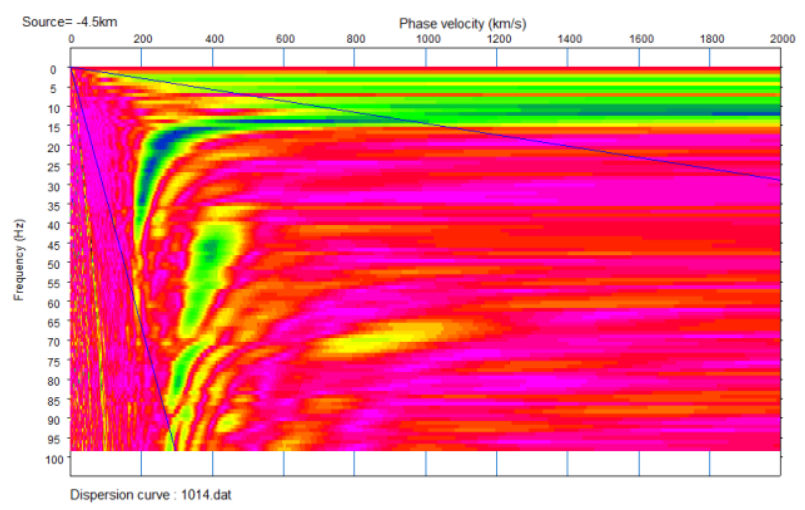

(a)

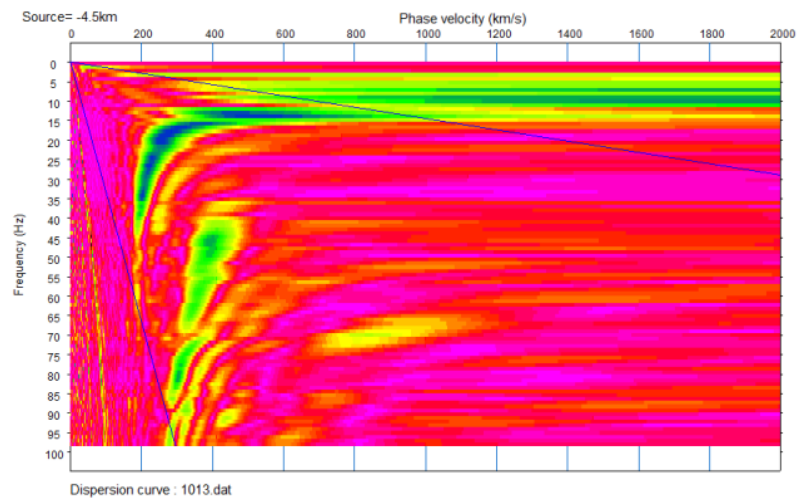

(b)

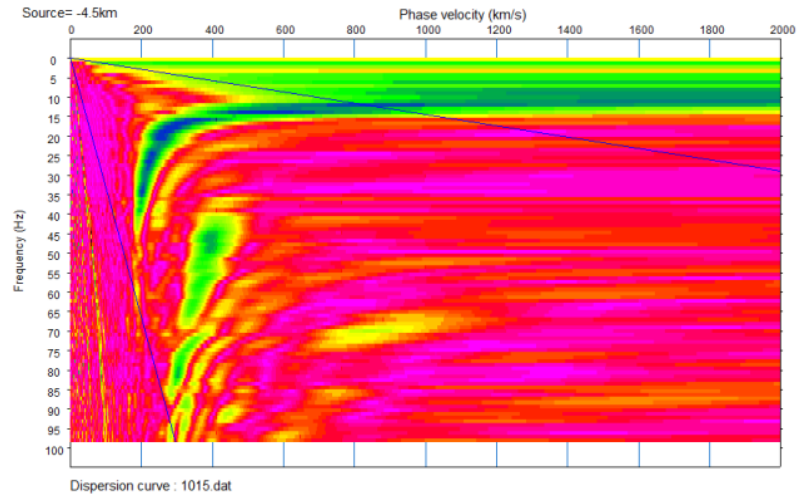

(c)

Fig. A-13: Dispersion images for the FEF site generated using a 8 lb sledgehammer located at -3dx from the closest geophone: (a) Aluminum base plate; (b) Aluminum over EPDM rubber base plate; and (c) Ultra-high-molecular-weight polyethylene base plate. 


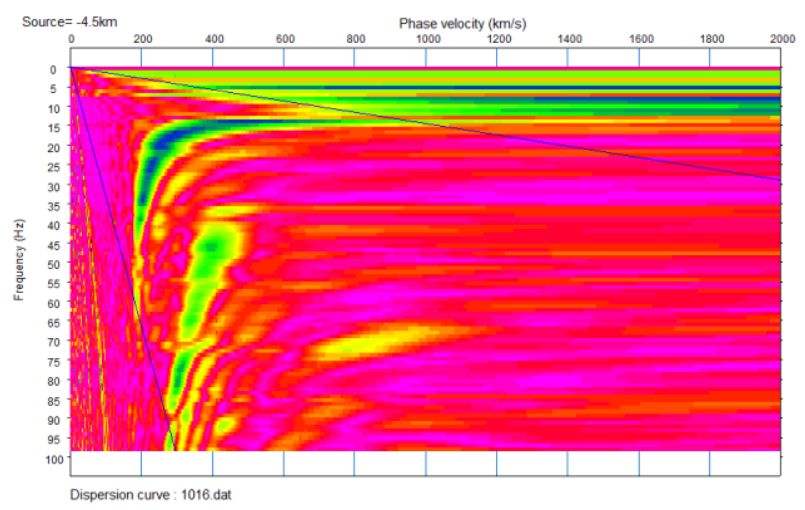

(a)

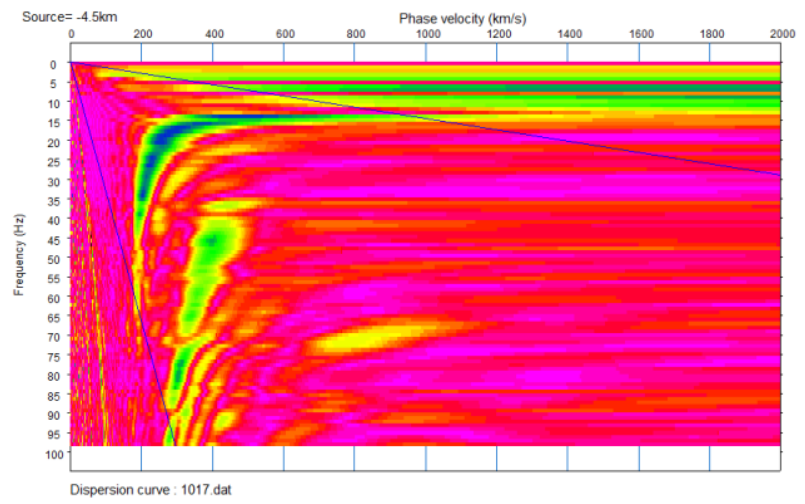

(b)

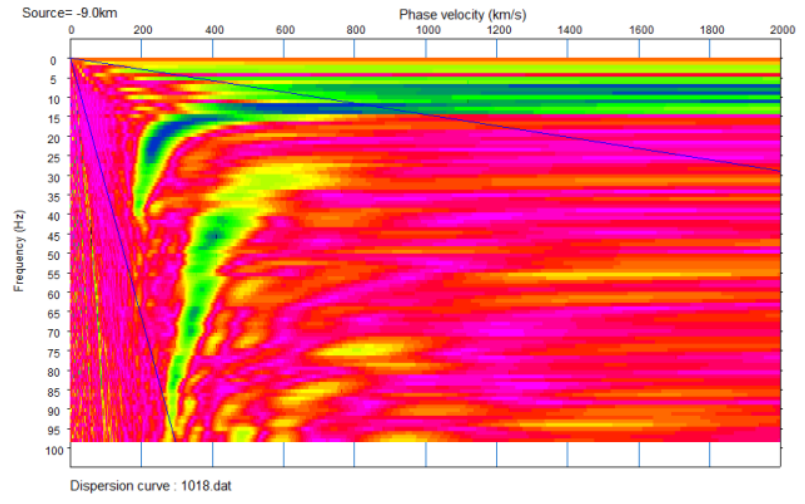

(c)

Fig. A-14: Dispersion images for the FEF site generated using a $4 \mathrm{lb}$ sledgehammer located at $-\mathbf{3 d x}$ from the closest geophone: (a) Aluminum base plate; (b) Aluminum over EPDM rubber base plate; and (c) Ultra-high-molecular-weight polyethylene base plate. 


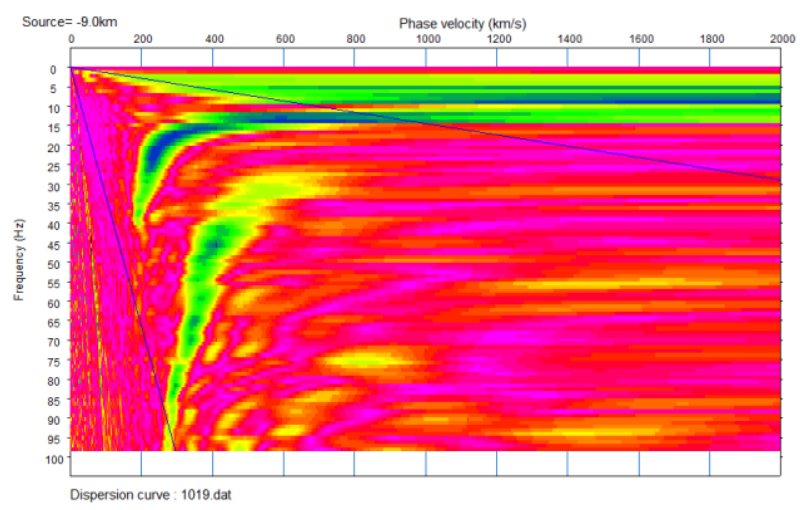

(a)

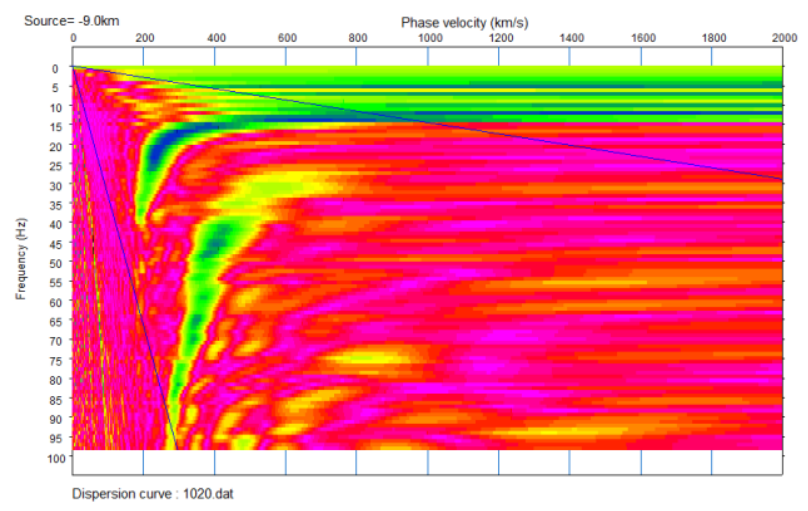

(b)

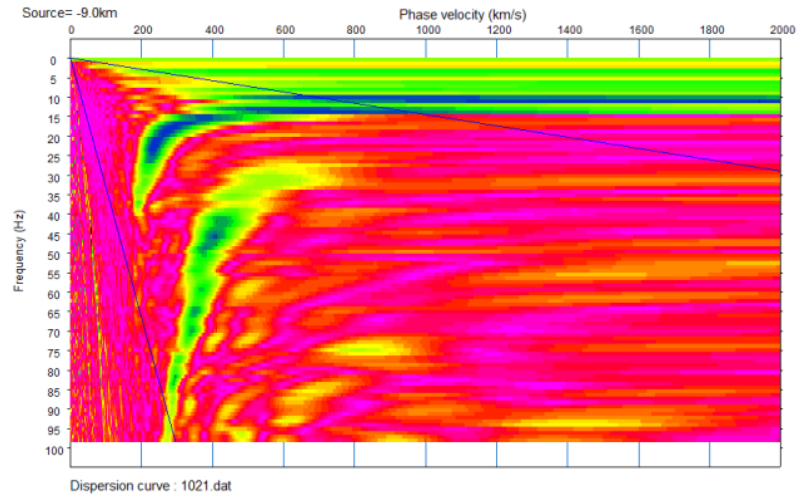

(c)

Fig. A-15: Dispersion images for the FEF site generated using a 20 lb sledgehammer located at -6dx from the closest geophone: (a) Aluminum base plate; (b) Aluminum over EPDM rubber base plate; and (c) Ultra-high-molecular-weight polyethylene base plate. 


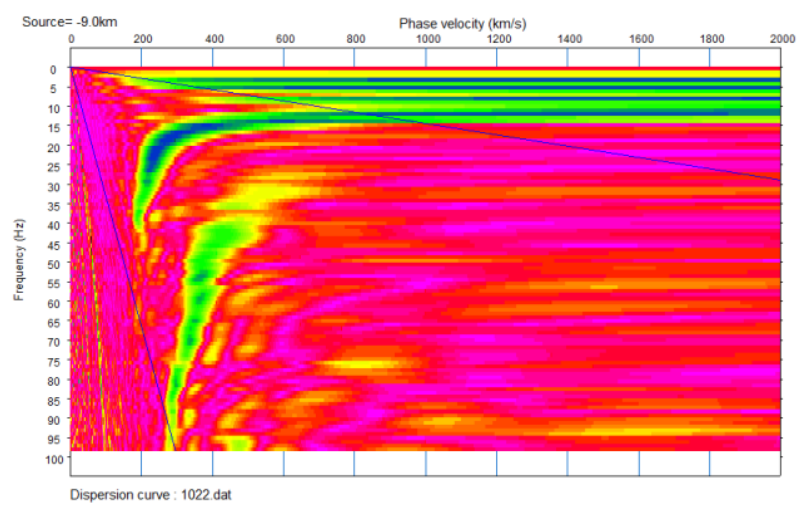

(a)

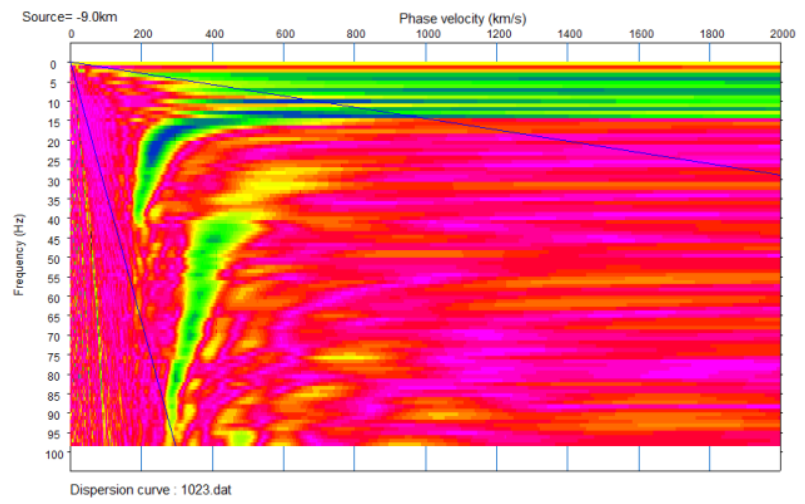

(b)

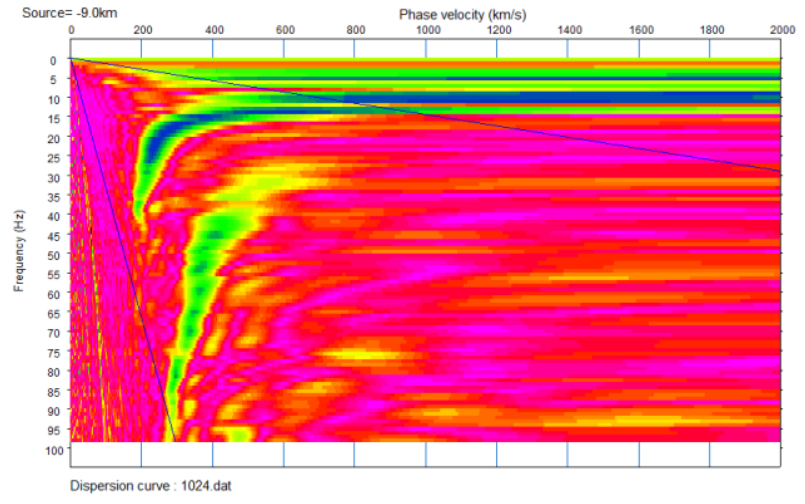

(c)

Fig. A-16: Dispersion images for the FEF site generated using a 8 lb sledgehammer located at -6dx from the closest geophone: (a) Aluminum base plate; (b) Aluminum over EPDM rubber base plate; and (c) Ultra-high-molecular-weight polyethylene base plate. 


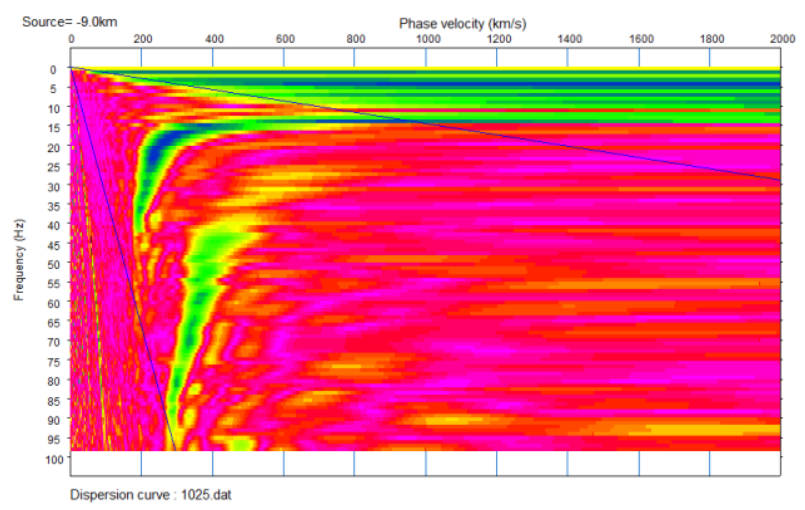

(a)

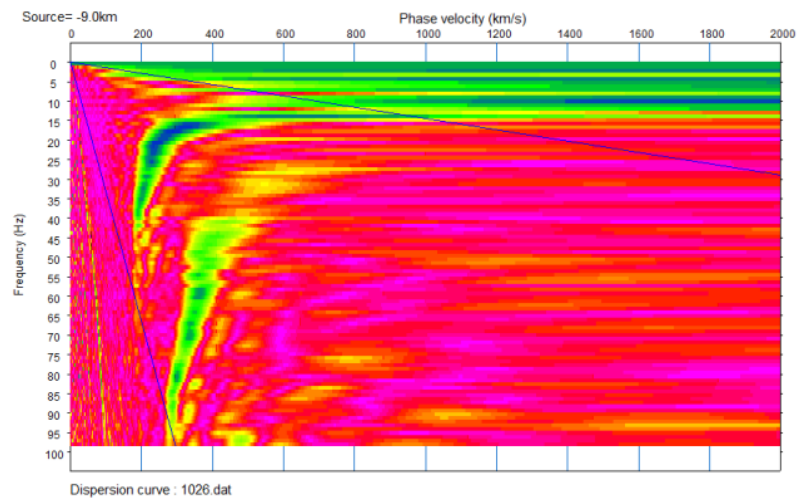

(b)

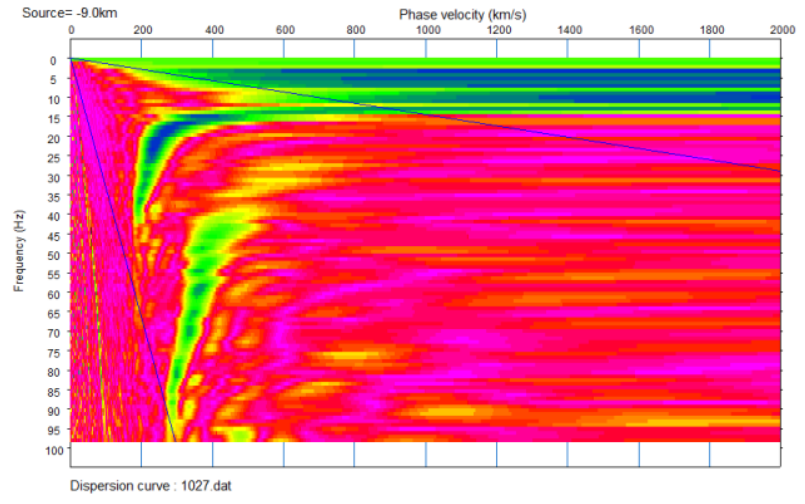

(c)

Fig. A-17: Dispersion images for the FEF site generated using a $4 \mathrm{lb}$ sledgehammer located at -6dx from the closest geophone: (a) Aluminum base plate; (b) Aluminum over EPDM rubber base plate; and (c) Ultra-high-molecular-weight polyethylene base plate. 


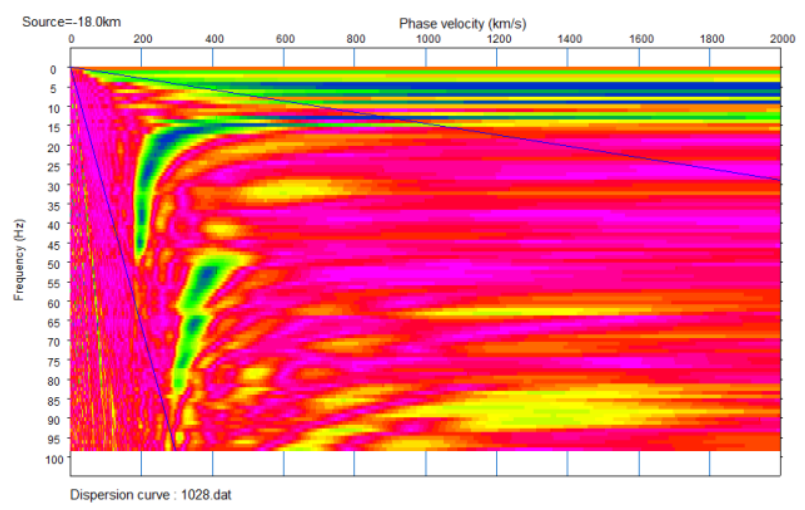

(a)

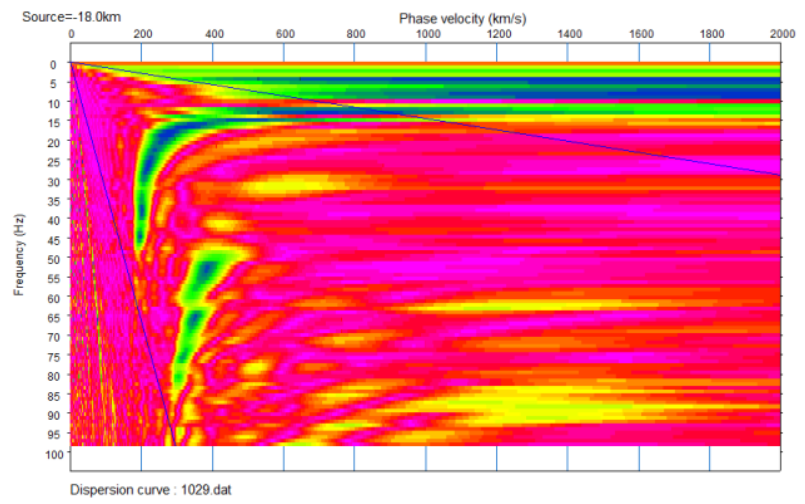

(b)

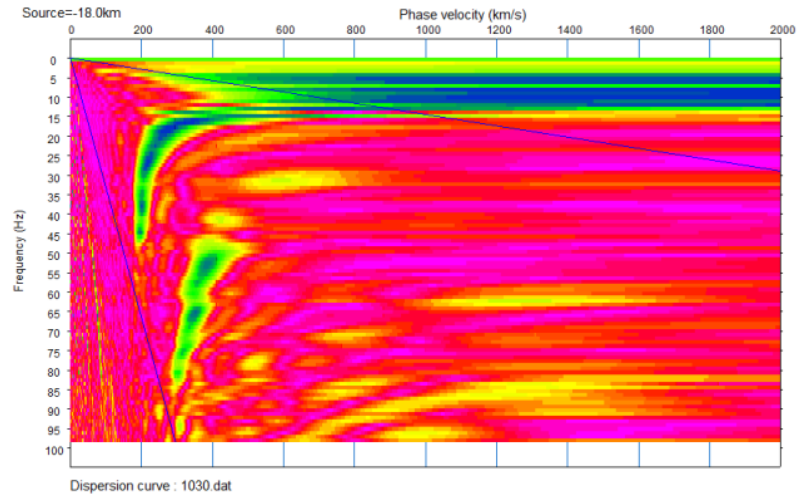

(c)

Fig. A-18: Dispersion images for the FEF site generated using a $20 \mathrm{lb}$ sledgehammer located at -12dx from the closest geophone: (a) Aluminum base plate; (b) Aluminum over EPDM rubber base plate; and (c) Ultra-high-molecular-weight polyethylene base plate. 


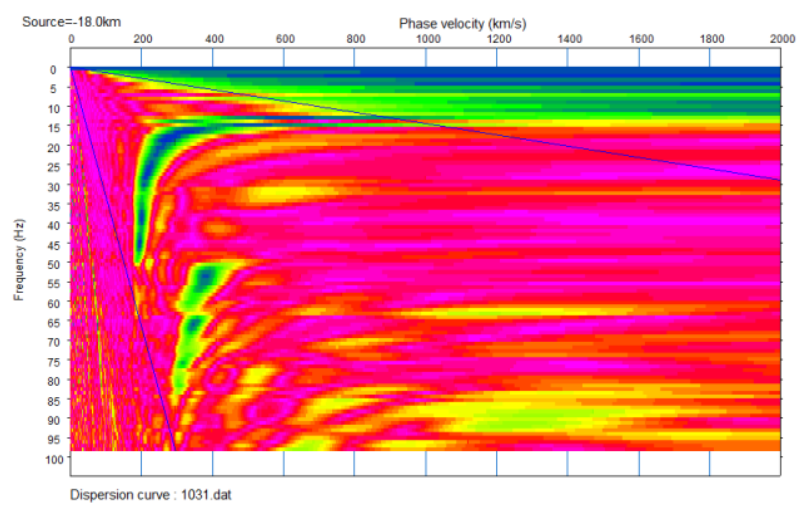

(a)

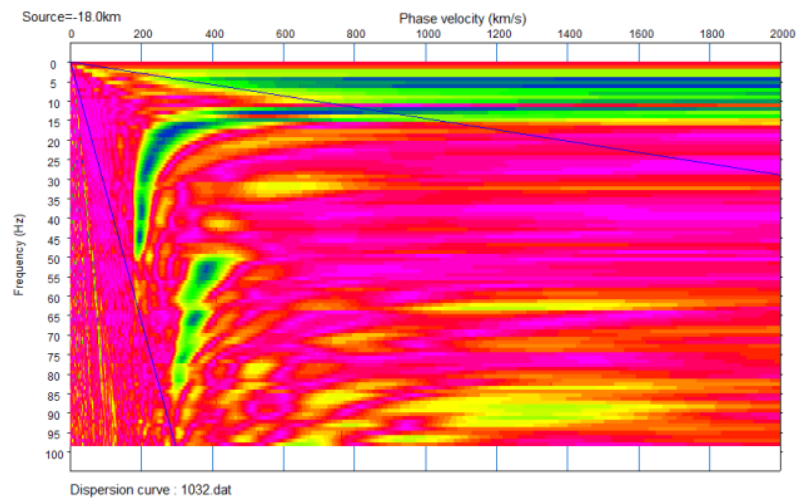

(b)

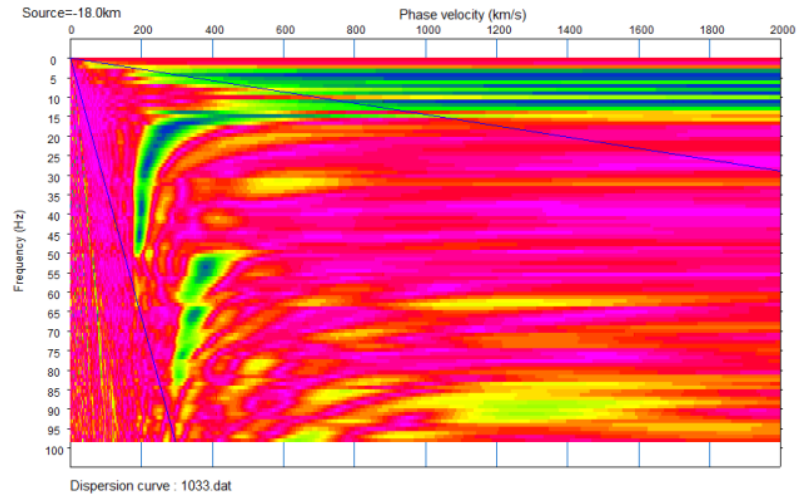

(c)

Fig. A-19: Dispersion images for the FEF site generated using a 8 lb sledgehammer located at -12dx from the closest geophone: (a) Aluminum base plate; (b) Aluminum over EPDM rubber base plate; and (c) Ultra-high-molecular-weight polyethylene base plate. 


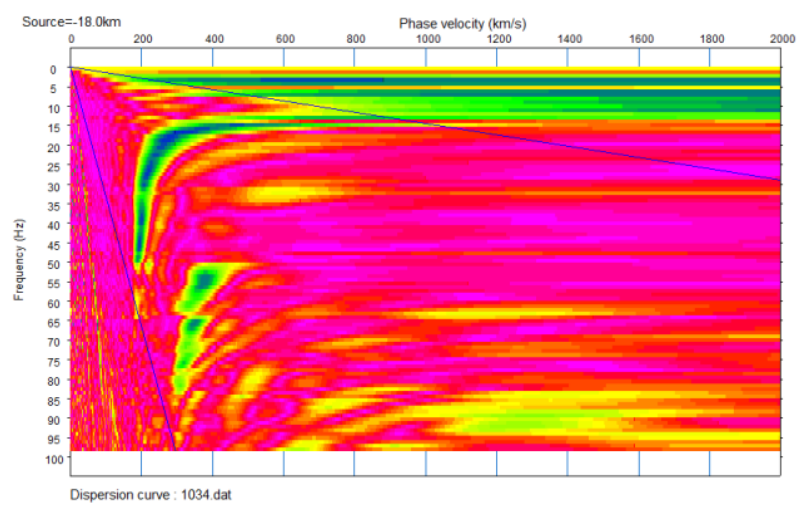

(a)

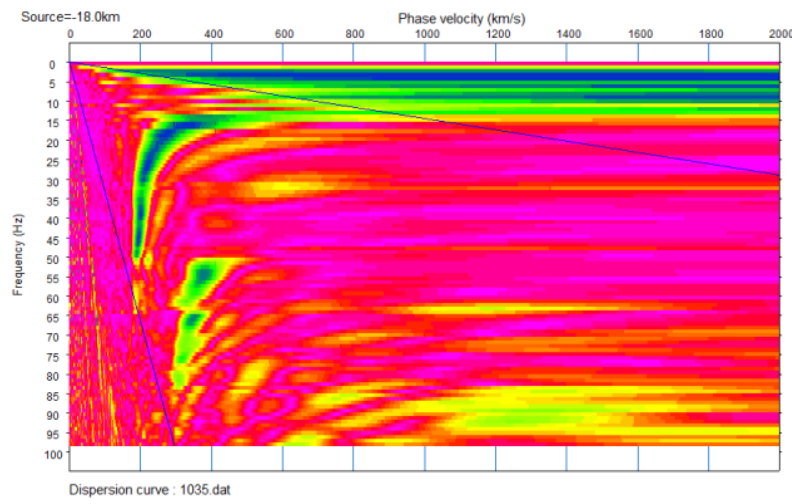

(b)

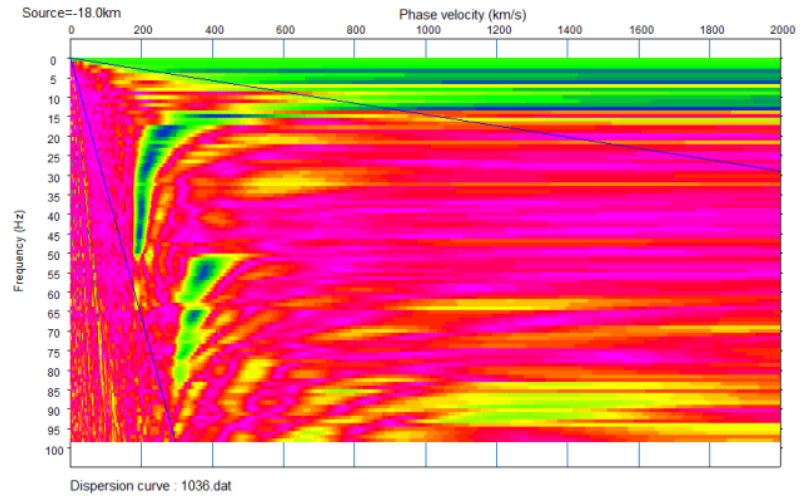

(c)

Fig. A-20: Dispersion images for the FEF site generated using a $4 \mathrm{lb}$ sledgehammer located at -12dx from the closest geophone: (a) Aluminum base plate; (b) Aluminum over EPDM rubber base plate; and (c) Ultra-high-molecular-weight polyethylene base plate. 


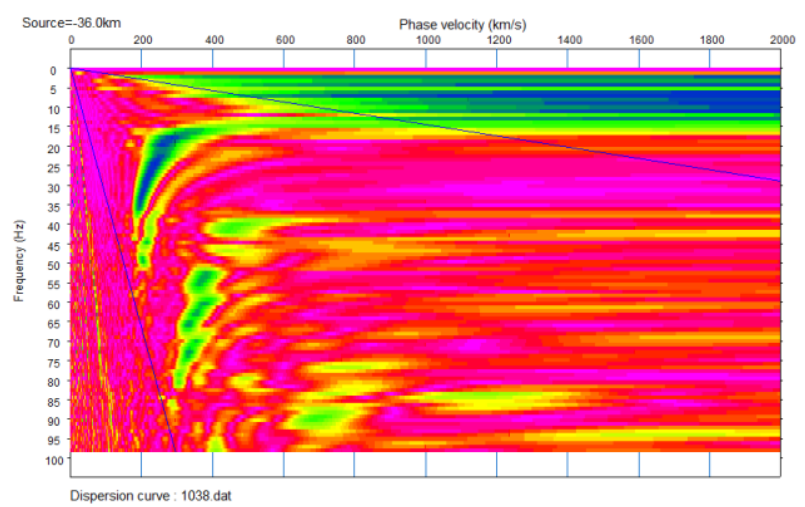

(a)

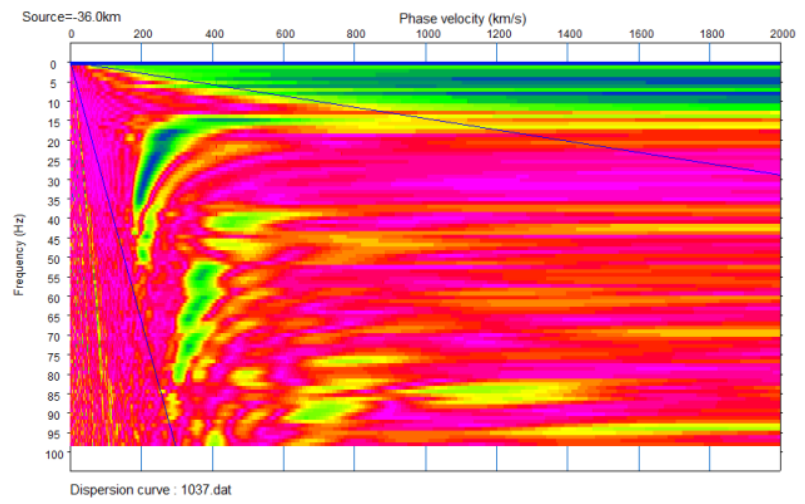

(b)

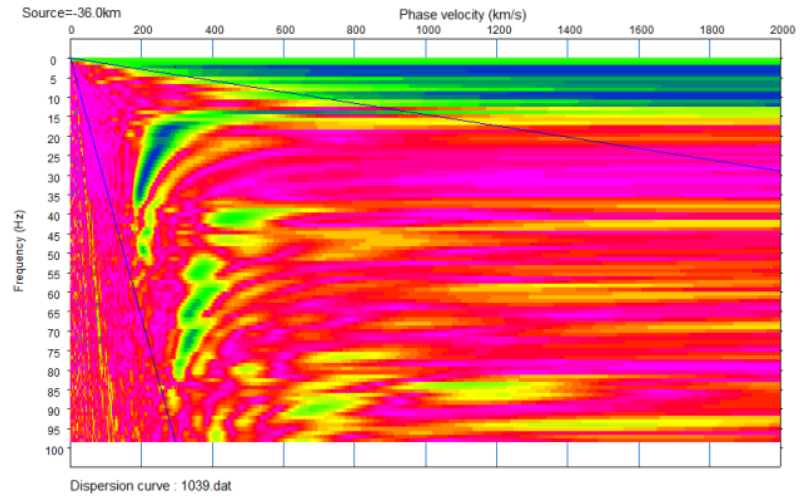

(c)

Fig. A-21: Dispersion images for the FEF site generated using a $20 \mathrm{lb}$ sledgehammer located at -24dx from the closest geophone: (a) Aluminum base plate; (b) Aluminum over EPDM rubber base plate; and (c) Ultra-high-molecular-weight polyethylene base plate. 


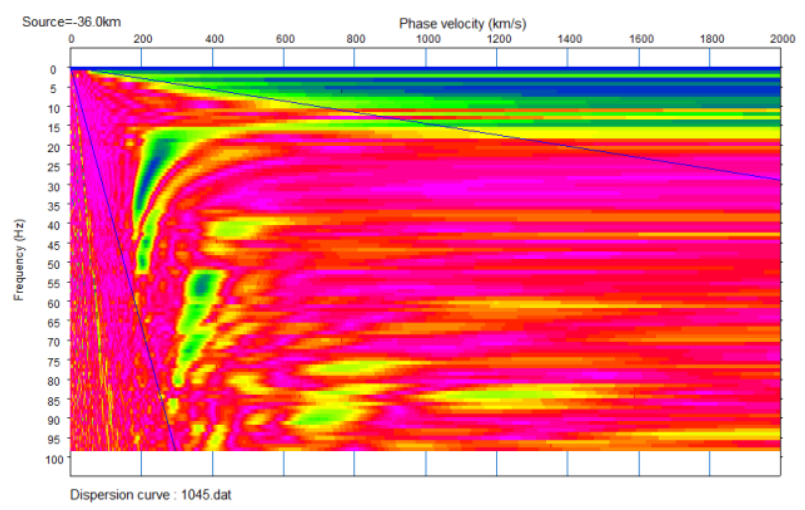

(a)

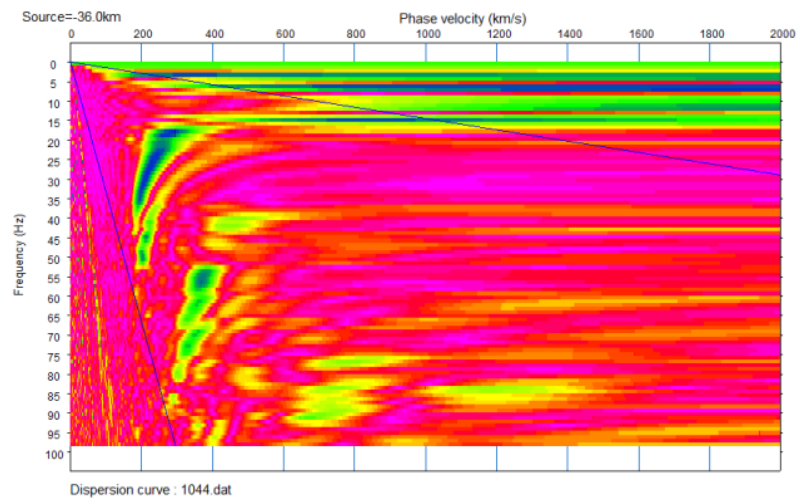

(b)

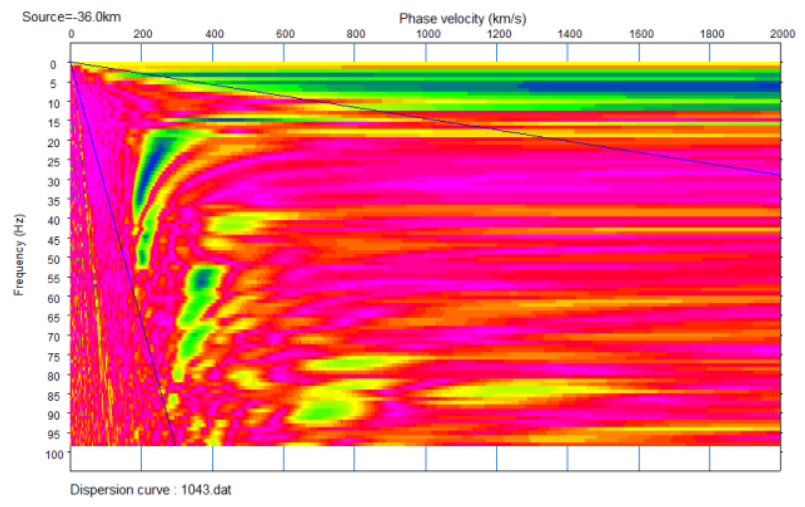

(c)

Fig. A-22: Dispersion images for the FEF site generated using a $4 \mathrm{lb}$ sledgehammer located at -24dx from the closest geophone: (a) Aluminum base plate; (b) Aluminum over EPDM rubber base plate; and (c) Ultra-high-molecular-weight polyethylene base plate. 


\section{APPENDIX A-3}

\section{DISPERSION IMAGES FROM MARTIN LUTHER KING JR. DRIVE NEAR BELMONT WATERWORKS (MLK)}




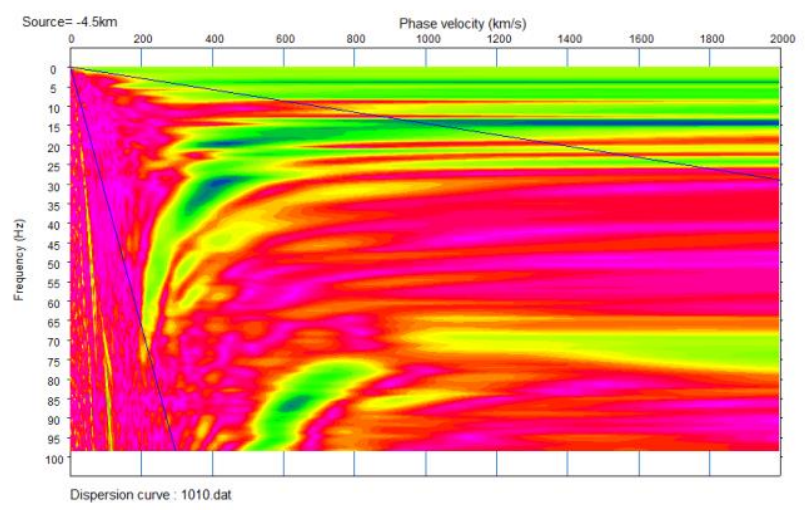

(a)

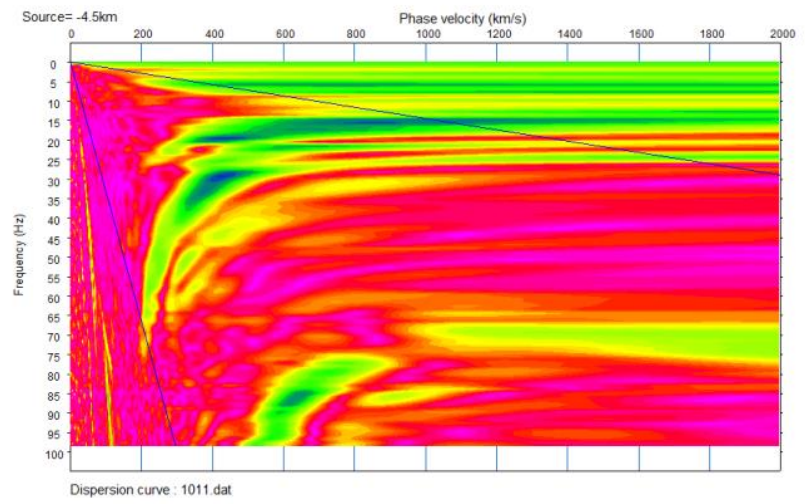

(b)

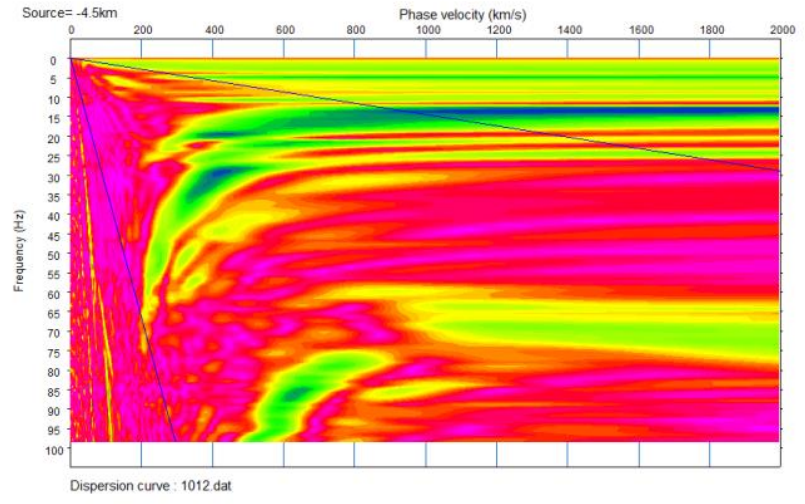

(c)

Fig. A-23: Dispersion images for the MLK site generated using a $20 \mathrm{lb}$ sledgehammer located at -3dx from the closest geophone: (a) Aluminum base plate; (b) Aluminum over EPDM rubber base plate; and (c) Ultra-high-molecular-weight polyethylene base plate 


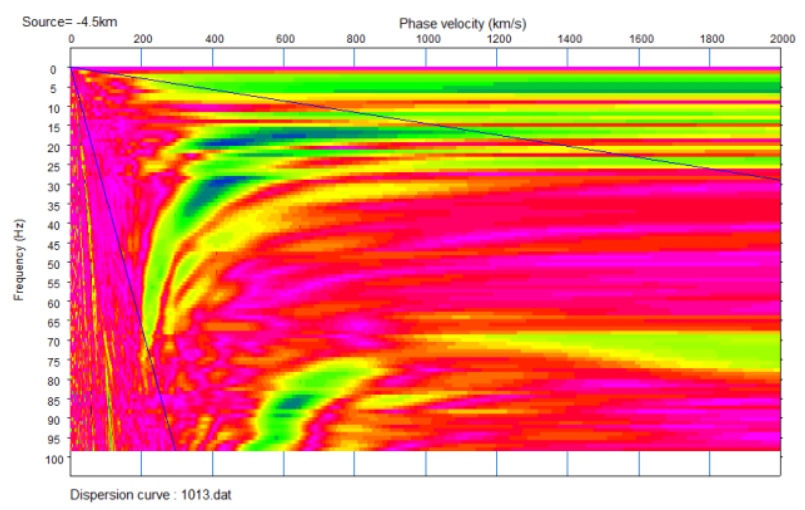

(a)

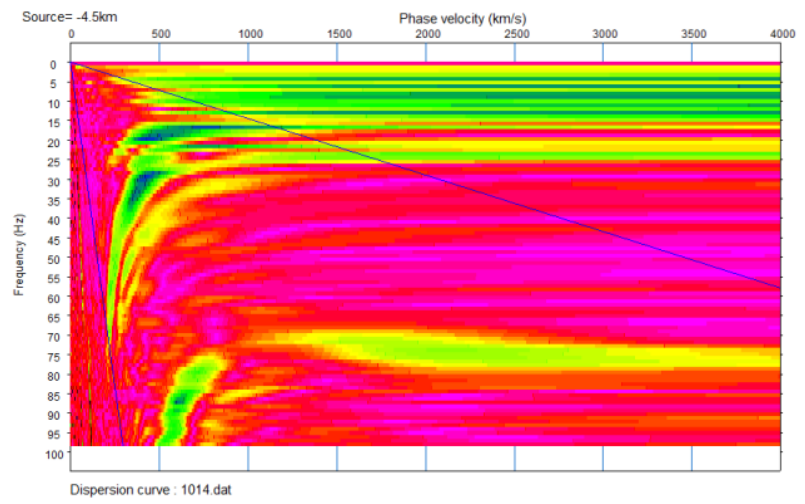

(b)

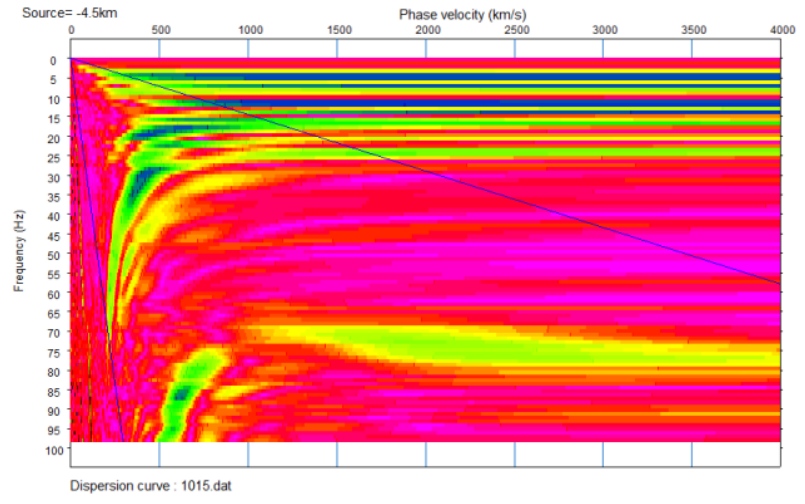

(c)

Fig. A-24: Dispersion images for the MLK site generated using a $8 \mathrm{lb}$ sledgehammer located at $-\mathbf{3 d x}$ from the closest geophone: (a) Aluminum base plate; (b) Aluminum over EPDM rubber base plate; and (c) Ultra-high-molecular-weight polyethylene base plate. 


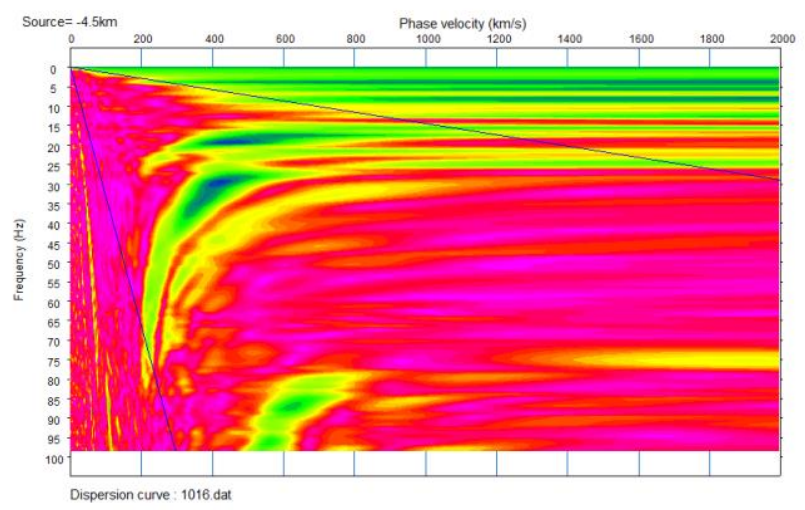

(a)

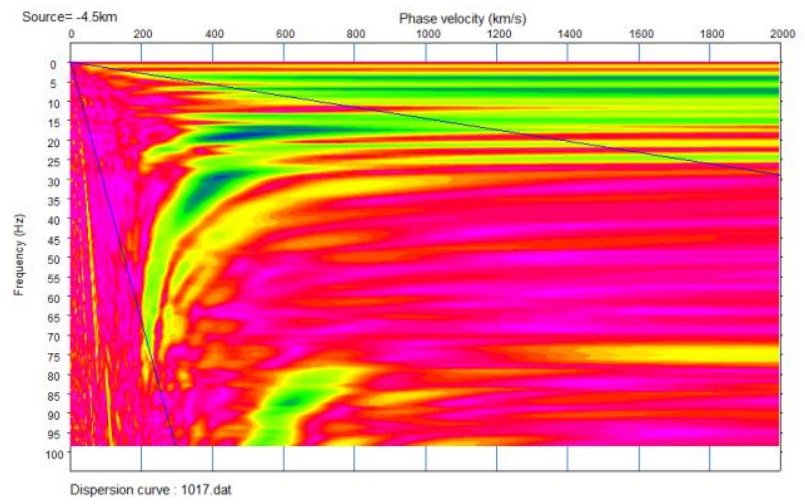

(b)

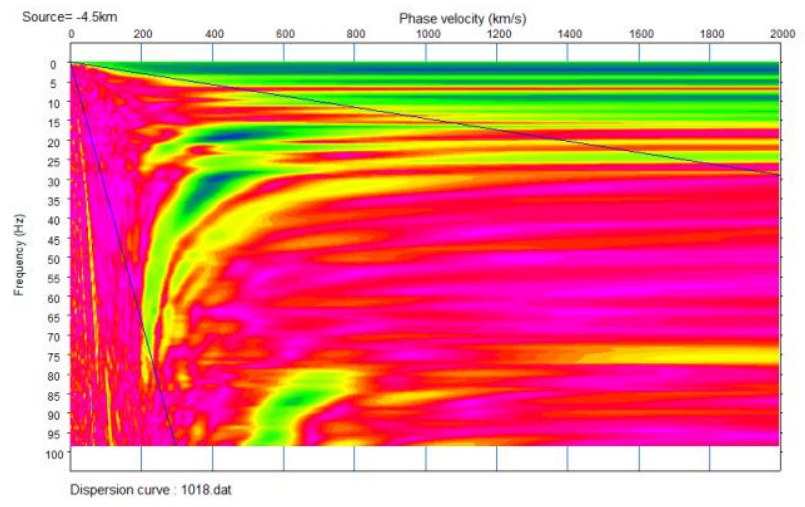

(c)

Fig. A-25: Dispersion images for the MLK site generated using a $4 \mathrm{lb}$ sledgehammer located at -3dx from the closest geophone: (a) Aluminum base plate; (b) Aluminum over EPDM rubber base plate; and (c) Ultra-high-molecular-weight polyethylene base plate. 


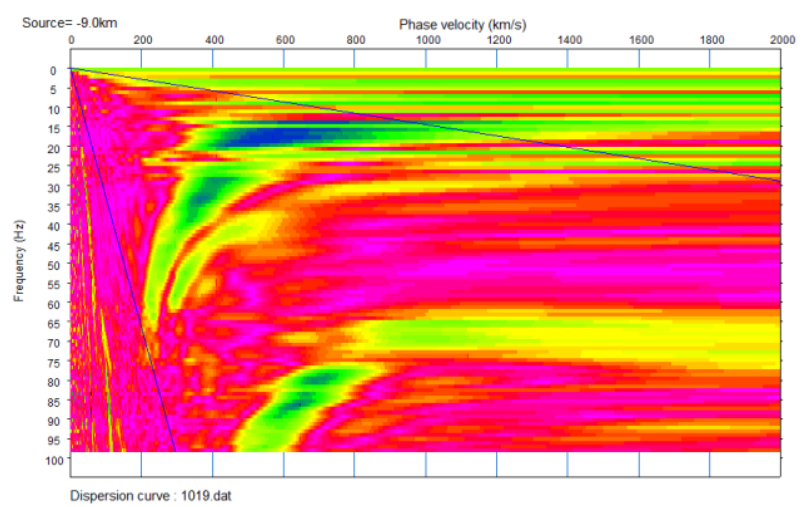

(a)

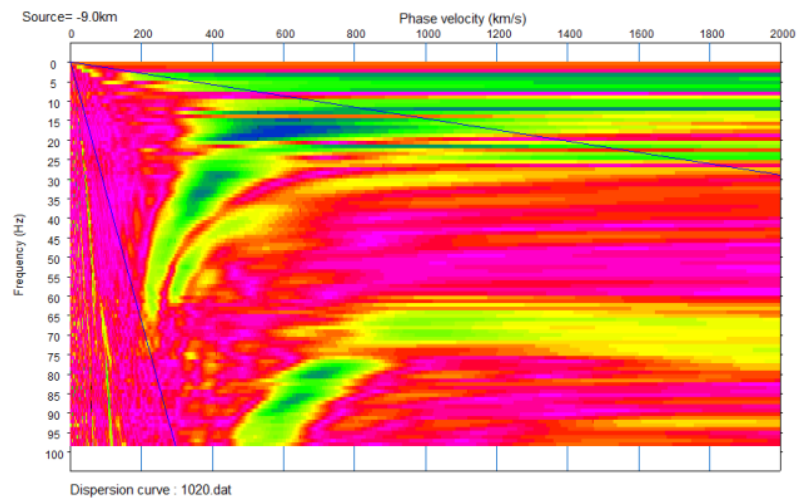

(b)

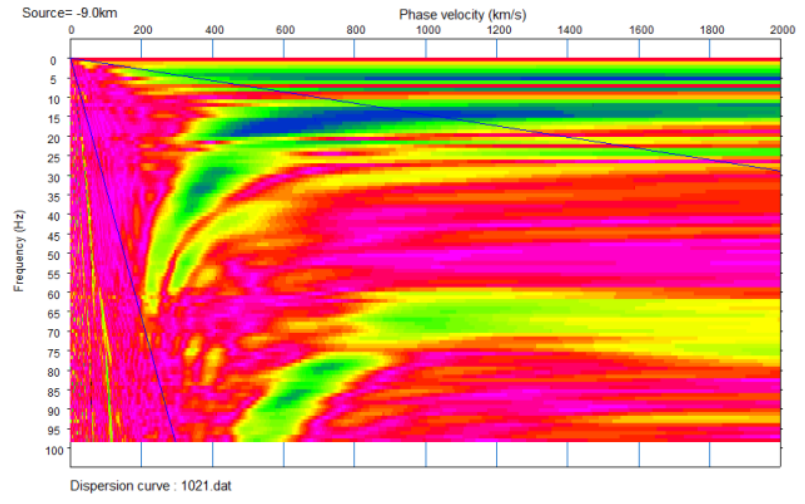

(c)

Fig. A-26: Dispersion images for the MLK site generated using a $20 \mathrm{lb}$ sledgehammer located at -6dx from the closest geophone: (a) Aluminum base plate; (b) Aluminum over EPDM rubber base plate; and (c) Ultra-high-molecular-weight polyethylene base plate. 


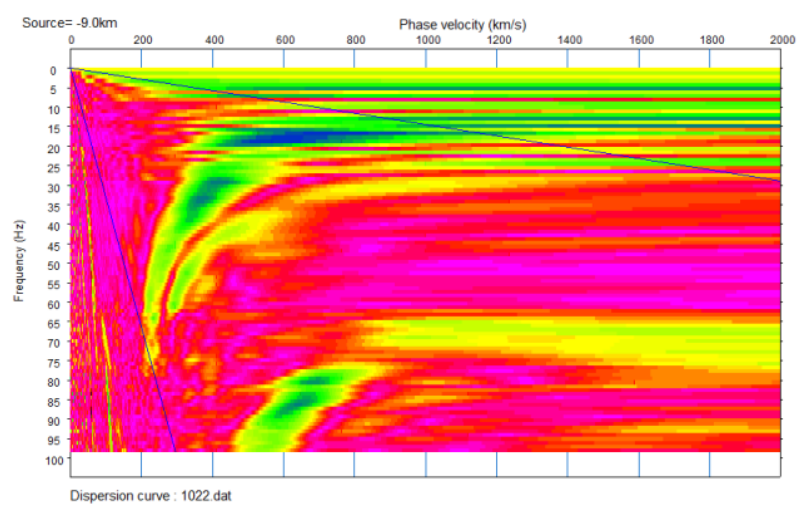

(a)

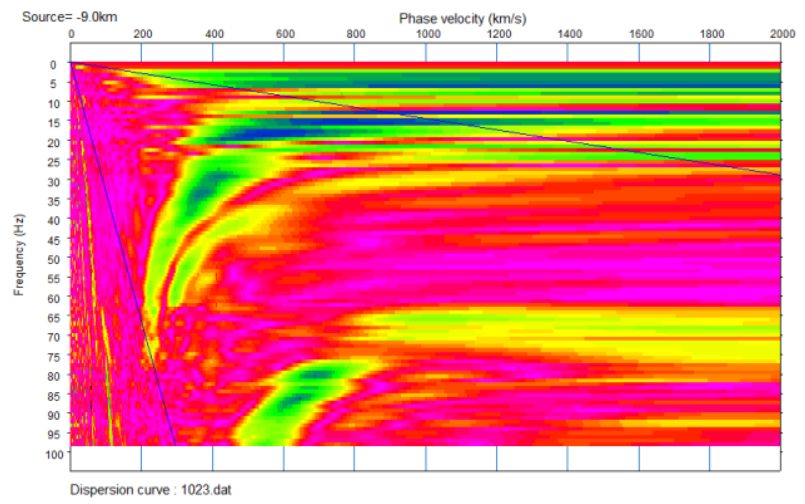

(b)

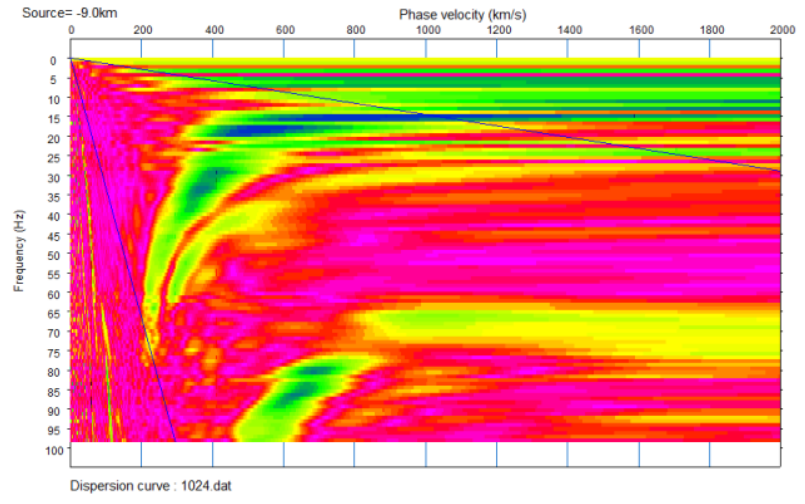

(c)

Fig. A-27: Dispersion images for the MLK site generated using a $8 \mathrm{lb}$ sledgehammer located at -6dx from the closest geophone: (a) Aluminum base plate; (b) Aluminum over EPDM rubber base plate; and (c) Ultra-high-molecular-weight polyethylene base plate. 


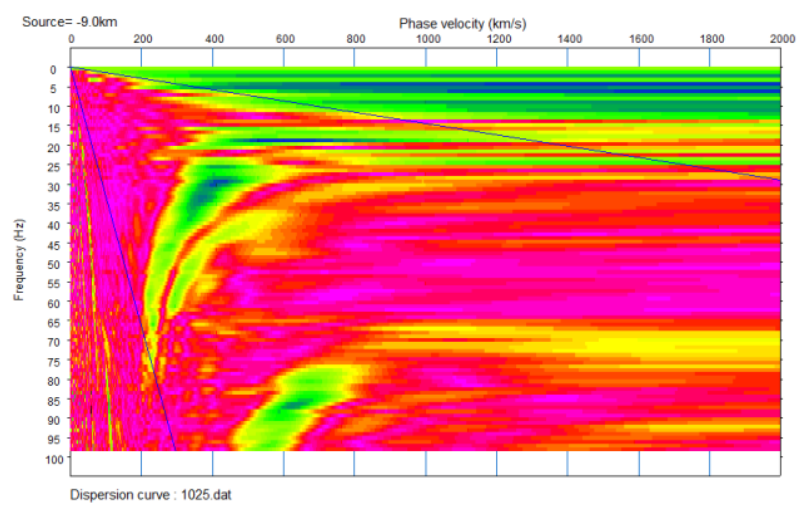

(a)

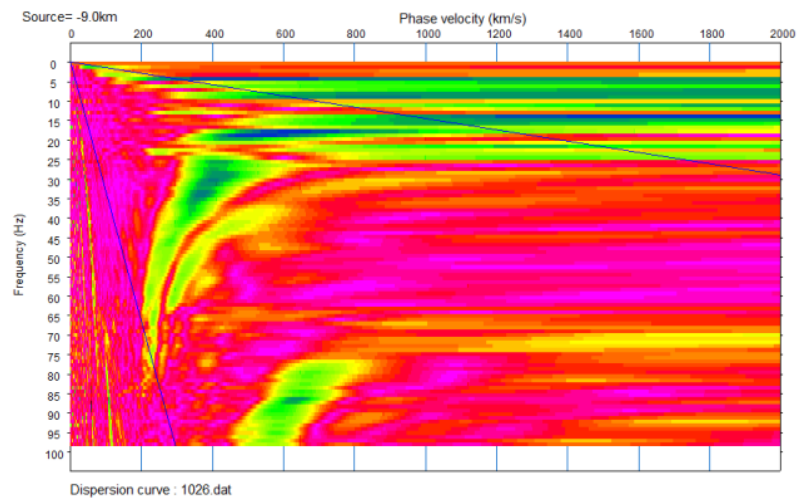

(b)

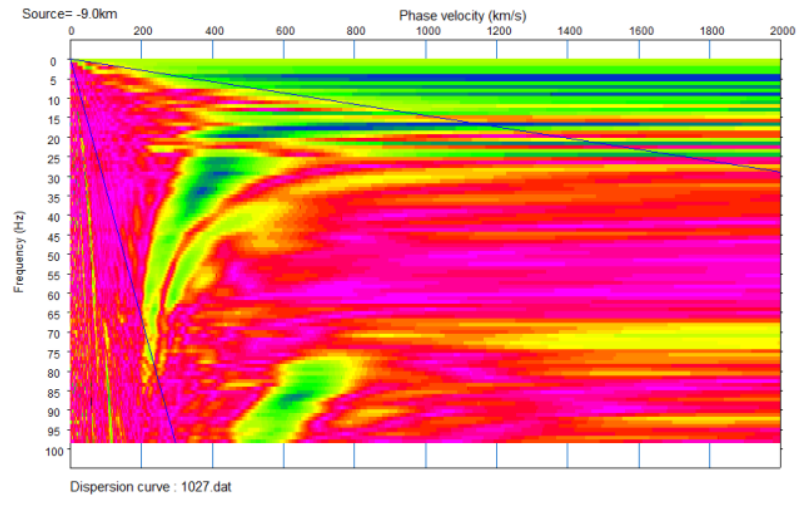

(c)

Fig. A-28: Dispersion images for the MLK site generated using a $4 \mathrm{lb}$ sledgehammer located at -6dx from the closest geophone: (a) Aluminum base plate; (b) Aluminum over EPDM rubber base plate; and (c) Ultra-high-molecular-weight polyethylene base plate. 


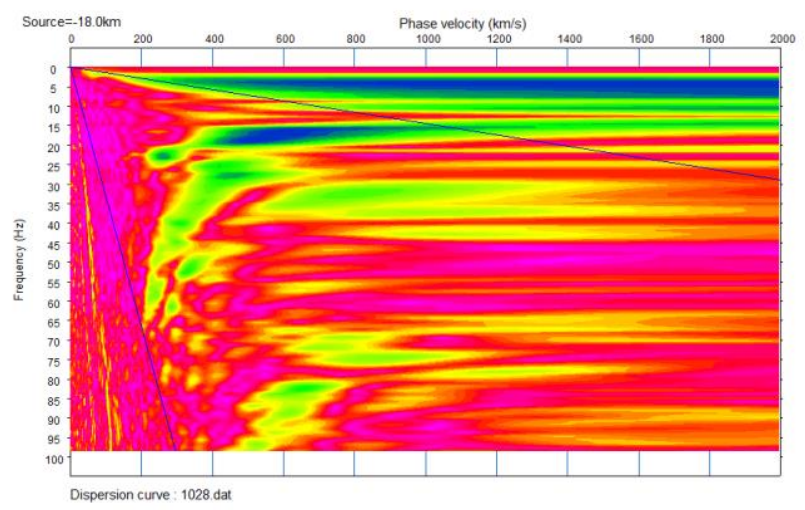

(a)

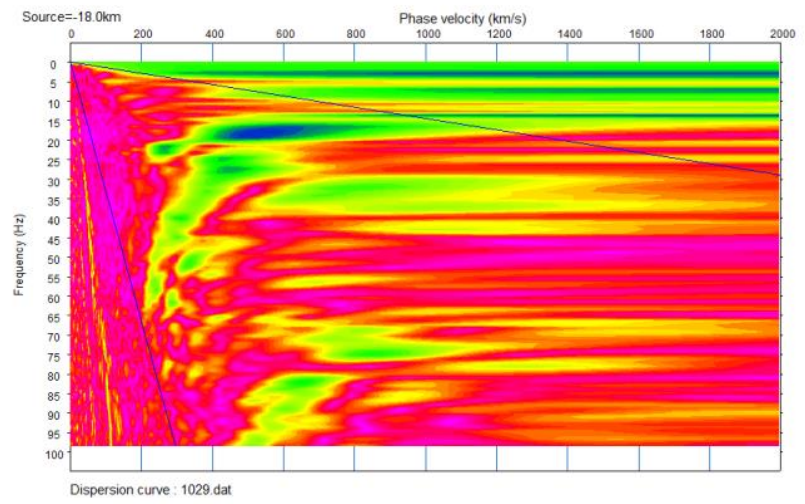

(b)

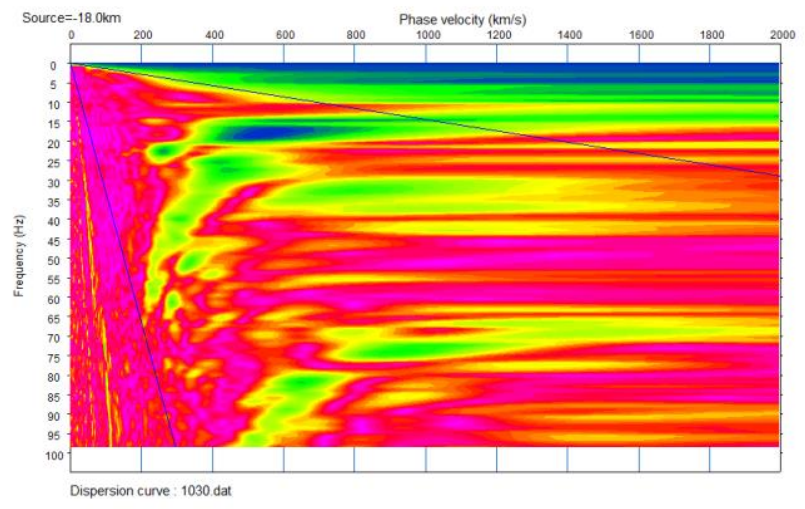

(c)

Fig. A-29: Dispersion images for the MLK site generated using a $20 \mathrm{lb}$ sledgehammer located at -12dx from the closest geophone: (a) Aluminum base plate; (b) Aluminum over EPDM rubber base plate; and (c) Ultra-high-molecular-weight polyethylene base plate. 


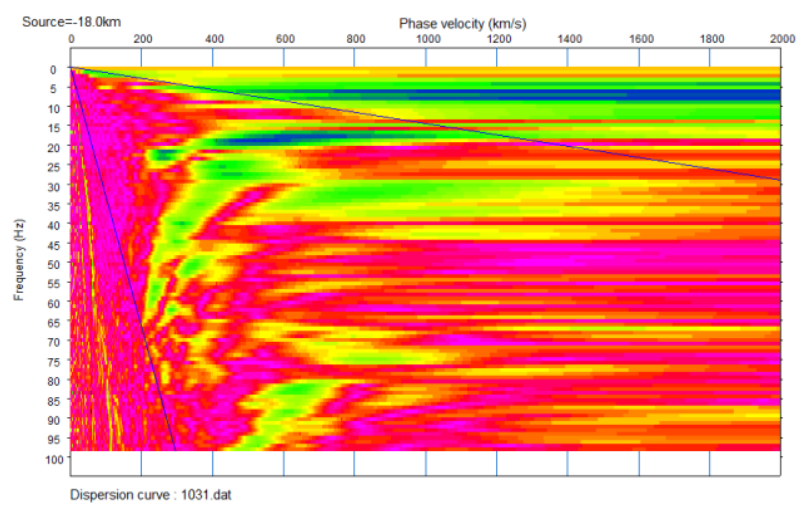

(a)

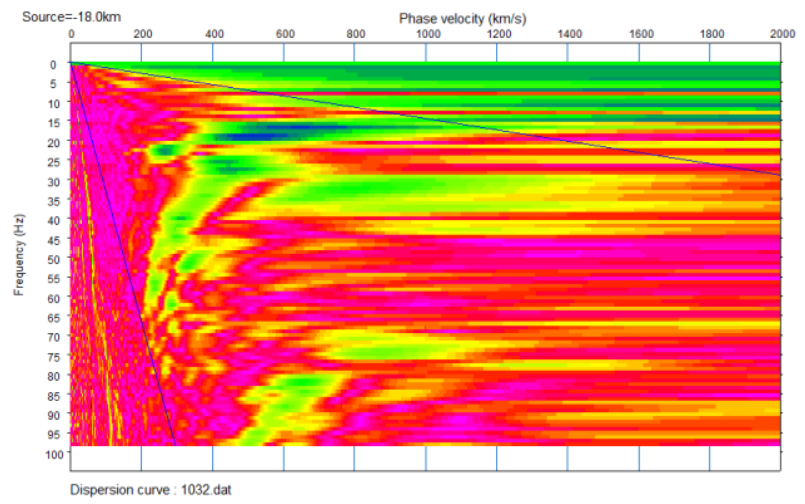

(b)

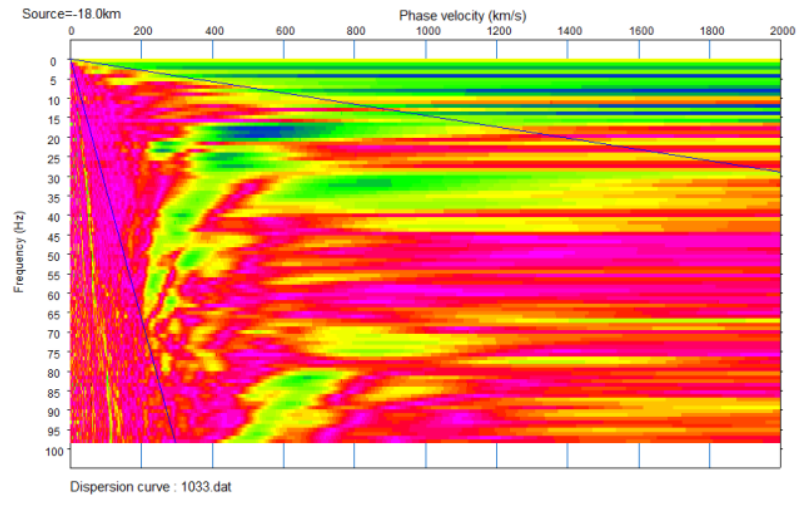

(c)

Fig. A-30: Dispersion images for the MLK site generated using a $8 \mathrm{lb}$ sledgehammer located at -12dx from the closest geophone: (a) Aluminum base plate; (b) Aluminum over EPDM rubber base plate; and (c) Ultra-high-molecular-weight polyethylene base plate. 


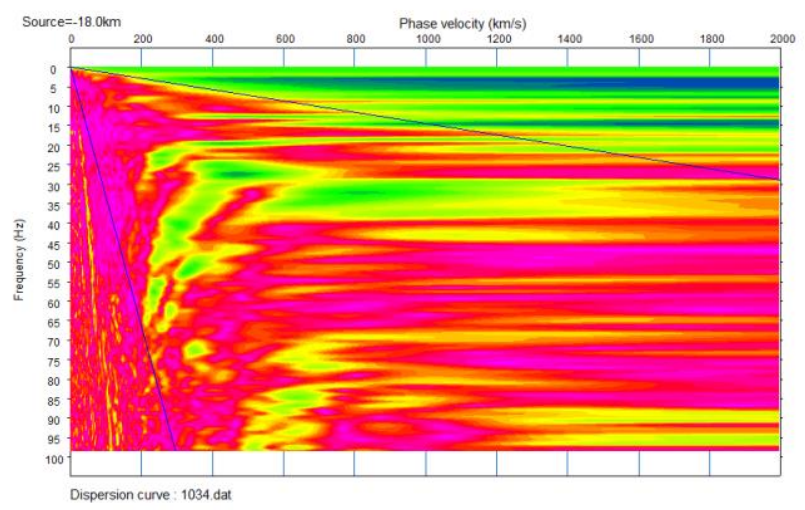

(a)

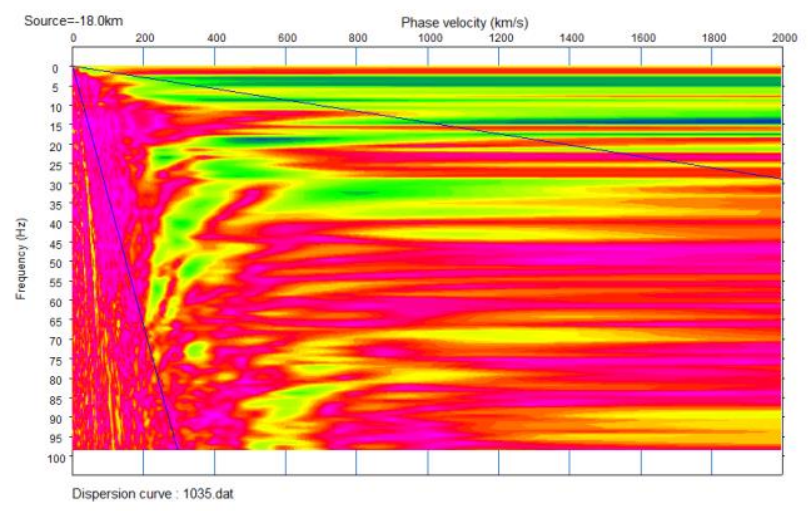

(b)

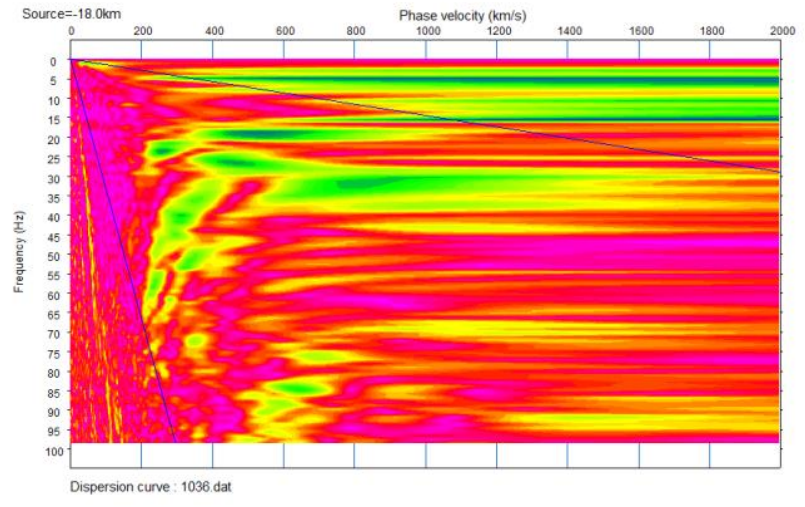

(c)

Fig. A-31: Dispersion images for the MLK site generated using a $4 \mathrm{lb}$ sledgehammer located at -12dx from the closest geophone: (a) Aluminum base plate; (b) Aluminum over EPDM rubber base plate; and (c) Ultra-high-molecular-weight polyethylene base plate. 


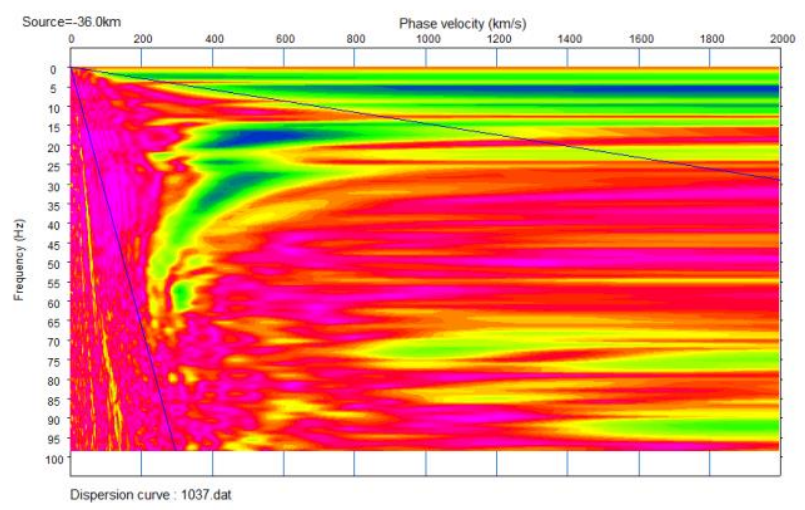

(a)

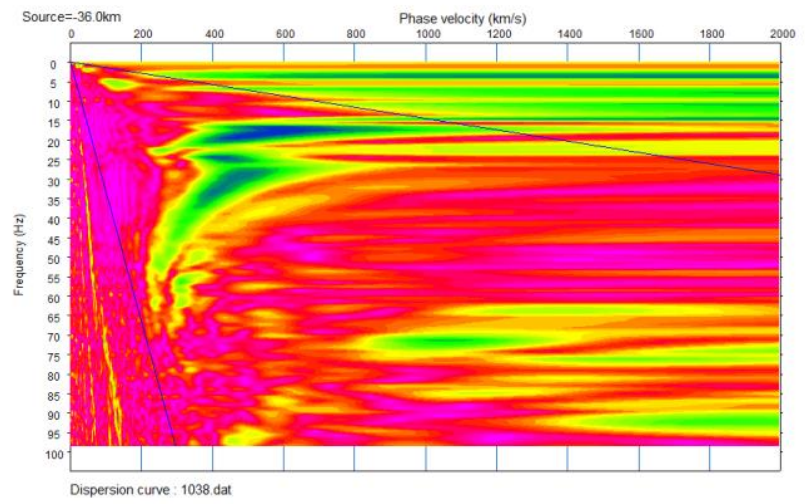

(b)

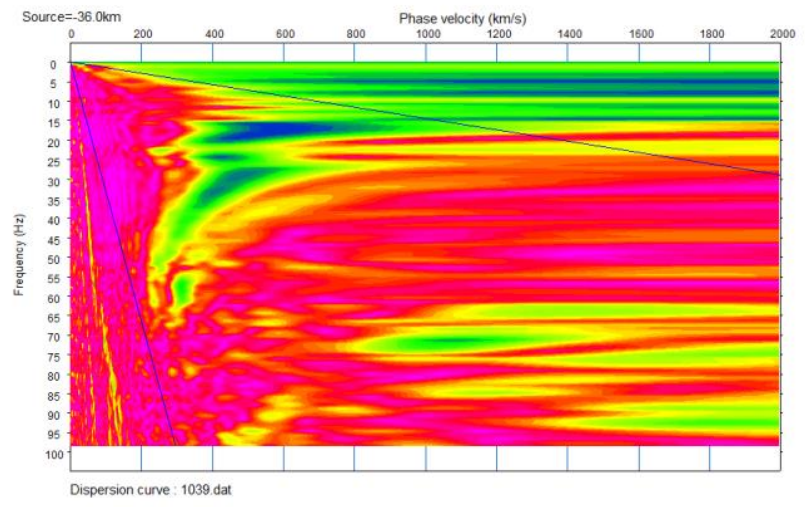

(c)

Fig. A-32: Dispersion images for the MLK site generated using a $20 \mathrm{lb}$ sledgehammer located at -24dx from the closest geophone: (a) Aluminum base plate; (b) Aluminum over EPDM rubber base plate; and (c) Ultra-high-molecular-weight polyethylene base plate. 


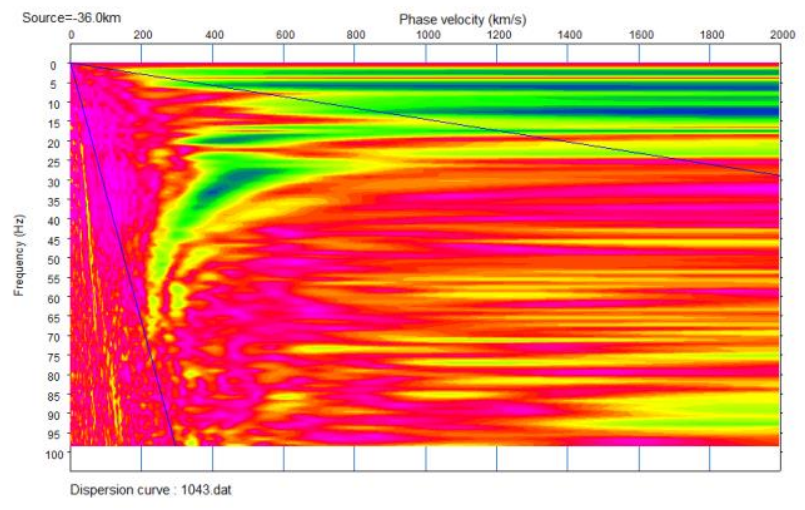

(a)

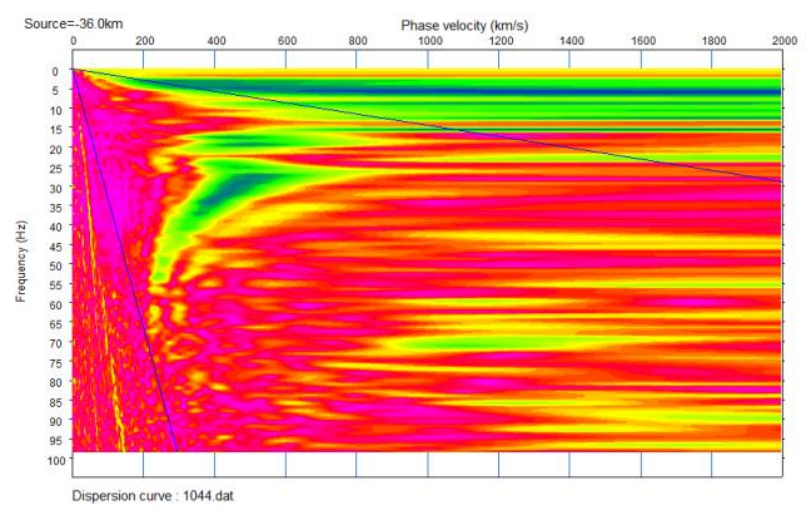

(b)

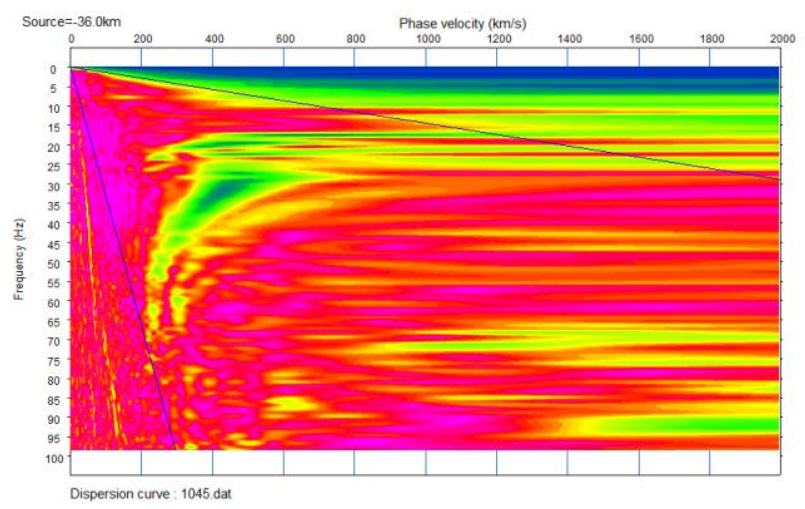

(c)

Fig. A-33: Dispersion images for the MLK site generated using a $4 \mathrm{lb}$ sledgehammer located at -24dx from the closest geophone: (a) Aluminum base plate; (b) Aluminum over EPDM rubber base plate; and (c) Ultra-high-molecular-weight polyethylene base plate. 
APPENDIX A-4

\section{DISPERSION IMAGES FROM TEMPLE AMBLER \\ CAMPUS (TA1)}




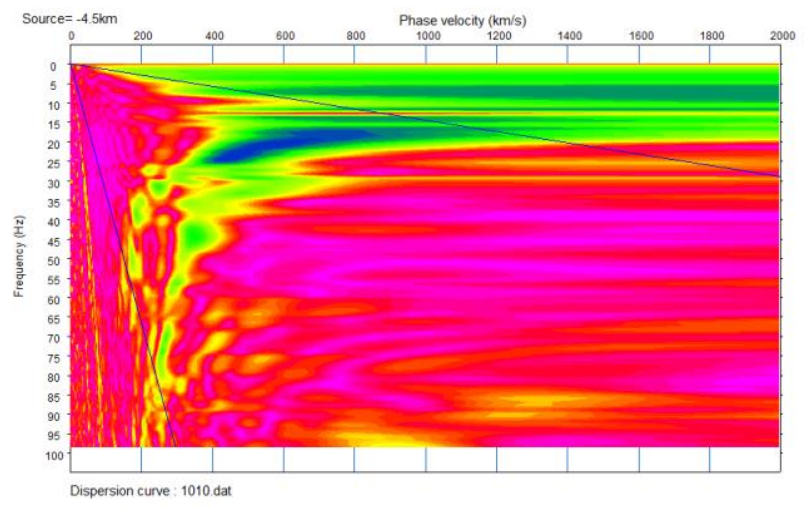

(a)

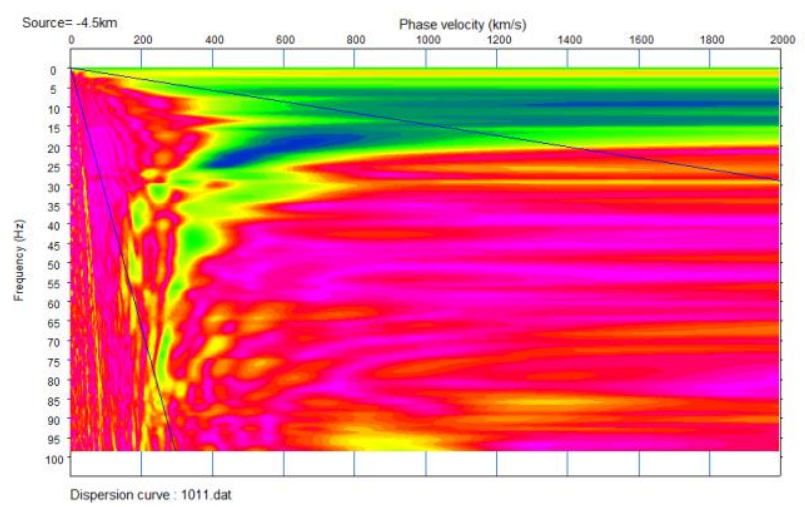

(b)

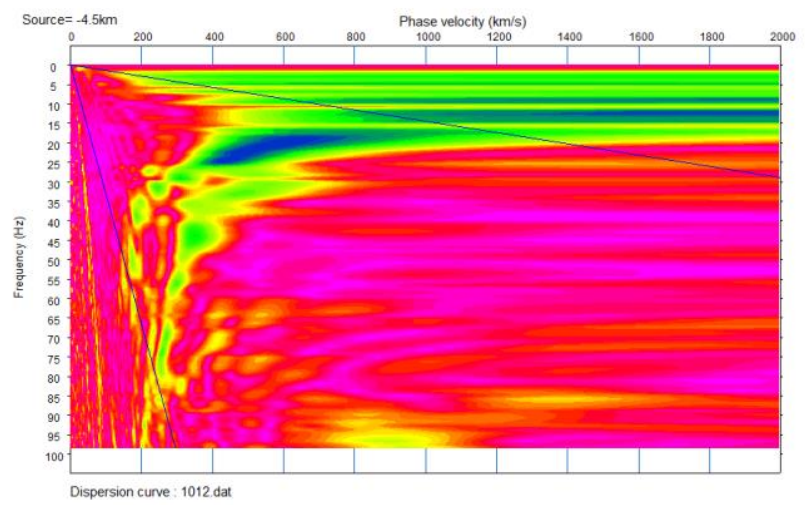

(c)

Fig. A-34: Dispersion images for the TA1 site generated using a $20 \mathrm{lb}$ sledgehammer located at $-\mathbf{3 d x}$ from the closest geophone: (a) Aluminum base plate; (b) Aluminum over EPDM rubber base plate; and (c) Ultra-high-molecular-weight polyethylene base plate. 


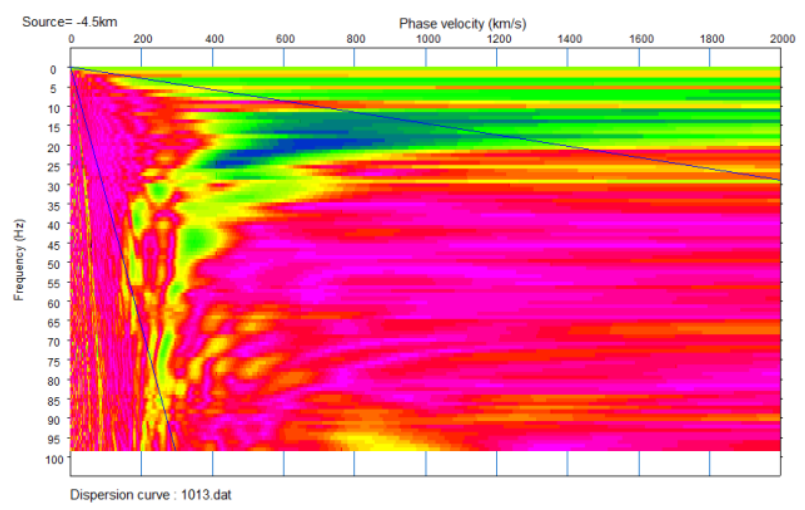

(a)

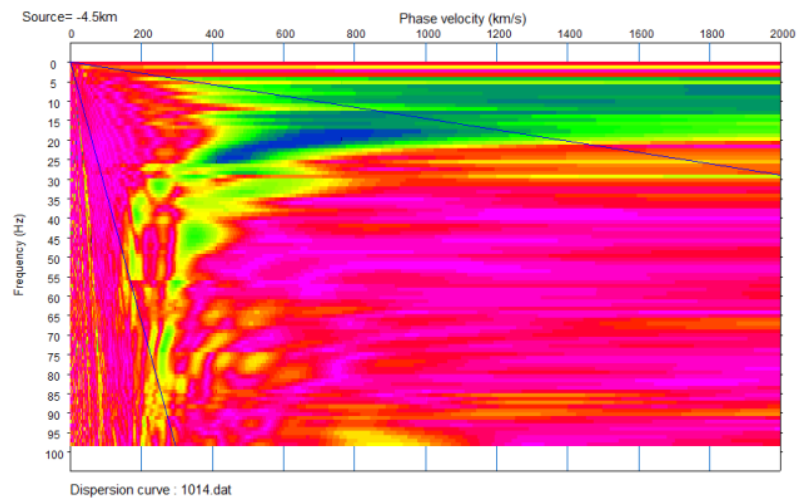

(b)

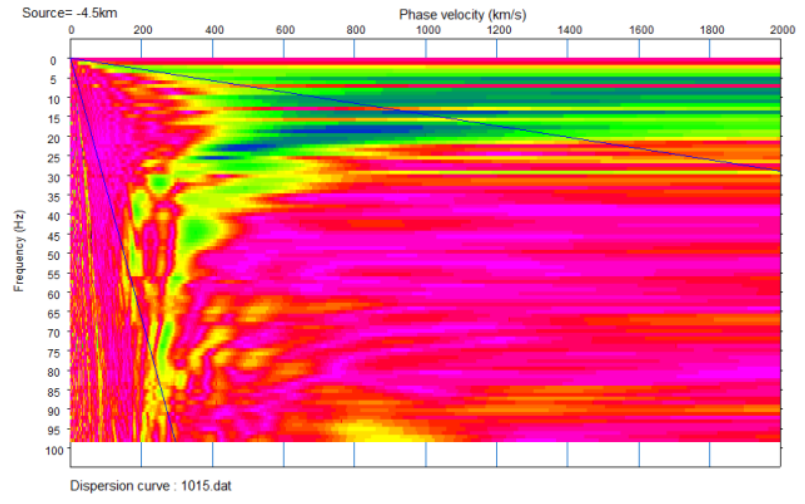

(c)

Fig. A-35: Dispersion images for the TA1 site generated using a 8 lb sledgehammer located at -3dx from the closest geophone: (a) Aluminum base plate; (b) Aluminum over EPDM rubber base plate; and (c) Ultra-high-molecular-weight polyethylene base plate. 


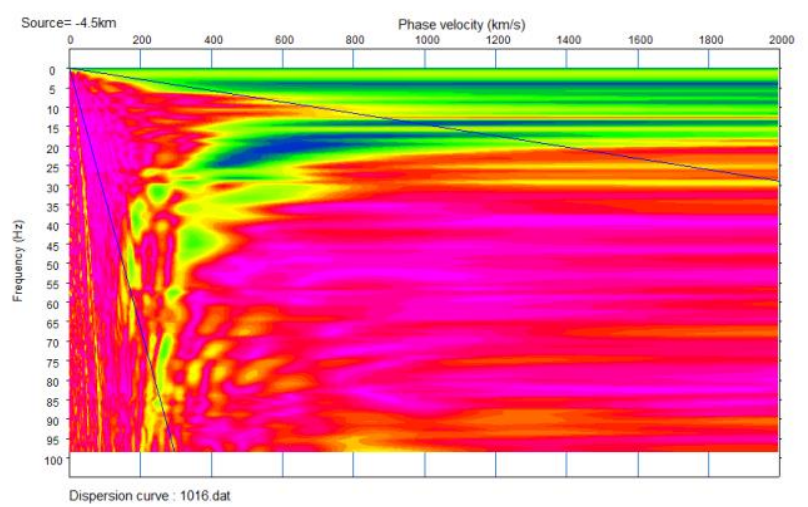

(a)

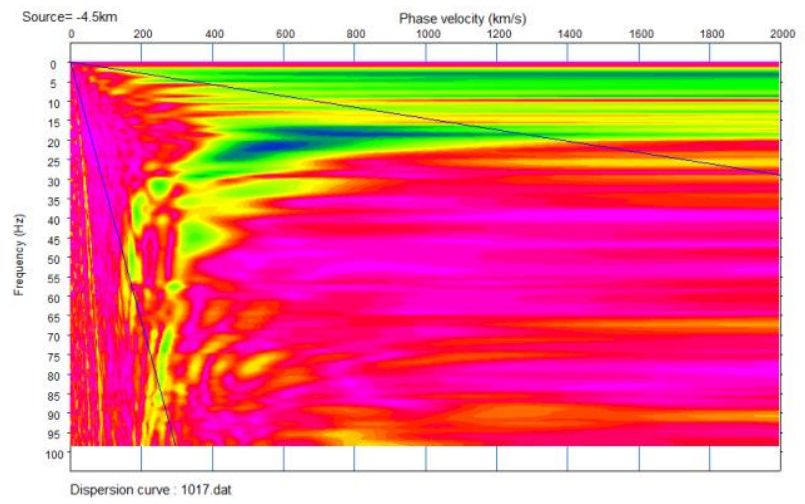

(b)

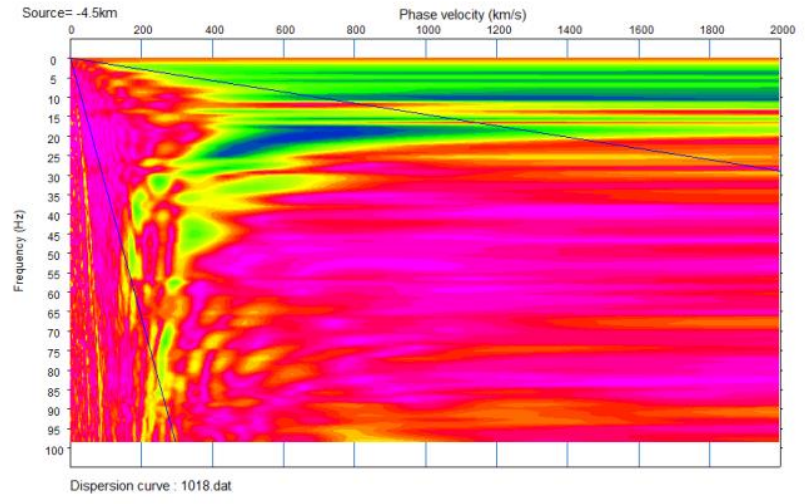

(c)

Fig. A-36: Dispersion images for the TA1 site generated using a $4 \mathrm{lb}$ sledgehammer located at $-\mathbf{3 d x}$ from the closest geophone: (a) Aluminum base plate; (b) Aluminum over EPDM rubber base plate; and (c) Ultra-high-molecular-weight polyethylene base plate. 


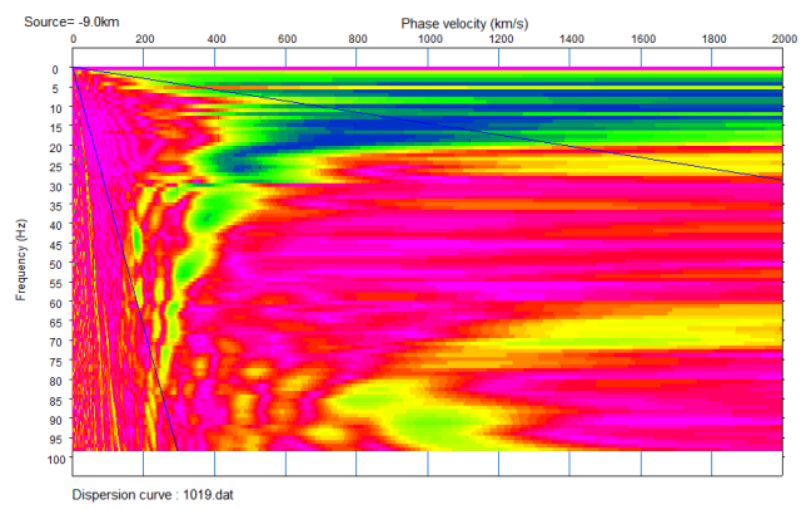

(a)

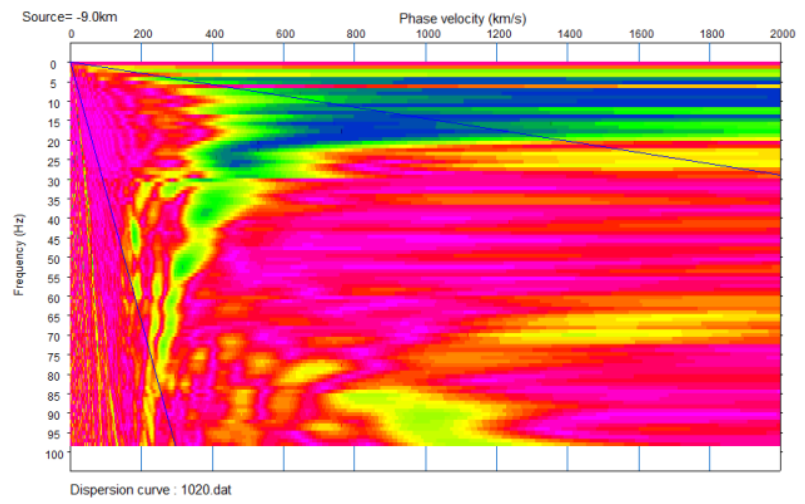

(b)

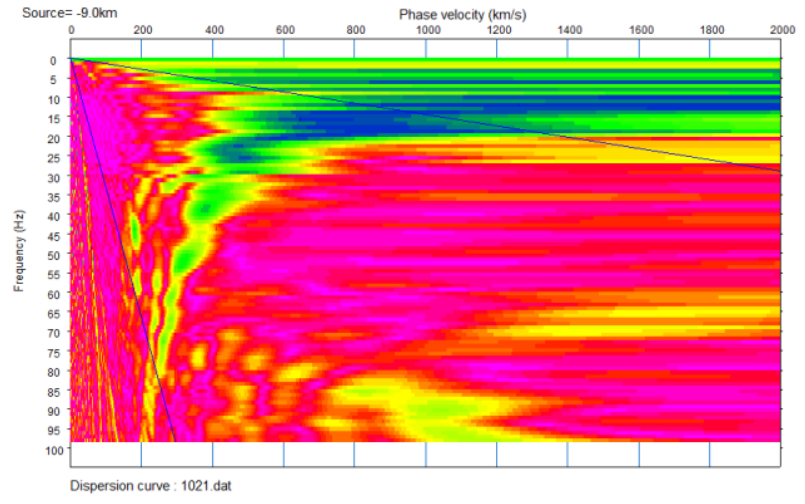

(c)

Fig. A-37: Dispersion images for the TA1 site generated using a $20 \mathrm{lb}$ sledgehammer located at -6dx from the closest geophone: (a) Aluminum base plate; (b) Aluminum over EPDM rubber base plate; and (c) Ultra-high-molecular-weight polyethylene base plate. 


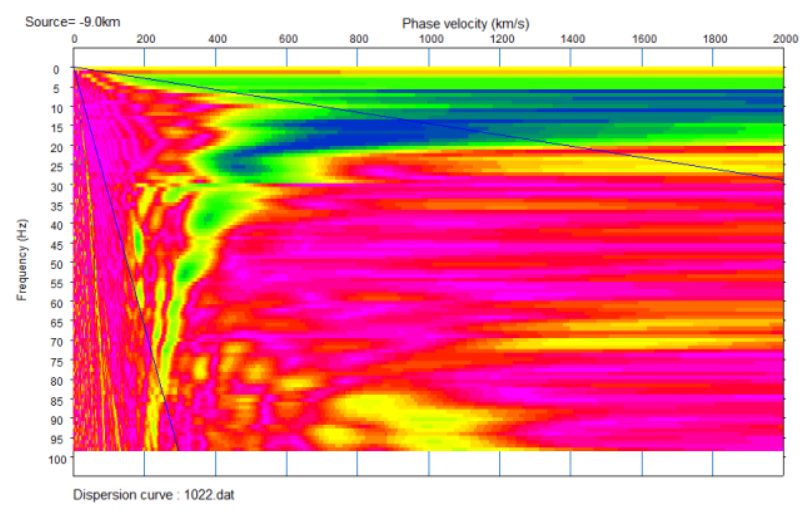

(a)

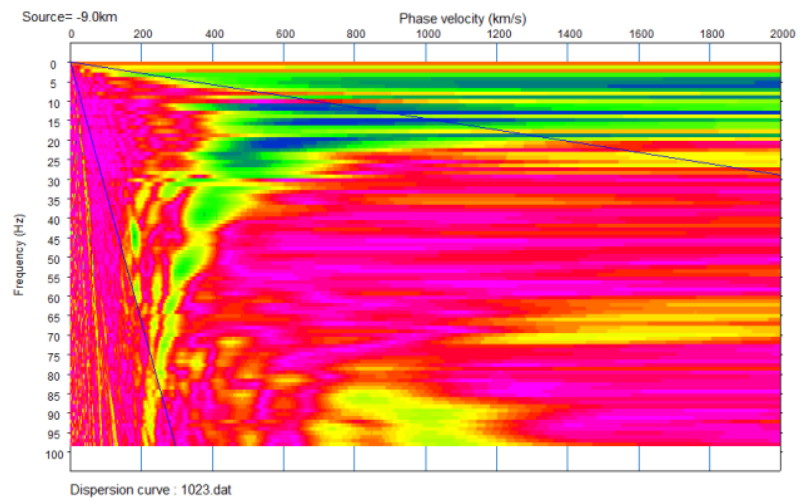

(b)

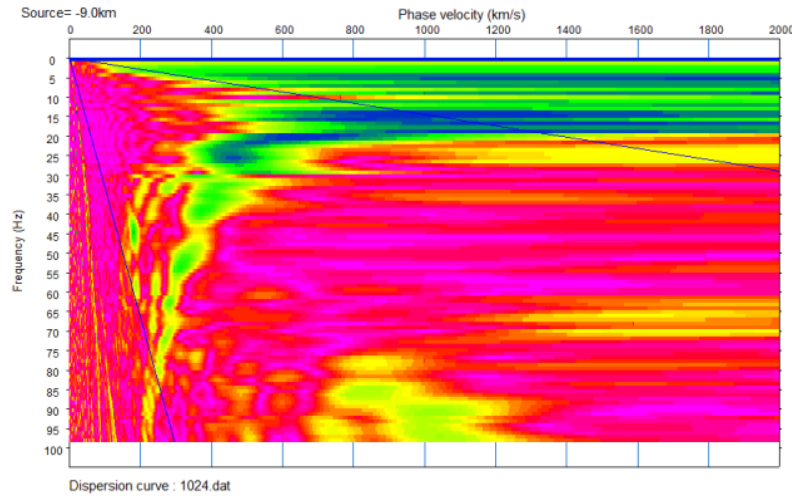

(c)

Fig. A-38: Dispersion images for the TA1 site generated using a $8 \mathrm{lb}$ sledgehammer located at $-\mathbf{6 d x}$ from the closest geophone: (a) Aluminum base plate; (b) Aluminum over EPDM rubber base plate; and (c) Ultra-high-molecular-weight polyethylene base plate. 


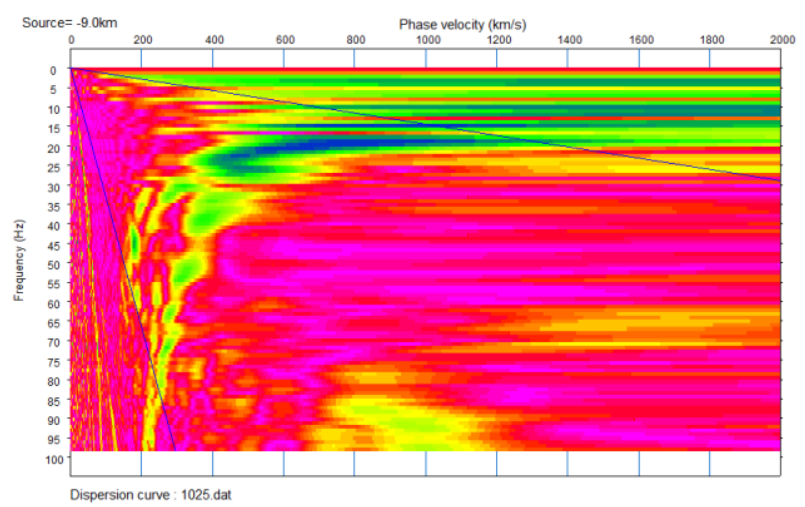

(a)

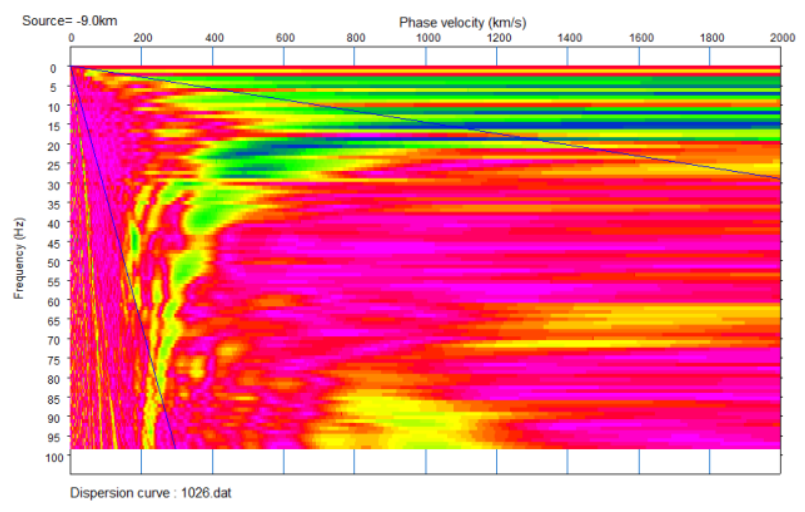

(b)

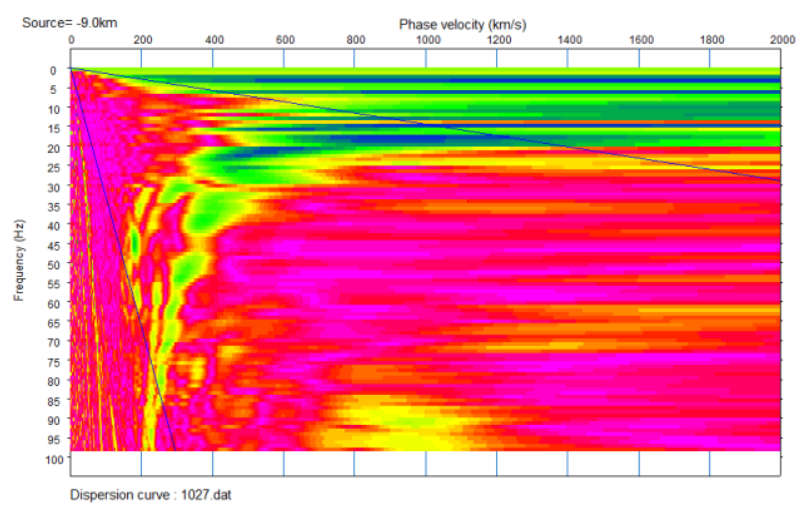

(c)

Fig. A-39: Dispersion images for the TA1 site generated using a $4 \mathrm{lb}$ sledgehammer located at -6dx from the closest geophone: (a) Aluminum base plate; (b) Aluminum over EPDM rubber base plate; and (c) Ultra-high-molecular-weight polyethylene base plate. 


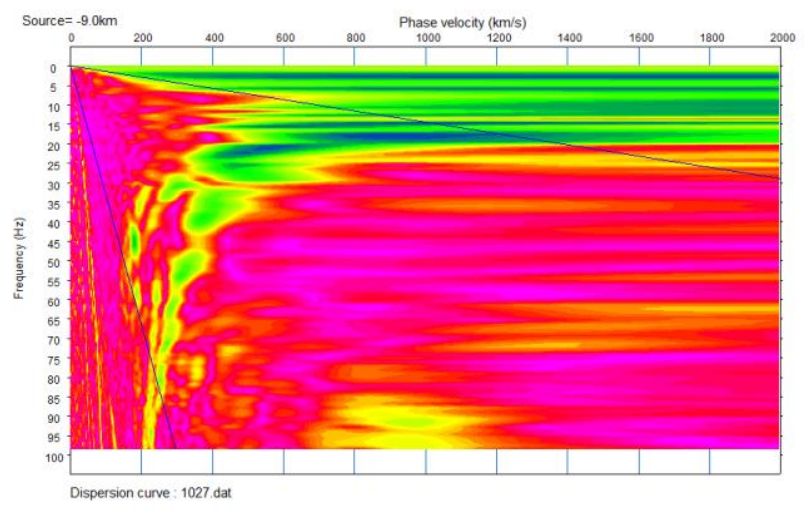

(a)

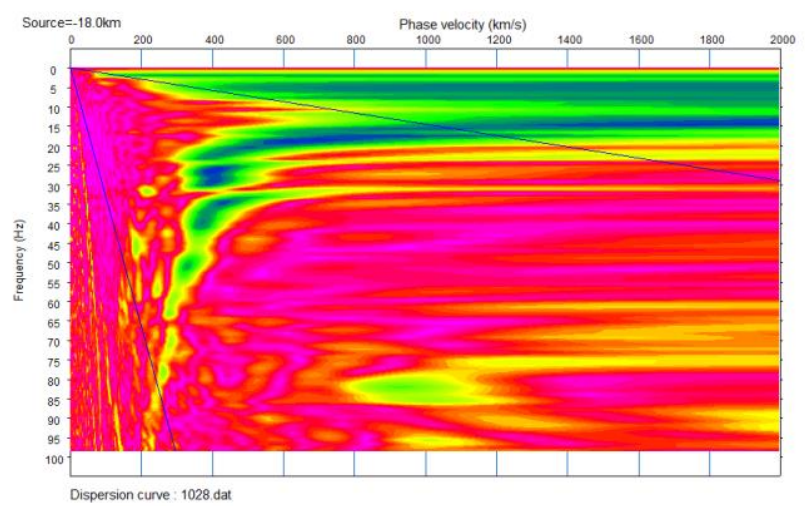

(b)

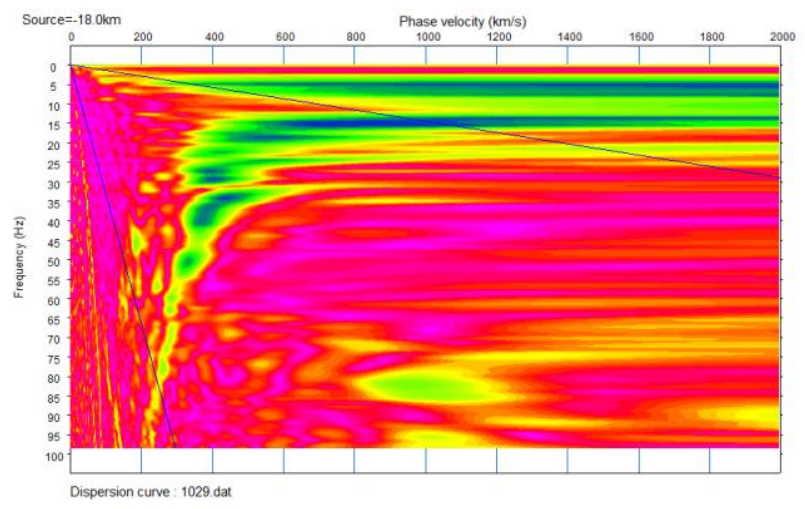

(c)

Fig. A-40: Dispersion images for the TA1 site generated using a $20 \mathrm{lb}$ sledgehammer located at $-12 \mathrm{dx}$ from the closest geophone: (a) Aluminum base plate; (b) Aluminum over EPDM rubber base plate; and (c) Ultra-high-molecular-weight polyethylene base plate. 


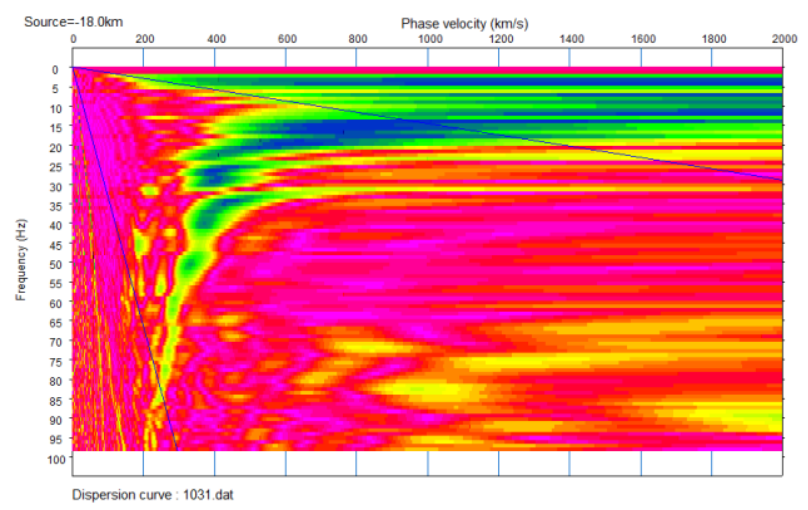

(a)

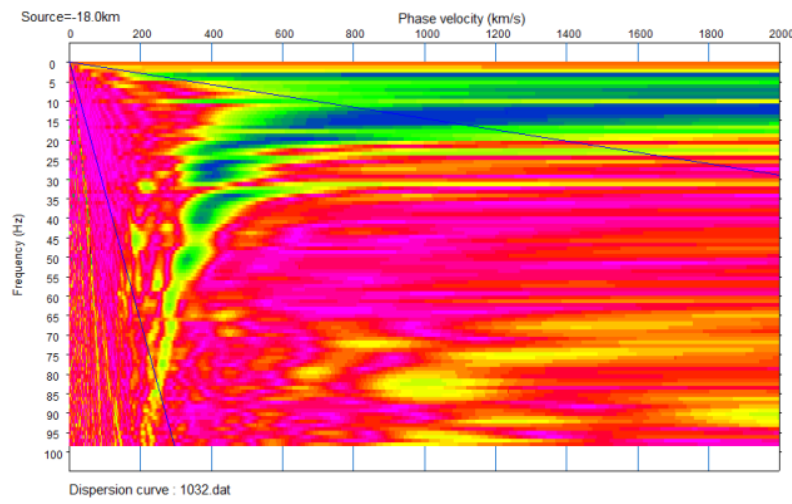

(b)

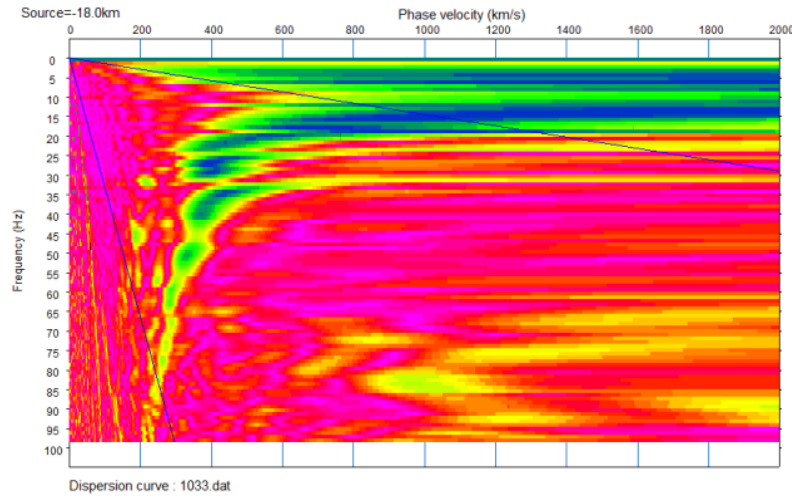

(c)

Fig. A-41: Dispersion images for the TA1 site generated using a $8 \mathrm{lb}$ sledgehammer located at $\mathbf{- 1 2 \mathrm { dx }}$ from the closest geophone: (a) Aluminum base plate; (b) Aluminum over EPDM rubber base plate; and (c) Ultra-high-molecular-weight polyethylene base plate. 


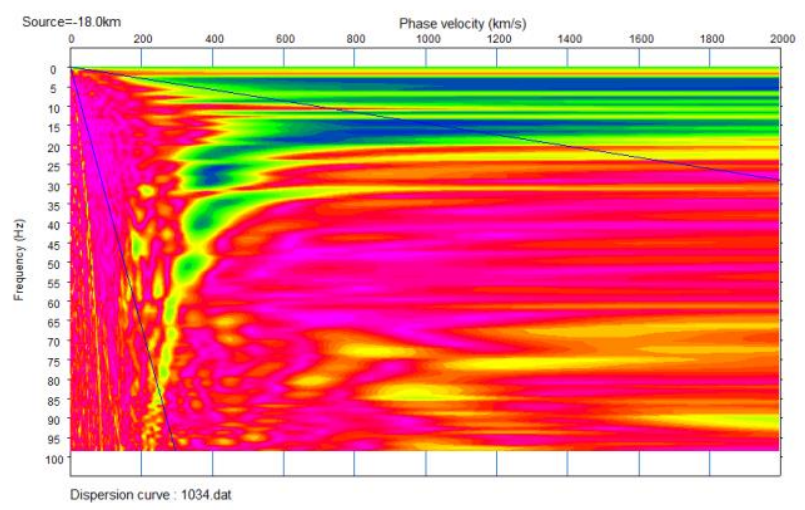

(a)

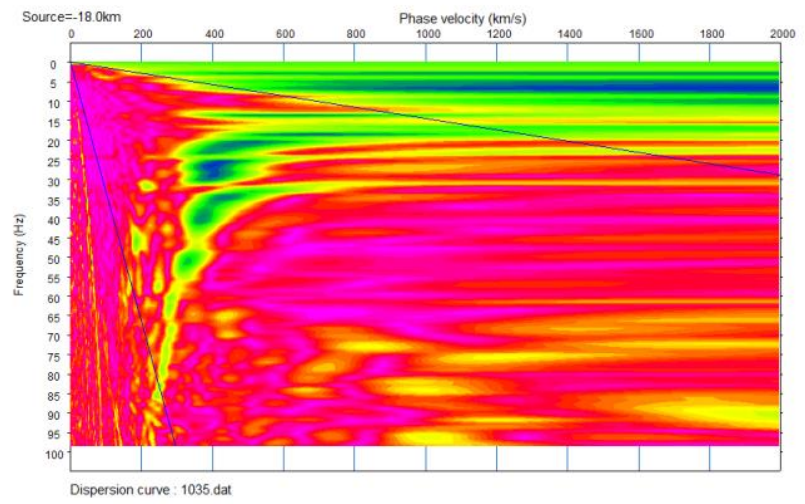

(b)

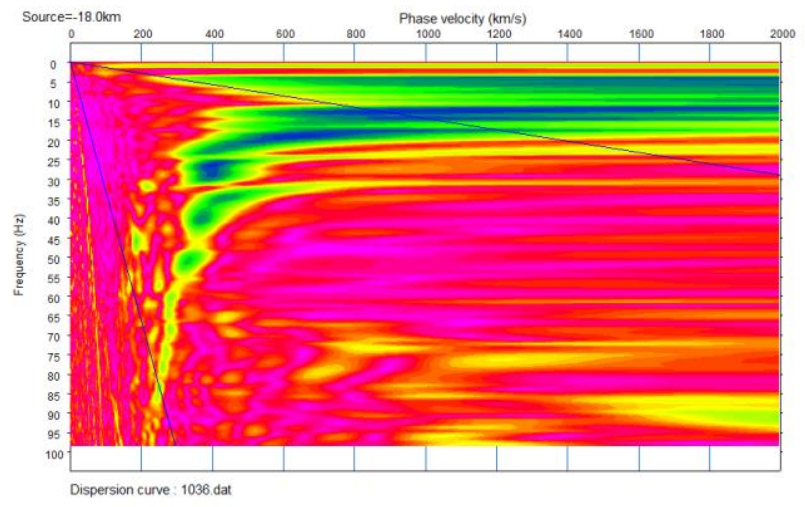

(c)

Fig. A-42: Dispersion images for the TA1 site generated using a $4 \mathrm{lb}$ sledgehammer located at $-12 \mathrm{dx}$ from the closest geophone: (a) Aluminum base plate; (b) Aluminum over EPDM rubber base plate; and (c) Ultra-high-molecular-weight polyethylene base plate. 


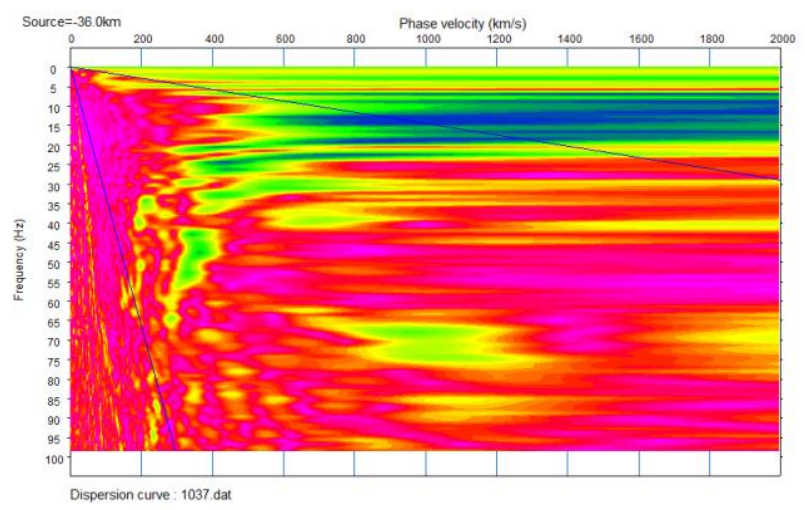

(a)

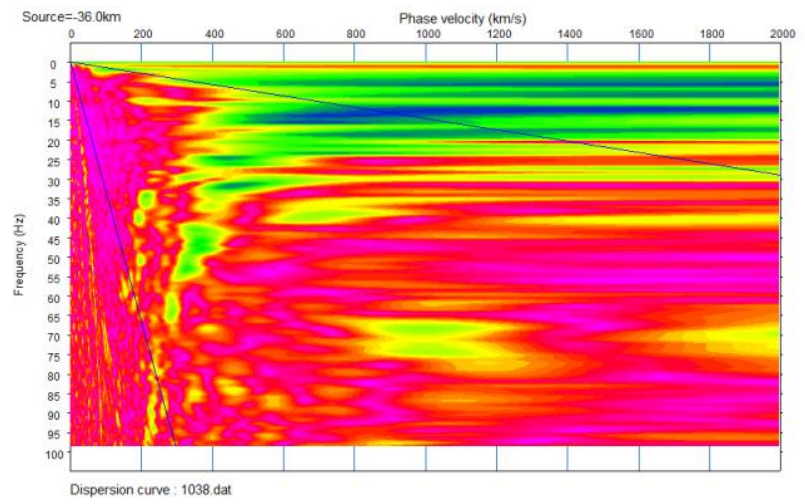

(b)

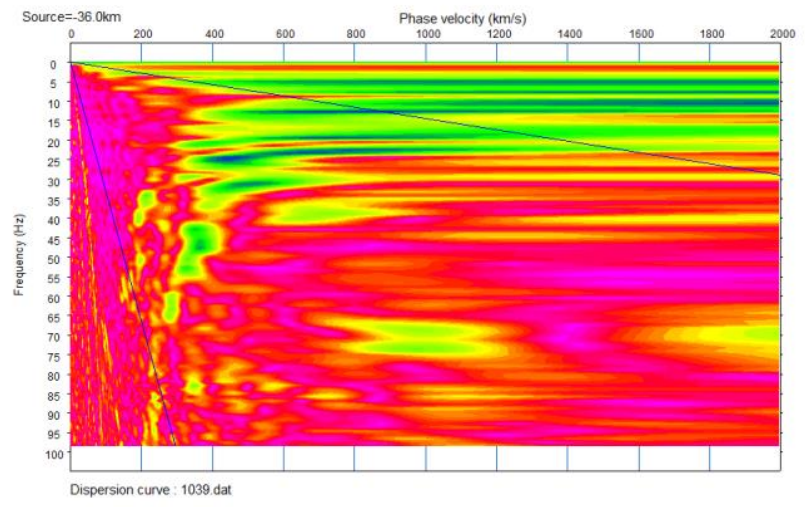

(c)

Fig. A-43: Dispersion images for the TA1 site generated using a $20 \mathrm{lb}$ sledgehammer located at $-24 \mathrm{dx}$ from the closest geophone: (a) Aluminum base plate; (b) Aluminum over EPDM rubber base plate; and (c) Ultra-high-molecular-weight polyethylene base plate. 


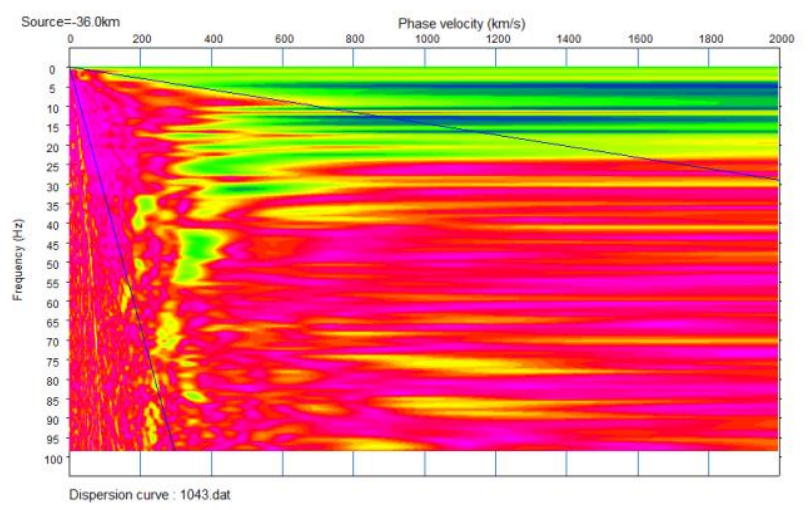

(a)

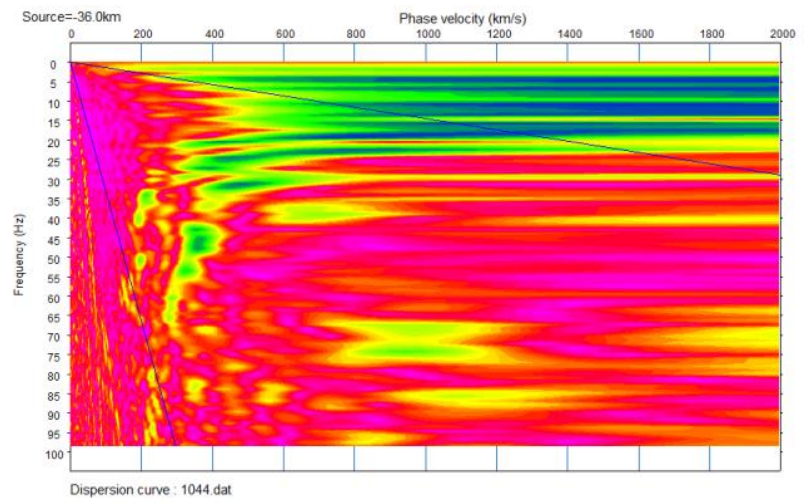

(b)

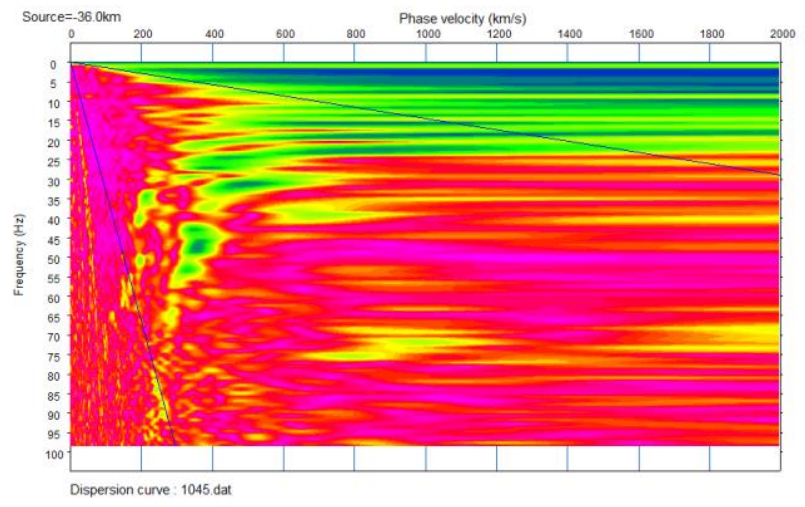

(c)

Fig. A-44: Dispersion images for the TA1 site generated using a $4 \mathrm{lb}$ sledgehammer located at $-24 \mathrm{dx}$ from the closest geophone: (a) Aluminum base plate; (b) Aluminum over EPDM rubber base plate; and (c) Ultra-high-molecular-weight polyethylene base plate. 


\section{APPENDIX A-5}

\section{DISPERSION IMAGES FROM TEMPLE TRACK FIELD \\ (TTF)}




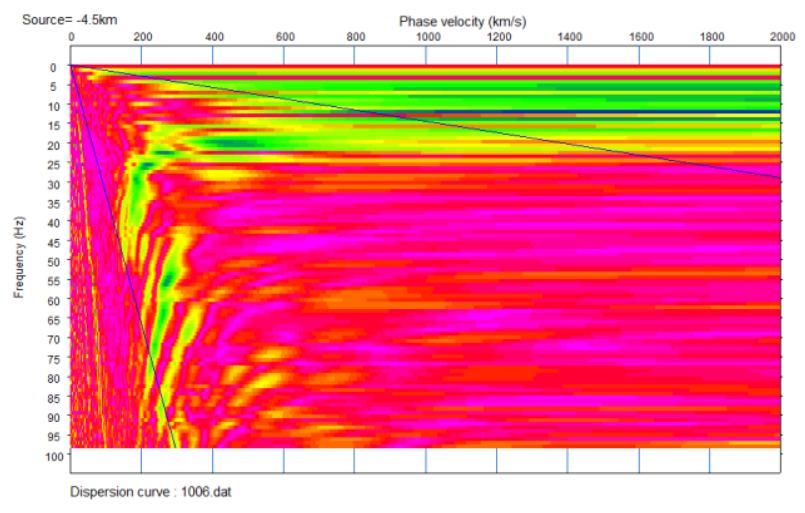

(a)

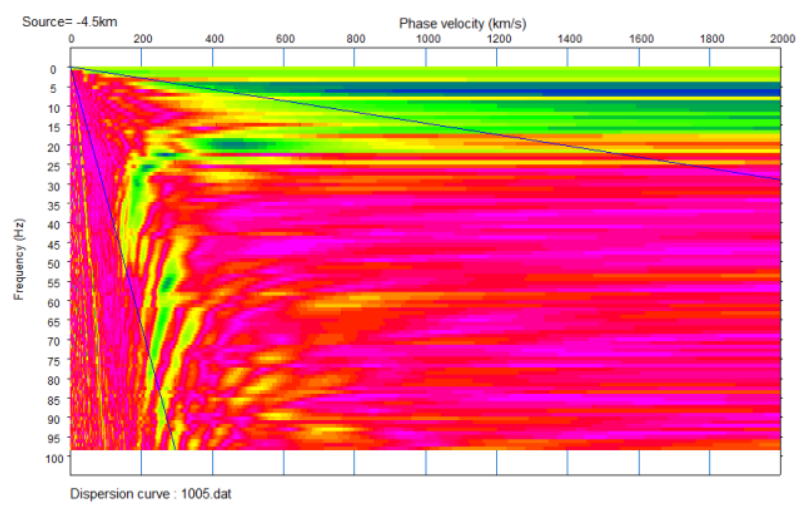

(b)

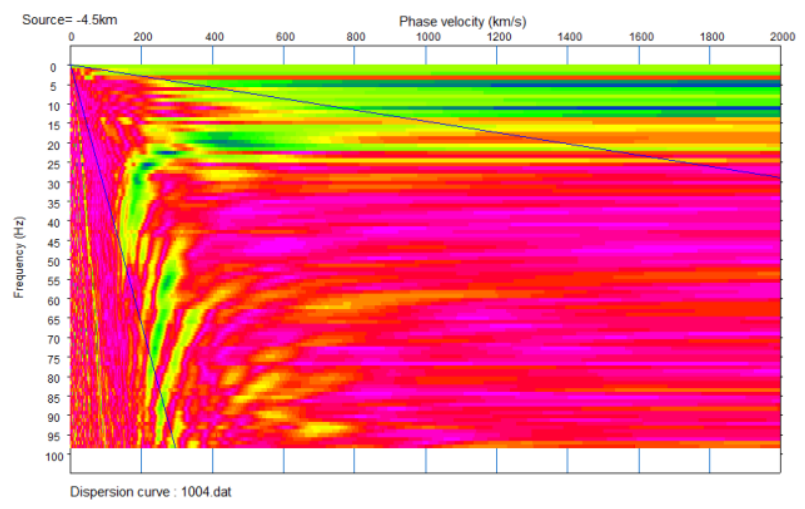

(c)

Fig. A-45: Dispersion images for the TTF site generated using a $20 \mathrm{lb}$ sledgehammer located at -3dx from the closest geophone: (a) Aluminum base plate; (b) Aluminum over EPDM rubber base plate; and (c) Ultra-high-molecular-weight polyethylene base plate. 


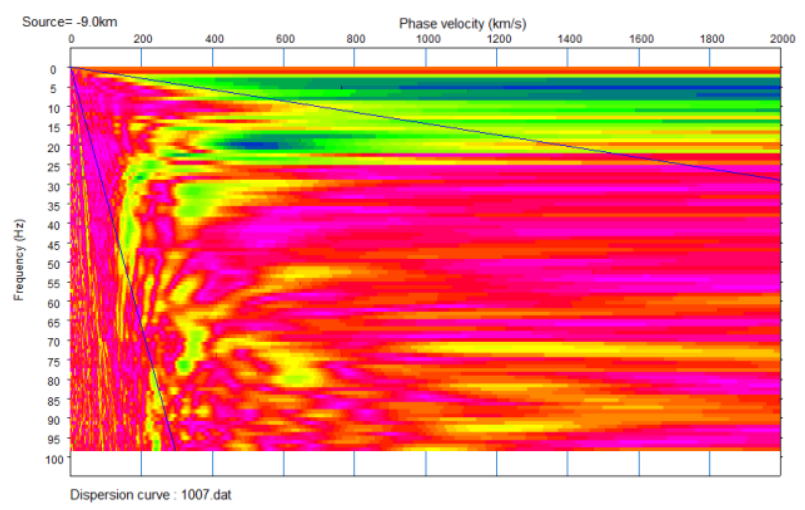

(a)

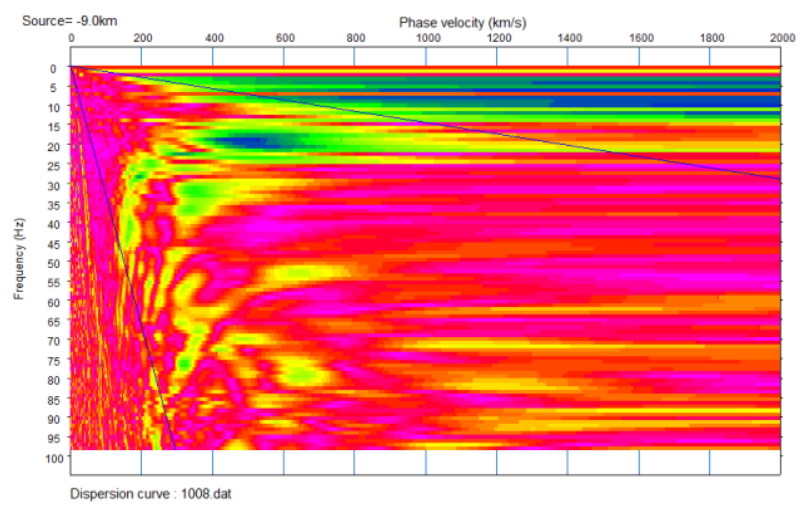

(b)

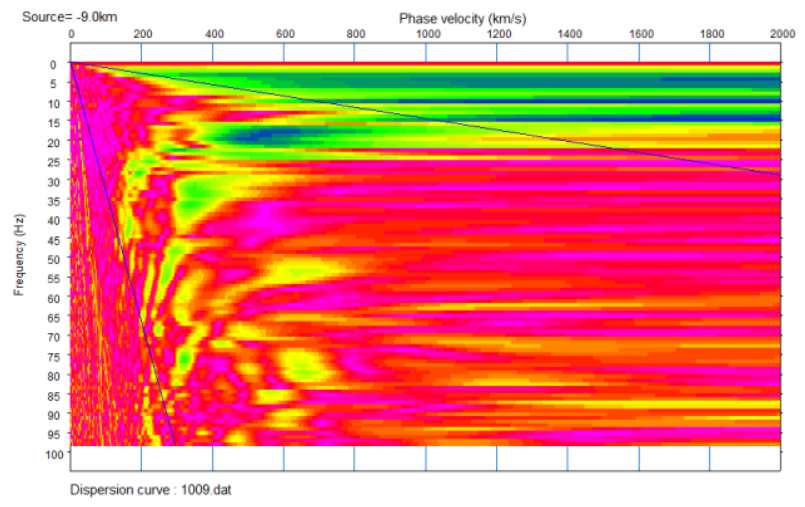

(c)

Fig. A-46: Dispersion images for the TTF site generated using a $20 \mathrm{lb}$ sledgehammer located at -6dx from the closest geophone: (a) Aluminum base plate; (b) Aluminum over EPDM rubber base plate; and (c) Ultra-high-molecular-weight polyethylene base plate. 


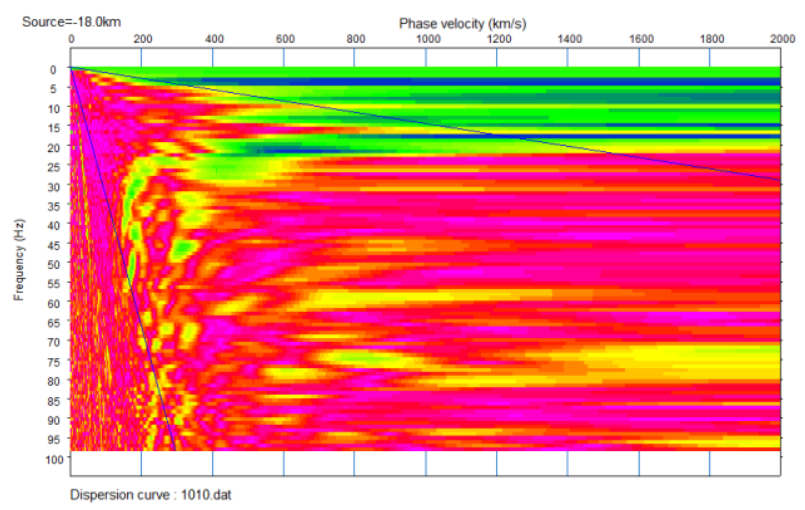

(a)

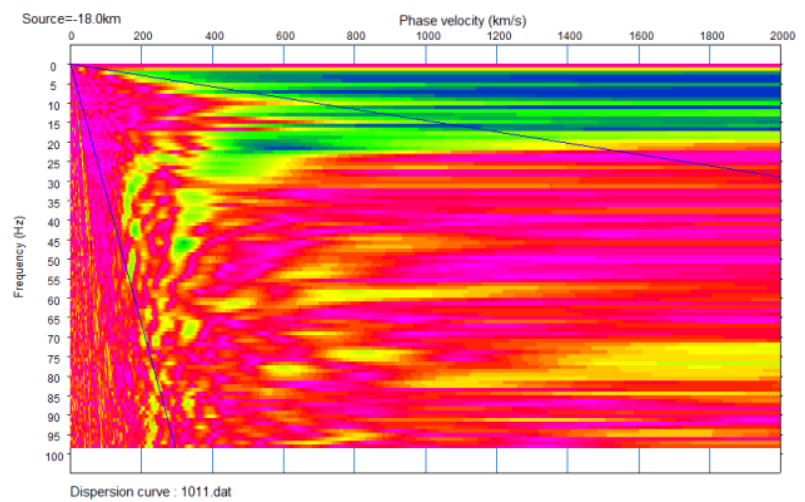

(b)

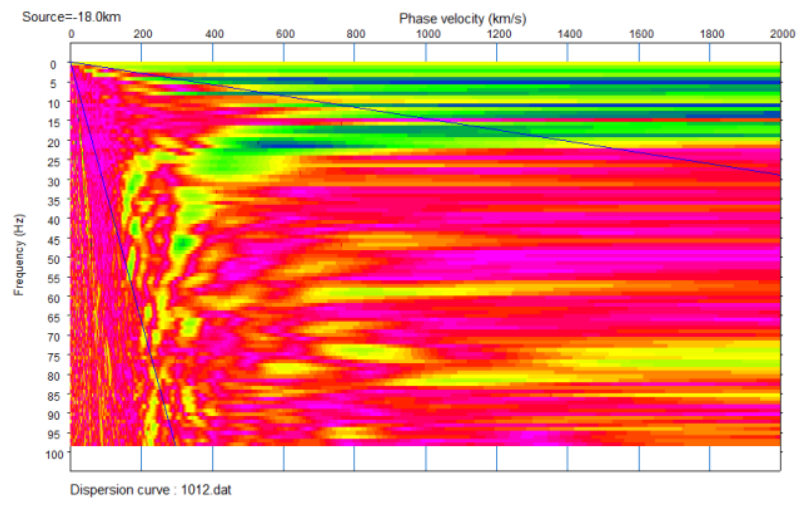

(c)

Fig. A-47: Dispersion images for the TTF site generated using a $20 \mathrm{lb}$ sledgehammer located at -12dx from the closest geophone: (a) Aluminum base plate; (b) Aluminum over EPDM rubber base plate; and (c) Ultra-high-molecular-weight polyethylene base plate. 


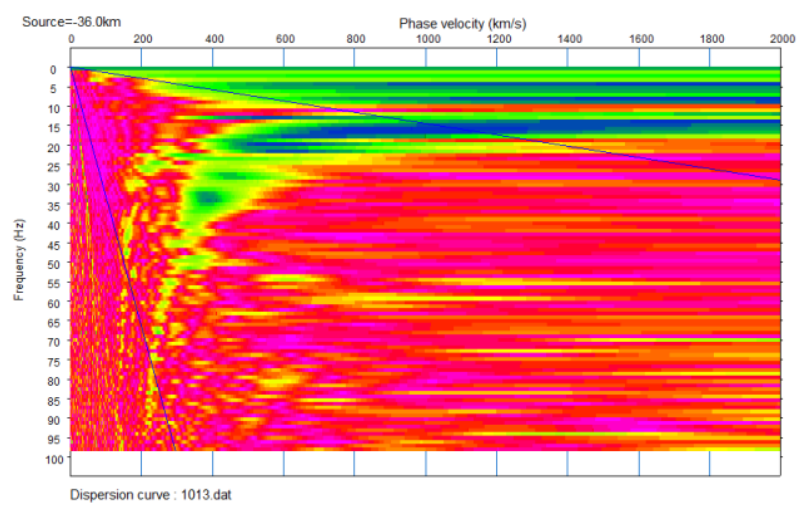

(a)

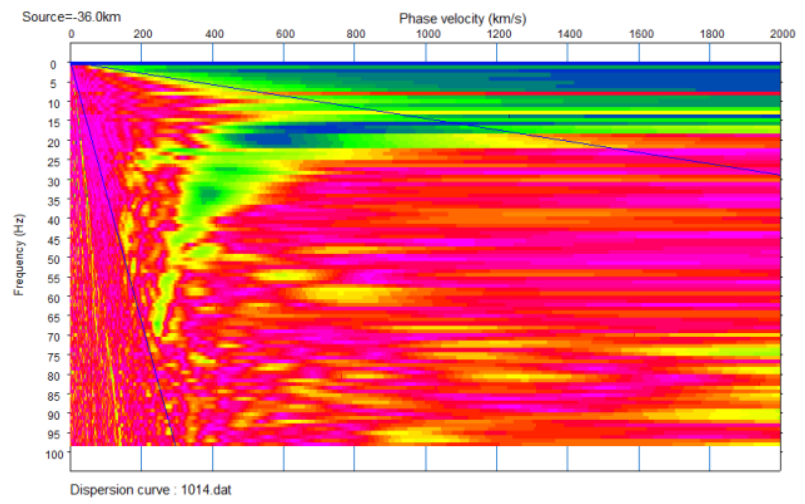

(b)

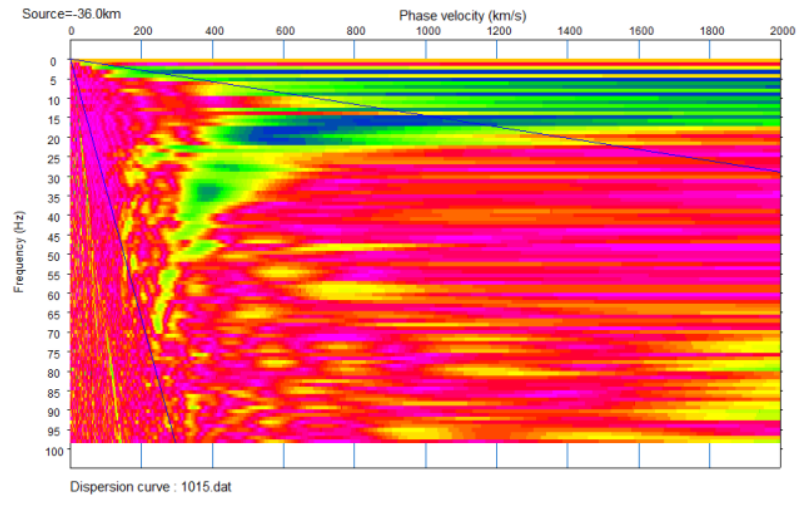

(c)

Fig. A-48: Dispersion images for the TTF site generated using a $20 \mathrm{lb}$ sledgehammer located at -24dx from the closest geophone: (a) Aluminum base plate; (b) Aluminum over EPDM rubber base plate; and (c) Ultra-high-molecular-weight polyethylene base plate. 


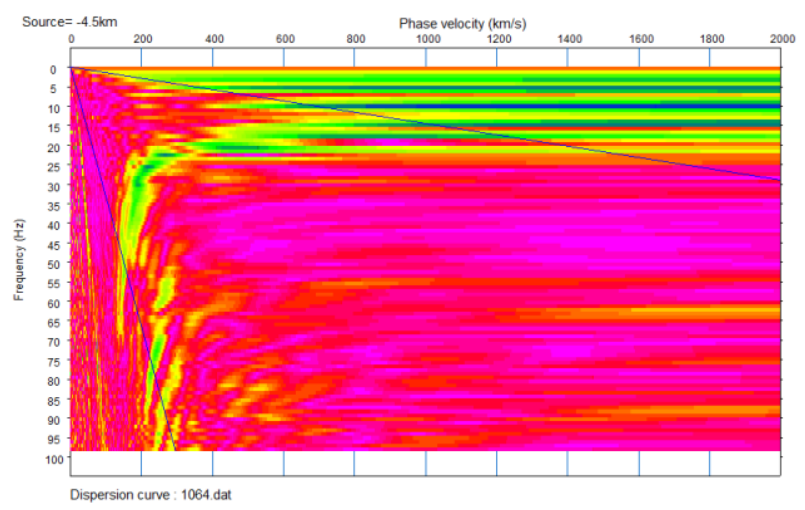

(a)

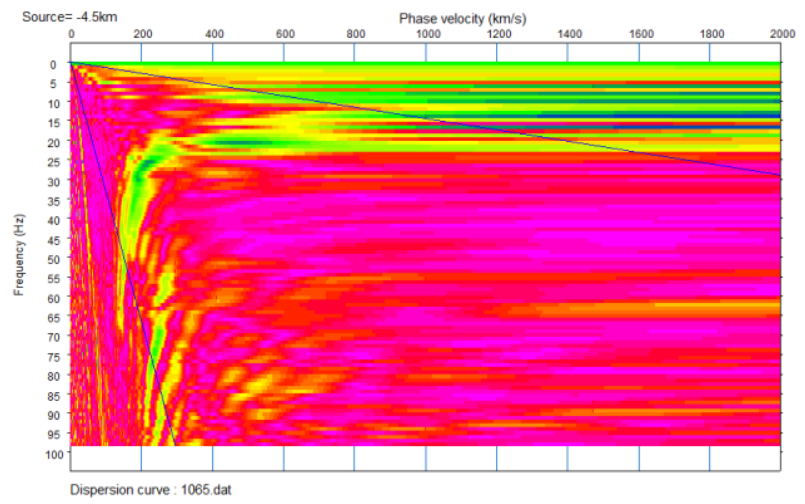

(b)

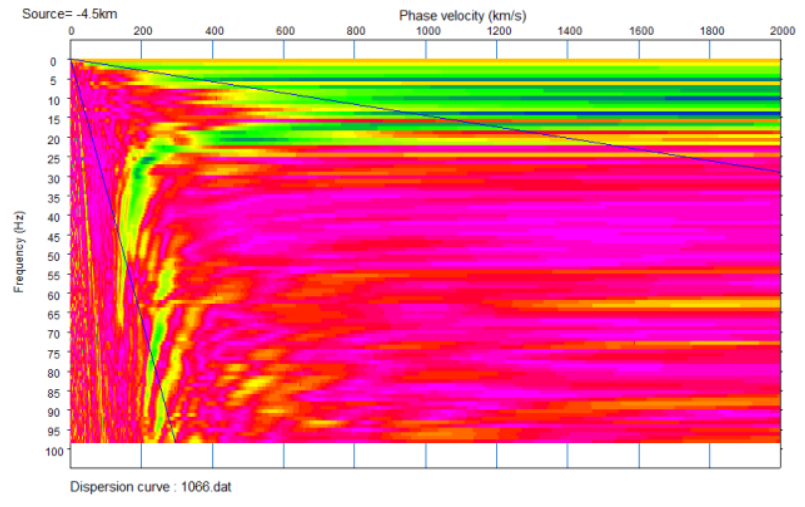

(c)

Fig. A-49: Dispersion images for the TTF site generated using a $4 \mathrm{lb}$ sledgehammer located at $-\mathbf{3 d x}$ from the closest geophone: (a) Aluminum base plate; (b) Aluminum over EPDM rubber base plate; and (c) Ultra-high-molecular-weight polyethylene base plate. 


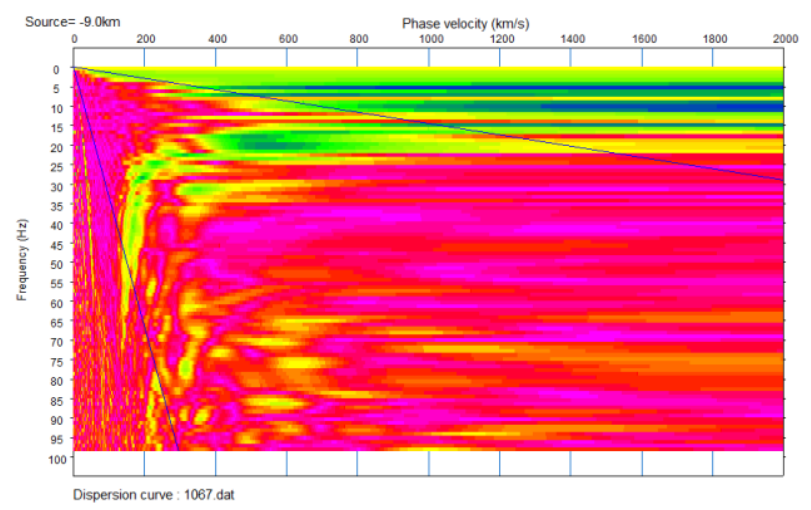

(a)

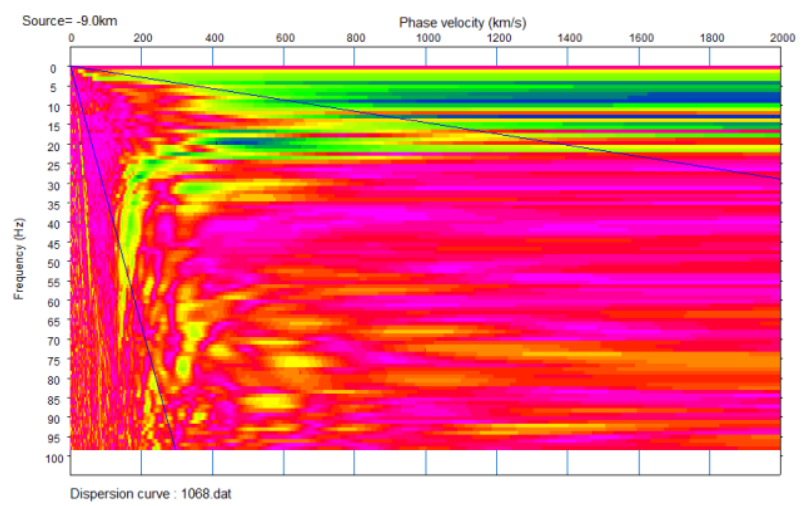

(b)

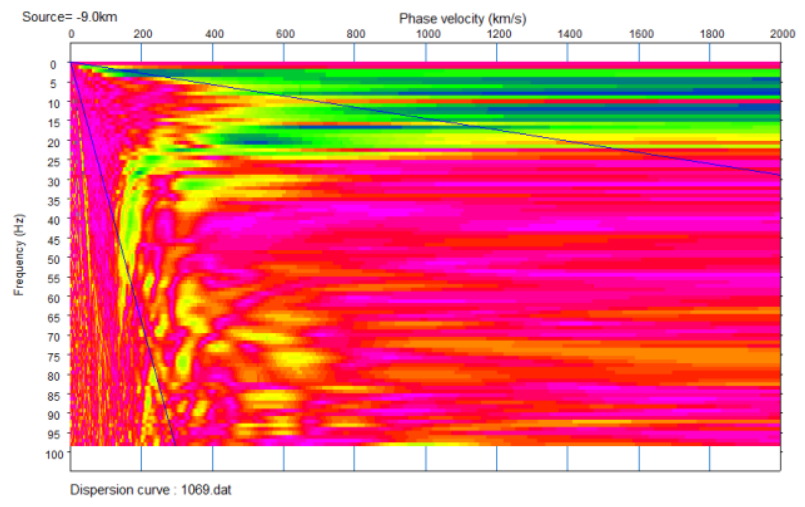

(c)

Fig. A-50: Dispersion images for the TTF site generated using a $4 \mathrm{lb}$ sledgehammer located at $-\mathbf{6 d x}$ from the closest geophone: (a) Aluminum base plate; (b) Aluminum over EPDM rubber base plate; and (c) Ultra-high-molecular-weight polyethylene base plate. 


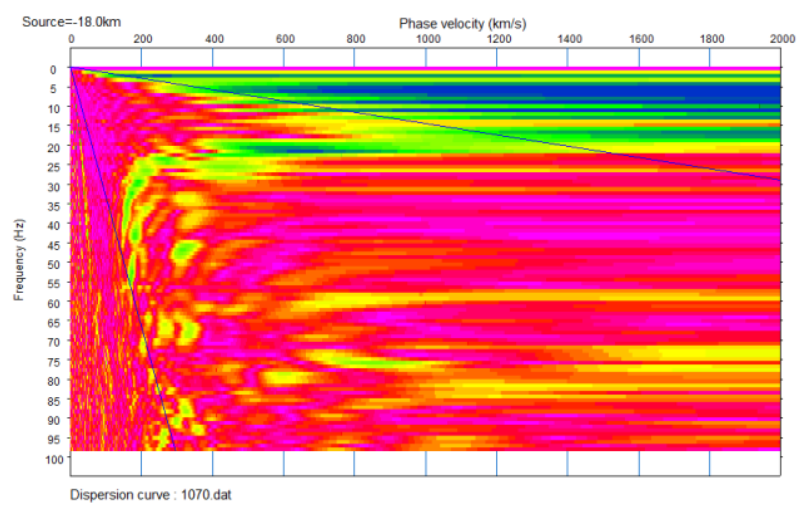

(a)

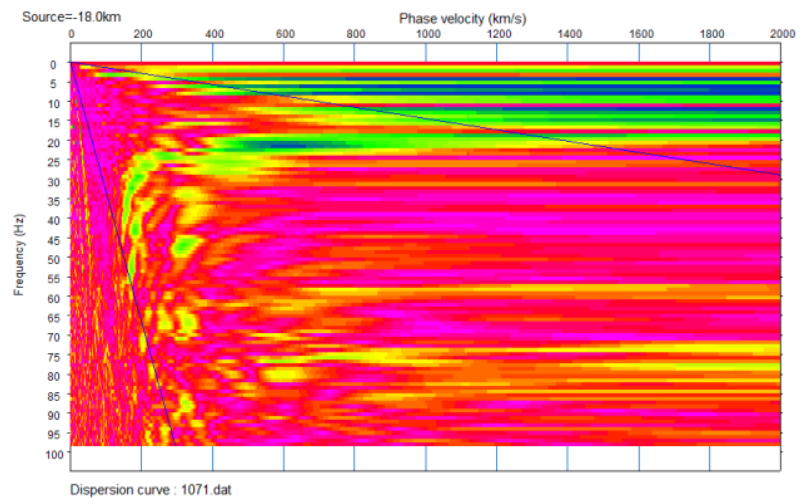

(b)

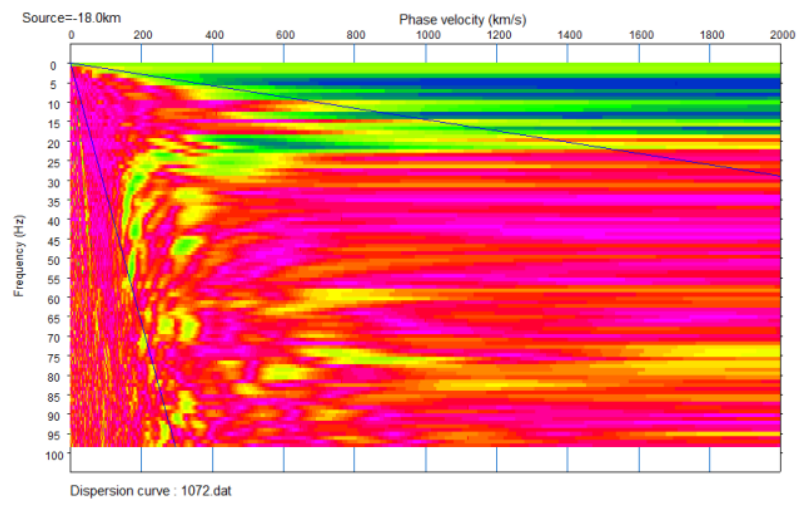

(c)

Fig. A-51: Dispersion images for the TTF site generated using a $4 \mathrm{lb}$ sledgehammer located at $-12 \mathrm{dx}$ from the closest geophone: (a) Aluminum base plate; (b) Aluminum over EPDM rubber base plate; and (c) Ultra-high-molecular-weight polyethylene base plate. 


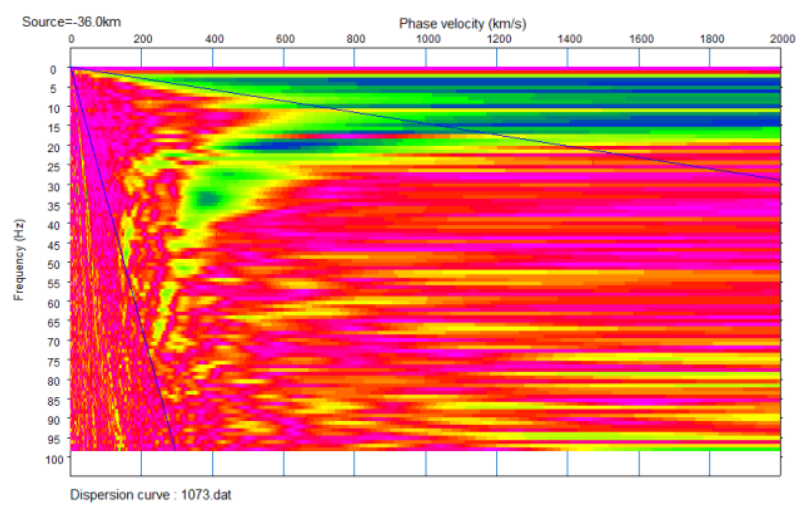

(a)

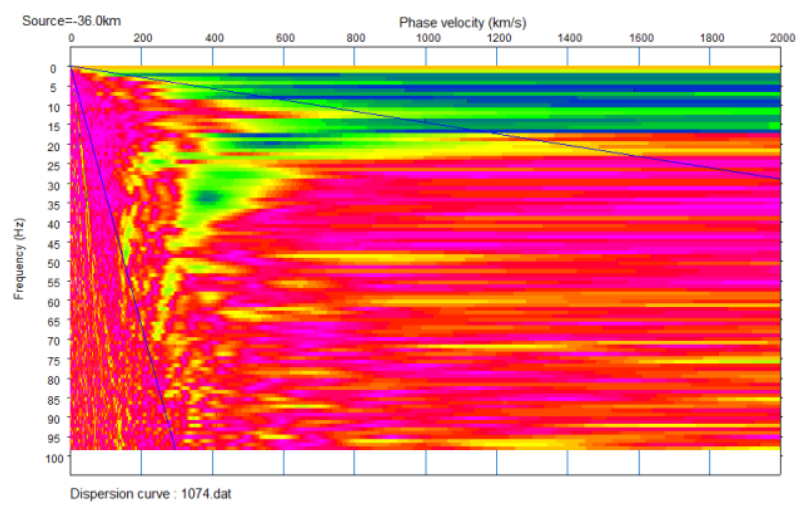

(b)

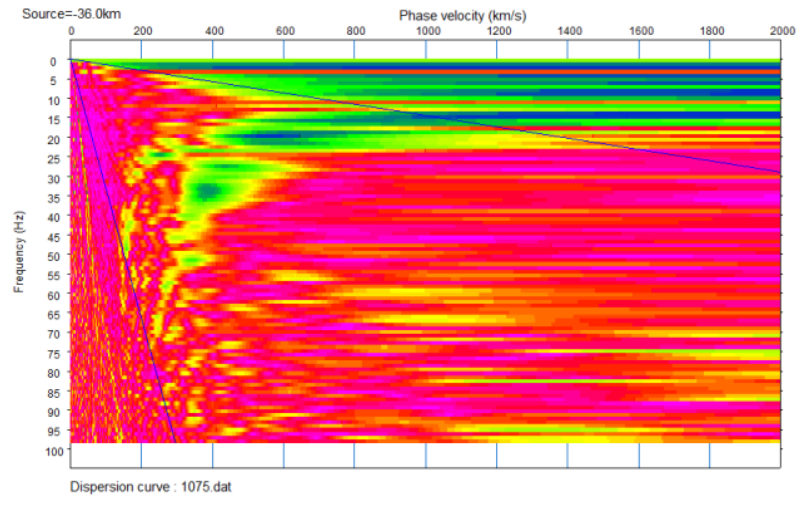

(c)

Fig. A-52: Dispersion images for the TTF site generated using a $4 \mathrm{lb}$ sledgehammer located at -24dx from the closest geophone: (a) Aluminum base plate; (b) Aluminum over EPDM rubber base plate; and (c) Ultra-high-molecular-weight polyethylene base plate. 


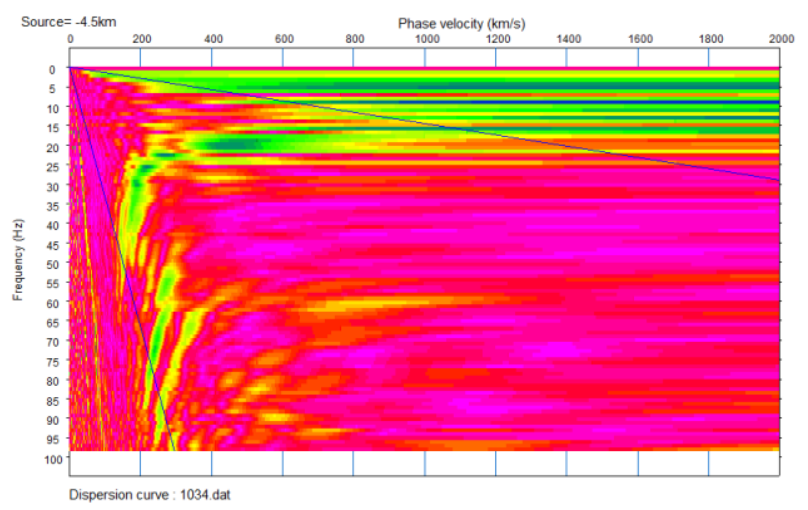

(a)

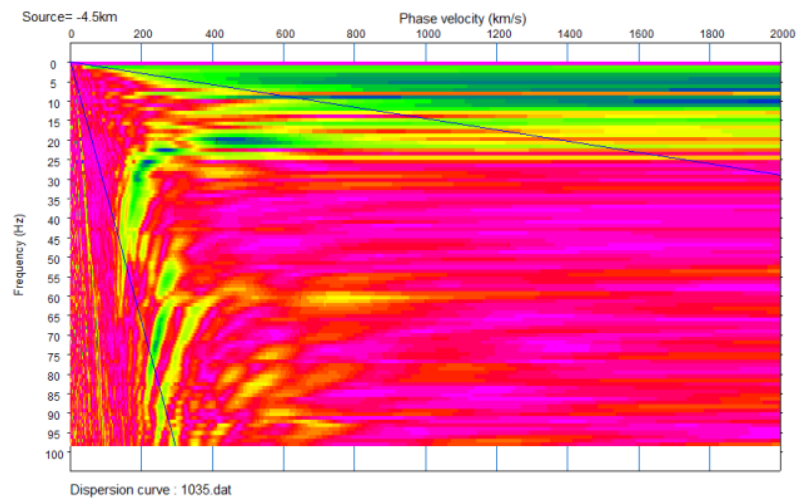

(b)

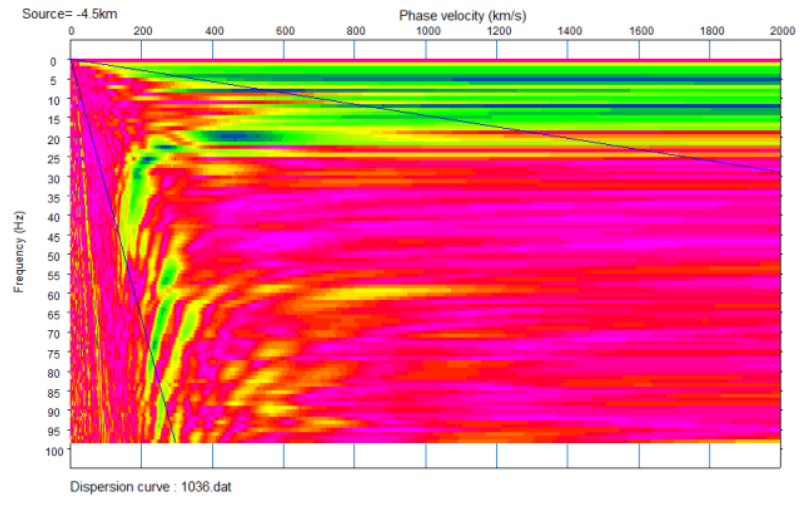

(c)

Fig. A-53: Dispersion images for the TTF site generated using a 8 lb sledgehammer located at -3dx from the closest geophone: (a) Aluminum base plate; (b) Aluminum over EPDM rubber base plate; and (c) Ultra-high-molecular-weight polyethylene base plate. 


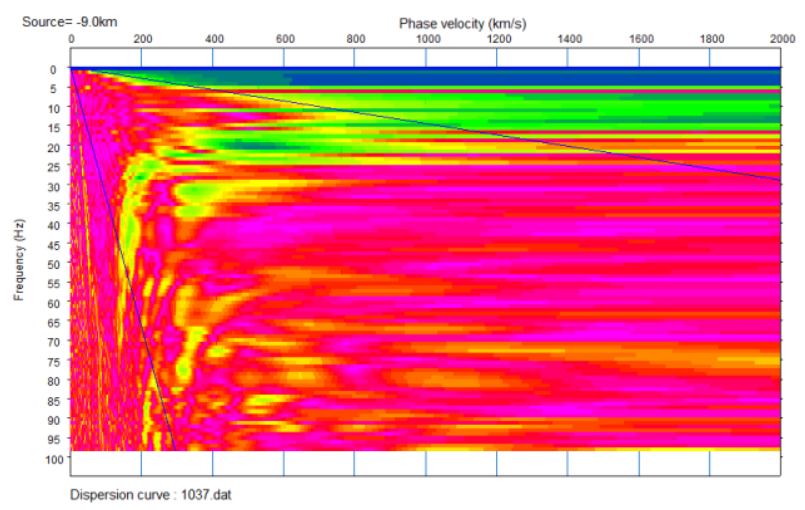

(a)

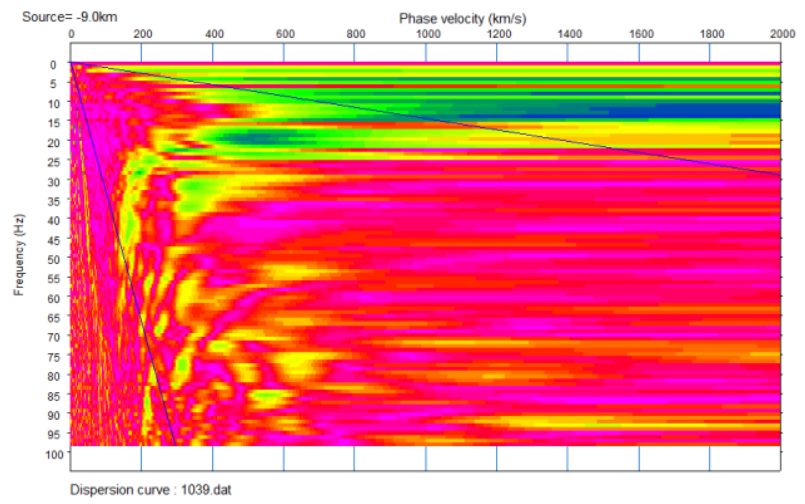

(b)

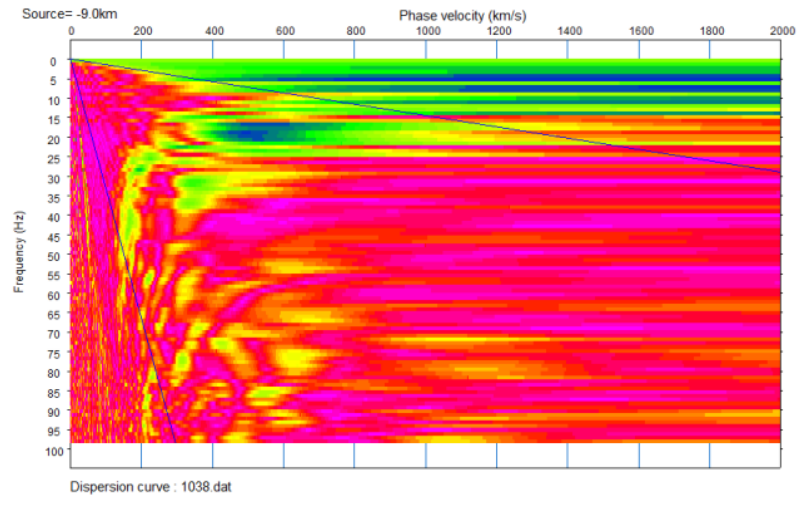

(c)

Fig. A-54: Dispersion images for the TTF site generated using a 8 lb sledgehammer located at -6dx from the closest geophone: (a) Aluminum base plate; (b) Aluminum over EPDM rubber base plate; and (c) Ultra-high-molecular-weight polyethylene base plate. 


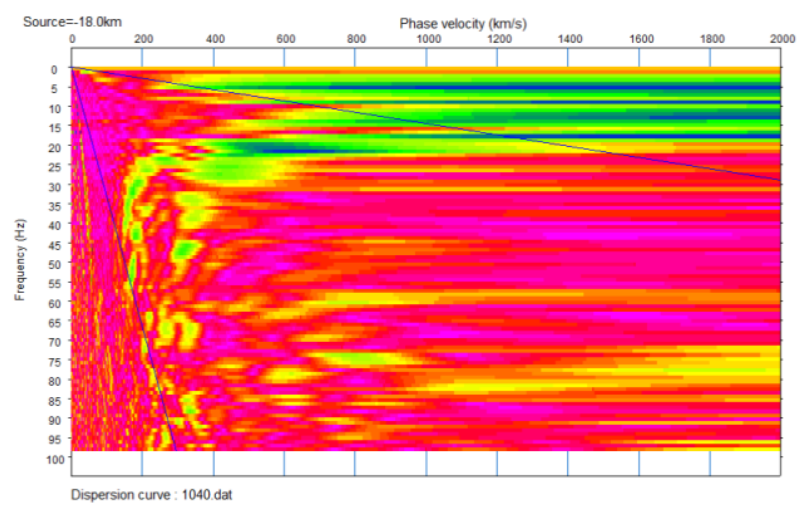

(a)

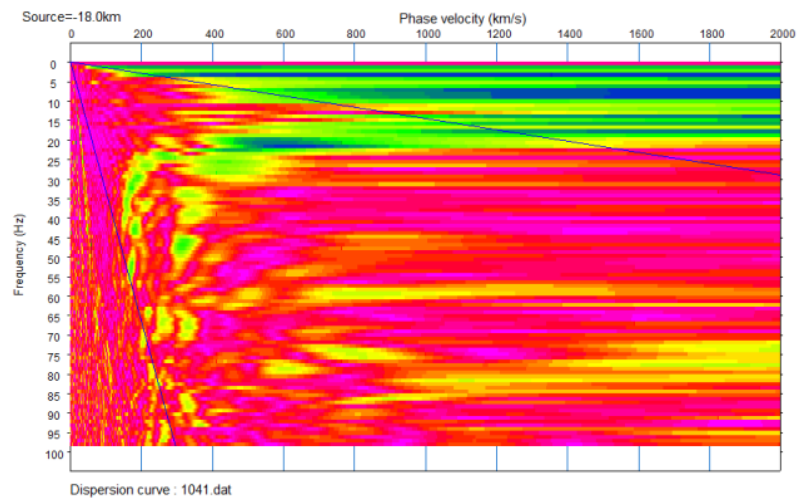

(b)

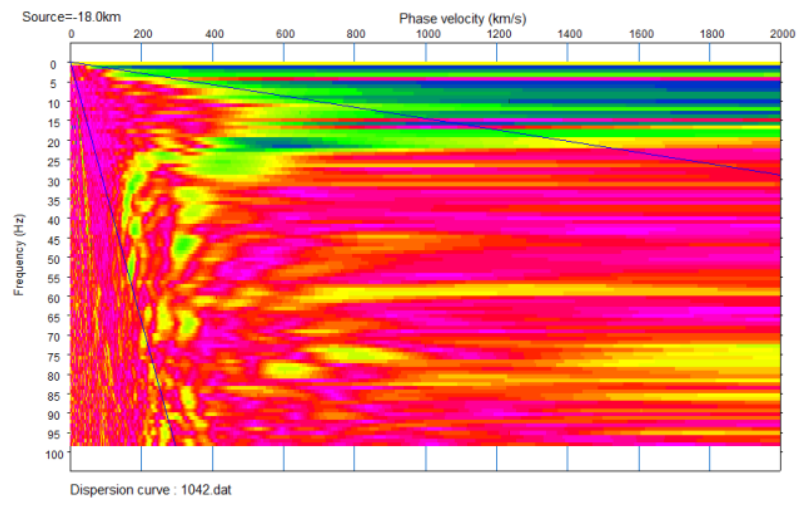

(c)

Fig. A-55: Dispersion images for the TTF site generated using a $8 \mathrm{lb}$ sledgehammer located at $\mathbf{- 1 2 \mathrm { dx }}$ from the closest geophone: (a) Aluminum base plate; (b) Aluminum over EPDM rubber base plate; and (c) Ultra-high-molecular-weight polyethylene base plate. 
APPENDIX A-6

DISPERSION IMAGES FROM PENN TREATY PARK (PTP) 


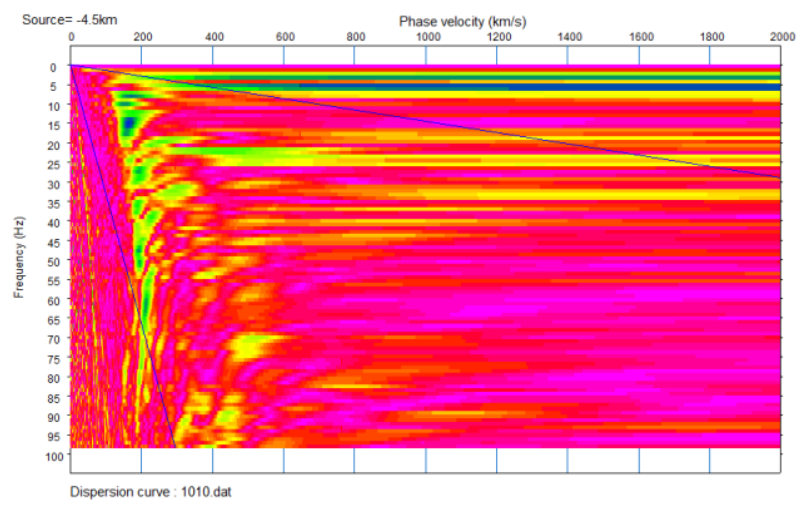

(a)

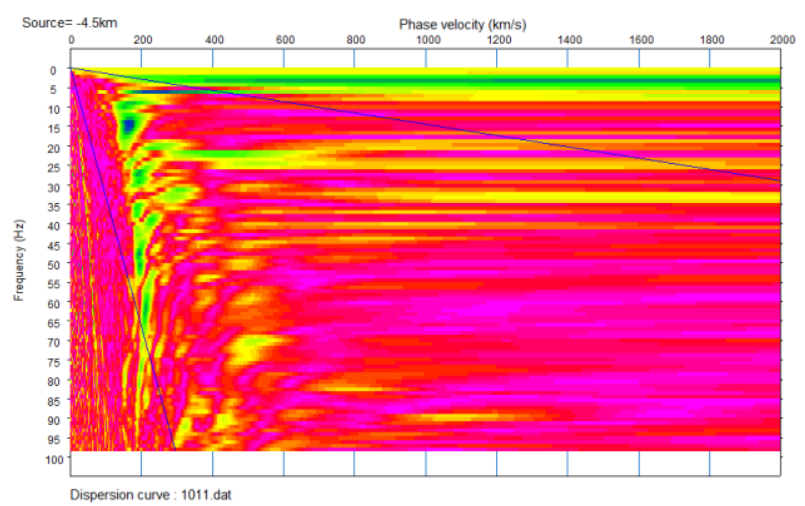

(b)

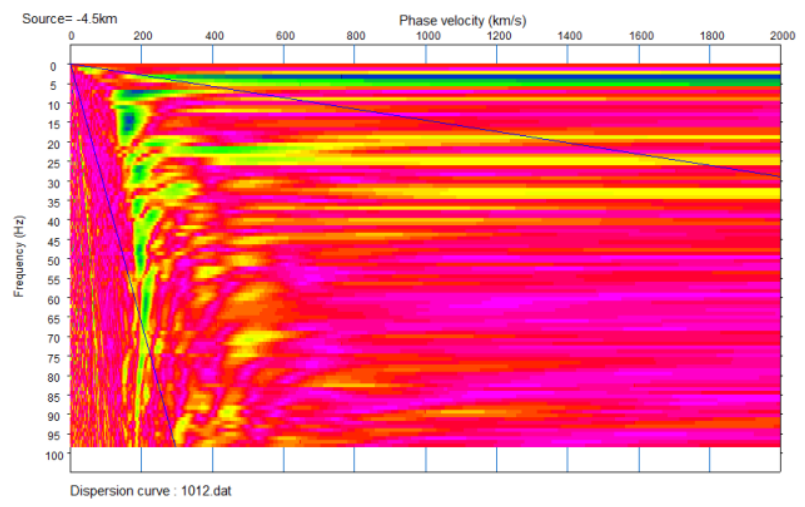

(c)

Fig. A-56: Dispersion images for the PTP site generated using a $20 \mathrm{lb}$ sledgehammer located at -3dx from the closest geophone: (a) Aluminum base plate; (b) Aluminum over EPDM rubber base plate; and (c) Ultra-high-molecular-weight polyethylene base plate. 


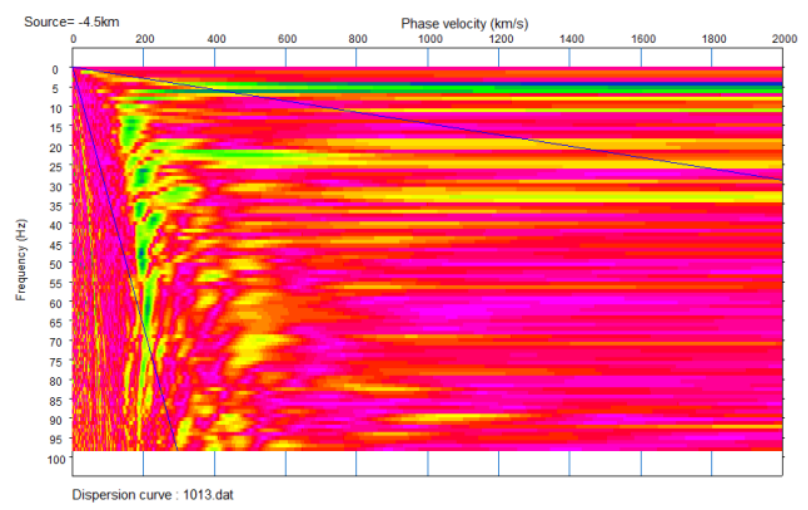

(a)

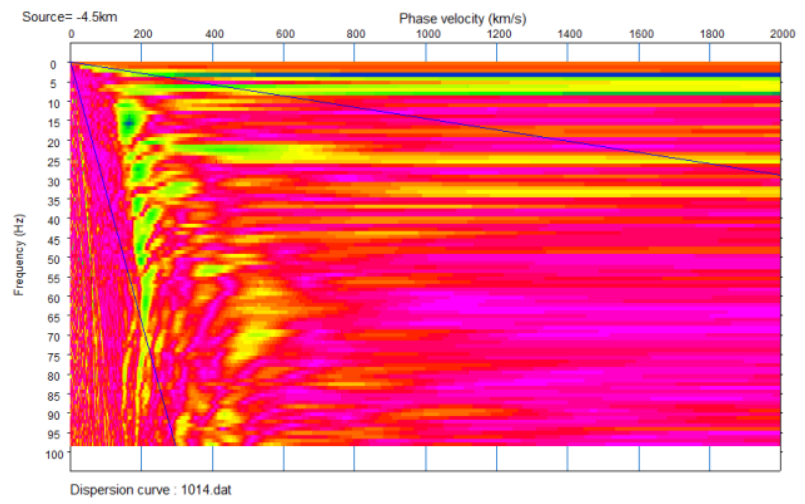

(b)

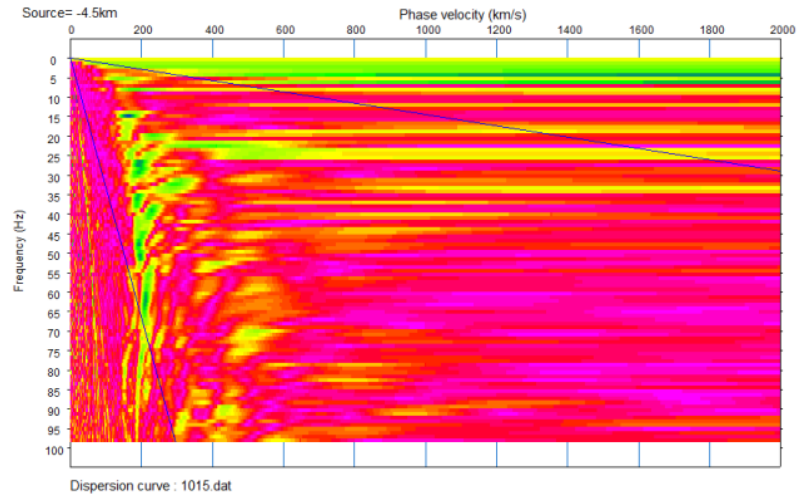

(c)

Fig. A-57: Dispersion images for the PTP site generated using a 8 lb sledgehammer located at $-\mathbf{3 d x}$ from the closest geophone: (a) Aluminum base plate; (b) Aluminum over EPDM rubber base plate; and (c) Ultra-high-molecular-weight polyethylene base plate. 


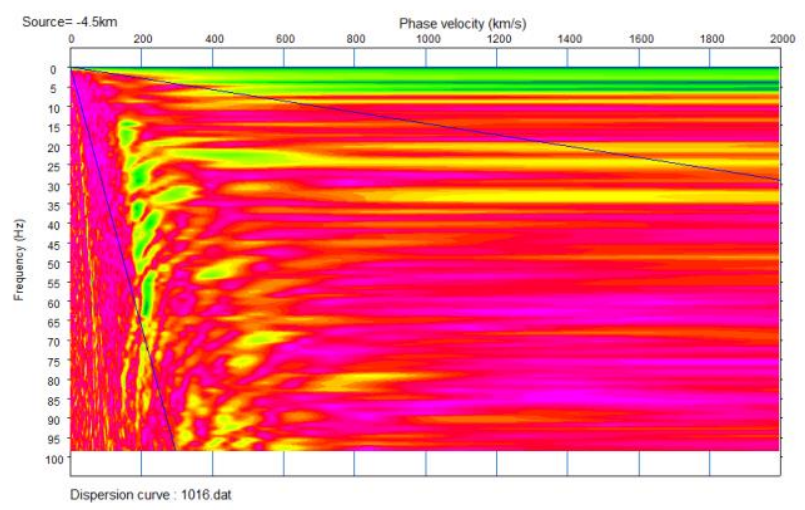

(a)

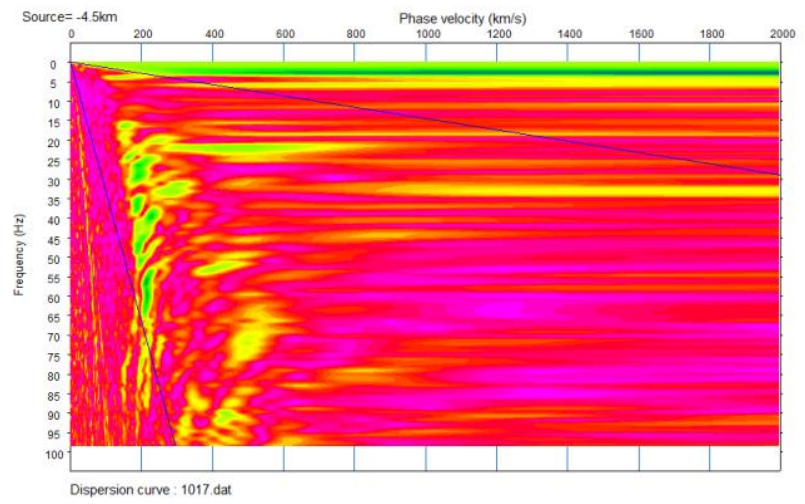

(b)

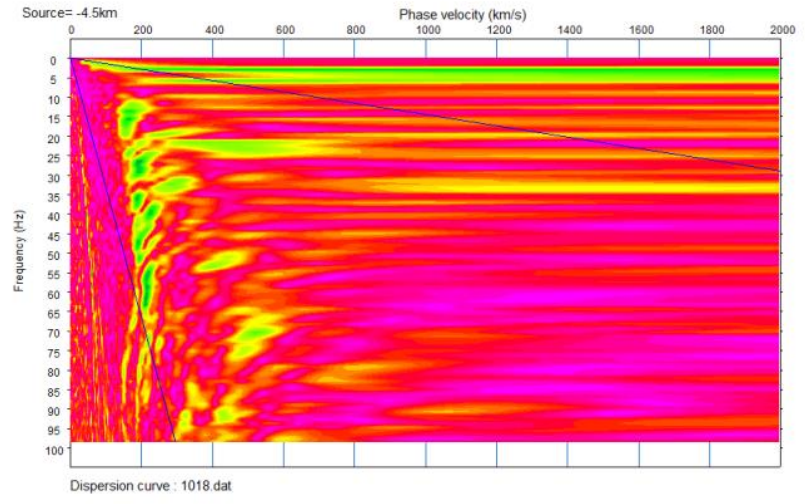

(c)

Fig. A-58: Dispersion images for the PTP site generated using a $4 \mathrm{lb}$ sledgehammer located at $-\mathbf{3 d x}$ from the closest geophone: (a) Aluminum base plate; (b) Aluminum over EPDM rubber base plate; and (c) Ultra-high-molecular-weight polyethylene base plate. 


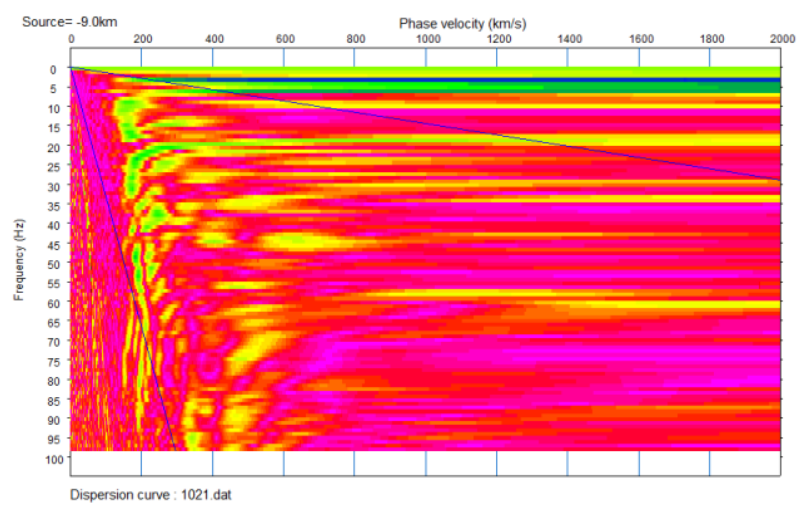

(a)

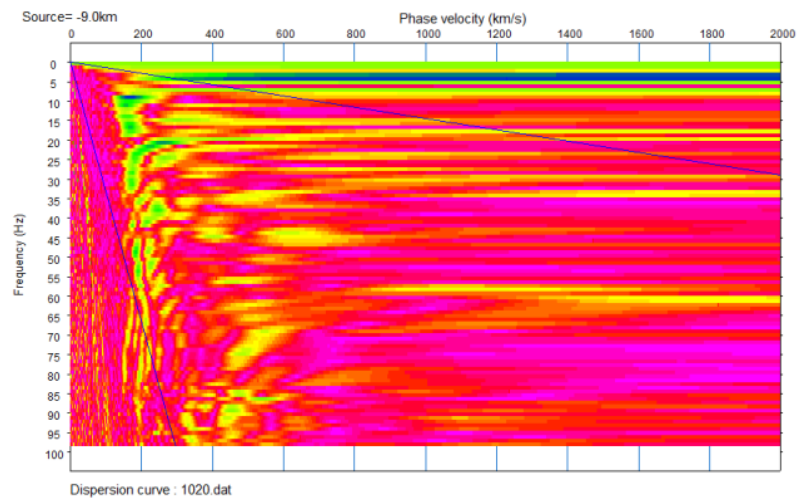

(b)

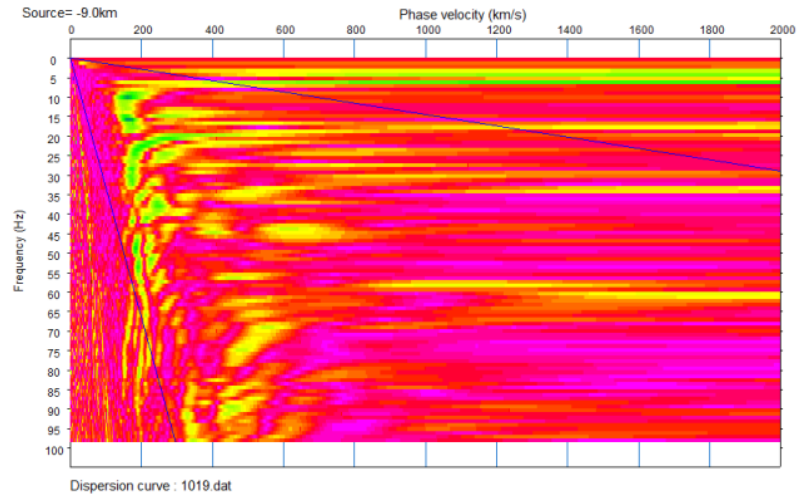

(c)

Fig. A-59: Dispersion images for the PTP site generated using a 20 lb sledgehammer located at -6dx from the closest geophone: (a) Aluminum base plate; (b) Aluminum over EPDM rubber base plate; and (c) Ultra-high-molecular-weight polyethylene base plate. 


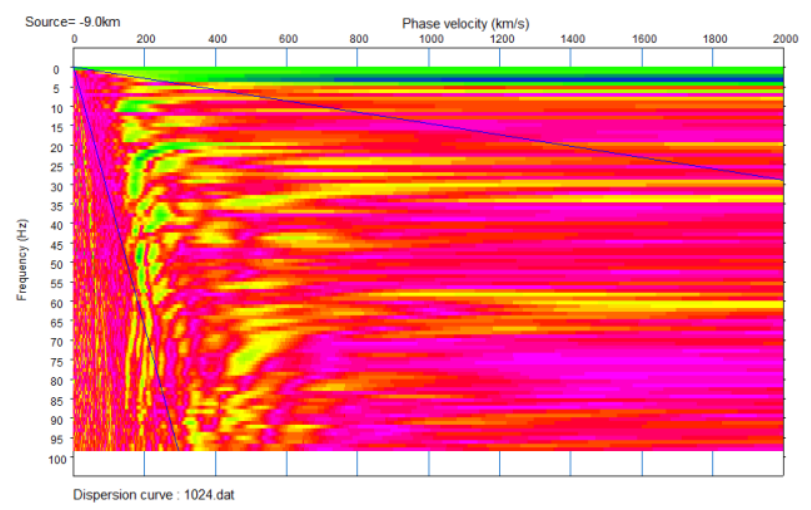

(a)

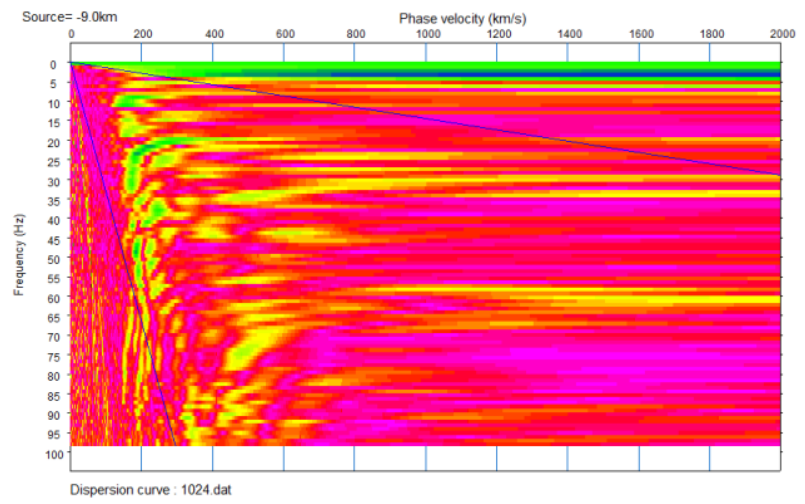

(b)

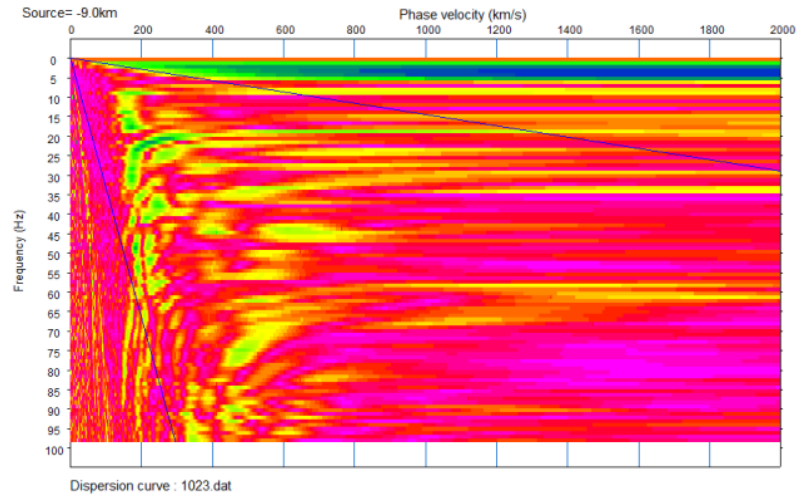

(c)

Fig. A-60: Dispersion images for the PTP site generated using a $8 \mathrm{lb}$ sledgehammer located at $-6 \mathrm{dx}$ from the closest geophone: (a) Aluminum base plate; (b) Aluminum over EPDM rubber base plate; and (c) Ultra-high-molecular-weight polyethylene base plate. 


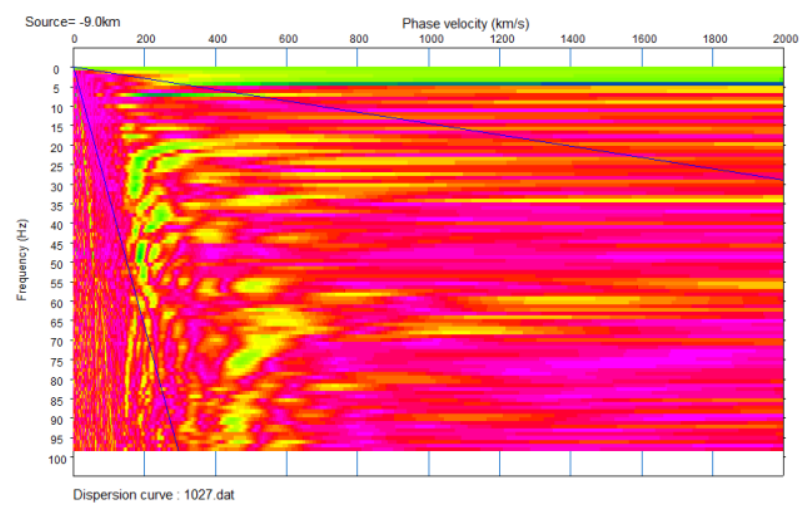

(a)

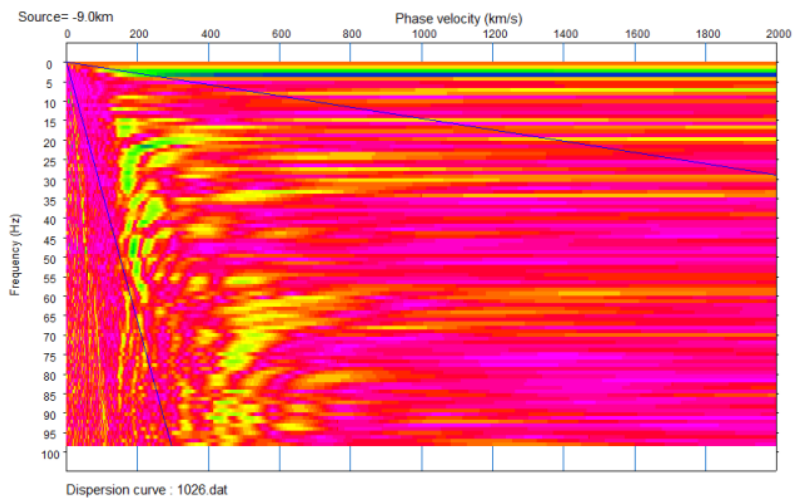

(b)

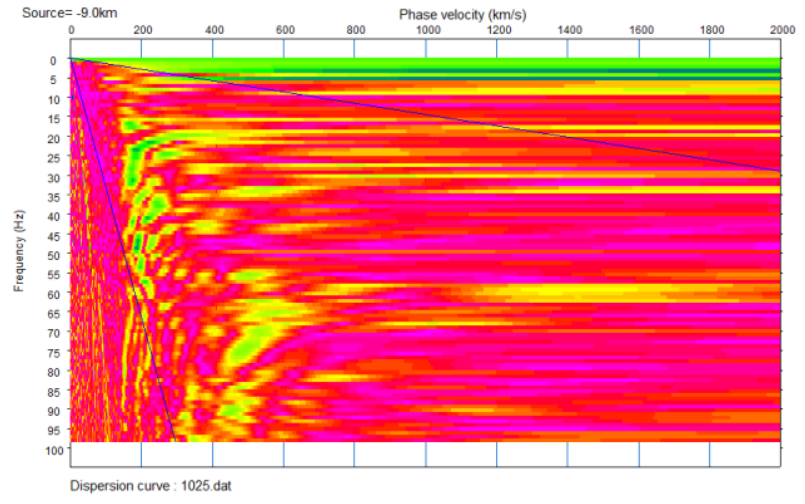

(c)

Fig. A-61: Dispersion images for the PTP site generated using a $4 \mathrm{lb}$ sledgehammer located at -6dx from the closest geophone: (a) Aluminum base plate; (b) Aluminum over EPDM rubber base plate; and (c) Ultra-high-molecular-weight polyethylene base plate. 


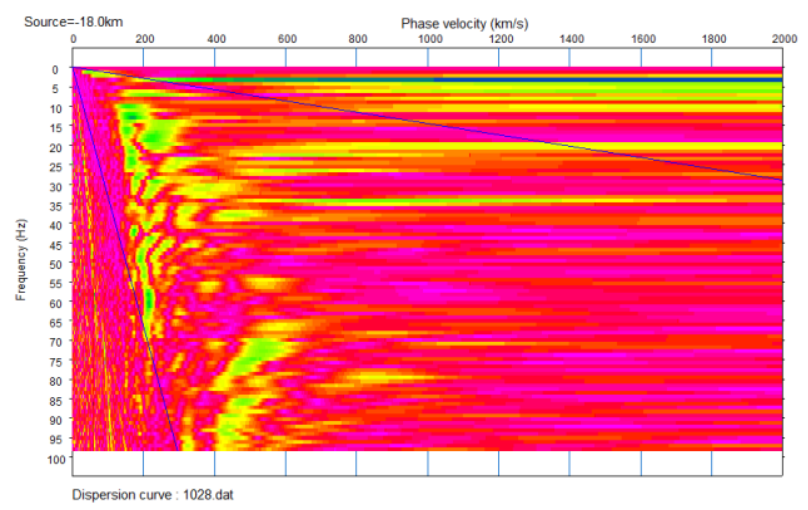

(a)

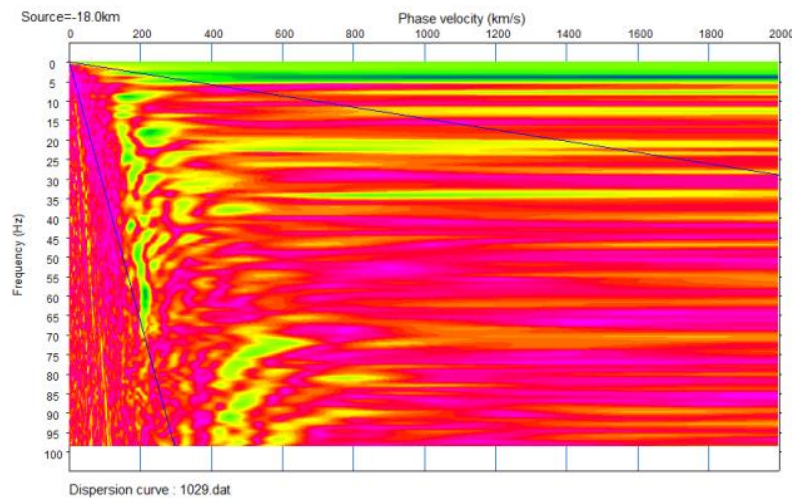

(b)

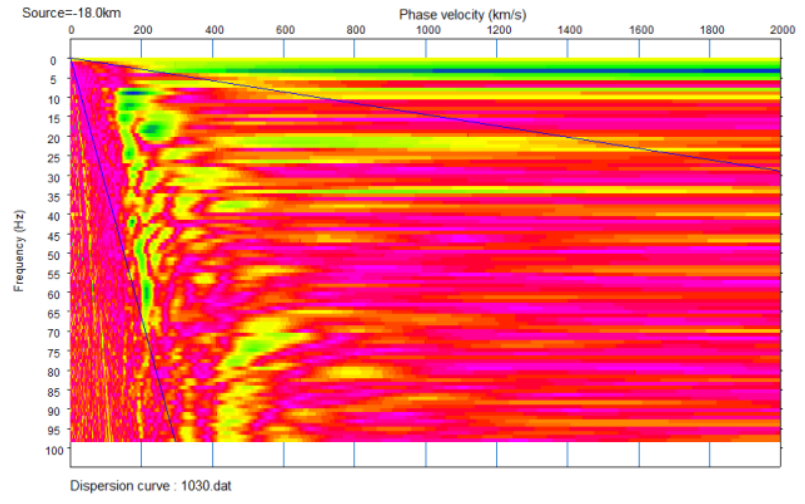

(c)

Fig. A-62: Dispersion images for the PTP site generated using a $20 \mathrm{lb}$ sledgehammer located at -12dx from the closest geophone: (a) Aluminum base plate; (b) Aluminum over EPDM rubber base plate; and (c) Ultra-high-molecular-weight polyethylene base plate. 


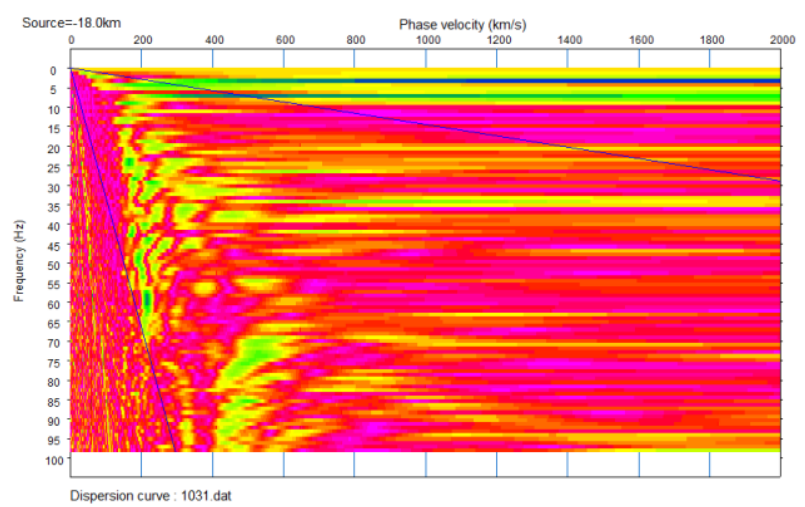

(a)

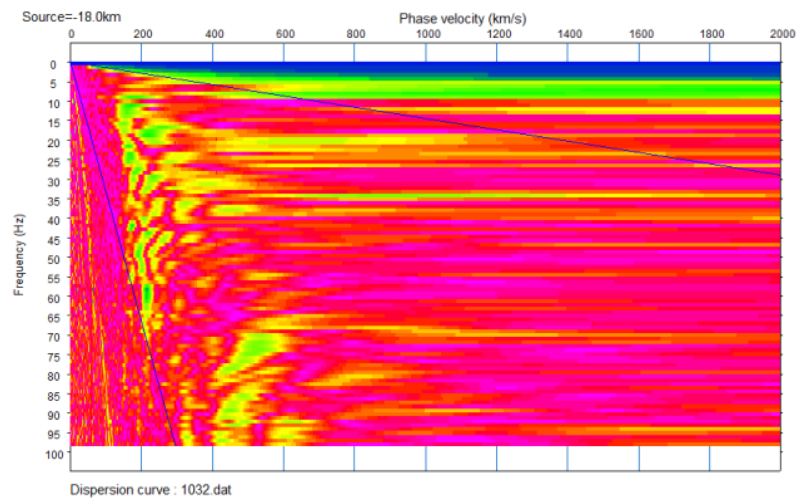

(b)

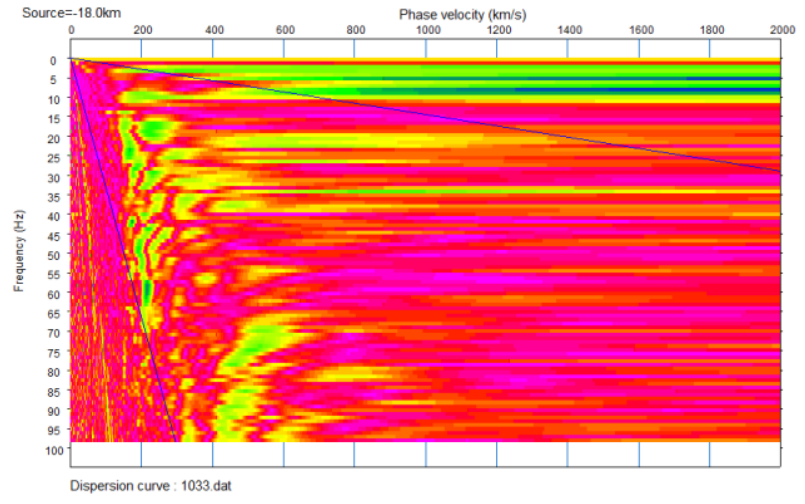

(c)

Fig. A-63: Dispersion images for the PTP site generated using a $8 \mathrm{lb}$ sledgehammer located at $\mathbf{- 1 2 \mathrm { dx }}$ from the closest geophone: (a) Aluminum base plate; (b) Aluminum over EPDM rubber base plate; and (c) Ultra-high-molecular-weight polyethylene base plate. 


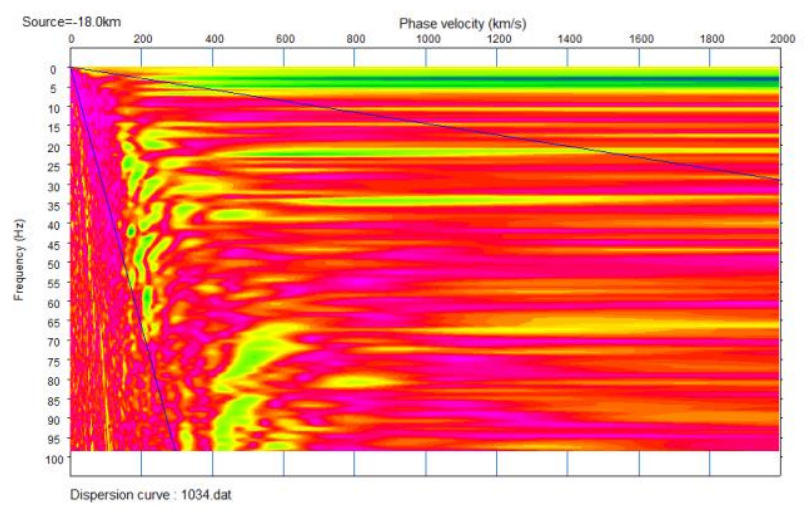

(a)

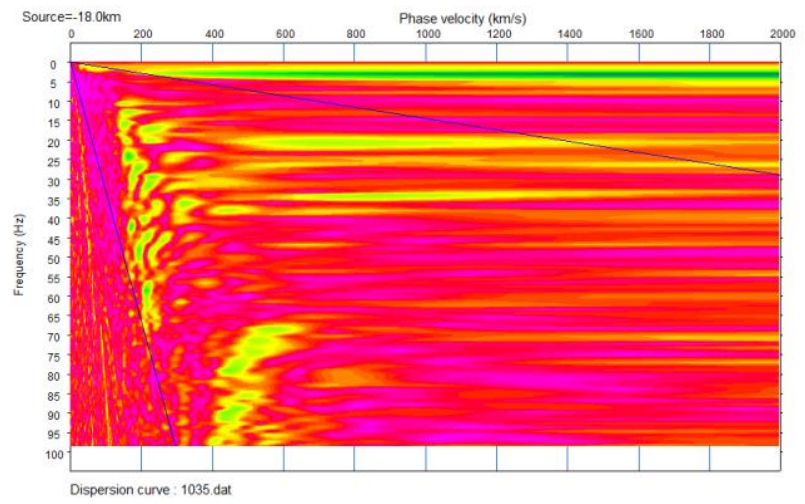

(b)

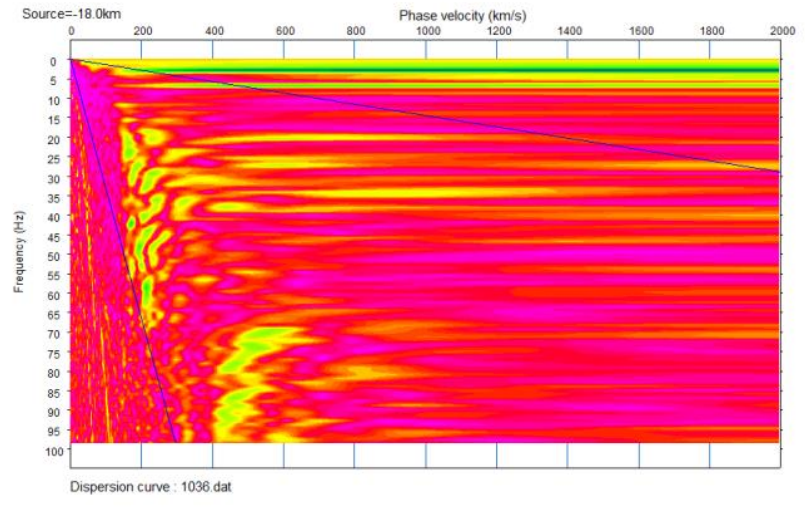

(c)

Fig. A-64: Dispersion images for the PTP site generated using a $4 \mathrm{lb}$ sledgehammer located at $-12 \mathrm{dx}$ from the closest geophone: (a) Aluminum base plate; (b) Aluminum over EPDM rubber base plate; and (c) Ultra-high-molecular-weight polyethylene base plate. 


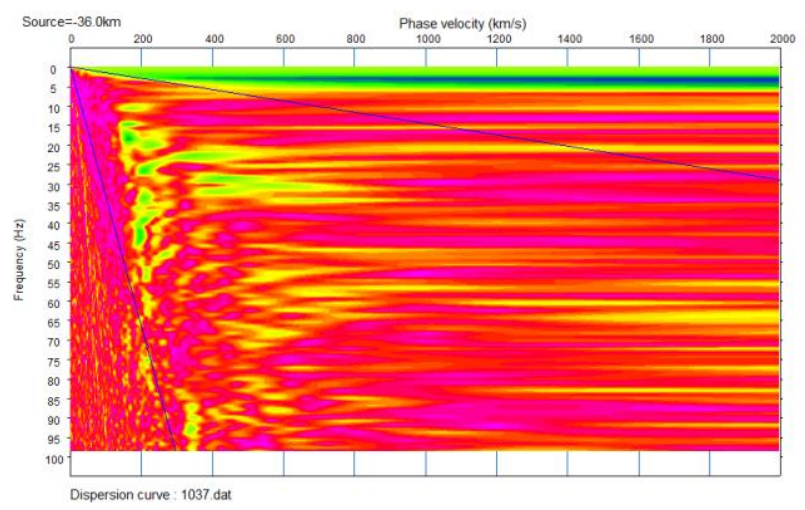

(a)

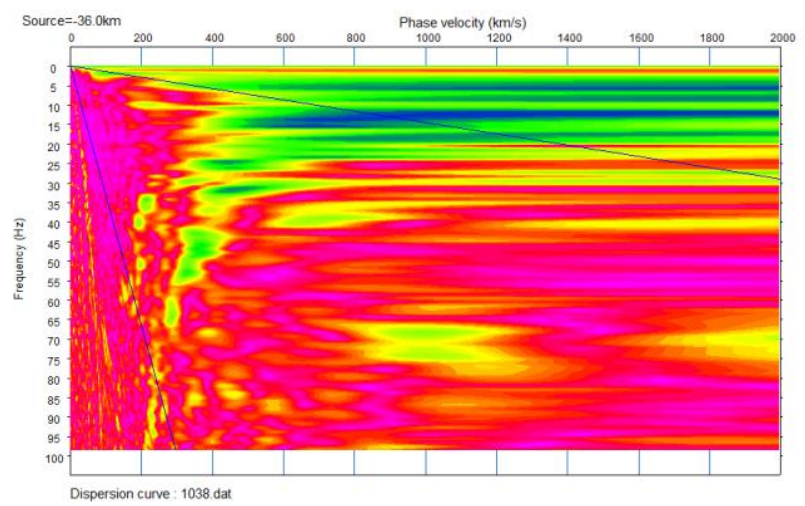

(b)

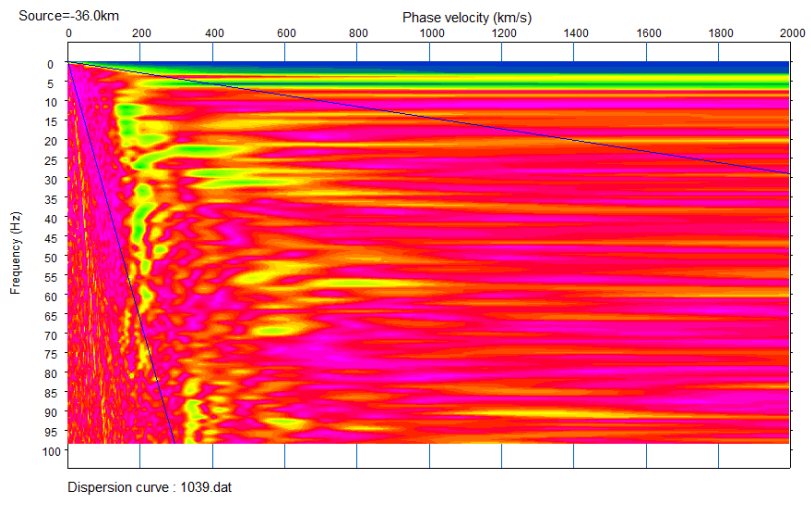

(c)

Fig. A-65: Dispersion images for the PTP site generated using a $20 \mathrm{lb}$ sledgehammer located at -24dx from the closest geophone: (a) Aluminum base plate; (b) Aluminum over EPDM rubber base plate; and (c) Ultra-high-molecular-weight polyethylene base plate. 


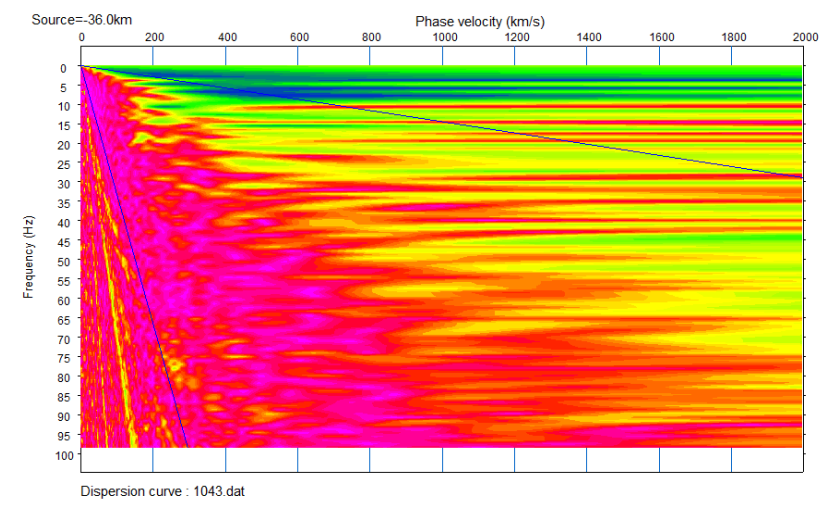

(a)

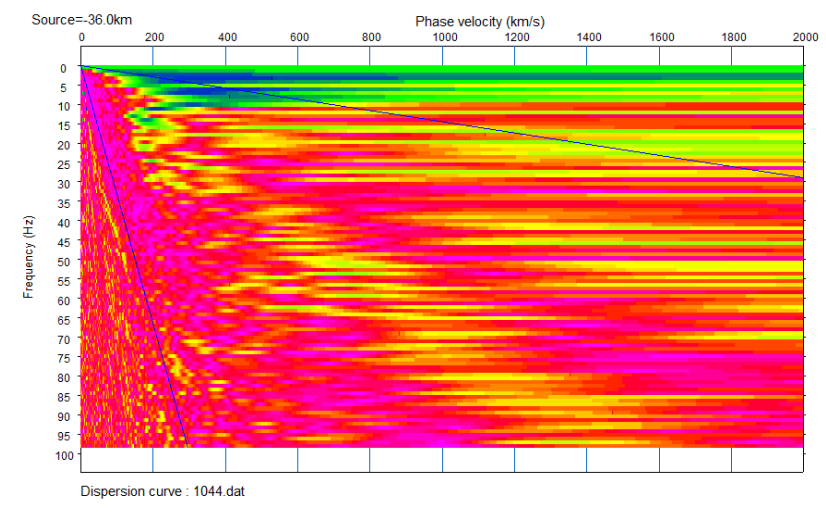

(b)

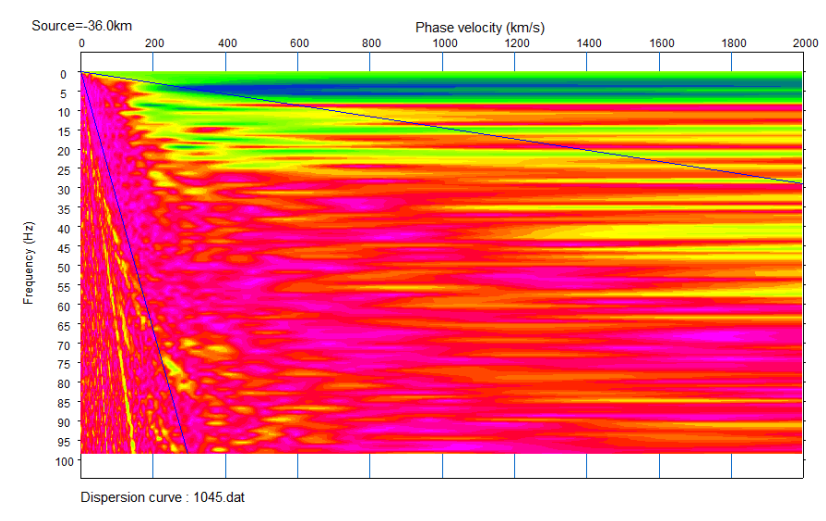

(c)

Fig. A-66: Dispersion images for the PTP site generated using a $4 \mathrm{lb}$ sledgehammer located at -24dx from the closest geophone: (a) Aluminum base plate; (b) Aluminum over EPDM rubber base plate; and (c) Ultra-high-molecular-weight polyethylene base plate. 